\title{
Innovative Fe(III)-dosed Anaerobic Biological Treatment System: From Fe and S Biogeochemical Reactions to Engineering Process
}

\author{
Musfique Ahmed \\ West Virginia University, mfahmed@mix.wvu.edu
}

Follow this and additional works at: https://researchrepository.wvu.edu/etd

Part of the Environmental Engineering Commons

\footnotetext{
Recommended Citation

Ahmed, Musfique, "Innovative Fe(III)-dosed Anaerobic Biological Treatment System: From Fe and S Biogeochemical Reactions to Engineering Process" (2020). Graduate Theses, Dissertations, and Problem Reports. 7752.

https://researchrepository.wvu.edu/etd/7752

This Dissertation is protected by copyright and/or related rights. It has been brought to you by the The Research Repository @ WVU with permission from the rights-holder(s). You are free to use this Dissertation in any way that is permitted by the copyright and related rights legislation that applies to your use. For other uses you must obtain permission from the rights-holder(s) directly, unless additional rights are indicated by a Creative Commons license in the record and/ or on the work itself. This Dissertation has been accepted for inclusion in WVU Graduate Theses, Dissertations, and Problem Reports collection by an authorized administrator of The Research Repository @ WVU. For more information, please contact researchrepository@mail.wvu.edu.
} 
Innovative $\mathrm{Fe}$ (III)-dosed Anaerobic Biological Treatment System:

From Fe and S Biogeochemical Reactions to Engineering Process

\author{
Musfique Ahmed
}

\author{
Dissertation submitted \\ to the Statler College of Engineering and Mineral Resources \\ at West Virginia University
}

in partial fulfillment of the requirements for the degree of

Doctor of Philosophy in Civil Engineering

\author{
Lian-Shin Lin, Ph.D., P.E., Committee Chairperson \\ Leslie Hopkinson, Ph.D. \\ Antarpreet Jutla, Ph.D. \\ Nianqiang (Nick) Wu, Ph.D. \\ Michael J. Wilkins, Ph.D.
}

Wadsworth Department of Civil and Environmental Engineering

Morgantown, West Virginia

2020

Keywords: Iron-dosed anaerobic wastewater treatment, Fe/S ratio, Ferric and sulfate reduction rate, Organic oxidation, Iron reducers and sulfate reducers, Resource recovery from sludge, Nutrient recovery

Copyright 2020 Musfique Ahmed 


\section{Abstract \\ Innovative Fe(III)-dosed Anaerobic Biological Treatment System: From Fe and S Biogeochemical Reactions to Engineering Process}

\section{By Musfique Ahmed}

In moving toward more sustainable wastewater management, anaerobic treatment is gaining increasing popularity due to its simplicity, low energy requirement, low sludge production and less emission of greenhouse gases compared to typical aerobic wastewater treatment systems. Electron acceptors such as nitrate, sulfate, and $\mathrm{CO}_{2}$ have been used in various anaerobic processes for removal of organic matters from wastewater under anoxic or anaerobic environments. In energy producing regions, ferric iron, $\mathrm{Fe}(\mathrm{III})$, is a predominant element in iron containing wastes such as acid mine drainage (AMD) and coal ash, which can potentially be used as a source of iron in novel anaerobic wastewater treatment. Such an iron-based treatment approach can offer multi-faceted benefits over existing treatment methods including use of ironcontaining wastes, no aeration, unique reaction mechanisms for coagulation, sulfide control, organic micropollutant removal, and useful sludge byproducts. The overall goal of this research was to develop an innovative Fe(III)-dosed anaerobic wastewater treatment process through incorporating known and novel biogeochemical reactions of iron in an engineered biological system.

The major research objectives include (1) identifying the critical factors and investigating their effects on the treatment performance of Fe(III)-dosed wastewater treatment; (2) developing a continuous $\mathrm{Fe}$ (III)-dosed anaerobic biological treatment system and examining its technical feasibility and potential issues in long-term operations; (3) developing a method for transforming the sludge materials from the Fe(III)-dosed bioreactor into magnetic byproducts; and (4) exploring the applicability of this $\mathrm{Fe}(\mathrm{III})$-dosed treatment method for nutrient removal and recovery.

A detail literature review was first conducted to evaluate the suitability of using iron reduction for wastewater treatment and identify critical factors affecting the treatment. Several factors were identified that affect organics oxidation coupled to iron reduction, including the types of the ferric compound, microorganisms, ferric bioavailability and availability of substrate. Amorphous iron materials (e.g. iron sludge from AMD) with large surface areas and high ferric dissolution rates have great potential to be used in Fe(III)-dosed wastewater treatment process to enhance ferric bioavailability to iron reducers. Given the significant levels of sulfate $\left(\mathrm{SO}_{4}{ }^{2-}\right)$ in wastewater, sulfate reduction is expected to be co-occurring with iron reduction in the iron-dosed anaerobic treatment. Shift in microbial composition in relation to ferric and sulfate concentrations (expressed as Fe/S ratio) and their effects on organics removal are important knowledge gaps for developing such treatment technology. In particular, there is a need to understand the nature of the relationships between iron reducing bacteria (IRB) and sulfate reducing bacteria (SRB) (i.e., symbiotic or competitive) to identify optimal operating conditions for this type of wastewater treatment.

Batch experiments on iron-dosed anaerobic biological treatment of wastewater under three different molar Fe/S ratios (1,2 and 3) showed positive correlation between organics (chemical oxygen demand, COD) oxidation rate and Fe/S ratio. Microbiological analysis suggested that both 
iron reducers and sulfate reducers contributed to this organic oxidation. Maximum COD oxidation rate, $V_{\max }$ estimated from Michaelis-Menten model ranged from $0.47 \mathrm{mg} / \mathrm{L} \cdot \mathrm{min}$ to $1.09 \mathrm{mg} / \mathrm{L} \cdot \mathrm{min}$ as $\mathrm{Fe} / \mathrm{S}$ ratio increased from 1 to 3 . A positive correlation was also observed between COD oxidation rate and the relative abundance of iron reducers, and both increased with the Fe/S ratio.

Long-term continuous wastewater treatment using an anaerobic bioreactor dosed with ferric iron showed satisfactory COD removal of $84 \pm 4 \%, 86 \pm 4 \%$ and $89 \pm 2 \%$ under Fe/S molar ratio 0.5 , 1 and 2 respectively. Fe/S ratio was also observed to regulate the effluent quality by removing excess sulfide from aqueous phase with increasing quantity of ferrous through ferrous sulfide precipitation. The sludge materials contained both biomass $(20-40 \mathrm{w} / \mathrm{w} \%)$ and inorganic precipitates $(80-60 \mathrm{w} / \mathrm{w} \%)$ with the inorganic fraction increasing with $\mathrm{Fe} / \mathrm{S}$ ratio. Spectroscopic and chemical elemental analyses indicated that the inorganic fraction of the sludge materials mainly contained $\mathrm{FeS}$ and $\mathrm{FeS}_{2}$. Microbiological analyses of the sludge materials identified Geobacter sp., Geothrix sp. and Ignavibacteria sp. as putative iron reducers, and Desulfovibrio sp., Desulfobulbus sp., Desulfatirhabdium sp., Desulforhabdus sp. and Desulfomonile sp. as putative sulfate reducers.

A simple thermal treatment method was applied to transform the iron sulfide sludge from the bioreactor into magnetic particles. Sludge samples were treated at five different temperatures $\left(300,350,400,450\right.$, and $\left.500^{\circ} \mathrm{C}\right)$ to evaluate the transformation of iron sulfide sludge into different magnetic phases of iron oxide particles. X-ray Diffraction (XRD) analysis and magnetization measurements showed successful transformation of the sludge to magnetic byproducts and indicated the presence of ferromagnetic magnetite and maghemite phases at different temperatures. The magnetic sludge byproducts have potential applications in biomedicine sector and wastewater treatment (e.g. coagulant, adsorbent). Crystallinity and crystallite size of the thermally derived particles were observed to play a noteworthy role in regulating the magnetization of the byproducts. Adsorption study revealed that both samples baked at $350^{\circ} \mathrm{C}$ and $500^{\circ} \mathrm{C}$ had high adsorption capacities to remove phosphate from aqueous solutions.

A study to explore applicability of this $\mathrm{Fe}$ (III)-dosed treatment process for nutrient removal and recovery was conducted with synthetic wastewater containing typical concentrations of COD (420 $\mathrm{mg} / \mathrm{L})$, phosphate $(10 \mathrm{mg} / \mathrm{L}), \mathrm{SO}_{4}{ }^{2-}(50 \mathrm{mg} / \mathrm{L})$ and ammonium $(50 \mathrm{mg} / \mathrm{L})$. Average removal efficiencies of COD, phosphate, $\mathrm{SO}_{4}{ }^{2-}$ and ammonium were $97 \pm 2 \%, 99.7 \pm 0.5 \%, 87.1 \pm 3 \%$ and $20.3 \pm 9 \%$ respectively. The results showed in addition to organics oxidation, significant phosphate and ammonium removals were achieved in the bioreactor. Potential removal mechanisms include chemical precipitation as ferric phosphate $\left(\mathrm{FePO}_{4}\right)$ or ferrous ammonium phosphate (FAP). SEM-EDS and XPS analysis suggested the presence of FAP in the sludge materials.

This innovative treatment process has shown consistent treatment performance and long-term stability under different operating conditions, suggesting its potential for large scale applications. Pilot-scale applications of this treatment approach using iron-containing wastes will give better understanding on the functionality of this process in a field scale environment. Utilizing iron wastes in this novel wastewater treatment process along with recovery of useful sludge byproducts not only can create new avenues to alleviate iron waste disposal, but also improve the sustainability of wastewater treatment. 


\section{Acknowledgements}

Firstly, I would like to thank my Ph.D. supervisor Dr. Lian-Shin Lin, whose professional knowledge, academic experience, guidance, mentorship and continuous support have played the most significant part in my doctoral study and professional career development. His guidance assisted me in designing experiments, writing manuscripts and dissertation and overall in my progress as a researcher.

I am truly grateful to Dr. Michael J. Wilkins for his constant support as an external member of my Ph.D committee, specifically while carrying out the microbiological study of my research and during preparing manuscripts. Furthermore, my whole-hearted gratitude goes to my other committee members as well: Dr. Leslie Hopkinson, Dr. Antarpreet Jutla, and Dr. Nianqiang (Nick) Wu for their invaluable comments and encouragements throughout my research work. I would also like to acknowledge Dr. Matt Johnson and Mina Aziziha from Department of Physics, WVU and Casey M. Saup from Ohio State University for their help with various analyses and contributions in manuscript writing.

My colleagues and lab mates from Dr. Lin's lab: Dr. Karen Buzby, Dr. Hoi Park, Dr. Dongyang Deng, Edouard Kolimedje, Golnoosh Khajouei, Robyn Christopherson deserve sincere appreciation for the great time I had with them over various academic and personal discussions. Additionally, all the help I received from the undergraduate students who worked with me during last five years, specially Oliver Lin and Jenna Henry, is noteworthy.

Most importantly, I must give credits to my friends from Morgantown, without whose unconditional support I would not have lasted these many years, during the stressful time of Ph.D. work. I strongly believe whatever I have achieved till today is due to the uncountable prayers and sacrifices of my parents MD. Jasim Uddin and Maksuda Begum, who have always encouraged me toward thriving my academic goals. I would also like to thank my sister Jinia Sharmeen, brother-in-law Nymul Haque, father-in-law Nurul Anwar, mother-in-law Parveen Fatema for their supports and blessings during these years.

I must mention my dear wife Rifat Anwar here. There is no way I can thank her enough for all her love, care and generosity which have always kept me strong and resilient in achieving my goals. Her academic inputs were also very helpful during my research work. Last but not the least, I have to say that indeed I am truly fortunate and blessed to have come so far in my career. 


\section{Table of Contents}

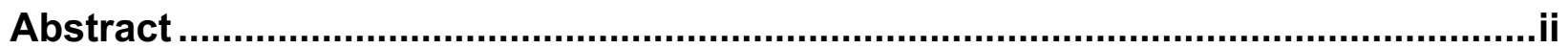

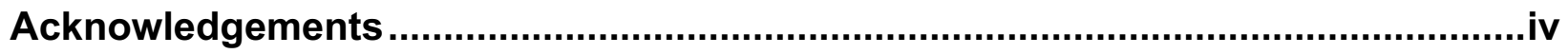

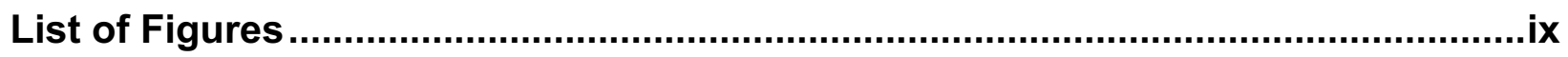

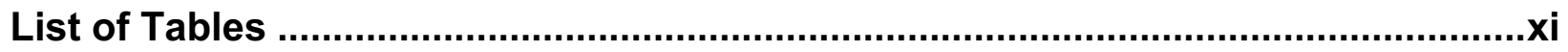

List of Symbols/ Nomenclature ..............................................................................

Chapter 1: Background and Research Objectives ................................................1

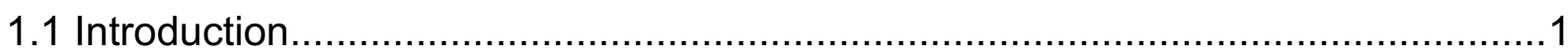

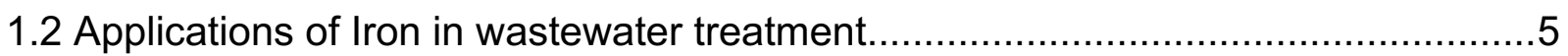

1.3 Ph.D. Research Rationale, Goal, and Objectives ..........................................

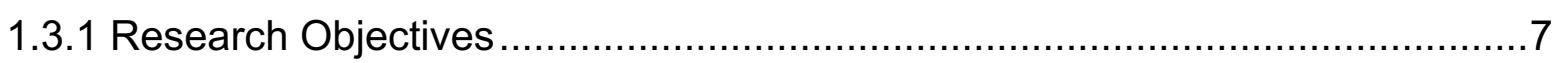

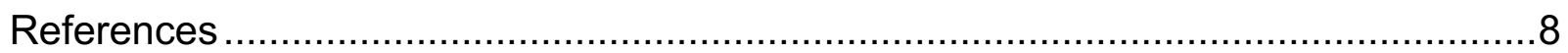

Chapter 2: Ferric Reduction in Organic Matter Oxidation and Its Applicability for Anaerobic Wastewater Treatment: A Review and Future Aspects........................12

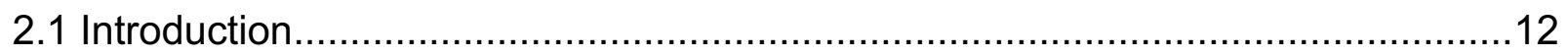

2.2 Significance and fundamentals of iron reduction process ..................................14

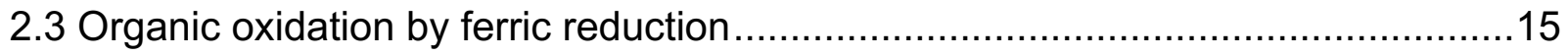

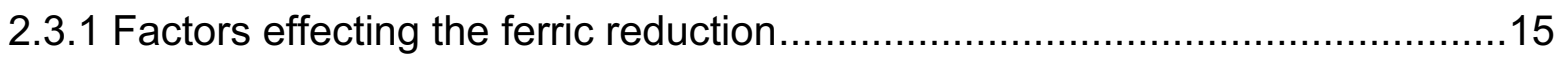

2.3.2 Kinetics of ferric reduction in organics oxidation .......................................17

2.3.3 Iron reduction process in environmental remediation ...................................19

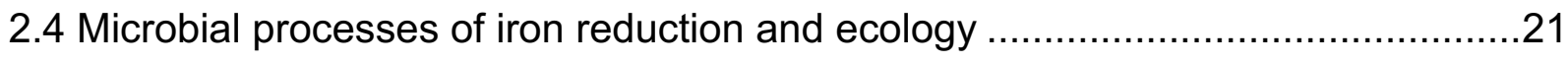

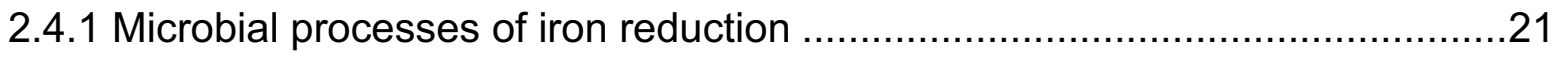

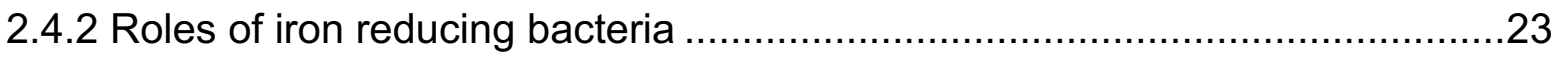

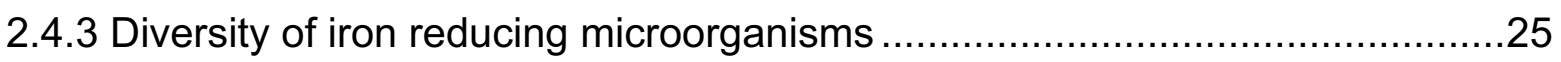

2.5 Iron reduction in wastewater treatment and future prospect ..............................27

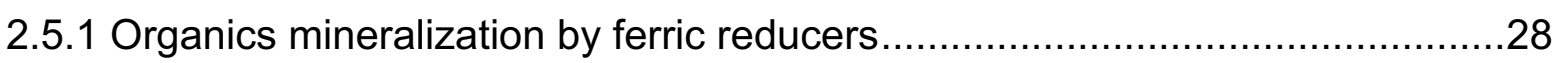

2.5.2 Ferric iron bioavailability and bioreduction kinetics ...................................29 


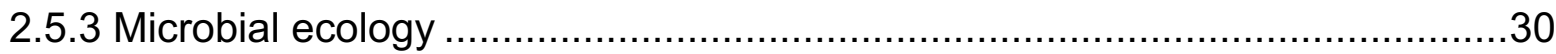

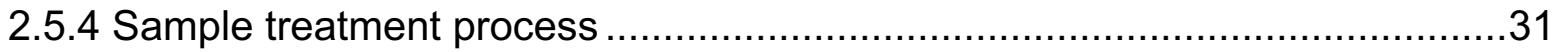

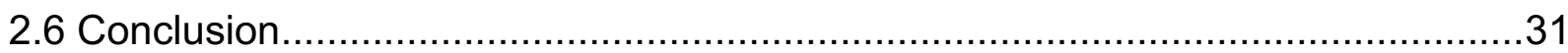

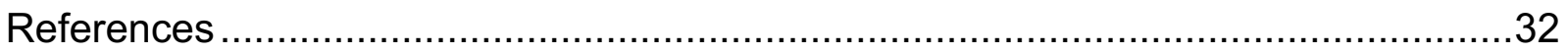

Chapter 3: Effects of Fe/S Ratio on the Kinetics and Microbial Ecology of an Fe(III)-dosed Anaerobic Wastewater Treatment System .........................................38

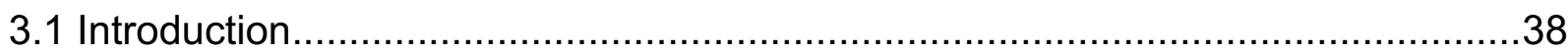

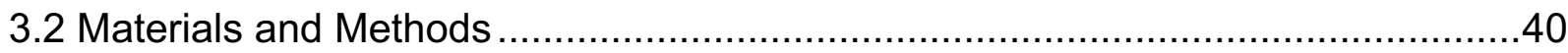

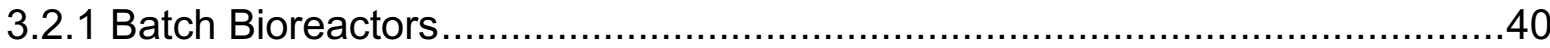

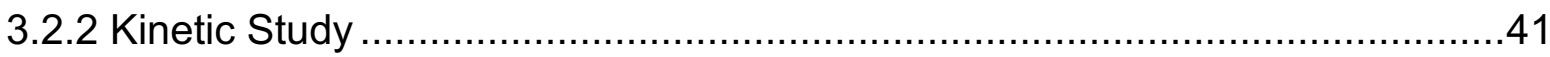

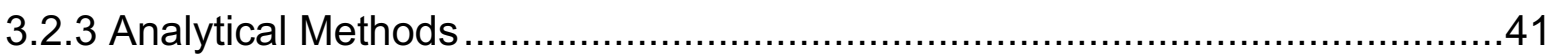

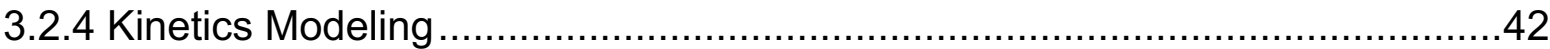

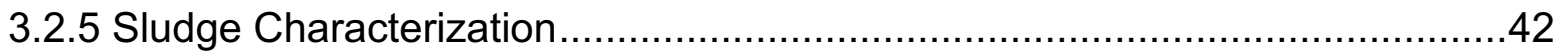

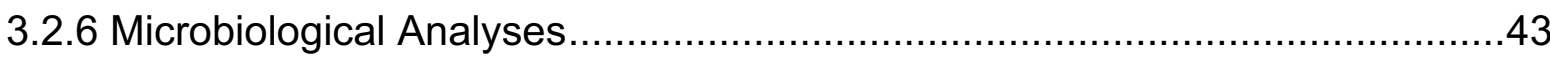

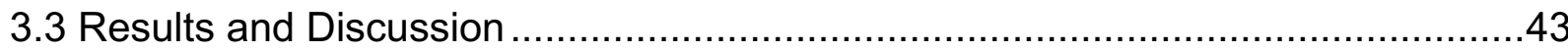

3.3.1 Oxidation Kinetics under different Fe/S ratios.........................................43

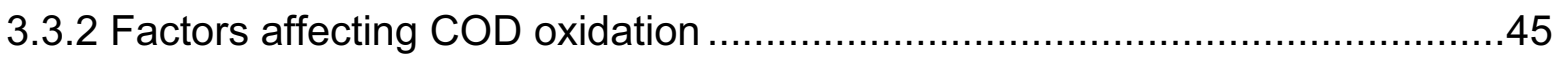

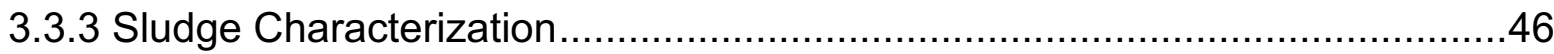

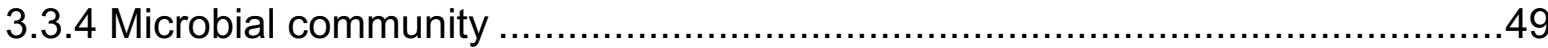

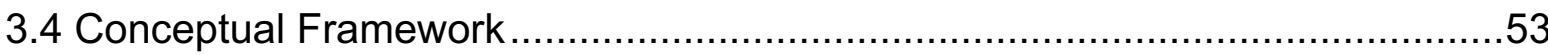

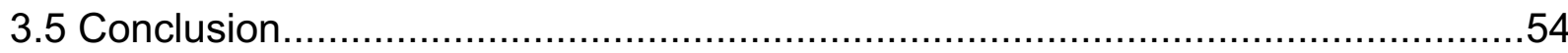

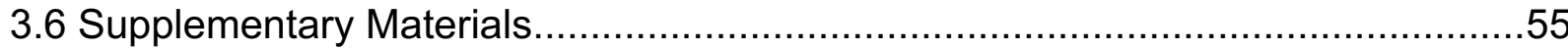

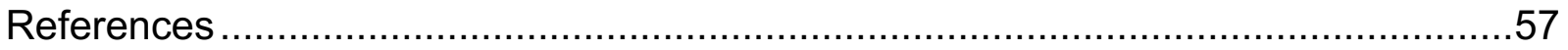

Chapter 4: Continuous Ferric Iron-dosed Anaerobic Wastewater Treatment: Treatment Performance, Sludge Characteristics, and Microbial Composition ......63

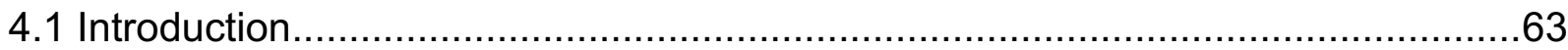

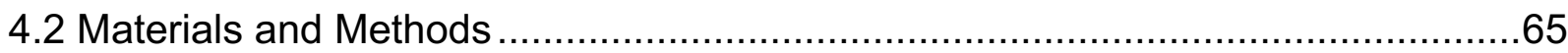

4.2.1 Bench-scale iron-dosed treatment system ............................................65 


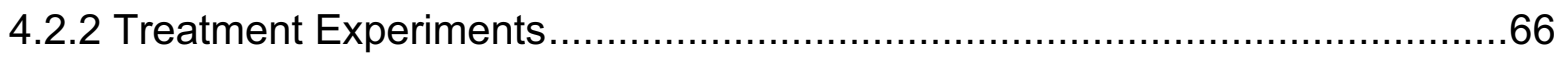

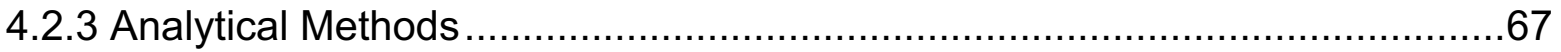

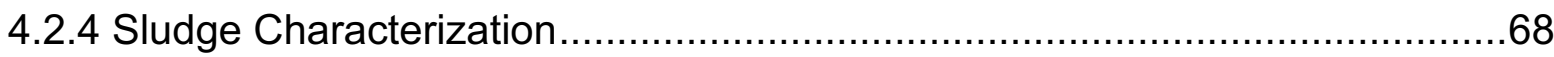

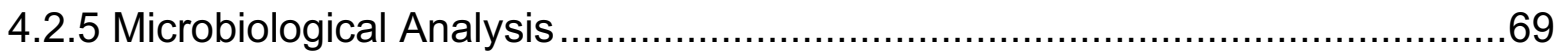

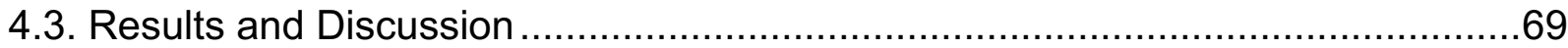

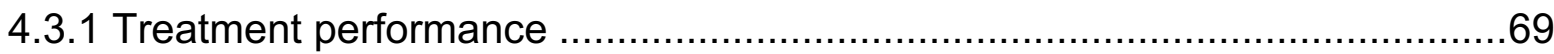

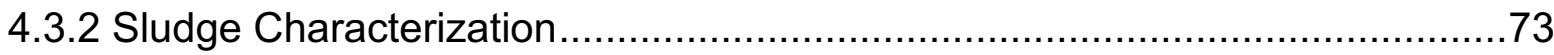

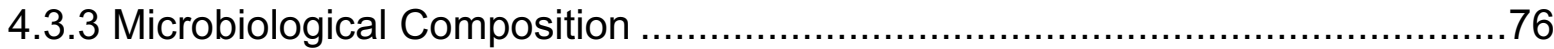

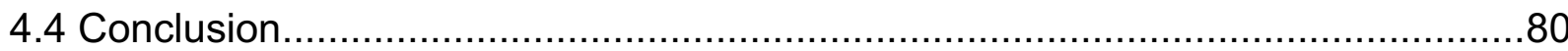

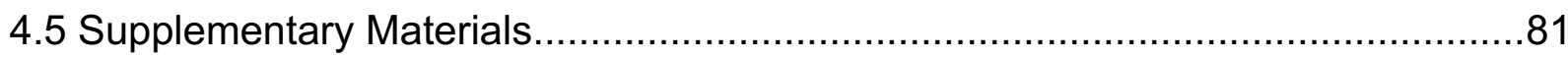

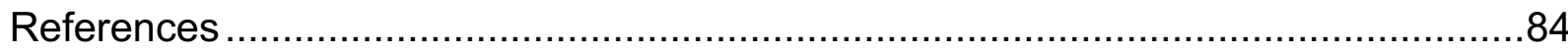

Chapter 5: Magnetic Sludge Byproducts for Adsorptive Removal of Phosphorus:

Resource Recovery from Iron-based Anaerobic Sewage Sludge............................90

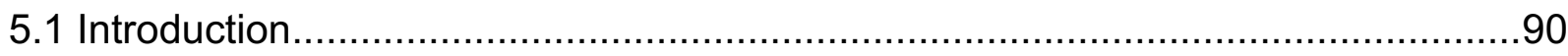

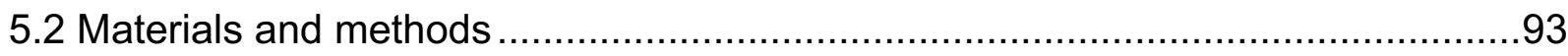

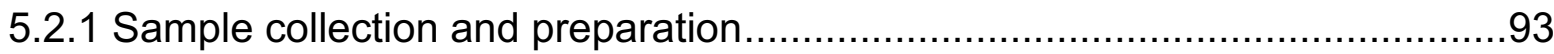

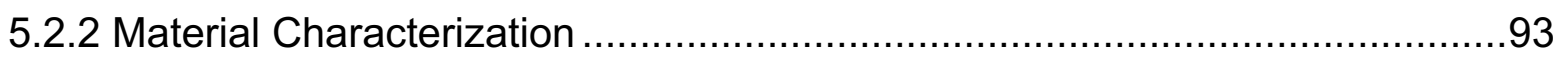

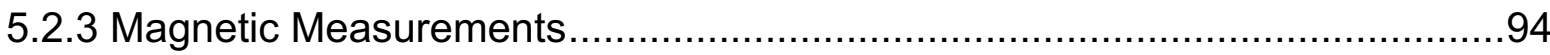

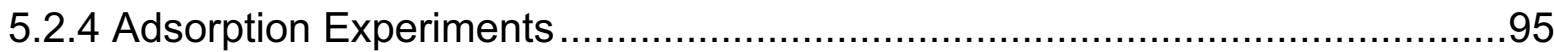

5.2.5 Adsorption Kinetics and Isotherm Modeling..............................................95

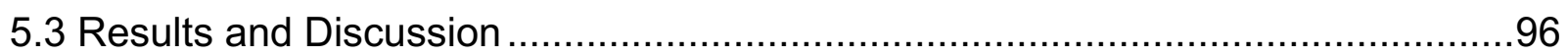

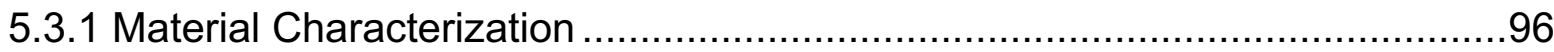

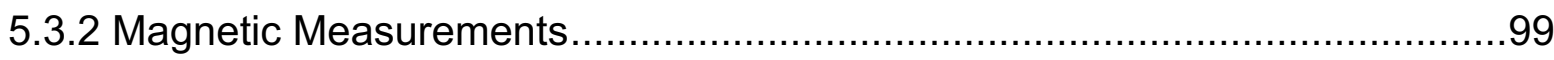

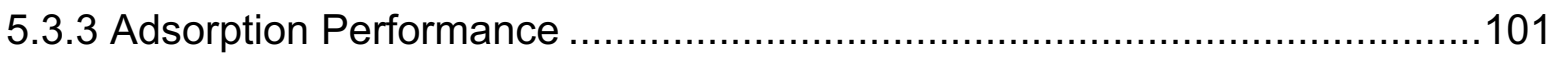

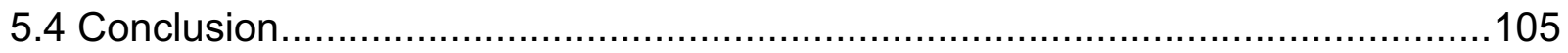

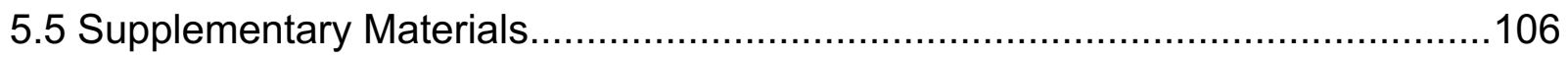

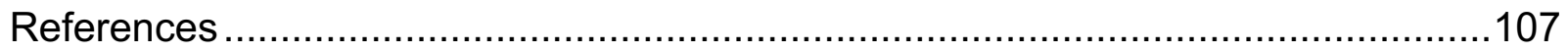


Chapter 6: Chemical Fate of Nutrients and Their Recovery Potential Through the Fe(III)-dosed Wastewater Treatment .......................................................................113

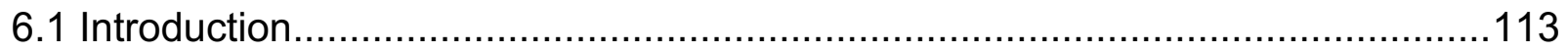

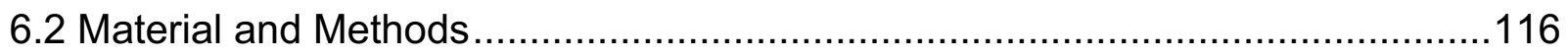

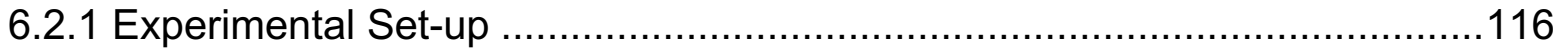

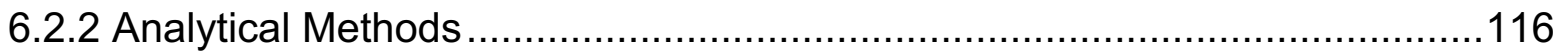

6.2.3 Sludge Characterization...................................................................117

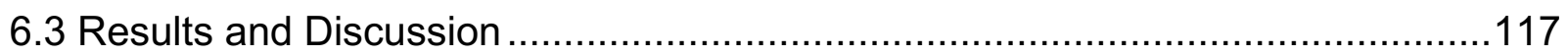

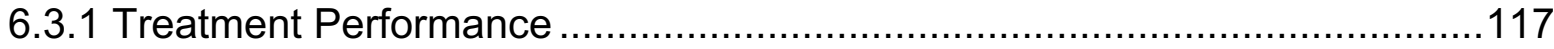

6.3.2 Sludge Characterization.................................................................... 118

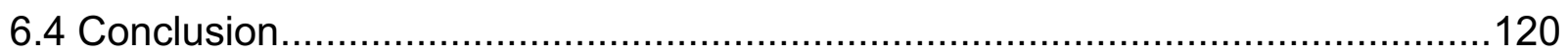

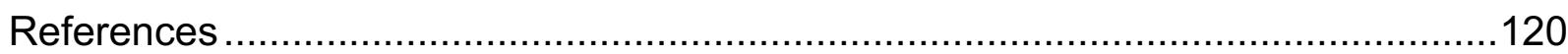

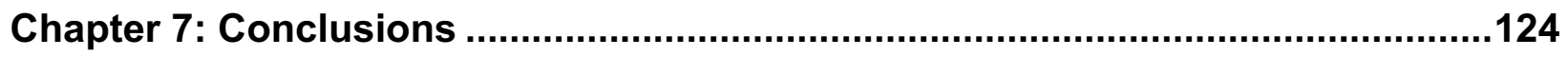




\section{List of Figures}

Fig. 1: Major sources of wastewater 1

Fig. 2: Typical energy consumption in representative aerobic WWTP (adapted from WEF, 2009). Numbers in bracket represent the percentages of energy requirement in each treatment unit. 3

Fig. 3: Different strategies of microbial and ferric surface interaction (a) Direct Contact, (b) Contact with ligand, (c) Contact with electron shuttle, (d) Contact with nanowires;

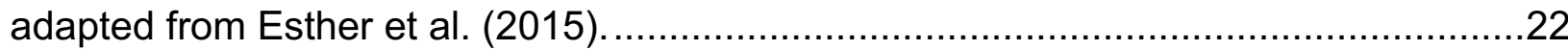

Fig. 4: Oxidation of organic matters with ferric reduction adapted from Lovley (1993) ..24

Fig. 5: Schematic diagram of the possible treatment process. 31

Fig. 6: Nonlinear kinetic models of COD oxidation under three different Fe/S molar ratios 44

Fig. 7: Dissolved sulfide and ferrous iron concentrations in the bioreactors under different $\mathrm{Fe} / \mathrm{S}$ ratios .45

Fig. 8: (a) Solid concentrations and (b) VSS/TSS and NVSS/TSS ratios of the sludge materials 47

Fig. 9: Sample SEM micrograph and EDS spectrum of the sludge material under $\mathrm{Fe} / \mathrm{S}$ molar ratio 3 .

Fig. 10: XPS spectra of (a) Fe and (b) $\mathrm{S}$ in the sludge material under Fe/S molar ratio 3 49

Fig. 11: (a) Relative abundances of major microbial species and (b) diversity index.....52 Fig. 12: Conceptual framework of the effects of $\mathrm{Fe} / \mathrm{S}$ ratio on organic carbon oxidation kinetics. .53

Fig. 13: (a) COD removal, sulfate reduction and iron retention and (b) COD removal rates under different $\mathrm{Fe} / \mathrm{S}$ molar ratios .70

Fig. 14: (a) Effluent total iron, ferrous and sulfide concentration and (b) Influent and effluent $\mathrm{pHs}$ at different $\mathrm{Fe} / \mathrm{S}$ molar ratios .71

Fig. 15: Mass flow rates of $\mathrm{Fe}$ and $\mathrm{S}$ throughout the biological treatment under $\mathrm{Fe} / \mathrm{S}$ molar ratio 2 . .72

Fig. 16: VSS/TSS and NVSS/TSS as percentage (\%) of sludge samples under different $\mathrm{Fe} / \mathrm{S}$ ratios 
Fig. 17: (a) SEM micrograph and (b) EDS spectrum for sludge sample under Fe/S molar ratio 2; (c) \& (d): SEM images of cells present in anaerobic sludge .............................74

Fig. 18: XPS spectrum of (a) Fe2p and (b) S2p region of a sludge sample .................75

Fig. 19: (a) Microbial distribution and (b) relative abundances of putative IRB and SRB .78

Fig. 20: XRD spectra of the sludge byproducts derived from the thermal treatment. Red: XRD spectrum, Blue: Rietveld fit, Cyan: Background, Pink: Difference between the experimental and Rietveld refinement. 97

Fig. 21: Weight percentages of different phases of iron minerals derived from the sludge materials at different temperatures .99

Fig. 22: High-resolution hysteresis measurements of the sludge byproducts derived at different temperatures 100

Fig. 23: Remanent magnetization (Mr) of the sludge byproducts derived at different temperatures 101

Fig. 24: Adsorption kinetic data and pseudo-second-order kinetic models for (a) S350 and (b) $\mathrm{S} 500$ 102

Fig. 25: Adsorption capacity of S350 for phosphate ions 103

Fig. 26: Adsorption isotherm data, and (a) Langmuir and (b) Freundlich models for S350 and $\mathrm{S} 500$ at $\mathrm{pH} 7.0$ 105

Fig. 27: Adaptation of the $\mathrm{N}$ - cycle in the Feammox reaction for $\mathrm{NH}_{4}{ }^{+}$oxidation 115 Fig. 28: Influent and effluent concentrations of $\mathrm{COD}, \mathrm{NH}_{4}{ }^{+}-\mathrm{N}, \mathrm{PO}_{4}{ }^{3-}-\mathrm{P}$ and $\mathrm{SO}_{4}{ }^{2-} \ldots \ldots .118$ Fig. 29: SEM micrograph and EDS spectrum of the sludge material 119

Fig. 30: XPS spectra of the sludge sample for (a) Fe2 $p_{3 / 2}$, (b) N1s, and (c) P2 $p_{3 / 2 \ldots \ldots 120}$ 


\section{List of Tables}

Table 1: Major iron reducing bacteria and their primary electron donors

Table 2: Major bacteria observed with their phyla and averaged relative abundance in all

the bioreactors .50

Table 3: Daily loads of $\mathrm{Fe}$ and $\mathrm{S}$ for three target $\mathrm{Fe} / \mathrm{S}$ molar ratios .67

Table 4: Major bacteria and their phylum identified in the bioreactor ..........................77

Table 5: Langmuir and Freundlich Isotherm model parameters for S350 and S500 ....104 


\title{
List of Symbols/ Nomenclature
}

\author{
AMD - Acid Mine Drainage \\ WWTP - Wastewater Treatment Plant \\ COD - Chemical Oxygen Demand \\ BOD - Biochemical Oxygen Demand \\ TSS - Total Suspended Solid \\ VSS - Volatile Suspended Solid \\ NVSS - Nonvolatile Suspended Solid \\ IRB - Iron Reducing Bacteria \\ SRB - Sulfate Reducing Bacteria \\ EPS - Extra Polymeric Substance \\ TOC - Total Organic carbon \\ SEM - Scanning Electron Microscope \\ EDS - Energy Dispersion Spectroscopy \\ XPS - X-ray Photoelectron Spectroscopy \\ VSM - Vibrating Sample Magnetometer
}




\section{Chapter 1: Background and Research Objectives}

\subsection{Introduction}

Wastewater originates from a variety of different sources including point sources such as domestic, industrial, commercial, agricultural and non-point sources such as groundwater infiltration, stormwater runoff and sewer overflows (Fig. 1). Untreated wastewater contains organic matters which can decompose and lead to nuisance conditions with production of malodorous gases. Additionally, it contains pathogenic microorganisms and nutrients that can have serious effect on human body and environment (Metcalf \& Eddy et al., 2014). Therefore, proper treatment of wastewater is required before its discharge to the environment to protect public health and aquatic ecosystems.

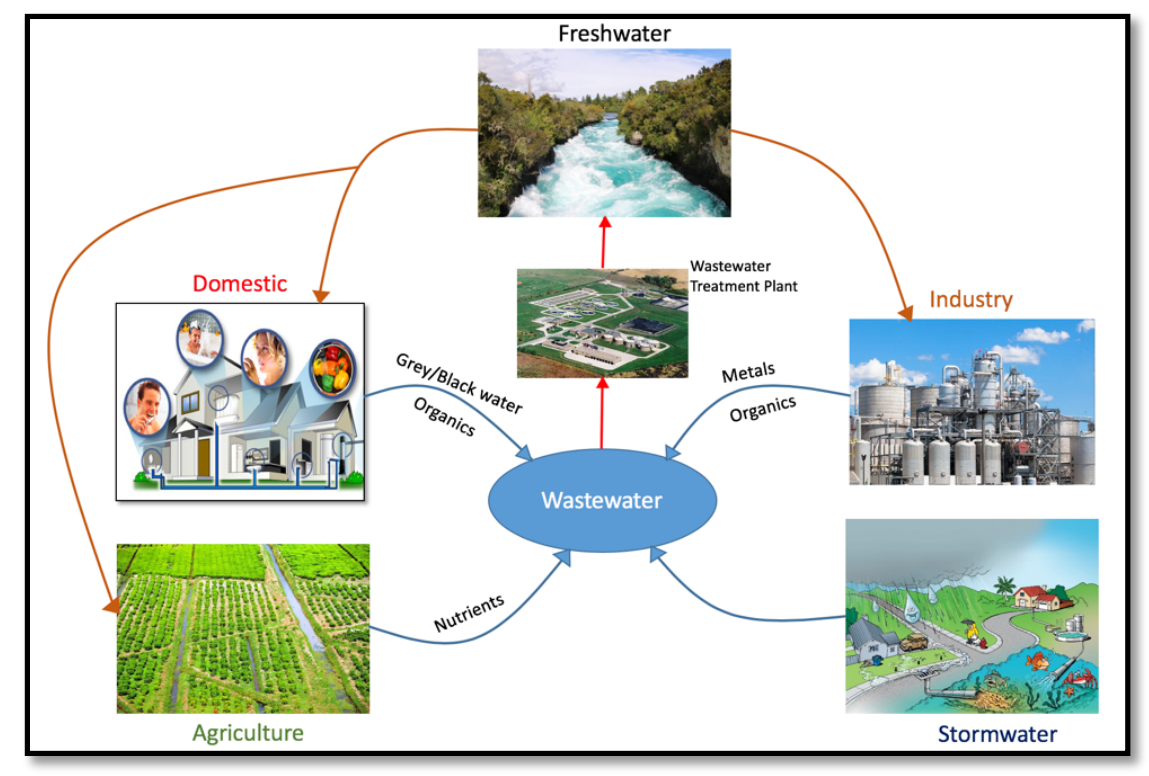

Fig. 1: Major sources of wastewater

Globally, most common wastewater treatment methods are centralized aerobic wastewater treatment plants and lagoons for both domestic and industrial wastewater (Doorn et al., 2006). Domestic wastewater may also be treated in decentralized septic systems which may treat wastewater from one or multiple households. Wastewater treatment plant (WWTP) are designed to satisfy different treatment objectives. Large particles, grits and rags are removed from wastewater by physical operation in primary treatment and remaining particulates are allowed to settle in primary clarifiers. Secondary treatment generally consists of biological and chemical processes that remove organic 
matters (Metcalf \& Eddy et al., 2014). In general, $85 \%$ of chemical oxygen demand (COD) and total suspended solid (TSS) can be removed by secondary treatment. Tertiary treatment is used in WWTPs to remove pathogens, contaminants and remaining nutrients such as nitrogen $(N)$ and phosphorus $(P)$ by using various advanced processes such as disinfection, carbon adsorption, filtration, ion exchange (Doorn et al., 2006; Metcalf \& Eddy et al., 2014). Till late 1980s, conventional secondary treatment was the most common method for removal of biological oxygen demand (BOD) and TSS from wastewater. In the U.S., treatment for nutrient removal was used for special circumstances, such as great lakes area, Florida, and the Chesapeake Bay where nutrient related water quality problems were identified. However, with time nutrient removal processes have evolved and now are used more commonly. The changing nature of wastewater, emerging health and environmental concerns, treatment plant performance and reliability, new methods of process analysis and control, and impact of new regulations are some of the important factors that raise new concerns and directions in wastewater treatment (Metcalf \& Eddy et al., 2014). New technologies and processes are explored and introduced by the scientists and authorities in wastewater treatment to make it more effective and reliable according to regional environment and setting.

Due to various operational and environmental characteristics such as pollutant loads, plant size, and type of treatment plant, energy consumption in WWTPs varies from 0.26 to $0.84 \mathrm{kWh}$ per $\mathrm{m}^{3}$ of wastewater treated. The average energy consumption in WWTPs in the U.S., United Kingdom, Germany and Italy are $0.45,0.64,0.67$ and $0.55 \mathrm{kWh} / \mathrm{m}^{3}$ respectively (Guerrini et al., 2017). Approximately $50-65 \%$ of the energy consumption is used in the activated sludge process which is the secondary treatment of typical WWTPs (Guerrini et al., 2017). Typical energy consumption of a representative wastewater treatment plant is illustrated in Fig. 2 (WEF, 2009). Typically, to treat wastewater of 500 $\mathrm{mg} / \mathrm{L} \mathrm{COD}$, energy consumption in conventional activated sludge process is estimated as $3.20 \mathrm{~kJ} / \mathrm{g} \mathrm{COD}$. On the other hand, average potential energy of typical domestic wastewater has been estimated as $16.2 \mathrm{~kJ} / \mathrm{g}$ COD which is about five times the electrical energy required to operate wastewater treatment in conventional activated sludge process (Wan et al., 2016). This suggests that WWTPs can be energy self-sufficient if 
proper energy recovery technology is implemented, but this can be expensive and less feasible.

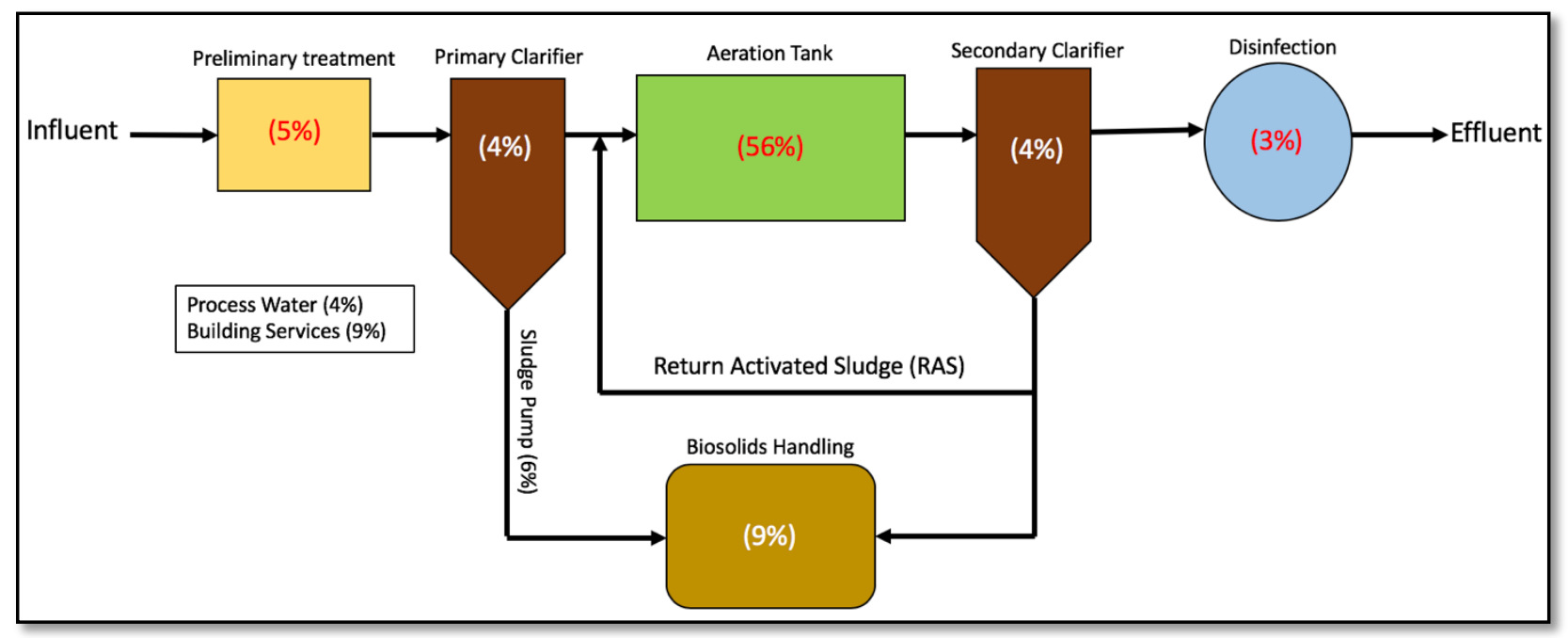

Fig. 2: Typical energy consumption in representative aerobic WWTP (adapted from WEF, 2009). Numbers in bracket represent the percentages of energy requirement in each treatment unit

Because of the high energy consumption in aerobic wastewater treatment, various alternative technologies have been developed to make WWTPs cost effective and energy efficient. Anaerobic treatment process is gaining immense popularity due to its simplicity, low energy requirement, low sludge production and less emission of greenhouse gases. The net operating cost is approximately $\$ 160$ per metric ton less for anaerobic process than aerobic process, which can be as high as $\$ 250$ for some instances (Speece, 1983). Various high rate anaerobic treatment reactors have been developed in last 40 years, including anaerobic filter (AF), upflow anaerobic sludge blanket (UASB), fluidized bed $(F B)$, and anaerobic baffled reactor (ABR), which can contribute to significant organics removal from both domestic and industrial wastewater (Van Lier et al., 2015). In anaerobic microbiological process, anaerobic bacteria utilize organic matters as electron donor for metabolizing at oxygen-free environment with the help of different electron acceptors like $\mathrm{CO}_{2}$, sulfate, nitrate (Damianovic and Foresti, 2007; Hubert and Voordouw, 2007; Jeong et al., 2008). Anaerobic treatment with methanogens is the most common treatment process where organics are converted to methane $\left(\mathrm{CH}_{4}\right)$ gas through bioconversion. Although, $\mathrm{CH}_{4}$ is a well-known biogas, production of heat and electricity with this gas 
require combined heat and power (CHP) system, which is complex and labor intensive (Mes et al., 2003). For on-site wastewater treatment at community level, treatment system needs to be designed with greater simplicity than centralized treatment systems. Several studies have been reported on the performance of sulfidogenic bioreactors where sulfate is utilized to treat sulfate-rich wastewater and significant organics removal has been observed (Dar et al., 2007; Deng et al., 2016; Oude Elferink et al., 1994; Widdel, 1988). There are opportunities to incorporate other redox active elements in anaerobic treatment and develop new field for research in the context of technology innovation.

An area of such opportunities is utilization of acid mine drainage (AMD) in wastewater treatment. AMD originating from active and abandoned mine, is a significant environmental liability in the mining regions worldwide. It affects the rivers, lakes, estuaries and coastal waters by various direct and indirect pathways. AMD is recognized as a multi-factor pollutant where the main factors are acidity, salinization, metal toxicity and sedimentation processes (Gray, 1997; Hill and Bates, 1979). In the Appalachian region of the U.S., approximately $12,000 \mathrm{~km}$ of rivers and streams are impacted by drainage from abandoned mines (Koryak et al., 2004). According to West Virginia Division of Environmental Protection (WVDEP), AMD has affected 484 streams for a total of 2,852 stream miles in West Virginia (USGS, 1997). Surface runoff polluted by iron (Fe), sulfur (S), acid and various heavy metals (copper, zinc, aluminum, manganese) has often leached away from the mines and discharged into the streams. Various active and passive treatment methods have been performed to neutralize the AMD impacts (Johnson and Hallberg, 2005). Although, active treatment can provide effective remediation of AMD, but it requires high operation costs and deals with large amount of sludge production (Chang et al., 2000). Passive biological methods for AMD treatment use wetlands, lagoons and bioreactors, but they require large land areas and higher construction costs (Neculita et al., 2007). In the last decade, co-treatment of AMD and municipal wastewater (MWW) was explored more extensively and recent developments on the co-treatment approach have created new avenues to utilize waste materials as green agent for wastewater treatment in energy producing regions (Deng and Lin, 2013; Hughes and Gray, 2013; Strosnider and Nairn, 2010). Co-treatment studies have shown significant removal of $B O D, C O D$, nutrients and metals through aerobic mixing and 
anaerobic biological reactions. As both sulfur $(\mathrm{S})$ and iron $(\mathrm{Fe})$ are prevalent elements of AMD and both are highly redox active elements, they are utilized for degradation of organics from wastewater.

Although numerous studies have been reported in literature which used sulfidogenic bioreactors to treat sulfate-rich wastewater (Dar et al., 2007; Deng and Lin, 2017; Widdel, 1988), not many studies focused on utilization of iron reduction in biological wastewater treatment. In addition to AMD, iron is predominant in many other iron containing waste materials such as coal fly ash, mill industries etc. These iron wastes can potentially be used as a source of iron for wastewater treatment.

\subsection{Applications of Iron in wastewater treatment}

Iron has been widely used in wastewater treatment for removal of pollutants chemically from wastewater. Various cheap ferric iron salts $\left(\mathrm{FeCl}_{3}, 6 \mathrm{H}_{2} \mathrm{O}\right)$ and ferrous iron salts $\left(\mathrm{FeCl}_{2}, \mathrm{FeSO}_{4} .6 \mathrm{H}_{2} \mathrm{O}\right)$ have been used for phosphorous $(\mathrm{P})$ removal from wastewater (Fytianos et al., 1998; Waite, 2002; Zhang et al., 2015). The removal mechanisms include precipitation, co-precipitation, adsorption, formation of ferric-phosphate complexes, depending on the type and concentration of iron particles, and other factors (e.g., pH, ORP) (Takács et al., 2006). P removal from wastewater before discharge into rivers and lakes is very important as it can create eutrophication problem in receiving water bodies. Different types of iron oxide minerals including ferrihydrate $\left(\mathrm{Fe}(\mathrm{OH})_{3}\right)$, goethite $(\mathrm{FeOOH})$, hematite $\left(\mathrm{Fe}_{2} \mathrm{O}_{3}\right)$, and magnetite $\left(\mathrm{Fe}_{3} \mathrm{O}_{4}\right)$ showed varied adsorption capacity for phosphorus removal (Ajmal et al., 2018). In recent years, synthesis and utilization of various iron oxide nanoparticles have also been used in heavy metal and organic contaminant adsorption due to their extremely small size, high surface area to volume ratios and superparamagnetism (Xu et al., 2012).

Fenton is a well-recognized advanced oxidation method that uses iron for removing organic and inorganic compounds from wastewater. This process utilizes iron as catalyst to form active oxygen species like $\bullet \mathrm{OH}$ that can oxidize the larger organics to smaller organics or completely mineralized them into carbon dioxide $\left(\mathrm{CO}_{2}\right)$ and water (Babuponnusami and Muthukumar, 2014, 2012; Wang et al., 2016). This process has shown high efficiency of organic removal from different types of wastewaters such as 
those containing textile, pesticide, pharmaceutical, pulp mill, olive oil and phenolic compounds (Arslan-Alaton, 2007; Benatti et al., 2006; Bianco et al., 2011). Natural ironbearing mineral materials, such as goethite, pyrite $\left(\mathrm{FeS}_{2}\right)$, hematite, magnetite, and ferrihydrite are used as the catalysts for the Fenton processes (Wang, Zheng, Zhang, \& Wang, 2016). Fenton process has been modified by combining different photochemical and electrochemical phenomena to improve the performance of organic degradation.

Ferrous iron is also commonly used to reduce sulfide toxicity and odor problem of the wastewater. Iron can precipitate with sulfide as iron sulfide and precipitate out the soluble sulfide. This can reduce the toxicity to the microorganisms present in the biological treatment systems and improve the treatment efficiency (Davison and Heaney, 1978; Waite, 2002). Ferric iron can be used in anaerobic biological treatment to oxidize organic materials and reduced to ferrous iron by iron reducing bacteria (IRB). As $\mathrm{Fe}^{3+} / \mathrm{Fe}^{2+}$ reduction potential is comparatively high $(+0.77 \mathrm{~V}$ at pH 2 and $+0.2 \mathrm{~V}$ at $\mathrm{pH} 7)$ than other electron acceptors, IRB can use this energy to respire a wide range of organic compounds. In these redox reactions, ferric iron is utilized as an electron acceptor and organic materials are used as electron donor.

\subsection{Ph.D. Research Rationale, Goal, and Objectives}

Motivated by abundance of iron and potential of utilizing iron-containing wastes for wastewater treatment, the overall goal of this research is to develop a novel $\mathrm{Fe}$ (III)-dosed anaerobic biological wastewater treatment technology to create multi-faceted benefits (no requirement of aeration, simple design and operation, low sludge production, lower emission of $\mathrm{CO}_{2}$ than aerobic process, unique reaction mechanisms for coagulation, sulfide control and organic pollutant removal, useful by-product from sludge materials).

In this research, a detailed literature review on the prospect and benefits of utilizing ferric iron in wastewater treatment was conducted (Chapter 2). This review covers all the important factors that can affect the reaction of ferric reduction coupled to organics oxidation, microbial ecology of IRB, and their interactions with other microorganisms (e.g., methanogens and SRB). Various knowledge gaps related to the application of ferric reduction in wastewater treatment were identified and research objectives were proposed to address the knowledge gaps. Ferric and Sulfate concentrations (expressed as Fe/S 
ratio) have been identified as an important regulating parameter in this kind of $\mathrm{Fe}(\mathrm{III})-$ dosed treatment process. In typical wastewater, where organic concentration is abundant, concentration of ferric and sulfate may play the major role in regulating the abundance of IRB and SRB and their subsequent performance in organic oxidation. However, the effect of $\mathrm{Fe} / \mathrm{S}$ ratio on the relationship of IRB and SRB in wastewater treatment is currently unknown. To design a treatment system like this, it is important to evaluate the performance based on the pollutant removal, kinetics and sludge production, that can help eventually for large scale application. Microbiological study can help to recognize the microbial communities of the system and their roles in pollutant oxidation. The sludge characterization is also an important part of this kind of treatment system, that can help to explore the possibility of resource recovery from the sludge materials. Transformation of the waste sludge into valuable materials and their application in different aspects can make this proposed treatment system more valuable and sustainable.

\subsubsection{Research Objectives}

The following research objectives are proposed to accomplish the research goal:

1. Identify critical factors and investigate their effects on the treatment performance of the iron-dosed wastewater treatment using batch bioreactors to develop optimal treatment conditions of the treatment method.

2. Develop a continuous $\mathrm{Fe}(\mathrm{III})$-dosed wastewater treatment to investigate technical feasibility and potential issues in long-term operation of the treatment process.

3. Evaluate the potential of resource recovery from the sludge materials produced in this treatment process.

4. Investigate chemical fate of nutrients (ammonium and phosphate) and potential of their recovery from wastewater through the $\mathrm{Fe}(\mathrm{III})$-dosed treatment.

The first research objective is set to identify the major aspects of this $\mathrm{Fe}(\mathrm{III})$-dosed treatment process, specifically the organic oxidation kinetics, microbial distribution, sludge production and their interrelations. This can ultimately help to design the treatment system for long term operation with the goal of large-scale application (Chapter 3 ). The second objective is expected to investigate the feasibility of the treatment system during 
long-term operation with a proto-type treatment system. These results can show the influence of $\mathrm{Fe} / \mathrm{S}$ ratio on four aspects (organic removal, organic oxidation rate, sludge characterization, microbial composition) of the treatment performance (Chapter 4). The third research objective is expected to explore the opportunity of extracting valuable materials like magnetite, maghemite from the sludge materials and their contribution in removing pollutants from wastewater. This can help to transform the sludge waste into useful resource (Chapter 5). The last objective is set to explore the applicability of this novel Fe(III)-dosed treatment process for nutrient removal and recovery, which will assist to remove both organics and nutrient together with the same treatment system (Chapter $6)$.

\section{References}

Ajmal, Z., Muhmood, A., Usman, M., Kizito, S., Lu, J., Dong, R., Wu, S., 2018. Phosphate removal from aqueous solution using iron oxides: Adsorption, desorption and regeneration characteristics. J. Colloid Interface Sci. 528, 145-155. https://doi.org/10.1016/j.jcis.2018.05.084

Arslan-Alaton, I., 2007. Degradation of a commercial textile biocide with advanced oxidation processes and ozone. J. Environ. Manage. 82, 145-154. https://doi.org/10.1016/j.jenvman.2005.12.021

Babuponnusami, A., Muthukumar, K., 2014. A review on Fenton and improvements to the Fenton process for wastewater treatment. J. Environ. Chem. Eng. 2, 557-572. https://doi.org/10.1016/j.jece.2013.10.011

Babuponnusami, A., Muthukumar, K., 2012. Advanced oxidation of phenol: A comparison between Fenton, electro-Fenton, sono-electro-Fenton and photo-electro-Fenton processes. Chem. Eng. J. 183, 1-9. https://doi.org/10.1016/j.cej.2011.12.010

Benatti, C.T., Tavares, C.R.G., Guedes, T.A., 2006. Optimization of Fenton's oxidation of chemical laboratory wastewaters using the response surface methodology. J. Environ. Manage. 80, 66-74. https://doi.org/10.1016/j.jenvman.2005.08.014

Bianco, B., Michelis, I. De, Vegliò, F., 2011. Fenton treatment of complex industrial wastewater: Optimization of process conditions by surface response method. J. Hazard. Mater. 186, 1733-1738.

Chang, I.S., Shin, P.K., Kim, B.H., 2000. Biological treatment of acid mine drainage under sulphate-reducing conditions with solid waste materials as substrate. Water Res. 34, 1269-1277. https://doi.org/10.1016/S0043-1354(99)00268-7

Damianovic, M.H.R.Z., Foresti, E., 2007. Anaerobic degradation of synthetic wastewaters at different levels of sulfate and COD/sulfate ratios in horizontal-flow anaerobic reactors (HAIB). Environ. Eng. Sci. 24, 383-393. 
Dar, S.A., Yao, L., Van Dongen, U., Kuenen, J.G., Muyzer, G., 2007. Analysis of diversity and activity of sulfate-reducing bacterial communities in sulfidogenic bioreactors using $16 \mathrm{~S}$ rRNA and dsrB genes as molecular markers. Appl. Environ. Microbiol. 73, 594-604. https://doi.org/10.1128/AEM.01875-06

Davison, W., Heaney, S.I., 1978. Ferrous iron-sulfide anoxic hypolimnetic interactions waters. Limnol. Oceanogr. 23, 1194-1200.

Deng, D., Lin, L.S., 2017. Continuous sulfidogenic wastewater treatment with iron sulfide sludge oxidation and recycle. Water Res. 114, 210-217. https://doi.org/10.1016/j.watres.2017.02.048

Deng, D., Lin, L.S., 2013. Two-stage combined treatment of acid mine drainage and municipal wastewater. Water Sci. Technol. 67, 1000-1007. https://doi.org/10.2166/wst.2013.653

Deng, D., Weidhaas, J.L., Lin, L.-S., 2016. Kinetics and microbial ecology of batch sulfidogenic bioreactors for co-treatment of municipal wastewater and acid mine drainage. J. Hazard. Mater. $305, \quad 200-8$. https://doi.org/10.1016/j.jhazmat.2015.11.041

Doorn, M.R.J., Towprayoon, S., Vieira, S.M.M., Irving, S.W., Palmer, C., Pipatti, R., Wang, C., 2006. Wastewater Treatment and Discharge, 2006 IPCC Guidelines for National Greenhouse Gas Inventories.

Fytianos, K., Voudrias, E., Raikos, N., 1998. Modelling of phosphorus removal from aqueous and wastewater samples using ferric iron. Environ. Pollut. 101, 123-130. https://doi.org/10.1016/S0269-7491(98)00007-4

Gray, N.F., 1997. Environmental impact and remediation of acid mine drainage: A management problem. Environ. Geol. 30, 62-71. https://doi.org/10.1007/s002540050133

Guerrini, A., Romano, G., Indipendenza, A., 2017. Energy efficiency drivers in wastewater treatment plants: A double bootstrap DEA analysis. Sustainability 9, 1-13. https://doi.org/10.3390/su9071126

Hill, R.D., Bates, E.R., 1979. Acid mine drainage and subsidence: effects of increased coal utilization. Environ. Health Perspect. Vol. 33, 177-190.

Hubert, C., Voordouw, G., 2007. Oil field souring control by nitrate-reducing Sulfurospirillum spp. that outcompete sulfate-reducing bacteria for organic electron donors. Appl. Environ. Microbiol. 73, 2644-2652. https://doi.org/10.1128/AEM.02332-06

Hughes, T.A., Gray, N.F., 2013. Co-treatment of acid mine drainage with municipal wastewater: Performance evaluation. Environ. Sci. Pollut. Res. 20, 7863-7877. https://doi.org/10.1007/s11356-012-1303-4

Jeong, T.Y., Cha, G.C., Seo, Y.C., Jeon, C., Choi, S.S., 2008. Effect of COD/sulfate ratios on batch anaerobic digestion using waste activated sludge. J. Ind. Eng. Chem. 14, 693-697. https://doi.org/10.1016/j.jiec.2008.05.006 
Johnson, D.B., Hallberg, K.B., 2005. Acid mine drainage remediation options: A review. Sci. Total Environ. 338, 3-14. https://doi.org/10.1016/j.scitotenv.2004.09.002

Koryak, M., Stafford, L.J., Reilly, R.J., 2004. Declining intensity of acid mine drainage in the northern Appalachian bituminous coal fields: Major Allegheny River tributaries. J. Am. Water Resour. Assoc. 40, 677-689. https://doi.org/10.1111/j.17521688.2004.tb04452.x

Mes, T.Z.D. de, Stams, A.J.M., Reith, J.H., Zeeman, G., 2003. Methane production by anaerobic digestion of wastewater and solid wastes, in: Reith, J.H., Wijffels, R.H., Barten, H. (Eds.), Biomethane and Biohydrogen. Status and Perspectives of Biological Methane and Hydrogen Production. pp. 58-94. https://doi.org/10.1016/j.biortech.2010.08.032

Metcalf \& Eddy, I., Tchobanoglous, G., Stensel, H.D., Tsuchihashi, R., Burton, F., 2014. Wastewater Engineering: Treatment and Resorce Recovery. McGraw-Hill, New York.

Neculita, C.-M., Zagury, G.J., Bussière, B., 2007. Passive Treatment of Acid Mine Drainage in Bioreactors using Sulfate-Reducing Bacteria. J. Environ. Qual. 36, 1. https://doi.org/10.2134/jeq2006.0066

Oude Elferink, S.J.W.H., Visser, A., Pol, L.W.H., Stams, A.J.., 1994. Sulfate reduction in methanogenic bioreactors. FEMS Microbiol. Rev. 15, 119-136.

Speece, R.E., 1983. Anaerobic biotechnology for industrial wastewater treatment. Environ. Sci. Technol. 17, 416A-427A. https://doi.org/10.1021/es00115a001

Strosnider, W.H., Nairn, R.W., 2010. Effective passive treatment of high-strength acid mine drainage and raw municipal wastewater in Potosí, Bolivia using simple mutual incubations and limestone. J. Geochemical Explor. 105, 34-42. https://doi.org/10.1016/j.gexplo.2010.02.007

Takács, I., Murthy, S., Smith, S., McGrath, M., 2006. Chemical phosphorus removal to extremely low levels: Experience of two plants in the Washington, DC area. Water Sci. Technol. 53, 21-28. https://doi.org/10.2166/wst.2006.402

USGS, 1997. U.S. Geological Survey Programs in West Virginia. Charleston.

Van Lier, J.B., Van der Zee, F.P., Frijters, C.T.M.J., Ersahin, M.E., 2015. Celebrating 40 years anaerobic sludge bed reactors for industrial wastewater treatment. Rev. Environ. Sci. Biotechnol. 14, 681-702. https://doi.org/10.1007/s11157-015-9375-5

Waite, T.D., 2002. Challenges and opportunities in the use of iron in water and wastewater treatment. Rev. Environ. Sci. Biotechnol. 1, 9-15. https://doi.org/10.1023/A:1015131528247

Wan, J., Gu, J., Zhao, Q., Liu, Y., 2016. COD capture: A feasible option towards energy self-sufficient domestic wastewater treatment. Sci. Rep. 6, 1-9. https://doi.org/10.1038/srep25054

Wang, N., Zheng, T., Zhang, G., Wang, P., 2016. A review on Fenton-like processes for organic wastewater treatment. J. Environ. Chem. Eng. 4, 762-787. 
https://doi.org/10.1016/j.jece.2015.12.016

WEF, 2009. Energy Conservation in Water and Wastewater Treatment Facilities. McGraw-Hill, Alexandria.

Widdel, F., 1988. Microbiology and ecology of sulfate and sulfur- reducing bacteria, in: Zehnder, A. (Ed.), Biology of Anaerobic Microorganisms. Wiley, New York, pp. 459586.

Xu, P., Zeng, G.M., Huang, D.L., Feng, C.L., Hu, S., Zhao, M.H., Lai, C., Wei, Z., Huang, C., Xie, G.X., Liu, Z.F., 2012. Use of iron oxide nanomaterials in wastewater treatment: A review. Sci. Total Environ. 424, 1-10. https://doi.org/10.1016/j.scitotenv.2012.02.023

Zhang, Z., Wang, Y., Leslie, G.L., Waite, T.D., 2015. Effect of ferric and ferrous iron addition on phosphorus removal and fouling in submerged membrane bioreactors. Water Res. 69, 210-222. https://doi.org/10.1016/j.watres.2014.11.011 


\section{Chapter 2: Ferric Reduction in Organic Matter Oxidation and Its Applicability for Anaerobic Wastewater Treatment: A Review and Future Aspects}

(M. Ahmed and L.-S. Lin, Ferric Reduction in Organic Matter Oxidation and Its Applicability for Anaerobic Wastewater Treatment: A Review and Future Aspects, Reviews in Environmental Science and Bio/Technology, 16(2), 273-287, 2017, DOI:10.1007/s11157017-9424-3.)

\subsection{Introduction}

A wide range of treatment technologies have been developed and explored to dwindle the impacts of wastewater generated from household and industries on aquatic ecosystems. Although aerobic treatment process has been used worldwide to achieve high degree of treatment efficiency, anaerobic wastewater treatment has been gaining increasing attention because of its simplicity, energy efficiency, low sludge production (McCarty and Smith, 1986; Speece, 1983; Van Lier, 2008; Van Lier et al., 2015). Anaerobic treatment has distinct advantages over aerobic treatment when treating high concentrated organic wastewater including emission of significantly less amounts of greenhouse gas (Chan et al., 2009). Additional benefits such as lower capital, operational and maintenance costs and technological advancement of resource recovery have helped to justify the use of anaerobic treatment over aerobic treatment (Chan et al., 2009; Manariotis and Grigoropoulos, 2002). Currently, anaerobic treatment systems have not been efficaciously in practice around the world because of inaptness of their process and inadequate capacity of the reactors to treat great amount of water (Saravanane and Murthy, 2016). But, with recent scientific advancements in microbiological processes and environmental biotechnologies, these shortcomings are readily to be overcome if have not already been. In particular, continuous development in anaerobic treatment has led to the applications of different high-rate reactor systems. Among those, anaerobic fluidized bed reactor (AFBR), fixed film reactor, anaerobic baffled reactor (ABR) and upflow anaerobic sludge blanket (UASB) have demonstrated impressive organic removal rates (Chan et al., 2009; Saravanane and Murthy, 2016).

Given the reducing conditions, opportunities exist for innovative approaches of incorporating natural redox active elements in anaerobic treatment systems. In this 
context, co-treatment of acid mine drainage (AMD) and municipal wastewater (MWW) is an example of an innovative treatment approach. It was first explored in the early twentieth century to reduce pathogens by low $\mathrm{pHs}$ and elevated metal concentrations in AMD (Roetman, 1932). Recent developments of this co-treatment approach have produced impressive results of mitigating $A M D$ and reduction of organic materials from wastewater (Deng and Lin, 2013; Hughes and Gray, 2013; Strosnider et al., 2011). Strosnider et al. (2011) studied a co-treatment of synthetic AMD and municipal wastewater to reduce the biological oxygen demand (BOD), nutrients and metals in a four stage passive process. A two stage co-treatment consisting of aerobic mixing and anaerobic biological treatment was recently tested and has shown significant chemical oxygen demand (COD) removal and sulfate reduction (>80\%) under COD/sulfate ratios ranging from 0.6 to 5.4 in anaerobic biological reactors (Deng and Lin, 2013). The two stage treatment also resulted in an average $75 \%$ reduction of a range of metals and excellent phosphorus removal. The kinetics and microbial ecology of the biological system were later quantified and characterized, with both affected by COD/sulfate ratio and iron concentrations (Deng et al., 2016). Hughes and Gray (2013) examined a cotreatment process by injecting AMD in different forms of organic wastes (i.e., raw AMD, pre-treated $A M D$ and pre-treated $A M D$ with screened MWW) and reported substantial removal of $C O D, B O D$, total organic carbon (around $90 \%$ ) with continuous loading of AMD into an activated sludge reactor.

Given high levels of sulfate in AMD, treatment of AMD has mainly focused on using sulfate reducing bacteria (SRB) to reduce sulfate to (bi)sulfide and metal sulfide precipitation by providing organics as electron donors. Iron is also a prevalent element in AMD as well as in a wide range of iron containing wastes. While numerous studies have been conducted to evaluate the performance of sulfidogenic bioreactors for treating sulfate-rich wastewater (Dar et al., 2007; Oude Elferink et al., 1994; Widdel, 1988), only limited studies on iron amendment and its effects on sulfidogenic treatment can be found in literature. The studies examining iron reduction processes and iron reducers in the literature mostly focused on sediment and soil systems (Jensen et al., 2003; Lovley, 1987; Roden and Wetzel, 2002; Urrutia et al., 1998) and studies related to wastewater is extremely scarce. 
This review focuses on fundamentals of iron reduction process in organics oxidation and potential utilities of iron reducing bacteria (IRB) for removing organic matters from wastewater. Specifically, significance of ferric reduction process and its applicability in oxidizing organic matters are reviewed. This review also covers applications of iron reduction process in environmental remediation and microbial ecology of IRB and their interactions with other microorganisms such as SRB and methanogens. Knowledge gaps in applying iron reduction in wastewater treatment are identified and its future research scope is discussed.

\subsection{Significance and fundamentals of iron reduction process}

A main feature of anaerobic/anoxic wastewater treatment is the use of alternative electron acceptors other than oxygen for organics oxidation. In such environments, metabolic energy is supplied by oxidation of organic carbons and reduction of ions like sulfate, nitrate, and ferric ions. Microbial reducers utilizing these alternative electron acceptors such as SRB, IRB, denitrifying bacteria can provide diverse metabolic pathways for oxidation of organic and inorganic wastes. Given its abundance in the environment, reduction of ferric iron has long been recognized as an important biologically-mediated process with significant influence on the fate of organic and inorganic pollutants.

The fundamental iron reduction process involves $\mathrm{Fe}^{3+} / \mathrm{Fe}^{2+}$ redox pair in which ferric ion is reduced to ferrous ion by receiving an electron from an electron donor. Dissimilatory IRB gain their energy for their metabolic functions and growth. This reduction half reaction (i.e., $\mathrm{Fe}^{3+}+\mathrm{e}^{-} \rightarrow \mathrm{Fe}^{2+}$ ) has a standard redox potential of $+0.77 \mathrm{~V}$ at $\mathrm{pH} 2$ and $+0.2 \mathrm{~V}$ at $\mathrm{pH}$ 7 (Madigan et al., 2015). However, this potential can vary from $-1 \vee$ to $+1 \vee$ due to the instability of complex compounds and dissimilar stability constants (Pierre et al., 2002). As $\mathrm{Fe}^{3+} / \mathrm{Fe}^{2+}$ reduction potential is comparatively high than other electron acceptors, ferric reducers can use this energy to respire a wide range of organic compounds. As a result, large number of organic materials can be used as a substrate by IRB as a mechanism of decomposing the organic matters. In the case of sulfate rich wastewater, ferric reduction and sulfate reduction can occur concurrently (Eq. 1 \& Eq. 2) and form ferrous sulfide (FeS) precipitation (Eq. 3). 
$\mathrm{Fe}^{3+}+$ Organic Compound $\longrightarrow \mathrm{Fe}^{2+}+\mathrm{HCO}_{3}{ }^{-}+\mathrm{CO}_{2}+\mathrm{H}^{+}$

$\mathrm{SO}_{4}{ }^{2-}+$ Organic Compound $\longrightarrow \mathrm{H}_{2} \mathrm{~S}+\mathrm{HCO}_{3}{ }^{-}+\mathrm{CO}_{2}+\mathrm{H}^{+}$

$\mathrm{Fe}^{2+}+\mathrm{H}_{2} \mathrm{~S} / \mathrm{HS}^{-} \longrightarrow \mathrm{FeS}+\mathrm{H}^{+}$

Previous studies have shown various $\mathrm{Fe}^{3+}$ compounds as electron acceptors are effective for organic matter mineralization in groundwater, soils and sediments (Lovley, 1995, 1987). This ferric to ferrous transformation can be an effective mechanism for organic oxidation in addition to its contribution to iron cycle in aquatic environments. For example, sediments found with comparatively higher concentration of $\mathrm{Fe}^{3+}$ than the other electron acceptors have the potential to use iron as oxidant to mineralize organic matters with releasing nutrients such as phosphate and trace metals adsorbed on ferric oxyhydroxides. In such sediment systems, most of the organic carbon has been found to be retained in the fermentation products (Lovley and Phillips, 1986). With amorphous ferric as terminal electron acceptor, major fermentation products of acetate could be oxidized (Kamura et al., 1963).

Another oxidation pathway involving ferric reduction is known as ferric ammonium oxidation (Feammox). In strict anaerobic condition, ferric reduction has been found to be an effective process to oxidize ammonium (Clément et al., 2005; Sawayama, 2006; Yang et al., 2012). Sawayama (2006) reported the evidence of ammonium oxidation to nitrate by IRB with $\mathrm{Fe}^{3+}$ EDTA as an oxidizing agent. This process was also observed to be thermodynamically feasible by Clément et al. (2005) by using goethite as the iron source for ferric reduction in wetland soils. All these examples substantiated the significance of ferric reduction process in remedying environmental pollutants.

\subsection{Organic oxidation by ferric reduction}

\subsubsection{Factors effecting the ferric reduction}

A number of factors have been reported to affect organics oxidation in iron reduction process, including the types of the ferric compound, microorganisms, and availability of substrate (Lovley, 1987). In general, increasing degree of crystallinity of the iron source materials results in lower iron reduction. Less crystalline or amorphous compounds have larger surface areas and higher solubility rate compared to highly crystalline ferric 
materials (Lovley, 1987). A sequence of preference had been established on different ferric compounds as $\mathrm{FePO}_{4} \cdot 4 \mathrm{H}_{2} \mathrm{O}>\mathrm{Fe}(\mathrm{OH})_{3}>\gamma-\mathrm{FeOH}>, \alpha-\mathrm{FeOH}>\mathrm{Fe}_{2} \mathrm{O}_{3}$ with respect to their microbial reduction rate (Munch and Ottow, 1983). This sequence corroborated on the hypothesis of decrease in microbial reduction rate with high crystallinity. Solubility of ferric compounds is another major factor to be considered in ferric reduction process. Most of the ferric compounds are highly insoluble and found as solid forms in nature. Due to this reason, ferric reduction may be hindered in sediments by other reducers such as denitrifiers, sulfate reducers, and methanogens that use highly soluble substrates (i.e., nitrate, sulfate, and carbon dioxide). Because of the low solubility of $\mathrm{Fe}^{3+}$ compounds, IRB may require direct contact with the surface of compounds to achieve the reduction process (Lovley, 1987). In this regard, addition of $\mathrm{Fe}^{3+}$ chelating agents (e.g. Fe ${ }^{3+} \mathrm{NTA}$, $\mathrm{Fe}^{3+}$ citrate) can increase bacterial iron reduction (Lovley and Phillips, 1988) and enhance ferric reduction rate of the cultures (Arnold et al., 1986; Jones et al., 1983).

Ferric reduction process has also been found to be $\mathrm{pH}$ dependent. Percentage of iron reduction was decreased when the seawater-nutrient medium was acidified and $\mathrm{pH}$ was decreased (De Castro and Ehrlich, 1970). With soil humic acid as a substrate, Chen et al. (2003) reported slower and lower ferric reduction capacity under a low pH condition (< $4)$, and an improved reduction capacity with a higher $\mathrm{pH}(>4)$.

Different pure ferric reducing cultures have been utilized in carbon oxidation studies (Arnold et al., 1988; Hyun et al., 1999; Lonergan et al., 1996; Lovley, 1995). These microorganisms gain their energy by the oxidation of organic materials or other available substrates via extracellular iron reduction, a process which is known as 'extracellular respiration' (Esther et al., 2015). Geobacter metallireducens, also known as GS-15 was first isolated and used as the model ferric reducing microorganism in several studies (Lovley, 1995; Lovley and Lonergan, 1990; Lovley and Phillips, 1988). This iron reducer was found to generate different biogenic iron products with different ferric compounds. For example, with acetate as the electron donor, amorphous ferric oxide was reduced to magnetite $\left(\mathrm{Fe}_{2} \mathrm{O}_{3}\right)$, and ferric citrate was reduced to ferrous compound. Shewanella $\mathrm{Sp}$. has also been identified as an important and effective ferric reducer (Hyun et al., 1999; Lovley, 1993; Nealson and Myers, 1990). The direct contact between the cells of 
microorganism and solid surface might be required for the ferric oxyhydroxide reduction by Shewanella putrefaciens, which reveals the occurrence of ferric reduction at membrane-bound sites (Arnold et al., 1988; Beliaev and Saffarini, 1998). A detail section has been presented on the microbial iron reduction process and ecological diversity of these iron reducers in later part of this paper.

The effectiveness of $\mathrm{Fe}^{3+}$ reduction process in organic matter decomposition also depends on the competition of IRB with SRB and methanogens for electron donors. With amorphic ferric oxide added to sediments, $\mathrm{Fe}^{3+}$ reduction process was observed to inhibit sulfate reduction by $90 \%$ and methane production by $50-90 \%$ where sulfate reduction and methane production was the major terminal electron acceptors respectively (Lovley and Phillips, 1987). In sediments, IRB can divert the electron flow away from SRB and methanogens and maintain low concentration of major substrates. As a result, SRB and methanogens do not get the enough substrate for metabolizing. Thermodynamically, ferric iron is a more favorable electron acceptor than sulfate and $\mathrm{CO}_{2}$ (Madigan et al., 2015), causing this electron flow diversion. In some cases, however, ferric reduction was not found to hinder the sulfate reduction and methane production with sufficient substrate available in the environment (Lovley and Phillips, 1987) and co-existence of ferric reduction and sulfate reduction were observed (Achtnich et al., 1995; Thomsen et al., 2004). Distinct to sediments, wastewater contains high amount of organic materials and availability of substrate may not be a limiting factor for sulfate reduction and methane production. However, evidences have been found where ferric reduction process inhibited the sulfate reduction and methane production in wastewater (Zhang et al., 2009). Utgikar et al. (2002) suggested that precipitation of metal sulfide on the surface of sulfate reducers and methanogens might be a possible reason behind such inhibition. But, the authors recommended further research at cellular and enzymatic levels to validate this hypothesis.

\subsubsection{Kinetics of ferric reduction in organics oxidation}

Most of the studies examining the kinetics of ferric reduction in organic matter oxidation focused on aquatic and freshwater sediment systems (Bonneville et al., 2004; Jensen et al., 2003; Roden and Wetzel, 2002; Thamdrup, 2000). Bioavailability of amorphous or 
poorly crystalline $\mathrm{Fe}^{3+}$ is an important factor and their concentration has been used as a variable for quantifying the ferric reduction rate as well as a predictor of the contribution of $\mathrm{Fe}^{3+}$ reduction to carbon mineralization (Lovley and Phillips, 1987, 1988). Jensen et al. (2003) quantified the ferric reduction rate in a marine sediment system and found that the organics mineralization was highly correlated with the concentration of poorly crystalline $\mathrm{Fe}^{3+}$. The authors then justified the use of $\mathrm{Fe}^{3+}$ concentration for estimating the ferric reduction rate. The study assumed only iron and sulfate reductions contributed to anaerobic carbon oxidation and the individual reduction rates were combined to derive a ferric reduction rate expression.

The Monod model has been used to characterize microbial ferric reduction by several iron reducers. Liu et al. (2001) studied goethite $(\alpha-\mathrm{FeOOH})$ reduction rate with lactate as the electron donor using a $S$. putrefaciens culture. The ferric bioreduction rate and extent were quantified with respect to the electron donor and electron acceptor. The initial ferric reduction rate was found to increase with increasing goethite and lactate concentrations. The authors used $\mathrm{FeOOH}$ sorption capacity for $\mathrm{Fe}(\mathrm{II})$ as a surrogate measure of the electron acceptor concentration to normalize the $\mathrm{Fe}(\mathrm{III})$ bioreduction rate. The normalized bioreduction rate was fairly constant $\left(\sim 0.027 \pm 0.0023 \mathrm{~h}^{-1}\right)$ over varied $\mathrm{FeOOH}$ concentrations, indicating a first-order relationship of the ferric bioreduction with the goethite surface area for the concentration range examined. Whereas, the normalized bioreduction rate was well characterized by the Monod rate expression as a function of the lactate concentration with the maximum rate $0.029 \pm 0.002 \mathrm{~h}^{-1}$ and half-saturation constant $0.52 \pm 0.1 \mathrm{mM}$. Another Fe(III)EDTA- reduction study has been done by Van der Maas (2005) in BioDeNOx reactors with different electron donors. The highest reduction rate has been observed by glucose $\left(13.9 \mathrm{mM}^{-1}\right)$ followed by ethanol $\left(8.2 \mathrm{mM} \cdot \mathrm{h}^{-1}\right)$,

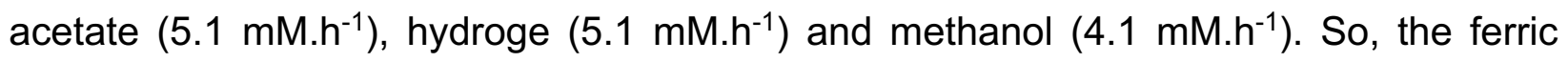
reduction rate can fluctuate respect to the type of electron donors.

Bonneville et al. (2004) investigated the changes in ferric reduction rate with different forms of ferric oxyhydroxide with lactate as an electron donor. Using the MichaelisMenten kinetics with $\mathrm{Fe}^{3+}$ concentration as the substrate for the rate expression, the maximum reduction rate $\left(V_{\max }\right)$ varied from $0.2 \times 10^{-11}$ to $399 \times 10^{-11} \mu \mathrm{mol} \mathrm{h}^{-1} \mathrm{cell}^{-1}$. The 
highest rates were observed with ferric citrate as the reductant and the lowest rate was obtained with hematite. A positive correlation was observed between the solubility of the ferric hydroxides with the maximum ferric reduction rate. Postma (1993) showed that the kinetic reactivity of iron oxides can be distinctive from each other by comparing the reduction rate of ferrihydrate with reductive dissolution of hematite and goethite. At same $\mathrm{pH}$, the ferric reduction rate of ferrihydrate had been observed much higher than hematite and goethite. At $\mathrm{pH} 3$, the initial reduction rate of ferrihydrate was $1.2 \times 10^{-8} \mathrm{~mol} \mathrm{~s}^{-1} \mathrm{~m}^{-2}$ whereas the initial reduction rate was $6.1 \times 10^{-11} \mathrm{~mol} \mathrm{~s}^{-1} \mathrm{~m}^{-2}$ for hematite and $1.8 \times 10^{-11}$ mol s$~^{-1} \mathrm{~m}^{-2}$ for goethite (Banwart et al., 1989; Zinder et al., 1986). It was concluded that ferrihydrate dissolved much faster than hematite and goethite, resulting in 180 times faster reaction rate than hematite and 100 times faster than goethite.

Roden and Wetzel (2002) used a first-order rate expression to model $\mathrm{Fe}^{3+}$ oxide concentration as a function of time in sediments from a freshwater wetland system. The rate expression contained a fraction of ferric oxide as non-reacting. The study found that the exponential decrease in ferric reduction with time was most likely due to limited availability of $\mathrm{Fe}^{3+}$ oxide rather than organic matters. This study also provided an evidence to support the hypothesis that in wetland sediments, ferric reduction rate followed a first order relationship with amorphous $\mathrm{Fe}^{3+}$ oxide concentration.

\subsubsection{Iron reduction process in environmental remediation}

The potential of IRB to be employed in environmental remediation can be measured by the degree to which the IRB can utilize ferric compounds in successful organic oxidization and removal of organic pollutants from environment. Several aliphatic and aromatic organic compounds have been reported to be successfully oxidized by ferric reduction (Azam and Finneran, 2013; Lovley and Lonergan, 1990; Lovley and Phillips, 1988). In this section, evidences of aliphatic and aromatic organic matter oxidation reported in the literature are summarized.

\section{$\mathrm{Fe}^{3+}$ reduction in aliphatic compound oxidation}

Azam and Finneran, (2013) successfully demonstrated that various ferric amendments increased the rates and extent of mineralization of carbon compounds to different degrees in a septic tank system. Lepidocrocite and $\mathrm{Fe}^{3+}$ EDTA were found as the most effectual 
ferric compounds with high mineralization rate compared to $\mathrm{Fe}^{3+}$ citrate, ferrihydrate, $\mathrm{Fe}^{3+}$ NTA and $\mathrm{Fe}^{3+}$ pyrophosphate. Lepidocrocite achieved maximum mineralization rate for acetate $(92 \%)$, lipid $(98 \%)$ and lactate $(82 \%)$ and $\mathrm{Fe}^{3+}$ EDTA attained the highest mineralization of glucose $(74 \%)$, starch $(93 \%)$ and butyrate $(88 \%)$. The ferric amendment increased the generation of carbon dioxide and reduced the rate of greenhouse gas methane $\left(\mathrm{CH}_{4}\right)$ production. While most of the ferric compounds showed better results in carbon mineralization, there were exceptions such as ferric citrate which actually had a decreased mineralization rate of acetate. Fermentation of citrate to acetate was probably the reason of this anomaly (Azam and Finneran, 2013). Finneran and Lovley (2001) studied anaerobic degradation of methyl tert- butyl ether (MTBE) and tert-butyl alcohol (TBA) in aquatic sediments amended with poorly crystalline ferric oxide. The study found that approximately 30 moles of $\mathrm{Fe}^{3+}$ compound was required to completely oxidize MTBE, and addition of humic substances stimulated the degradation. In their study, rapid degradation of TBA was observed in a strictly anaerobic condition which differed the observation of slow degradation of TBA in previous studies.

\section{$\mathrm{Fe}^{3+}$ reduction in aromatic compound oxidation}

Groundwater contaminated by organic materials develops an anaerobic environment in the aquifer and aromatic hydrocarbons present in this anaerobic condition can be oxidized by reducers using nitrate, sulfate and iron as electron acceptor (Lovley et al., 1989; Major et al., 1988; Reinhard et al., 1984; Wilson et al., 1986). Geochemical evidences of accretion of $\mathrm{Fe}^{2+}$ precipitation in groundwater systems and depletion of $\mathrm{Fe}^{3+}$ from the aquifer sediments have suggested the applicability of ferric reduction as a remedial mechanism for groundwater systems contaminated by aromatic hydrocarbons (Major et al., 1988; Reinhard et al., 1984; Wilson et al., 1986). Previous studies have shown the effective decomposition of aromatic carbons by injecting ferric compounds (Lovley, 1995; Lovley and Lonergan, 1990; Lovley and Phillips, 1988).

Various monoaromatic compounds (benzene, xylene, toluene) have been found to be oxidized by microorganisms such as GS-15 using $\mathrm{Fe}^{3+}$ as the major electron acceptor. In one of the preliminary experiments by Lovley et al. (1989), toluene was successfully oxidized with poorly crystalline ferric oxide to carbon dioxide. More different aromatic 
compounds (toluene, phenol and p-cresol) were later shown oxidized by an enriched culture of GS-15 in the ferric reduction process (Lovley and Lonergan, 1990). Thirty six (36) moles of ferric oxide was required to completely oxidize 1 mole of toluene to carbon dioxide where ferric oxide was the sole oxidant. Likewise, 28 and 34 moles of ferric compound were required for oxidation of phenol and p-cresol respectively. The oxidation rates were highly varied with the type of ferric compounds that were used in the experiment. In contrast to the toluene oxidation with ferric oxide, 108 moles of ferric hydroxide, $\mathrm{Fe}(\mathrm{OH})_{3}$ were required to oxidize 1 mole of toluene. However, these stoichiometric ratios do not represent the actual amounts as these metabolic reactions are much more complicated. Various forms of $\mathrm{Fe}^{2+}$ and $\mathrm{Fe}^{3+}$ and incorporation of some organic compounds on the cells of reducing microorganisms may be the reason for this complexity. Furthermore, these reactions are endothermic as good amount of energy is produced for the cell growth (Lovley and Lonergan, 1990).

\subsection{Microbial processes of iron reduction and ecology}

Iron reducing bacteria gain their energy by the oxidation of organic materials or other available substrates via extracellular iron reduction, a process known as 'extracellular respiration' (Esther et al., 2015). Different mechanisms of microbial iron reduction have been proposed which include direct and indirect contact of IRB with the iron minerals (Esther et al., 2015; Weber et al., 2006). Also, a wide range of microorganisms belong to different taxa have been identified as iron reducers which can adapt to different chemical environments.

\subsubsection{Microbial processes of iron reduction}

The microbial iron reduction is mainly transpired by extracellular electron transfer from iron reducers to the solid surface of the $\mathrm{Fe}^{3+}$ compounds, typically insoluble $\mathrm{Fe}^{3+}$ oxide minerals. Several strategies of electron transference had been investigated and reported in the literature (Esther et al., 2015; Weber et al., 2006), and the strategies are dependent on the type of microorganism and the surrounding environment. In microbial ferric reduction, interaction of iron reducers with ferric mineral surface is often interceded by the formation of biofilm that is composed of extra polymeric substance (EPS) matrix (Franks et al., 2010; Thormann et al., 2004). Electron transfer is then mediated by the 
EPS as it creates support for electron transport proteins to attach with the microbes and improves the conductivity of the biofilm. Four approaches have been hypothesized by researchers on the interactions of microbial cells and $\mathrm{Fe}^{3+}$ surface which are illustrated in Fig. 3:

1. Direct contact between the bacteria surface and $\mathrm{Fe}^{3+}$ surface

2. Contact through pili, which is also known as 'protein nanowires'

3. Contact by using complex ligands which solubilize the $\mathrm{Fe}^{3+}$ compound

4. Electron shuttle which facilitates the electron transfer from and to solid $\mathrm{Fe}^{3+}$ surface

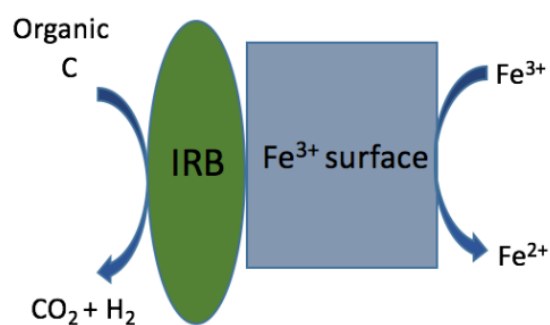

(a)

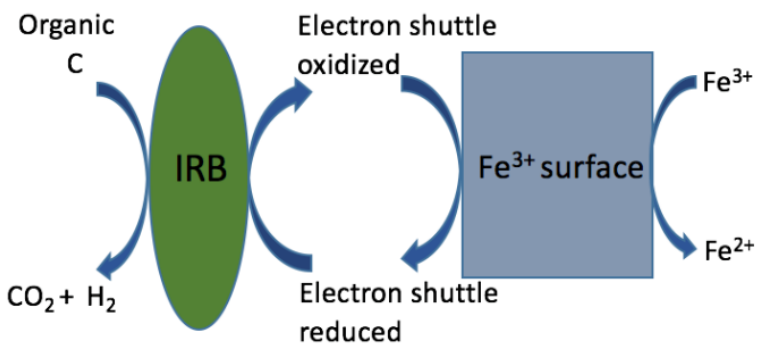

(c)

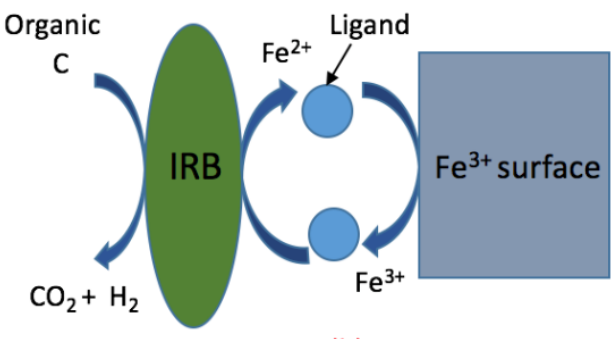

(b)

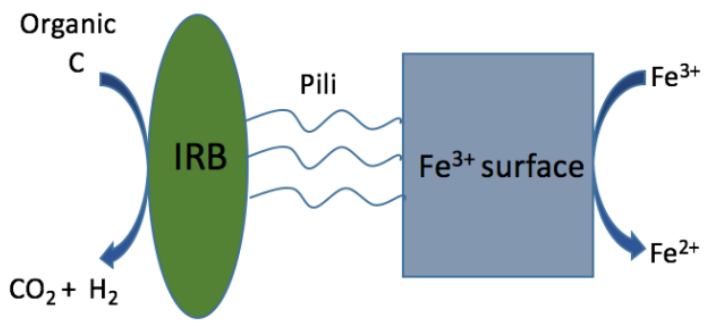

(d)

Fig. 3: Different strategies of microbial and ferric surface interaction (a) Direct Contact, (b) Contact with ligand, (c) Contact with electron shuttle, (d) Contact with nanowires; adapted from Esther et al. (2015).

Understanding the complex interactions between iron surface and microorganism is a convoluted task. Most of the research on microbial iron reduction has been progressed around two model iron reducers: Geobacter and Shewanella (Esther et al., 2015; Fredrickson and Gorby, 1996; Lovley, 1993; Nealson and Myers, 1990; Weber et al., 
2006). The interactions of these two reducers with the ferric surface are quite dissimilar from each other. Shewanella has been found to have direct and indirect electron transfer to insoluble $\mathrm{Fe}^{3+}$ surface, including protein nanowires. In contrast, Geobacter species are strictly anaerobe and do not contain enough electron shuttling or chelating compounds to solubilize $\mathrm{Fe}^{3+}$ and hence have been found to mostly rely on pilin filaments (Esther et al., 2015). Direct electron transfer by Shewanella oneidensis occurs by following the "porincytochorme model' via a Mtr pathway. This Mtr pathway was formed by four multi-heme cytochromes (MtraA, MtrB, CymA and OmcA) and one non-heme protein MtrB (Beliaev et al., 2001; Myers and Myers, 1997, 2001; Pitts et al., 2003) that help in transferring electrons to the cell surface (Esther et al., 2015). The development of nanowire like pili was assumed as a requirement for the attachment of bacteria with ferric surface. But, later evidences showed, it works more likely as an electron conduit rather than an attachment medium (Weber et al., 2006). These conductive nanowires help to increase the spatial area outside the cell membrane and improve the cell to cell communications. Eventually, it improves the electron transfer to insoluble ferric oxide surface and other potential electron acceptors. Soluble redox-active compounds can serve as exogenous and endogenous electron shuttles mediating indirect electron transfer between iron reducers and the ferric mineral surfaces (Weber et al., 2006). Exogenous electron shuttles (e.g., humic substances and sulfur compounds) are compounds present in the surrounding environment and endogenous electron shuttles are mainly secreted from the microorganism itself (Esther et al., 2015). These compounds are reduced by the ferric reducers upon oxidization of an electron donor and that reduced electron shuttle subsequently diffuses and donates electrons to ferric oxide abiotically. These strategies are mainly investigated in sediments, submerged soils and aquifers, and are conceptually applicable in new applications of ferric reduction such as wastewater treatment.

\subsubsection{Roles of iron reducing bacteria}

Various bacterial strains have shown effectiveness to catalyze organics oxidation reactions coupled with ferric reduction. Dissimilatory ferric reducers have been shown to facilitate oxidation of glucose, amino acid, aromatics, long and short chain fatty acids (Lovley, 1993; Lovley and Phillips, 1989). Fermented sugar and amino acid could be 
metabolized by $\mathrm{Fe}^{3+}$ reducers to produce two major fermentative products: acetate and hydrogen $\left(\mathrm{H}_{2}\right)$. Other fermentative products include propionate and formate which could subsequently be transformed into $\mathrm{CO}_{2}$ with the help of Geobacter Desulfuromonas and Shewanella desulfovibrio, respectively (Lovley, 1993). Glucose can be oxidized directly to $\mathrm{CO}_{2}$ with $\mathrm{Fe}^{3+}$ as the electron acceptor but the microorganisms that conduct this transformation are still unknown. However, these bacterial strains would be at detriments compared to the fermentative bacterial strain as glucose is always found to be fermented rather than directly oxidized to $\mathrm{CO}_{2}$ in $\mathrm{Fe}^{3+}$ reducing sediments (Lovley and Phillips, 1989). Fig. 4 illustrates different pathways of organic matter oxidation coupled with ferric reduction and various microorganisms that have been found to catalyze the reactions. Although, most of the attempts to isolate these unknown species were unsuccessful, thermodynamic consideration has supported the assumption. Strains that help oxidize long chain fatty acids are still unknown whereas the aromatics are generally oxidized by Geobacter species with $\mathrm{Fe}^{3+}$ as the solitary electron acceptor (Lovley, 1993).

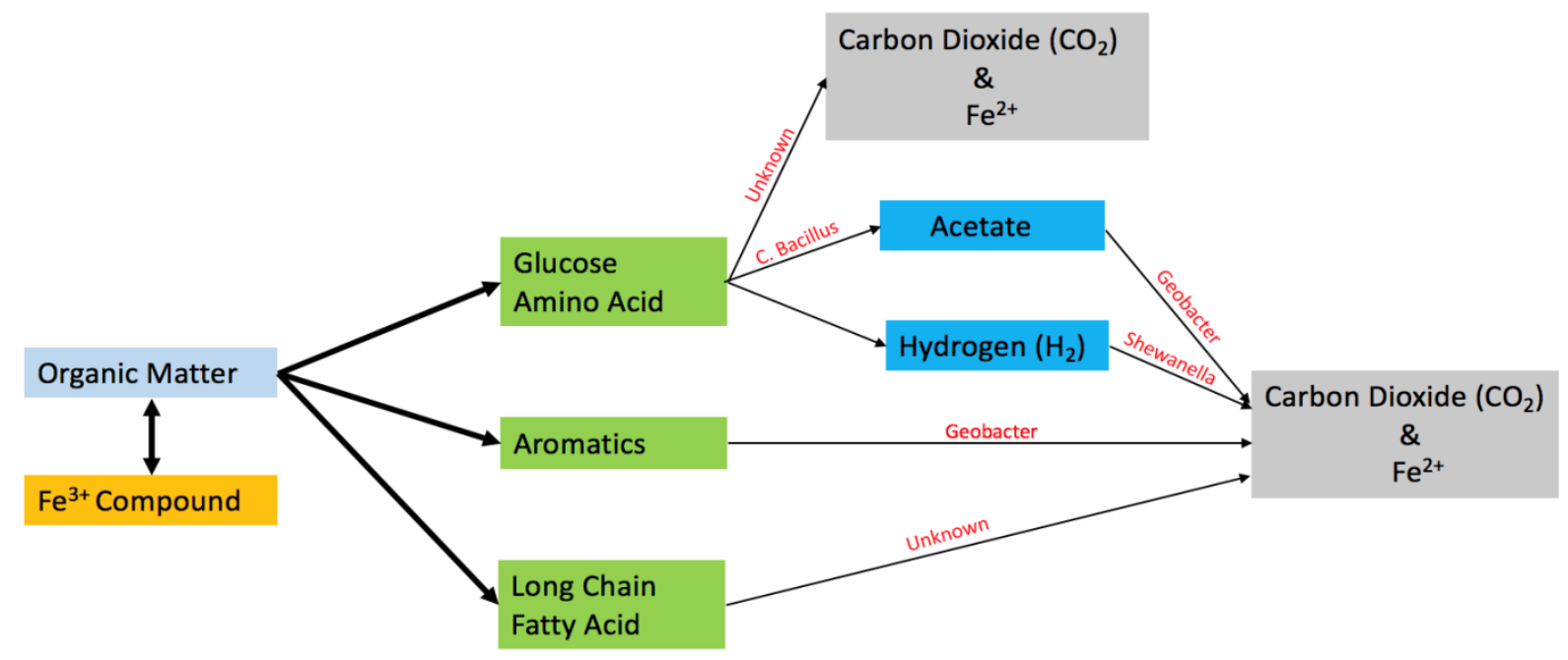

Fig. 4: Oxidation of organic matters with ferric reduction adapted from Lovley (1993) Apart from IRB, the iron reduction competency of anaerobic ammonium oxidation (Anammox) bacteria in wastewater has been investigated in several studies (Park et al., 2009; Zhao et al., 2014). The iron reduction ability of anammox bacteria showed impressive results when organic matters were used as electron donors and can be an impending way of removing ammonium from wastewater treatment. The heterotrophic 
IRB and autotrophic anammox bacteria compete against each other for utilizing ferric, but with the rising of nitrate production, the anammox bacteria outcompete the heterotroph (Park et al., 2009). However, the iron reduction activity of anammox bacteria was inhibited to around $93 \%$ when nitrite was coinciding with ferric compound. The performance of anammox bacteria in iron reduction varied with respect to the electron donors and acceptors (Zhao et al., 2014). Among formate, acetate and propionate, formate had been found as the most effective electron donor with the highest production of $\mathrm{Fe}^{2+}$ concentration ( 179.64 $\left.\mathrm{mol} \mathrm{L}^{-1}\right)$. Between $\mathrm{Fe}^{3+} \mathrm{NTA}$ and $\mathrm{Fe}^{3+}$ EDTA, first complex had better results as an electron donor at $\mathrm{pH} 7$.

\subsubsection{Diversity of iron reducing microorganisms}

A wide variety of bacteria and archaea belonging to diverse taxa have been found to perform the ferric reduction in different physical and chemical conditions (Esther et al., 2015; Fredrickson and Gorby, 1996; Weber et al., 2006), suggesting prevalence of these ferric reducers in the environment. Most of the bacterial iron reducers belong to the Firmicutes, Proteobacteria, Deferibacteres and Actinobacteria taxa where the proteobacteria are categorized in different classes as $\alpha$-Proteobacteria, $\beta$ Proteobacteria, $\Delta$ Proteobacteria and $\gamma$ Proteobacteria. They can be categorized as thermophilic, mesophilic, alkaliphilic, alkali-thermophilic, acido-thermophilic according to different adaptable conditions (Esther et al., 2015; Weber et al., 2006).

Model iron reducers Geobacter Sp. and Shewanella Sp. both belong to the group of Proteobacteria where Geobacter Sp. resides in delta sub division and Shewanella sp. in gamma sub division. Shewanella $S p$. generally use lactate as carbon source and oxidize it to acetate, and Geobacter Sp. use acetate and completely oxidize it to $\mathrm{CO}_{2}$ (Esther et al., 2015; Fredrickson and Gorby, 1996). Geobacter metallireducens, also known as GS15 is one of the oldest and common ferric reducers which showed the capacity to reduce not only iron oxides but also $\mathrm{Mn}^{4+}$ and $\mathrm{NO}_{3}^{-}$. GS-15 has been found to oxidize several carbon compounds to $\mathrm{CO}_{2}$ by using $\mathrm{Fe}^{3+}$ (Nealson and Myers, 1990). Some of the ion reducers have been found to be closely linked with sulfur reducers belonging to the same taxa and using same electron acceptor for growth. For example, Geobacter acetoxidans, another member of delta Proteobacteria have shown similarity with Desulfuromonas 
acetoxidans, a sulfur reducing bacteria (Fredrickson and Gorby, 1996) as both can use $\mathrm{Fe}^{3+}$ as electron acceptor for growth. Pelobacter carbinolicus has also shown ability to couple $\mathrm{Fe}^{3+}$ with oxidation of fermentation products and has an analogous phylogenetic relationship with Geobacter and Desulfuromonas. Pelobacter Sp. generally uses formate, ethanol and $\mathrm{H}_{2}$ as electron donors with $\mathrm{Fe}^{3+}$ as the electron acceptor. These bacterial strains were mainly isolated from iron-rich sediments. Apart from these, $G$. sulfurreducens and $D$. palmitatis which were isolated from submerged soils of a ditch and marine sediments, respectively, have been discovered to use $\mathrm{Fe}^{3+}$ as sole electron acceptor. Desulfuromusa kysingii and Desulfuromusa bakaii have also found to utilize $\mathrm{Fe}^{3+}$ as electron acceptor but were isolated as sulfur reducers. These findings supported the hypothesis that there are some sulfate reducers which can reduce $\mathrm{Fe}^{3+}$ as electron acceptor. Nevertheless, sulfate reducers with only iron as sole electron acceptor has not been found in any literature (Lonergan et al., 1996).

Shewanella putrefaciens, also known as MR-1, is a facultative anaerobe, in contrast to the Geobacter Sp. which is a strict anaerobe. This bacterial strain was isolated from a culture that used non-fermentable carbon as electron donor (Nealson and Myers, 1990). But, it has the capacity to use a wide range of electron donors including iron, manganese etc. Shewanella $S p$. is most effective in ferric reduction with lactate as the electron donor and the least effective with succinate. Although, these bacteria are proficient to preserve energy by ferric reduction, but possess extremely limited capacity to utilize organic matters as electron donors. Incomplete oxidation of lactate and pyruvate to acetate is commonly found redox reaction facilitated by these bacterial species (Lonergan et al., 1996). Similar to S. putrefaciens, BrY and Desulfovibrio species have also been noticed for their ability to oxidize lactate to acetate and $\mathrm{CO}_{2}$ coupling with $\mathrm{Fe}^{3+}$ reduction (Lovley, 1993). Shewanella $S p$. is also capable of reducing more crystalline form of ferric oxides compared to other iron reducers which reduce only amorphous or poorly crystalline ferric oxides. This revelation has helped to support the supposition that structure of ferric compound can also control the diversity of ferric reducing bacteria (Fredrickson and Gorby, 1996). A thermodynamically unfavorable magnetite reduction by S. putrefaciens has also been discovered, which has made them a bacterial strain of significant importance. In this case, formate or lactate could have been used by the S. putrefaciens 
to reduce magnetite. These finding can ultimately help to understand the ecological diversity of iron reducers in the wastewater with different compositions. A list of major iron reducers that can reduce $\mathrm{Fe}^{3+}$ compounds is provided below with their major characteristics (Table 1):

Table 1: Major iron reducing bacteria and their primary electron donors

\begin{tabular}{|c|c|c|c|c|}
\hline $\begin{array}{l}\text { SI } \\
\text { No. }\end{array}$ & Bacterial strain & $\begin{array}{l}\text { Adaptable } \\
\text { condition }\end{array}$ & Electron donors & Reference \\
\hline 1 & $\begin{array}{l}\text { Geobacter } \\
\text { fertireducens }\end{array}$ & Mesophilic & $\begin{array}{l}\text { Acetate, volatile fatty } \\
\text { acid, alcohol }\end{array}$ & Lovley (1993) \\
\hline 2 & $\begin{array}{l}\text { Shewanella } \\
\text { putrefaciens }\end{array}$ & Mesophilic & $\begin{array}{l}\text { Formate, lactate, } \\
\text { pyruvate }\end{array}$ & Hyun et al. (1999) \\
\hline 3 & $\begin{array}{l}\text { Aquaspirillum } \\
\text { magnetotacticum }\end{array}$ & Microaerophilic & Succinate & $\begin{array}{l}\text { Guerin and Blakemore } \\
\text { (1992) }\end{array}$ \\
\hline 4 & G.metallireducens & Mesophilic & $\begin{array}{l}\text { Mono aromatic } \\
\text { compounds like toluene, } \\
\text { p-cresol, and phenol }\end{array}$ & Lovley et al. (1989) \\
\hline 5 & G. chapelleii & Mesophilic & Acetate, Hydrogen & Lonergan et al. (1996) \\
\hline 6 & $\begin{array}{l}\text { G. } \\
\text { hydrogenophilus }\end{array}$ & Mesophilic & Acetate, Hydrogen & Lonergan et al. (1996) \\
\hline 7 & S. frigidimarina & Psychrotropic & $\begin{array}{l}\text { Sodium lactate, sodium } \\
\text { acetate }\end{array}$ & Bowman et al. (2009) \\
\hline 8 & $\begin{array}{l}\text { Geogemma } \\
\text { pacifica sp. }\end{array}$ & $\begin{array}{l}\text { Hyper } \\
\text { thermophilic }\end{array}$ & Formate, acetate, & Esther et al. (2015) \\
\hline 9 & Desulfovibrio sp. & Mesophilic & Hydrogen & Lovley (1993) \\
\hline 10 & $\begin{array}{l}\text { Shewanellasp. HN- } \\
41\end{array}$ & Mesophilic & $\begin{array}{l}\text { Formate, lactate, } \\
\text { pyruvate }\end{array}$ & Esther et al. (2015) \\
\hline 11 & $\begin{array}{l}\text { Pelobacter } \\
\text { carbinolicus }\end{array}$ & Mesophilic & $\begin{array}{l}\text { Fermentable substrate, } \\
\text { formate, ethanol and } \mathrm{H}_{2}\end{array}$ & Lonergan et al. (1996) \\
\hline
\end{tabular}

\subsection{Iron reduction in wastewater treatment and future prospect}

Given that typical untreated municipal wastewater has COD $339-1016 \mathrm{mg} / \mathrm{L}$ and sulfate 24-72 mg/L, free ammonia 14-41 mg/L, insignificant nitrate and nitrite levels, and 
phosphate 3.7-11 mg/L (Table 3-18, (Metcalf \& Eddy et al., 2014), using ferric Fe(III) in wastewater treatment has the following advantages: Low solubility of iron phosphate can be an effective mechanism for retaining phosphorus from wastewater and reducing $P$ loads to receiving waters. This could be achieved by mixing wastewater and iron to allow formation and settling of the chemical precipitation prior to the anaerobic treatment (Berner, 1973; Ivanov et al., 2005). This is an important treatment aspect that nitrate and sulfate can not provide. Given the significant levels of sulfate in wastewater, sulfate reduction is expected to co-exist with iron reduction in the proposed iron-dosed anaerobic treatment. Precipitation of iron sulfide due to its low solubility (amorphous ferrous sulfide $\mathrm{Ksp} \approx 10^{-3.05}$ ) can limit potential sulfide toxicity on iron reducers and sulfate reducers. With abundance and widespread presence of iron (in particular, various forms of Fecontaining wastes such as chemical sludge from acid mine drainage treatment and wastes from steel industry), tremendous opportunities exist for incorporating iron as a green agent in innovative wastewater treatment technologies.

In light of the literature findings that showed effectiveness of IRB for organic matter oxidation in sediments, groundwater, soil systems, applicability of ferric reduction for organic matter removal from wastewater is explored in this section. A few studies that evaluated the utilization of ferric reduction in wastewater treatment have been reported and future scope of this research is discussed here with the context of identified knowledge gaps. Although the composition of wastewater is distinctively different from the other environmental sources, the mechanisms of the reduction process in organic oxidation in the above-mentioned studies are beneficial for the applications of iron reduction process in wastewater treatment.

\subsubsection{Organics mineralization by ferric reducers}

Previous studies on co-treatment of AMD and municipal wastewater discussed in the introduction part of this paper have shown that substantial amount of COD, BOD, total organic carbon (TOC), sulfate and other nutrients can be reduced from the wastewater through the co-treatment process. These results have suggested the potential benefits of using iron in anaerobic wastewater treatment. The study of Azam and Finneran (2013) has explored the pertinence of ferric amendments in mineralization of various carbon 
compounds in on-site anaerobic wastewater treatment. The mineralization of wide range of carbon molecules by different ferric compounds was one of the major illustrations of the study. As the composition of wastewater can vary significantly depending on the source of origin, there is a possibility that different ferric compounds will differ in performance of removing organic matter from wastewater of different composition. Other reduction processes such as fermentation and methanogens have limited substrate range and can not oxidize carbon molecules with high molecular mass, whereas ferric reduction process can be effective for mineralizing a broad array of carbon molecules (Chang et al., 2010; Lowe and Siegrist, 2008; McKinley and Siegrist, 2010). Further studies are required to examine biodegradability of different categories of organic matters typically found in wastewater.

\subsubsection{Ferric iron bioavailability and bioreduction kinetics}

Previous studies have indicated ferric bioavailability for IRB is a critical factor affecting ferric bioreduction kinetics and consequently carbon oxidation rate (Bonneville et al., 2004; Liu et al., 2001; Roden and Wetzel, 2002). For iron-dosed wastewater treatment, identification of the chemical morphology and structure of ferric compounds which support and disfavor the ferric bioreduction can be used as a baseline for selecting iron source materials. To promote bioavailability and reduce environmental footprint of iron-dosed wastewater treatment processes, iron-containing materials with large surface areas and fast ferric dissolution rates are required. In this regard, chemical sludge from alkaline treatment of AMD could be suitable materials for such applications due to their amorphous nature and large surface areas. Use of AMD sludge would also reduce the environmental burdens and cost of disposing the sludge materials. However, presence of toxic heavy metals in the AMD sludge need to be examined and addressed. Formation of metal sulfides (e.g., PbS and CuS) with biogenic sulfide in the bioreactor can potentially be a mechanism used to remove heavy metals and address the concern. Alternatively, selective precipitation in AMD treatment to obtain high-purity iron hydroxide and exclude heavy metals in the chemical sludge (Wei et al., 2005) can be used to prevent introducing AMD heavy metals to the wastewater.

Another critical factor for ferric bioavailability is $\mathrm{pH}$ as ferric compounds are highly 
insoluble at circumneutral $\mathrm{pH}$ and most of the bacteria need an adaptable $\mathrm{pH}$ level of 58 (Straub et al., 2001). Soluble and insoluble ferric compounds can differ greatly in oxidizing the organic matters in wastewater. Hence, there is scope of future study to investigate optimal $\mathrm{pH}$ range for the biological treatment and variability in organics removal efficiency and kinetics in relation to $\mathrm{pH}$.

Kinetic models that characterize ferric bioreduction and/or carbon oxidation are needed for design the iron-dosed treatment process. The kinetic models can then be used to estimate hydraulic and biomass retention times in the design of the treatment process. Both retention times are critical design parameters to achieve sufficient wastewater treatment.

\subsubsection{Microbial ecology}

In wastewater treatment applications, organic substrate availability is typically not a limiting factor as wastewaters have relatively higher levels of organic matters available compared to electron acceptors (e.g., nitrate and sulfate). In the iron-dosed anaerobic treatment, IRB and SRB are expected to the dominant bacterial species in the bioreactors. Iron/sulfate ratio can be a suitable parameter for gauging microbial activities of iron and sulfate reducers in the bioreactors, and for developing kinetic models. Shift in microbial species distributions in relation to iron/sulfate ratio, and how the variations in microbial ecology affect organics removal represent important knowledge gaps that require studies for developing such treatment technology. In particular, there is a need to understand the nature of the relationships between IRB and SRB (i.e., symbiotic or competitive) to identify optimal operating conditions for the treatment.

In addition, studies aim to identify predominant microbial strains that truly responsible for ferric bioreduction and carbon oxidation are needed. The understanding of the microbial species and their ecology would help identify their mechanisms for utilizing ferric iron and carbon compounds. Although common strategies of IRB for utilizing ferric ion from iron material surface can be found in the literature, it is likely that new strategies and mechanisms can also be learned in wastewater treatment applications. Therefore, advancement in microbial studies is required to identify effective ferric reducers and their 
ecology, and their relationship with wastewater composition to better employ iron reduction in wastewater treatment.

\subsubsection{Sample treatment process}

A possible treatment train of the proposed iron-dosed wastewater treatment may consist of primary, secondary, and a polishing treatment unit (Fig. 5). The primary unit is a clarifier where the iron is mixed with raw wastewater to form iron phosphate precipitation and settle chemical sludge. The secondary treatment is an anaerobic bioreactor that receives the effluent from the clarifier. And the polishing unit is to remove the remaining biological instability (e.g., ferrous Fe, sulfide, etc.) of the effluent from the biological system. Chlorine can be used as an oxidant that achieve both removal of biological instability and control of pathogens. The treated effluent can possibly be reused for a range of different purposes, which may or may not require additional treatment.

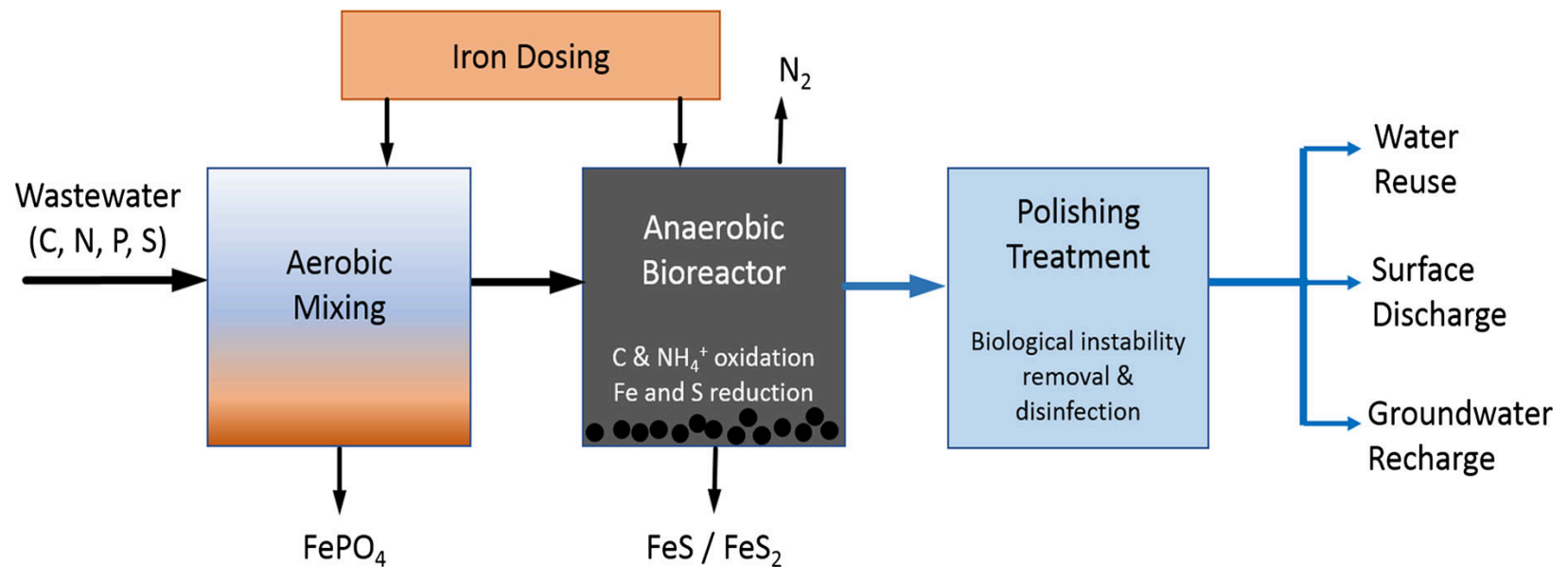

Fig. 5: Schematic diagram of the possible treatment process

\subsection{Conclusion}

Microbial reduction processes are drawing increasing attention because of their benefits over conventional aerobic processes. Ferric reduction process has shown astonishing results in organic degradation in natural systems and has a great potential to be used in novel wastewater treatment applications that provide multiple energy and environmental benefits. Majority of the studies on ferric reducers focused on their fundamental biochemical mechanisms in soil and groundwater systems. Better understanding on ferric 
reduction process in engineering systems can broaden its applications such as wastewater treatment. Future research in the areas identified in this paper is required to further develop this treatment concept and capitalize the benefits that are made available through adopting the biochemical reactions of IRB in wastewater treatment.

\section{References}

Achtnich, C., Bak, F., Conrad, R., 1995. Competition for electron donors among nitrate reducers, ferric iron reducers, sulfate reducers, and methanogens in anoxic paddy soil. Biol. Fertil. Soils 19, 65-72. https://doi.org/10.1007/BF00336349

Arnold, R.G., DiChristina, T.J., Hoffmann, M.R., 1986. Inhibitor studies of dissimilative $\mathrm{Fe}$ (III) reduction by Pseudomonas sp. strain 200 ('Pseudomonas ferrireductans'). Appl. Environ. Microbiol. 52, 281-289.

Arnold, R.G., DiChristina, T.J., Michael R. Hoffmann, 1988. Reductive dissolution of fe(III) oxides by Pseudomonas sp. 200. Biotechnol. Bioeng. 32, 1081-1096.

Azam, H.M., Finneran, K.T., 2013. Ferric iron amendment increases Fe(III)-reducing microbial diversity and carbon oxidation in on-site wastewater systems. Chemosphere 90, 1435-1443. https://doi.org/10.1016/j.chemosphere.2012.09.002

Banwart, S., Davies, S., Stumm, W., 1989. The role of oxalate in accelerating the reductive dissolution of hematite ( $\alpha-\mathrm{Fe} 2 \mathrm{O} 3)$ by ascorbate. Colloids and Surfaces 39, 303-309. https://doi.org/10.1016/0166-6622(89)80281-1

Beliaev, A.S., Saffarini, D.A., 1998. Shewanella putrefaciens $\mathrm{mtrB}$ encodes an outer membrane protein required for Fe(III) and Mn(IV) reduction. J. Bacteriol. 180, 62926297.

Beliaev, A.S., Saffarini, D.A., McLaughlin, J.L., Hunnicutt, D., 2001. MtrC, an outer membrane decahaem c cytochrome required for metal reduction in Shewanella putrefaciens MR-1. Mol. Microbiol. 39, 722-730. https://doi.org/10.1046/j.13652958.2001.02257.x

Berner, R.A., 1973. Phosphate removal from sea water by adsorption on volcanogenic ferric oxides. Earth Planet. Sci. Lett. 18, 77-86. https://doi.org/10.1016/0012821X(73)90037-X

Bonneville, S., Van Cappellen, P., Behrends, T., 2004. Microbial reduction of iron(III) oxyhydroxides: Effects of mineral solubility and availability. Chem. Geol. 212, 255268. https://doi.org/10.1016/j.chemgeo.2004.08.015

Bowman, J.P., McCammon, S.A., Nichols, D.S., Skerratt, J.H., Rea, S.M., Nichols, P.D., McMeekin, T.A., 2009. Shewanella gelidimarina sp. nov. and Shewanella frigidimarina sp. nov., Novel Antarctic Species with the Ability To Produce Eicosapentaenoic Acid (20:53) and Grow Anaerobically by Dissimilatory $\mathrm{Fe}(\mathrm{III})$ Reduction. Int. J. Syst. Bacteriol. 47, 1040-1047. https://doi.org/10.1099/0020771347-4-1040

Chan, Y.J., Chong, M.F., Law, C.L., Hassell, D.G., 2009. A review on anaerobic-aerobic treatment of industrial and municipal wastewater. Chem. Eng. J. 155, 1-18. https://doi.org/10.1016/j.cej.2009.06.041

Chang, N.-B., Xuan, Z., Daranpob, A., Wanielista, M., 2010. A Subsurface Upflow Wetland System for Removal of Nutrients and Pathogens in On-Site Sewage 
Treatment and Disposal Systems. Environ. Eng. Sci. 28, 11-24. https://doi.org/10.1089/ees.2010.0087

Chen, J., Gu, B., Royer, R.A., Burgos, W.D., 2003. The roles of natural organic matter in chemical and microbial reduction of ferric iron. Sci. Total Environ. 307, 167-178. https://doi.org/10.1016/S0048-9697(02)00538-7

Clément, J.C., Shrestha, J., Ehrenfeld, J.G., Jaffé, P.R., 2005. Ammonium oxidation coupled to dissimilatory reduction of iron under anaerobic conditions in wetland soils. Soil Biol. Biochem. 37, 2323-2328. https://doi.org/10.1016/j.soilbio.2005.03.027

Dar, S.A., Yao, L., Van Dongen, U., Kuenen, J.G., Muyzer, G., 2007. Analysis of diversity and activity of sulfate-reducing bacterial communities in sulfidogenic bioreactors using 16S rRNA and dsrB genes as molecular markers. Appl. Environ. Microbiol. 73, 594-604. https://doi.org/10.1128/AEM.01875-06

De Castro, A.F., Ehrlich, H.L., 1970. Reduction of iron oxide minerals by a marine Bacillus. Antonie Van Leeuwenhoek 36, 317-327. https://doi.org/10.1007/BF02069033

Deng, D., Lin, L.S., 2013. Two-stage combined treatment of acid mine drainage and municipal wastewater. Water Sci. Technol. 67, 1000-1007. https://doi.org/10.2166/wst.2013.653

Deng, D., Weidhaas, J.L., Lin, L.-S., 2016. Kinetics and microbial ecology of batch sulfidogenic bioreactors for co-treatment of municipal wastewater and acid mine drainage. J. Hazard. Mater. 305, 200-8. https://doi.org/10.1016/j.jhazmat.2015.11.041

Esther, J., Sukla, L.B., Pradhan, N., Panda, S., 2015. Fe (III) reduction strategies of dissimilatory iron reducing bacteria. Korean J. Chem. Eng. 32, 1-14. https://doi.org/10.1007/s11814-014-0286-x

Franks, A.E., Malvankar, N., Nevin, K.P., 2010. Bacterial biofilms: the powerhouse of a microbial fuel cell. Biofuels 1, 589-604. https://doi.org/10.4155/bfs.10.25

Fredrickson, J.K., Gorby, Y.A., 1996. Environmental processes mediated by ironreducing bacteria. Curr. Opin. Biotechnol. 7, 287-294.

Guerin, W.F., Blakemore, R.P., 1992. Redox cycling of iron supports growth and magnetite synthesis by Aquaspirillum magnetotacticum. Appl. Environ. Microbiol. 58, 1102-1109.

Hughes, T.A., Gray, N.F., 2013. Co-treatment of acid mine drainage with municipal wastewater: Performance evaluation. Environ. Sci. Pollut. Res. 20, 7863-7877. https://doi.org/10.1007/s11356-012-1303-4

Hyun, M., Kim, B., Chang, I., Park, H., Kim, H., Kim, G., Kim, M., DH, P., 1999. Isolation and identification of metalreducing bacterium, Shewanella putrefaciens IR-1. J. Microbiol. 37, 206-212.

Ivanov, V., Stabnikov, V., Zhuang, W.Q., Tay, J.H., Tay, S.T.L., 2005. Phosphate removal from the returned liquor of municipal wastewater treatment plant using iron-reducing bacteria. J. Appl. Microbiol. 98, 1152-1161. https://doi.org/10.1111/j.13652672.2005.02567.x

Jensen, M.M., Thamdrup, B., Rysgaard, S., Holmer, M., Fossing, H., 2003. Rates and Regulation of Microbial Iron Reduction in Sediments of the Baltic-North Sea Transition 65, 295-317.

Jones, J.G., Gardener, S., Simon, B.M., 1983. Bacterial Reduction of Ferric Iron in a 
Stratified Eutrophic Lake. J. Gen. Microbiol. 129, 131-139. https://doi.org/10.1099/00221287-129-1-131

Kamura, T., Takai, Y., Ishikawa, K., 1963. Microbial reduction mechanism of ferric iron in paddy soils (part I). Soil Sci. Plant Nutr. 9, 5-9. https://doi.org/10.1080/00380768.1963.10431048

Liu, C., Kota, S., Zachara, J.M., Fredrickson, J.K., Brinkman, C.K., 2001. Kinetic analysis of the bacterial reduction of goethite. Environ. Sci. Technol. 35, 2482-2490. https://doi.org/10.1021/es001956c

Lonergan, D., Jenter, H., Coates, J., Phillips, E., Schmidt, T., Lovley, D., 1996. Phylogenetic analysis of dissimilatory Fe (III)-reducing bacteria. J. Bacteriol. 178, 2402-2408. https://doi.org/10.1128/JB.178.8.2402-2408.1996

Lovley, D.R., 1995. Bioremediation of organic and metal contaminants with dissimilatory metal reduction. J. Ind. Microbiol. 14, 85-93. https://doi.org/10.1007/BF01569889

Lovley, D.R., 1993. Dissimilatory metal reduction. Annu. Rev. Microbiol. 47, 20-29.

Lovley, D.R., 1987. Organic matter mineralization with the reduction of ferric iron: A review. Geomicrobiol. J. 5, 375-399. https://doi.org/10.1080/01490458709385975

Lovley, D.R., Baedecker, M.J., Lonergan, D.J., Cozzarelli, I.M., Phillips, E.J.P., Siegel, D.I., 1989. Oxidation of aromatic contaminants coupled to microbial iron reduction. Nature 339, 297-300. https://doi.org/10.1038/339297a0

Lovley, D.R., Lonergan, D.J., 1990. Anaerobic oxidation of toluene, phenol, and p-cresol by the dissimilatory iron-reducing organism, GS-15. Appl. Environ. Microbiol. 56, 1858-1864. https://doi.org/10.1128/aem.72.5.3236-3244.2006

Lovley, D.R., Phillips, E.J., 1987. Competitive mechanisms for inhibition of sulfate reduction and methane production in the zone of ferric iron reduction in sediments. Appl. Environ. Microbiol. 53, 2636-41.

Lovley, D.R., Phillips, E.J.P., 1989. Requirement for a microbial consortium to completely oxidize glucose in Fe(III)- reducing sediments. Appl. Environ. Microbiol. 55, 32343236.

Lovley, D.R., Phillips, E.J.P., 1988. Novel Mode of Microbial Energy Metabolism: Organic Carbon Oxidation Coupled to Dissimilatory Reduction of Iron or Manganese. Appl. Environ. Microbiol. 54, 1472-1480. https://doi.org/10.1103/PhysRevLett.50.1998

Lovley, D.R., Phillips, E.J.P., 1986. Organic Matter Mineralization with Reduction of Ferric Iron in Anaerobic Sediments. Appl. Environ. Microbiol. 51, 683-689. https://doi.org/10.1080/01490458709385975

Lowe, K.S., Siegrist, R.L., 2008. Controlled Field Experiment for Performance Evaluation of Septic Tank Effluent Treatment during Soil Infiltration. J. Environ. Eng. 134, 93101.

Madigan, M., Martinko, J., Bender, K., Buckley, D., Stahl, D., 2015. Brock biology of microorganism, 14th ed. Pearson Education, Illionis.

Major, D.W., Mayfield, C.I., Barker, J.F., 1988. Biotransformation of Benzene by Denitrification in Aquifer Sand. Groundwater 26, 8-14.

Manariotis, I.D., Grigoropoulos, S.G., 2002. Low-Strength Wastewater Treatment Using an Anaerobic Baffled Reactor. Water Environ. Res. 74, 170-176.

McCarty, P.L., Smith, D.P., 1986. Anaerobic wastewater treatment processes. Environ. Sci. Technol. 20, 1200-1206. https://doi.org/10.1021/es00154a002

McKinley, J.W., Siegrist, R.L., 2010. Accumulation of Organic Matter Components in Soil 
under Conditions Imposed by Wastewater Infiltration. Sci. Soc. Am. J. 74, 16901700.

Metcalf \& Eddy, I., Tchobanoglous, G., Stensel, H.D., Tsuchihashi, R., Burton, F., 2014. Wastewater Engineering: Treatment and Resorce Recovery. McGraw-Hill, New York.

Munch, J.C., Ottow, J.C.G., 1983. Reductive Transformation Mechanism of Ferric Oxides in Hydromorphic Soils. Environ. Biogeochem. 35, 383-394.

Myers, C.R., Myers, J.M., 1997. Cloning and sequence of cymA, a gene encoding a tetraheme cytochrome $c$ required for reduction of iron(III), fumarate, and nitrate by Shewanella putrefaciens MR-1. J. Bacteriol. 179, 1143-1152. https://doi.org/10.1128/jb.179.4.1143-1152.1997

Myers, J.M., Myers, C.R., 2001. Role for outer membrane cytochromes OmcA and OmcB of Shewanella putrefaciens MR-1 in reduction of manganese dioxide. Appl. Environ. Microbiol. 67, 260-269. https://doi.org/10.1128/AEM.67.1.260-269.2001

Nealson, K.H., Myers, C.R., 1990. Iron reduction by bacteria: A potential role in the genesis of banded iron formations. Am. J. Sci. 290, 35-45.

Oude Elferink, S.J.W.H., Visser, A., Pol, L.W.H., Stams, A.J.., 1994. Sulfate reduction in methanogenic bioreactors. FEMS Microbiol. Rev. 15, 119-136.

Park, W., Nam, Y.K., Lee, M.J., Kim, T.H., 2009. Anaerobic ammonia-oxidation coupled with $\mathrm{Fe} 3+$ reduction by an anaerobic culture from a piggery wastewater acclimated to $\mathrm{NH} \mathrm{4+} / \mathrm{Fe} 3+$ medium. Biotechnol. Bioprocess Eng. 14, 680-685. https://doi.org/10.1007/s12257-009-0026-y

Pierre, J.L., Fontecave, M., Crichton, R.R., 2002. Chemistry for an essential biological process: The reduction of ferric iron. BioMetals 15, 341-346. https://doi.org/10.1023/A:1020259021641

Pitts, K.E., Dobbin, P.S., Reyes-Ramirez, F., Thomson, A.J., Richardson, D.J., Seward, H.E., 2003. Characterization of the Shewanella oneidensis MR-1 Decaheme Cytochrome MtrA . J. Biol. Chem. 278, 27758-27765. https://doi.org/10.1074/jbc.m302582200

Postma, D., 1993. The reactivity of iron oxides in sediments: A kinetic approach. Geochim. Cosmochim. Acta 57, 5027-5034. https://doi.org/10.1016/S00167037(05)80015-8

Reinhard, M., Barker, J.F., Goodman, N.L., 1984. Occurrence and distribution of organic chemicals in two landfill leachate plumes. Environ. Sci. Technol. 18, 953-961. https://doi.org/10.1021/es00130a011

Roden, E.E., Wetzel, R.G., 2002. Kinetics of microbial Fe(III) oxide reduction in freshwater wetland sediments. Limnol. Oceanogr. 47, 198-211. https://doi.org/10.4319/lo.2002.47.1.0198

Roetman, E., 1932. The sterilization of sewage by acid mine water. West Virginia University.

Saravanane, R., Murthy, D.V.S., 2016. Application of anaerobic fluidized bed reactors in wastewater treatment: a review. Environ. Manag. Heal. 11, 97-117.

Sawayama, S., 2006. Possibility of anoxic ferric ammonium oxidation. J. Biosci. Bioeng. 101, 70-72. https://doi.org/10.1263/jbb.101.70

Speece, R.E., 1983. Anaerobic biotechnology for industrial wastewater treatment. Environ. Sci. Technol. 17, 416A-427A. https://doi.org/10.1021/es00115a001 
Straub, K.L., Benz, M., Schink, B., 2001. Iron metabolism in anoxic environments at near neutral pH. FEMS Microbiol. Ecol. 34, 181-186. https://doi.org/10.1016/S01686496(00)00088-X

Strosnider, W.H., Winfrey, B.K., Nairn, R.W., 2011. Biochemical oxygen demand and nutrient processing in a novel multi-stage raw municipal wastewater and acid mine drainage passive co-treatment system. Water Res. 45, 1079-1086. https://doi.org/10.1016/j.watres.2010.10.026

Thamdrup, B., 2000. Bacterial Manganese and Iron Reduction in Aquatic Sediments. Adv. Microb. Ecol. 16, 41-84. https://doi.org/10.1007/978-1-4615-4187-5_2

Thomsen, U., Thamdrup, B., Stahl, D.A., Canfield, D.E., 2004. Pathways of organic carbon oxidation in a deep lacustrine sediment, Lake Michigan. Limnol. Oceanogr. 49, 2046-2057. https://doi.org/10.4319/lo.2004.49.6.2046

Thormann, K.M., Shukla, S., Pelletier, D.A., Spormann, A.M., 2004. Initial Phases of Biofilm Formation in Shewanella oneidensis MR-1. J. Bacteriol. 186, 8096-8104. https://doi.org/10.1128/JB.186.23.8096

Urrutia, M.M., Roden, E.E., Fredrickson, J.K., Zachara, J.M., 1998. Microbial and surface chemistry controls on reduction of synthetic $\mathrm{Fe}(\mathrm{III})$ oxide minerals by the dissimilatory iron-reducing bacterium Shewanella alga. Geomicrobiol. J. 15, 269-291.

Utgikar, V.P., Harmon, S.M., Chaudhary, N., Tabak, H.H., Govind, R., Haines, J.R., 2002. Inhibition of sulfate-reducing bacteria by metal sulfide formation in bioremediation of acid mine drainage. Environ. Toxicol. 17, 40-48. https://doi.org/10.1002/tox.10031

Van der Maas, P., 2005. Fe(III) EDTA reduction in BioDeNOx reactors: kinetics and mechanism, in: Chemically Enhanced Biological NOx Removal from Flue Gases. Wageningen University, pp. 109-124.

Van Lier, J.B., 2008. High-rate anaerobic wastewater treatment: Diversifying from endof-the-pipe treatment to resource-oriented conversion techniques. Water Sci. Technol. 57, 1137-1148. https://doi.org/10.2166/wst.2008.040

Van Lier, J.B., Van der Zee, F.P., Frijters, C.T.M.J., Ersahin, M.E., 2015. Celebrating 40 years anaerobic sludge bed reactors for industrial wastewater treatment. Rev. Environ. Sci. Biotechnol. 14, 681-702. https://doi.org/10.1007/s11157-015-9375-5

Weber, K.A., Achenbach, L.A., Coates, J.D., 2006. Microorganisms pumping iron: Anaerobic microbial iron oxidation and reduction. Nat. Rev. Microbiol. 4, 752-764. https://doi.org/10.1038/nrmicro1490

Wei, X., Viadero, R.C., Buzby, K.M., 2005. Recovery of Iron and Aluminum from Acid Mine Drainage by Selective Precipitation. Environ. Eng. Sci. 22, 745-755. https://doi.org/10.1089/ees.2005.22.745

Widdel, F., 1988. Microbiology and ecology of sulfate and sulfur- reducing bacteria, in: Zehnder, A. (Ed.), Biology of Anaerobic Microorganisms. Wiley, New York, pp. 459586.

Wilson, B.H., Smith, G.B., Rees, J.F., 1986. Biotransformations of Selected Alkylbenzenes and Halogenated Aliphatic Hydrocarbons in Methanogenic Aquifer Material: A Microcosm Study. Environ. Sci. Technol. 20, 997-1002. https://doi.org/10.1021/es00152a005

Yang, W.H., Weber, K.A., Silver, W.L., 2012. Nitrogen loss from soil through anaerobic ammonium oxidation coupled to iron reduction. Nat. Geosci. 5, 538-541. https://doi.org/10.1038/ngeo1530 
Zhang, L., Keller, J., Yuan, Z., 2009. Inhibition of sulfate-reducing and methanogenic activities of anaerobic sewer biofilms by ferric iron dosing. Water Res. 43, 41234132. https://doi.org/10.1016/j.watres.2009.06.013

Zhao, R., Zhang, H., Li, Y., Jiang, T., Yang, F., 2014. Research of Iron Reduction and the Iron Reductase Localization of Anammox Bacteria. Curr. Microbiol. 69, 880-887. https://doi.org/10.1007/s00284-014-0668-7

Zinder, B., Furrer, G., Stumm, W., 1986. The coordination chemistry of weathering: II. Dissolution of Fe(III) oxides. Geochim. Cosmochim. Acta 50, 1861-1869. 


\section{Chapter 3: Effects of Fe/S Ratio on the Kinetics and Microbial Ecology of an Fe(III)-dosed Anaerobic Wastewater Treatment System}

(M. Ahmed, O. Lin, C. M. Saup, M. J. Wilkins, and L.-S. Lin, Effects of Fe/S Ratio on the Kinetics and Microbial Ecology of an Fe(III)- dosed Anaerobic Wastewater Treatment System, J. Hazardous Materials, 5 (369), 593-600, 2019)

\subsection{Introduction}

Anaerobic biological treatment of wastewater using alternative electron acceptors to oxygen can offer benefits of cost effectiveness and energy efficiency (Van Lier, 2008; Van Lier et al., 2015). It also provides opportunities of utilizing redox active elements such as iron and sulfate from waste materials in wastewater treatment. Previous studies have shown that iron reducing microorganisms are effective in organic matter mineralization in natural systems such as groundwater, soils, and sediments (Bonneville et al., 2004; Jensen et al., 2003; Lovley, 1995, 1987; Roden and Wetzel, 2002; Thamdrup, 2000). Therefore, engineering processes that couple reduction of ferric iron to organic carbon oxidation can potentially be an effective wastewater treatment method that provides multiple energy and environmental benefits (Ahmed and Lin, 2017).

Previous studies showed that ferric reduction kinetics was influenced by the type of electron donors. Van der Maas (2005) showed variations in ferric reduction rate by changing the electron donors in mixed liquor bioreactors, which ranged from $4.1 \mathrm{mM} . \mathrm{h}^{-1}$ with methanol to $13.9 \mathrm{mM} \cdot \mathrm{h}^{-1}$ with glucose. Microbial iron reduction rates are also affected by factors such as the crystallinity, mineralogy and solubility of ferric compounds, contact between ferric surface and iron reducing bacteria (IRB), and electron transfer mechanisms (Ahmed and Lin, 2017; Liu et al., 2008; Nevin and Lovley, 2002). In general, more poorly crystalline ferric compounds result in higher reduction rates than crystalline compounds (Bonneville et al., 2009), and less stable minerals such as ferrihydrite and lepidocrocite showed higher reactivity than stable minerals such as goethite and hematite (Postma, 1993). Bonneville et al. (2006) studied the variations in maximum specific reduction rates with different forms of ferric hydroxide, and reported a range of values from $0.27 \times 10^{-11} \mathrm{umolh}^{-1}$ cell $^{-1}$ with LSA hematite to $399 \times 10^{-11} \mu \mathrm{molh}^{-1} \mathrm{cell}^{-1}$ with soluble ferric citrate. The solubility of these different ferric compounds was considered as a factor 
causing the differences in the reduction rate as it affects the bioavailability of these compounds to IRB. While phylogenetically diverse microorganisms may be capable of dissimilatory iron reduction, majority of previous studies have focused on characterizing the metabolism and physiology of Shewanella and Geobacter species that can be easily cultivated in the laboratory (Aklujkar et al., 2010; Liu et al., 2002; Lovley et al., 1993; Mahadevan et al., 2011; Myers and Myers, 2001; Urrutia et al., 1998).

In anaerobic processes using ferric iron reduction for treating sulfate-containing wastewater, IRB and sulfate reducing bacteria (SRB) may co-exist and both contribute to organic carbon oxidation. Zhang et al. (2013) have observed a symbiotic relationship between SRB and IRB in an anaerobic wastewater treatment process, in which addition of ferric oxide into a sulfidogenic bioreactor elicited microbial iron reduction and improved both sulfate reduction and organic carbon oxidation. However, IRB can outcompete SRB under limited carbon substrate conditions by diverting electron flow away from SRB (Lovley and Phillips, 1989). Such symbiotic and/or competitive dynamics between IRB and SRB is regulated by the availability of carbon substrate and electron acceptors (ferric iron and sulfate), and largely unknown for engineering applications.

Production of ferrous iron and (bi)sulfide from the reductive microbial reactions along with the resulting iron sulfide sludge in the iron-dosed anaerobic bioreactors is another aspect concerning the treatment method. Excessive production of aqueous and gaseous sulfides at levels toxic to microorganisms may limit the extent of carbon oxidation (Cirne et al., 2008; Mosey et al., 1971). Aqueous sulfides can form sparingly soluble metal sulfide precipitates and reduce contact area between reactants and microbial enzymes (Utgikar et al., 2002). In generally, biogenic iron sulfide precipitating as FeS (mackinawite) is poorly crystalline (Herbert et al., 1998). This iron mono sulfide is also known as a precursor to well crystallized pyrite $\left(\mathrm{FeS}_{2}\right)$ as it provides an initial nucleation site for pyrite growth (Gramp et al., 2010; Herbert et al., 1998). Greigite $\left(\mathrm{Fe}_{3} \mathrm{~S}_{4}\right)$, smythite $\left(\mathrm{Fe}_{9} \mathrm{~S}_{11}\right)$, and pyrrhotite $\left(\mathrm{Fe}_{1-\mathrm{x}} \mathrm{S}\right)$ are some of the intermediate iron sulfide forms that may exist between the transformation of amorphous FeS to crystalline FeS2. Gramp et al. (2010) reported that mackinawite ( $\mathrm{FeS}$ ) was the dominant phase in the biologically produced precipitates with lower Fe/S molar ratio $(1: 3.25,1: 20,1: 50)$. The crystallinity of mackinawite was 
enhanced when the iron concentration increased (Fe/S ratio 0.5), which eventually increased the proportion of pyrite formation in the precipitates. Understanding the composition of iron sulfides produced in these systems may be critical given their potential beneficial applications due to magnetic and electrical properties.

This study addressed the knowledge gaps in the effects of iron-dosing on organic carbon oxidation kinetics, competitive/synergistic relationship of IRB and SRB, correlations of microbial ecology with the carbon oxidation, and sludge characteristics. Specifically, anaerobic batch bioreactors were used to treat sulfate-containing wastewater under three different $\mathrm{Fe} / \mathrm{S}$ molar ratios while maintaining the same total equivalent of electron acceptors (i.e., ferric iron and sulfate). Microbiological analyses were performed to characterize the microbial communities, and to investigate their relationships with the organic carbon oxidation kinetics. Sludge samples from the biological treatment were collected and characterized for their morphology, chemical composition, and elemental oxidation states. A conceptual framework was proposed to illustrate the major process factors that influence the organic carbon oxidation and to assist further development of this treatment method.

\subsection{Materials and Methods}

\subsubsection{Batch Bioreactors}

Six batch bioreactors ( $1.15 \mathrm{~L}$ glass bottles) were used to investigate the effects of $\mathrm{Fe} / \mathrm{S}$ ratio on the kinetics of organic carbon oxidation (Supplementary material, Fig. S1). The bioreactors were packed with plastic media (Kaldnes K1, specific surface area $=500$ $\mathrm{cm}^{2} / \mathrm{m}^{3}$, Evolution Aqua Ltd, UK) for attached growth of microorganisms. Each reactor was packed with 550 plastic media with a working volume of $0.7 \mathrm{~L}$. A mixture of anaerobic sludge from a wastewater treatment plant (Star City, West Virginia) and acid mine drainage (AMD) from St. Thomas, Morgantown, West Virginia at 1:1 volume ratio was used to inoculate the bioreactors. Enrichment of biomass lasted for approximately 3 months during which fresh synthetic wastewaters containing organic carbon, ferric iron and sulfate were prepared to replace the solutions in the bioreactors every week. The synthetic wastewater contained sodium acetate anhydrous $\left(\mathrm{C}_{2} \mathrm{H}_{3} \mathrm{NaO}_{2}\right)$, ethanol $\left(\mathrm{C}_{2} \mathrm{H}_{6} \mathrm{O}\right)$, 
lactose monohydrate $\left(\mathrm{C}_{12} \mathrm{H}_{22} \mathrm{O}_{11} \cdot \mathrm{H}_{2} \mathrm{O}\right)$, sodium bicarbonate $\left(\mathrm{NaHCO}_{3}\right)$ and trace elements (Deng and Lin, 2017). During this enrichment period, the concentration of chemical oxygen demand (COD) in the synthetic wastewaters was kept constant (400 $\mathrm{mg} / \mathrm{L}$ ) and iron and sulfate concentrations were varied to obtain three $\mathrm{Fe} / \mathrm{S}$ molar ratios (1, 2 and 3) using ferric chloride $\left(\mathrm{FeCl}_{3} \cdot 6 \mathrm{H}_{2} \mathrm{O}\right)$ and sodium sulfate $\left(\mathrm{Na}_{2} \mathrm{SO}_{4}\right)$ solutions. For all three $\mathrm{Fe} / \mathrm{S}$ ratios, the ferric iron and sulfate concentrations were predetermined to obtain the same total equivalent concentration of the electron acceptors $(4.68 \mathrm{mN})$. Specifically, ferric iron concentrations were 29,53 and $71 \mathrm{mg} / \mathrm{L}$ and sulfate concentrations were 50,45 and $41 \mathrm{mg} / \mathrm{L}$ for Fe/S molar ratio 1, 2 and 3 respectively. Each bioreactor was sealed with a rubber stopper and bubbled with $\mathrm{N}_{2}$ gas regularly to ensure an anaerobic condition in the bioreactors. Each bioreactor was equipped with two sampling ports through the rubber stopper to allow periodic sample collection and $\mathrm{pH} / \mathrm{redox}$ potential monitoring. The sampling ports were sealed except during sample collection.

\subsubsection{Kinetic Study}

After the biomass enrichment, the bioreactors were used to examine the effects of $\mathrm{Fe} / \mathrm{S}$ ratio on organic carbon oxidation using the synthetic wastewater described above. The concentrations of organic carbons were varied to obtain different COD levels (50, 100, $200,400,500,800$, and $1000 \mathrm{mg} / \mathrm{L}$ ). The $\mathrm{pH}$ of the mixed solutions was maintained at a moderate level (6-6.2) using a sodium hydroxide solution $(5 \mathrm{~N})$ to ensure a favorable environment for biological growth. The samples were collected after every three hours over a nine-hour period to monitor the COD, sulfate, sulfide, ferric and ferrous iron concentrations. Each sample was filtered with a $0.2 \mu \mathrm{m}$ membrane filter and stored at $4^{\circ} \mathrm{C}$ until analysis. Changes in COD concentrations during first three hours was used to estimate the COD oxidation rate $\left(V, \mathrm{mg} / \mathrm{L}^{*} \mathrm{~min}\right)$ using the initial rate method (Hegyi et al., 2013). The concentrations of dissolved sulfide and ferrous iron were monitored to help examine the degree of iron and sulfate reduction in the bioreactors and their stoichiometric relationships.

\subsubsection{Analytical Methods}

All the chemical analyses were conducted by following the Standard Methods (APHA et al., 2005). COD concentrations were measured by following a closed reflux, colorimetric 
method (Standard Method 5220 D) and using a spectrophotometer (HACH, DR 2800). The ferrous and sulfide concentrations were determined by the 1, 10 phenanthroline method (Standard Method 3500 B) and methylene blue method (Standard Method 4500 D) respectively using the spectrophotometer. Soluble sulfate was measured with a GENESYS 10UV (Thermo Scientific) spectrophotometer following the turbidimetric method (USEPA method 375.4). Total iron concentration was measured using an atomic absorption spectrophotometer (Perkin Elmer 3100) after the samples were acidified with a $70 \%$ nitric acid solution. Total sulfur in the sludge samples was analyzed using an optical emission spectrometer (Optima 2100 DV). Sample pH and redox potential were measured using a pH meter (AB15 Plus, Fisher Scientific) and a VWR traceable ORP meter.

\subsubsection{Kinetics Modeling}

The calculated COD oxidation rates $\left(V, \mathrm{mg} / \mathrm{L}^{*} \mathrm{~min}\right)$ at different substrate $(S, \mathrm{mg} / \mathrm{L})$ levels were used to characterize the COD oxidation kinetics of the biological treatment using the Michaelis-Menten model:

$$
V=\frac{V_{\max } \times S}{K_{\mathrm{m}}+S}
$$

where $V_{\max }\left(\mathrm{mg} / \mathrm{L}^{*} \min \right)$ is the maximum reaction rate and $K_{\mathrm{m}}(\mathrm{mg} / \mathrm{L})$ is the MichaelisMenten constant. The data were used to fit the model using both linear and nonlinear methods and estimate the model parameters $\left(K_{\mathrm{m}}\right.$ and $\left.V_{\max }\right)$. Specifically, LineweaverBurk transformation of the model, a double reciprocal plot, was used as the linear model (Deng et al., 2016; Kaksonen et al., 2006) and Microsoft Excel's "Solver" program was used for the nonlinear fitting.

\subsubsection{Sludge Characterization}

Once the kinetics experiment at different COD concentrations were concluded, the accumulated sludge samples were collected from the bioreactors for physical, chemical, and biological characterization. Total suspended solid (TSS), volatile suspended solid (VSS) and non-volatile suspended solid (NVSS) in the sludge materials were measured 
(Standard Method 2540). Sludge samples were also acidified using a $70 \% \mathrm{HNO}_{3}$ solution to quantify total $\mathrm{Fe}$ and S. A scanning electron microscope (SEM) equipped with an energy dispersion spectroscopy (SEM-EDS, Hitachi S 4700) was used to study the morphology and elemental composition of sludge materials. Specifically, the sludge samples were dried in a desiccator filled with calcium sulfate and flushed with nitrogen gas to prevent sludge oxidation. The sludge samples were prepared on aluminum mounts and coated with Au-Pd. For SEM analysis, both filtered and powdered sludge samples were used and analyzed under an accelerating voltage of $10 \mathrm{kV}$. Selected areas of the sludge samples were analyzed by the EDS for elemental information under the same accelerating voltage with online ZAF correction. Powdered samples of the sludge were also used for X-ray photoelectron spectroscopy (XPS) analysis (PHI 5000 Versaprobe) to identify the chemical states of $\mathrm{Fe}$ and $\mathrm{S}$. The sludge samples were prepared following the same method as that for the SEM analysis. Elemental scans of Fe and S were conducted using a pass energy of $23.5 \mathrm{eV}$.

\subsubsection{Microbiological Analyses}

DNA was extracted from biofilm samples using a DNeasy Powersoil DNA extraction kit (Qiagen, Maryland, USA) and quantified using a Qubit fluorometer (Invitrogen, Carlsbad, CA, USA). 16S rRNA genes in the extracted DNA were sequenced at Argonne National Laboratory using the bacterial/archaeal primer set 515F/806R that targets the $\mathrm{V} 4$ region of the gene. Resulting reads were checked for chimeras (DADA2) and subsequently clustered into exact sequence variant (ESV) classifications at $100 \%$ similarities using the DADA2 tool in the QIIME2 pipeline (Qiime2-2018.4) and SILVA 16S rRNA gene database. Sequences used in this study have been deposited in the NCBI Sequence Read Archive under accession number PRJNA504045.

\subsection{Results and Discussion}

\subsubsection{Oxidation Kinetics under different Fe/S ratios}

The nonlinear least square method (i.e., Microsoft Solver) consistently produced better fits of the data (Fig. 6) than the linear method (Supplementary Materials, Fig. S2) in this study. The Lineweaver-Burk plot can suffer from a highly-biased weighting of points and 
is discouraged to be used in many cases of enzyme kinetics (Martin, 1997; Perrin, 2017). The $V_{\max }$ values estimated by the nonlinear model were $0.47,0.73$ and $1.09 \mathrm{mg} / \mathrm{L}^{*} \min$ for $\mathrm{Fe} / \mathrm{S}$ ratio 1,2 and 3 , respectively.

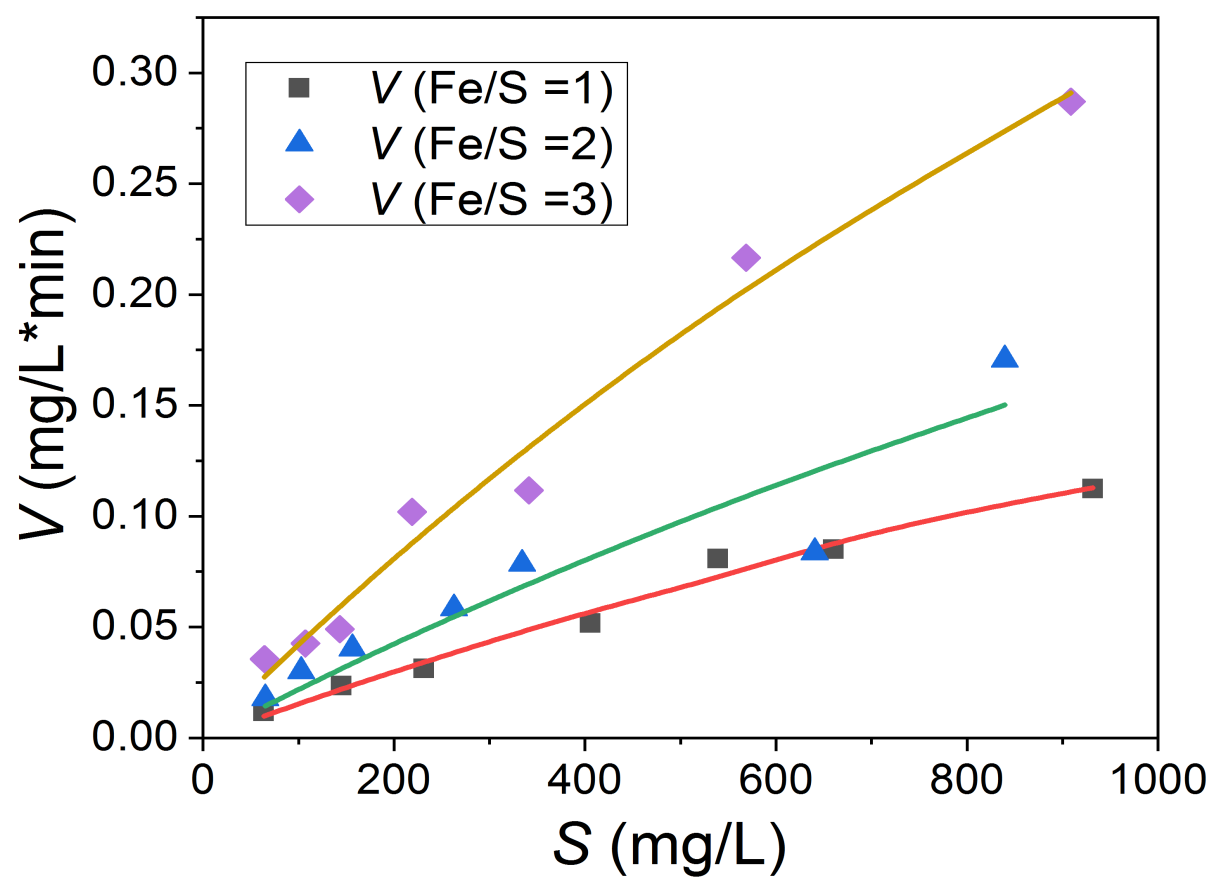

Fig. 6: Nonlinear kinetic models of COD oxidation under three different $\mathrm{Fe} / \mathrm{S}$ molar ratios At any substrate level in the range examined, increased $\mathrm{Fe} / \mathrm{S}$ ratios resulted in higher carbon oxidation rates. For example, at substrate level $400 \mathrm{mg} / \mathrm{L}$, the oxidation rate obtained from nonlinear model was $0.05,0.08$ and $0.15 \mathrm{mg} / \mathrm{L}^{*} \mathrm{~min}$ for ratio 1,2 and 3 respectively. This indicates that with same total equivalent concentration of the electron acceptors, a higher $\mathrm{Fe}^{3+}$ concentration along with its corresponding lower sulfate concentration improved the overall COD oxidation rate. From the wastewater treatment perspective, the improved COD oxidation kinetics driven by the increasing percentage of ferric iron would allow shorter hydraulic retention time. The COD oxidation rates were relatively less variable at low substrate levels and showed significantly larger differences at high substrate levels among the three $\mathrm{Fe} / \mathrm{S}$ ratios. $K_{\mathrm{m}}$ values ranged from $2,503 \mathrm{mg} / \mathrm{L}$ to $3,267 \mathrm{mg} / \mathrm{L}$ and they reflected the combined enzymatic activities of both iron reducers and sulfate reducers in the bioreactors. These $K_{m}$ values were substantially higher than the COD levels typically found in municipal wastewaters, indicating that this treatment 
method can be operated at higher COD oxidation rates under higher COD levels. These results indicate that $\mathrm{Fe} / \mathrm{S}$ ratio can play a significant role in regulating the kinetics of the COD oxidation processes with higher COD oxidation rates under increased $\mathrm{Fe} / \mathrm{S}$ ratios.

\subsubsection{Factors affecting COD oxidation}

\subsubsection{1 pH \& redox potential}

The $\mathrm{pH}$ value in the bioreactors ranged in 6.5-7, which was conducive to microbial activities of both iron and sulfate reducers. Redox potential of these bioreactors was low and varied from $-123.4 \mathrm{mV}$ to $-241.5 \mathrm{mV}$. These conditions were favorable for iron and sulfide to precipitate as ferrous sulfide (Gerardi, 2006).

\subsubsection{Dissolved ferrous and sulfide}

For each Fe/S ratio, all samples collected in the first nine hours under all tested COD concentrations $(n=50)$ were filtered $(0.2 \mu \mathrm{m})$ and analyzed for both dissolved ferrous iron and sulfide. Dissolved sulfide was consistently low under all $\mathrm{Fe} / \mathrm{S}$ ratios with median concentrations ranging in $0.02-0.034 \mathrm{mg} / \mathrm{L}$ (Fig. 7). The median concentration of ferrous iron increased from $0.02 \mathrm{mg} / \mathrm{L}$ to $5.6 \mathrm{mg} / \mathrm{L}$, indicating increasingly excessive quantities of ferrous iron over sulfide as Fe/S ratio increased (Fig. 7).

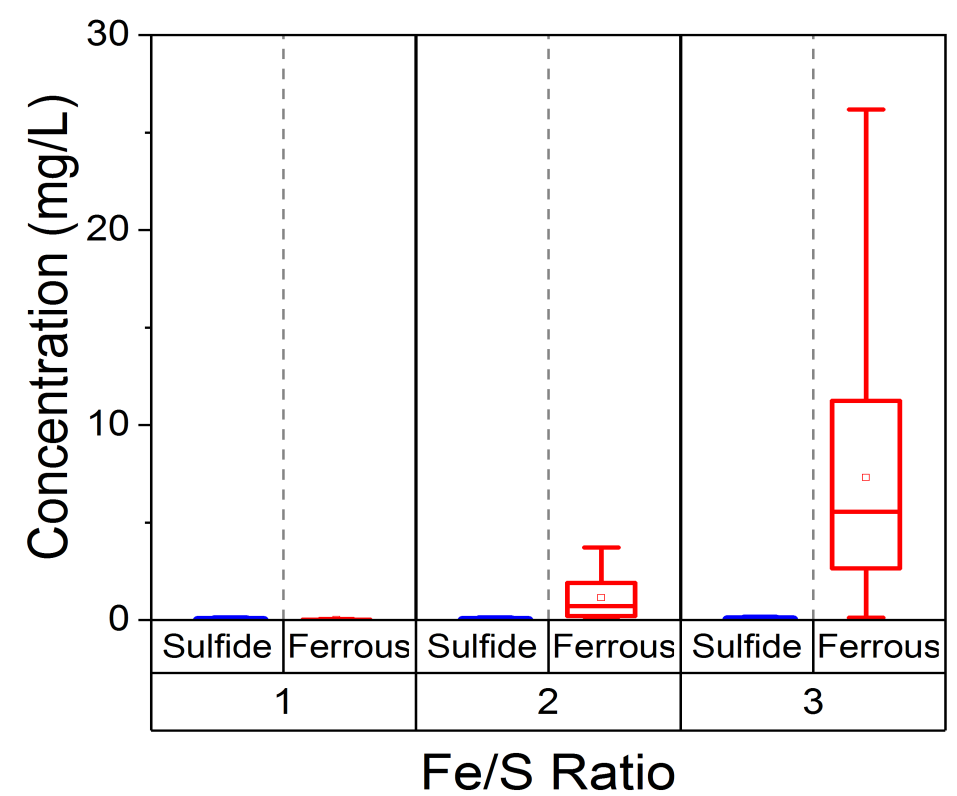

Fig. 7: Dissolved sulfide and ferrous iron concentrations in the bioreactors under different $\mathrm{Fe} / \mathrm{S}$ ratios 
The mean concentration products of ferrous iron and sulfide under different $\mathrm{Fe} / \mathrm{S}$ ratios ranged from $1.3 \times 10^{-10} \mathrm{M}^{2}$ to $1.6 \times 10^{-13} \mathrm{M}^{2}$, which were very low reflecting high degrees of iron sulfide precipitation in the bioreactors. Increasingly excessive ferrous production over sulfide was observed with increased Fe/S ratio (Fig. 7). For practical applications, the presence of ferrous iron and sulfide in the treated water can cause biological instability in its receiving water because of their oxygen demands. However, they can be removed through oxidation which can be conveniently achieved by chlorination in the disinfection treatment of the effluent (Cadena and Peters, 1988; Khadse et al., 2015). Other physical and chemical methods such as precipitation and absorption can also be used to remove these chemicals (Horikawa et al., 2004; Kapdi et al., 2005; Petersson and Wellinger, 2009).

\subsubsection{Sludge Characterization}

\subsubsection{Sludge Solid Contents}

The solid concentrations of the cumulated sludge collected after the kinetic tests varied significantly among the three different $\mathrm{Fe} / \mathrm{S}$ ratios. TSS concentrations of the samples ( $\mathrm{n}$ = 30) increased with Fe/S ratio (Fig. 8a), and were $339 \pm 28 \mathrm{mg} / \mathrm{L}, 505 \pm 97 \mathrm{mg} / \mathrm{L}$ and $652 \pm 143 \mathrm{mg} / \mathrm{L}$ for Fe/S ratio 1, 2 and 3, respectively. The increases were mostly caused by NVSS and relatively smaller variations caused by VSS. Mean VSS/TSS ratio varied from 0.32 to 0.45 and correspondingly NVSS/TSS ratio varied from 0.68 to 0.55 (Fig. 8 b). These results showed the range of the inorganic and organic fractions of the sludge materials, and that their differences increased with Fe/S ratio (Fig. 8a). They also showed that higher Fe/S ratios would increase overall sludge production rate from the treatment process. 


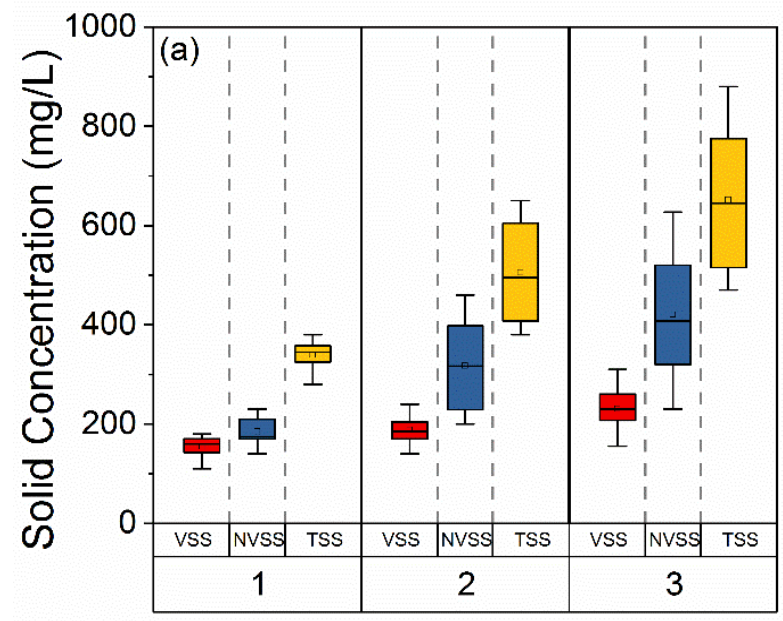

$\mathrm{Fe} / \mathrm{S}$ Ratio

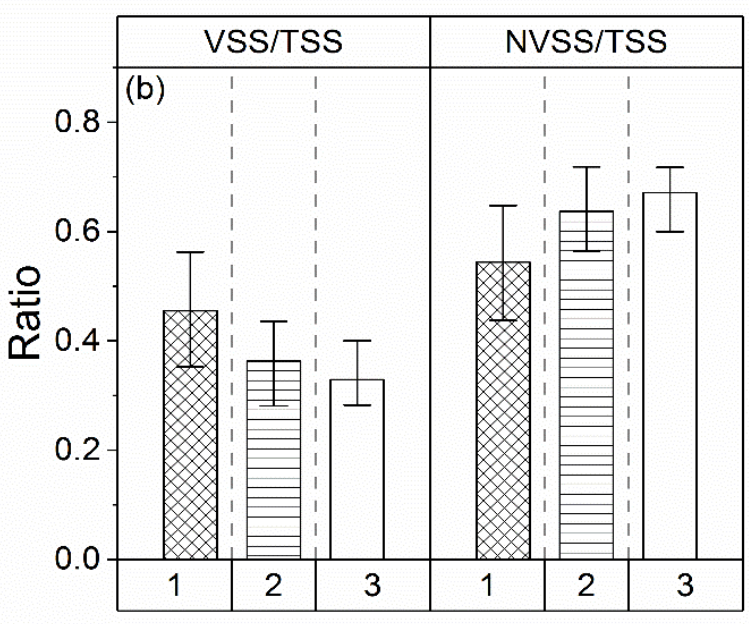

$\mathrm{Fe} / \mathrm{S}$ Ratio

Fig. 8: (a) Solid concentrations and (b) VSS/TSS and NVSS/TSS ratios of the sludge materials

\subsubsection{Iron and Sulfur}

In the feed solutions, sulfur (S) was in a soluble form, but ferric iron was in suspension as $\mathrm{Fe}(\mathrm{OH})_{3}$ flocs given the solution $\mathrm{pH}$ (6.5-7). Upon ferrous sulfide precipitation, Fe and $\mathrm{S}$ were mostly in particulate forms and only a small portion was in soluble forms given the low solubility of ferrous sulfide. In the sludge materials, approximately $95.5 \%$ of the total iron was in a solid form leaving $4.5 \%$ in a soluble form mostly as $\mathrm{Fe}^{2+}$ (Supplementary Material, Fig. S3). Similarly, particulate $S$ accounted for a much greater fraction of the sludge (90-97\%) and dissolved S made up only a small fraction (3-10\%). This chemically reduced inorganic material is a by-product of the treatment system and can possibly be extracted from the sludge for beneficial uses such as production of magnetite particles (Thorpe et al., 1984; Waters et al., 2008).

\subsubsection{Sludge morphology and chemical composition}

SEM-EDS analysis gave a synopsis on the morphology and chemical composition of the sludge. SEM images showed small grains of precipitate particles $(<1 \mu \mathrm{m})$ that were poorly ordered in structure (Fig. 9). The EDS analysis showed that major sludge elements included carbon (C), oxygen (O), Fe and S (Fig. 9). Chemical elements with a high atomic number generally reflect brighter contrast in SEM images due to their larger backscattered electron yield ( $\mathrm{Li}$ et al., 2015). Therefore, the bright elements were 
attributed to precipitates of $\mathrm{Fe}$ and $\mathrm{S}$ as they have higher atomic number than $\mathrm{C}$ and $\mathrm{O}$. The structural arrangement of inferred iron sulfide was comparable to those reported previously (Bratkova et al., 2018; Csákberényi-Malasics et al., 2012; Vaclavkova et al., 2014).
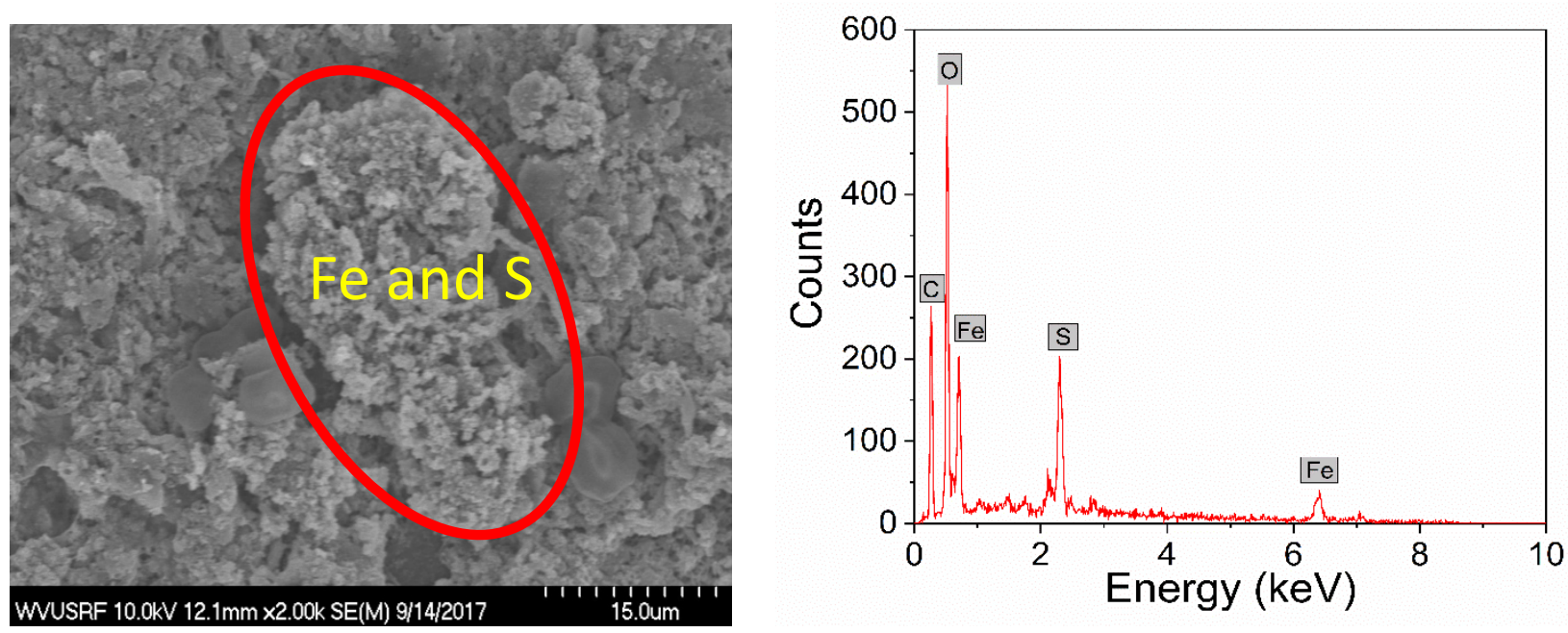

Fig. 9: Sample SEM micrograph and EDS spectrum of the sludge material under $\mathrm{Fe} / \mathrm{S}$ molar ratio 3

The ZAF correction quantitative analysis indicated the weight and atomic percentage ratios of $\mathrm{C}, \mathrm{O}, \mathrm{Fe}$, and $\mathrm{S}$ were comparable among the three $\mathrm{Fe} / \mathrm{S}$ ratios (Supplementary material, Fig. S4). The variations in weight and atomic percentages of each element were observed as measurements taken at different locations of the sludge samples. The atomic percentage ratios of C: O: Fe: $S$ were estimated as 47:34:9:10, 47:36:8:9 and 41:40:10:9 for $\mathrm{Fe} / \mathrm{S}$ ratio 1, 2 and 3, respectively (Fig. S4b). The atomic percentage ratios of $\mathrm{Fe}$ and $S$ were close to 1 suggesting the presence of iron sulfide $(\mathrm{FeS})$ as the major inorganic constituent of the biogenic sludge materials. The sludge was primarily precipitate as amorphous $\mathrm{FeS}$, but can be transformed to more crystalline form of $\mathrm{FeS}$ and $\mathrm{FeS}_{2}$ during long-term operation (Deng et al., 2019).

For all the $\mathrm{Fe} / \mathrm{S}$ ratios, similar XPS results were observed and XPS fitting for $\mathrm{Fe} / \mathrm{S}$ ratio 3 is illustrated as a representative example. The peak fitting of $\mathrm{Fe}$ and $\mathrm{S}$ binding energies showed significant presence of ferrous iron and moderate presence of sulfide in the sludge (Fig. 10). The strong peaks observed for ferrous iron at $708.5 \mathrm{kV}$ and sulfide at 
$162.4 \mathrm{kV}$ and $161.2 \mathrm{kV}$ suggested the presence of $\mathrm{FeS}$ and $\mathrm{FeS}_{2}$ in the sludge sample (Descostes et al., 2000; Lennie and Vaughan, 1996). The excessive iron that was not utilized by microbial process was mostly in the form of ferric hydroxide and showed a peak at $711 \mathrm{eV}$ in the Fe2p spectrum.
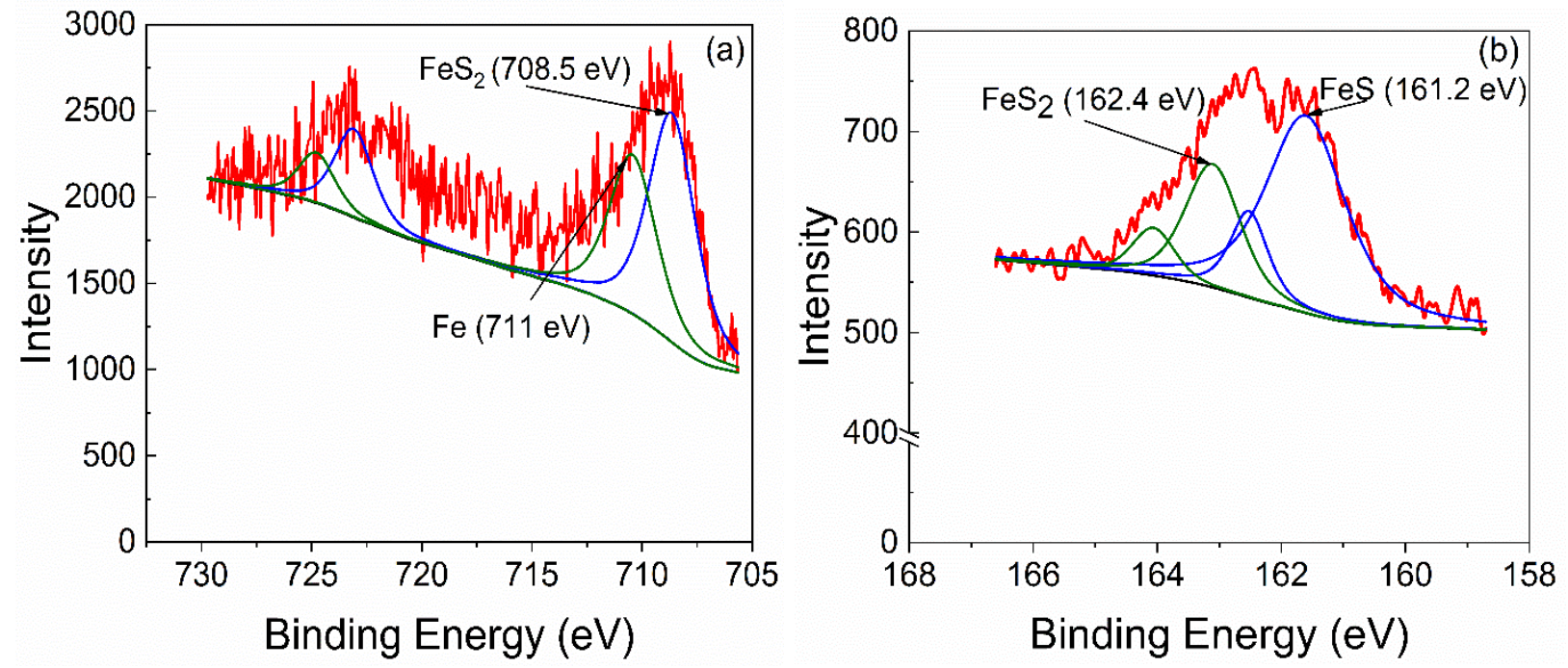

Fig. 10: XPS spectra of (a) Fe and (b) S in the sludge material under Fe/S molar ratio 3

\subsubsection{Microbial community}

$16 S$ rRNA genes affiliated with taxa spanning eight phyla were detected in the biofilm and sludge samples, including members of the Alphaproteobacteria, Gammaproteobacteria, Deltaproteobacteria, Acidobacteria, Actinobacteria, Bacteroidetes, Firmicutes and Euryarchaeota (Table 2). 
Table 2: Major bacteria observed with their phyla and averaged relative abundance in all the bioreactors

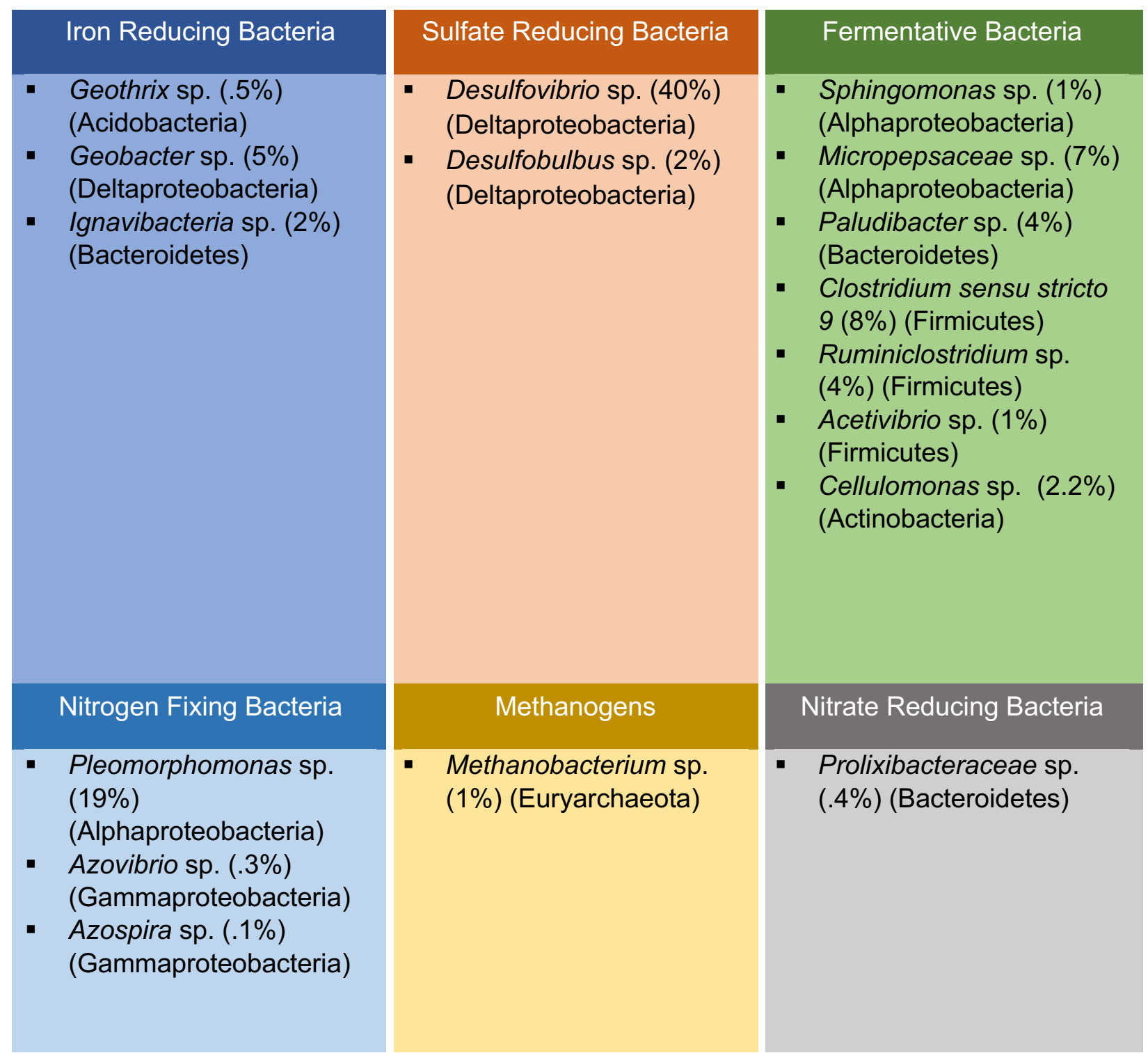

Assigning functional roles to the detected microorganisms on the basis of $16 \mathrm{~S}$ rRNA genes can be challenging, due to both the metabolic flexibility of some taxa and the limited knowledge of microbial metabolism in other taxonomic groups. However, conservative functional roles may be assigned in some instances where laboratory studies have identified conserved traits for specific taxonomic groups. Building on this concept, here we have classified Geobacter sp., Geothrix sp. and Ignavibacteria sp. as IRB. Members of the Geobacteraceae and Geothrix sp. are able to reduce ferric iron in laboratory studies 
(Childers et al., 2002; Coates et al., 2001, 1999; Nevin et al., 2005), while a number of recent studies have implicated Ignavibacteria in iron reduction (Fortney et al., 2018; Podosokorskaya et al., 2013). Similarly, we have classified both Desulfovibrio sp. and Desulfobulbus sp. as SRB in this study, due to their well-characterized ability to reduce sulfate (El Houari et al., 2017; Rabus et al., 2015). Both Geobacter sp. and Desulfovibrio $\mathrm{sp}$. were predominant across all the bioreactors, while Desulfobulbus $\mathrm{sp}$. relative abundances ranged between 0-24\%.

With the exception of Ignavibacteria, these putative IRB and SRB are heterotrophic, and belong to the Deltaproteobacteria. Dominant Geobacter species generally utilize small organic substrates (e.g., acetate) that are oxidized to $\mathrm{CO}_{2}$ (Esther et al., 2015; Lovley, 1993; Lovley et al., 1993), and may reduce insoluble iron oxides via direct contact with outer-membrane cytochromes and conductive pili structures. Acetate was present in the synthetic wastewater used in this experiment (30-600 mg/L), and may at least partly explain the dominance of Geobacter sp. in the communities. Similarly, both Geobacter sp. and Desulfovibrio sp. grow well at moderate temperatures $\left(20\right.$ to $\left.45^{\circ} \mathrm{C}\right)$ and near neutral $\mathrm{pH}(6-8.5)$ conditions found within the bioreactors (Straub et al., 2001).

SRB were identified as the major contributor for COD oxidation in the bioreactors although the higher $\mathrm{Fe} / \mathrm{S}$ ratios promoted the contribution of IRB to COD oxidation. Thermodynamically, IRB have a competitive advantage over SRB for organic carbon substrates due to higher energy gain from the coupled redox reactions, which should have resulted in higher IRB biomass production than SRB. However, at a near neutral $\mathrm{pH}$, ferric iron is present as $\mathrm{Fe}(\mathrm{OH})_{3}$, which reduces its bioavailability to IRB. Quantification of microbial populations indicated that approximately $50 \%$ of the community were putative SRB while the inferred IRB constituted $2 \%$ of the total population under Fe/S ratio 1 (Fig. 11a). The SRB populations decreased to $34 \%$ and $36 \%$, and correspondingly IRB increased to $8 \%$ and $10 \%$ relative abundances as the Fe/S ratio increased to 2 and 3 , respectively. This result indicates a positive correlation between the inferred IRB and the COD oxidation rate. The dominance of Desulfovibrio sp. in all the bioreactors was likely linked to the presence of lactate in the synthetic wastewater used in this study (Jones et al., 1984), and had additional implications for in situ redox reactions. In addition to sulfate 
reduction, Desulfovibrio sp. have been implicated in performing enzymatic ferric reduction in aquatic sediments and groundwater (Coleman et al., 1993; Lovley, 2000; Tebo and Obraztsova, 1998) and so may have contributed to the observed enzymatic iron reduction in the bioreactors.
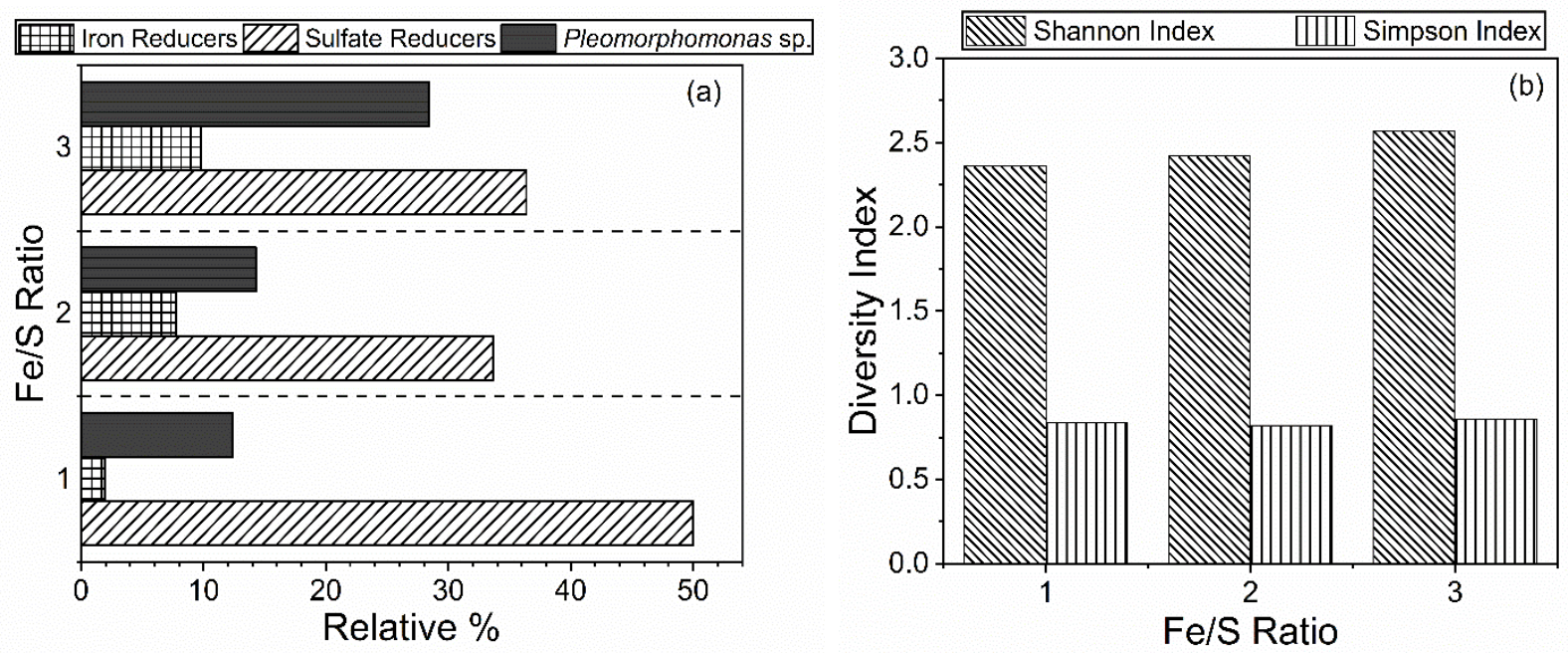

Fig. 11: (a) Relative abundances of major microbial species and (b) diversity index Microbial diversity indices generally increased with the Fe/S ratio (Fig. 11b). Shannon's $\mathrm{H}$, which measures both the diversity and evenness of a community, increased from low to high Fe/S ratio, and was calculated as $2.36,2.42$ and 2.57 for ratio 1,2 and 3 , respectively. Simpson's diversity index was estimated as $0.84,0.82$ and 0.86 for ratio 1 , 2 and 3 respectively. Increases in microbial diversity within the community may support both increased functionality that results in more efficient substrate utilization, and resilience to disturbance of the environmental and chemical conditions (e.g., temperature, electron donors). Here, the reactor with $\mathrm{Fe} / \mathrm{S}$ ratio 3 supported the most microbial diverse community - indicated by the highest Shannon's H index (2.57) and Simpson index (0.86) - and reported the highest COD oxidation rate. The low relative abundance of putative methanogens $(\sim 1 \%)$ in these bioreactors suggests that IRB and SRB were able to successfully outcompete these microorganisms for methanogenic substrates (e.g., acetate, $\mathrm{H}_{2}$ ).

Members of the genus Pleomorphomonas were also abundant in the bioreactors and their population increased with $\mathrm{Fe} / \mathrm{S}$ ratio. Characterized isolates from this genus are able to 
fix atmospheric nitrogen, suggesting that strains present in the bioreactor might be able to perform this same role where available $\mathrm{N}$ becomes limiting (Esquivel-Elizondo et al., 2018). $N_{2}$ gas sparged to maintain the anaerobic condition in this study was likely a nitrogen source for these $\mathrm{N}$-fixing bacteria.

Fermentative bacteria affiliated with the genus Clostridium sp. (8\%) and genus Ruminiclostridum sp. (4\%) were also identified in the bioreactors, and likely played a key role in degrading more complex carbon substrates into labile compounds for oxidation by IRB and SRB. Fermentative clostridial species have previously been shown to play roles in iron reduction through the disposal of reducing equivalents, and may have contributed to iron reduction through such a mechanism in the bioreactors (Dobbin et al., 1999; Shah et al., 2014).

\subsection{Conceptual Framework}

Based on the findings of this study, a conceptual framework is proposed to illustrate the effects of $\mathrm{Fe} / \mathrm{S}$ ratio on organic carbon oxidation rate of this iron-dosed treatment system (Fig. 12).

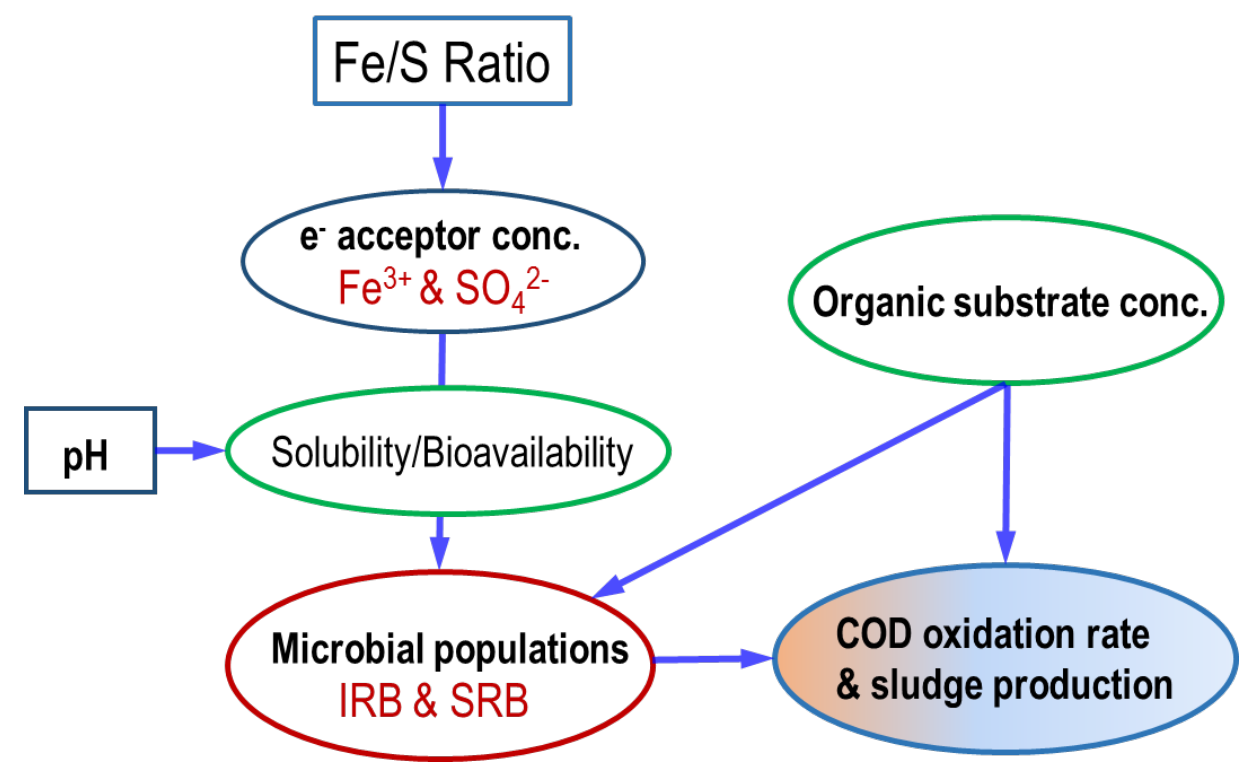

Fig. 12: Conceptual framework of the effects of Fe/S ratio on organic carbon oxidation kinetics 
This study finds that $\mathrm{Fe} / \mathrm{S}$ ratio plays a significant role in shaping multiple aspects of this iron-dosed wastewater treatment system. It regulates the quantities of ferric iron and sulfate as electron acceptors whose bioavailability to microorganisms is governed by their solubility and relevant environmental factors such as $\mathrm{pH}$. Populations of the major reducers (IRB and SRB) and other microbial species are then regulated by the concentrations and bioavailability of the electron acceptors and the organic substrates as electron donors. The overall COD oxidation rate is dependent on the individual oxidation rates of IRB and SRB and their respective populations. The results showed that overall COD oxidation and sludge production rates were enhanced by increased $\mathrm{Fe} / \mathrm{S}$ ratios. The COD oxidation rate has a positive correlation with abundance of IRB, suggesting that IRB facilitated faster COD oxidation kinetics than SRB.

\subsection{Conclusion}

$\mathrm{Fe} / \mathrm{S}$ ratio was found to be an important factor that affects critical aspects of this $\mathrm{Fe}(\mathrm{III})-$ dosed treatment system, which include bioavailability of the two electron acceptors, microbial populations and distribution of IRB and SRB, organics oxidation rate, sludge production, and treated water quality. For practical applications of wastewater treatment and design, this ratio can be used for regulating the treatment performance and optimizing cost-effectiveness. Enhancing the organics oxidation rate can be achieved by increasing iron dosing and help reduce environmental footprint of the treatment process. However, excessive amounts of ferrous iron that may present in the treated water and cause biological instability in receiving waters need to be considered. Removing ferrous iron from the effluent can be achieved concurrently with disinfection using oxidants such as chlorine and provide an opportunity for collecting precipitated ferric hydroxide for recycled use of ferric iron. The inorganic fraction of the produced sludge consisted of mostly ferrous sulfides, and can potentially render beneficial applications given their magnetic and electrical properties. The proposed conceptual framework helps illustrate how iron dosing affects treatment kinetics, microbial ecology, and their interplays. It also provides a basis for further developing the treatment process. Future studies are required on continuous, long-time operations of this novel process, sludge composition, microbial ecology evolution in the bioreactors, and methods for enhancing ferric iron bioavailability. 


\section{Acknowledgements}

The authors wish to thank Dr. Marcela Redigolo and Dr. Qiang wang of West Virginia University Shared Research Facility (SRF) for assistance in SEM and XPS analysis of the sludge samples. The authors also appreciate the help from Dr. Eugenia PenaYewtukhiw, Associate Professor of Davis college of Agriculture, Natural Resources and Design of West Virginia University during the total sulfur analysis with optical emission spectrometer. This research is partially supported by the National Science Foundation [grant number OIA-1458952]. Any opinions, findings and conclusions, or recommendations expressed in this material are those of the author(s) and do not necessarily reflect the views of the National Science Foundation. The authors are thankful for the support.

\subsection{Supplementary Materials}
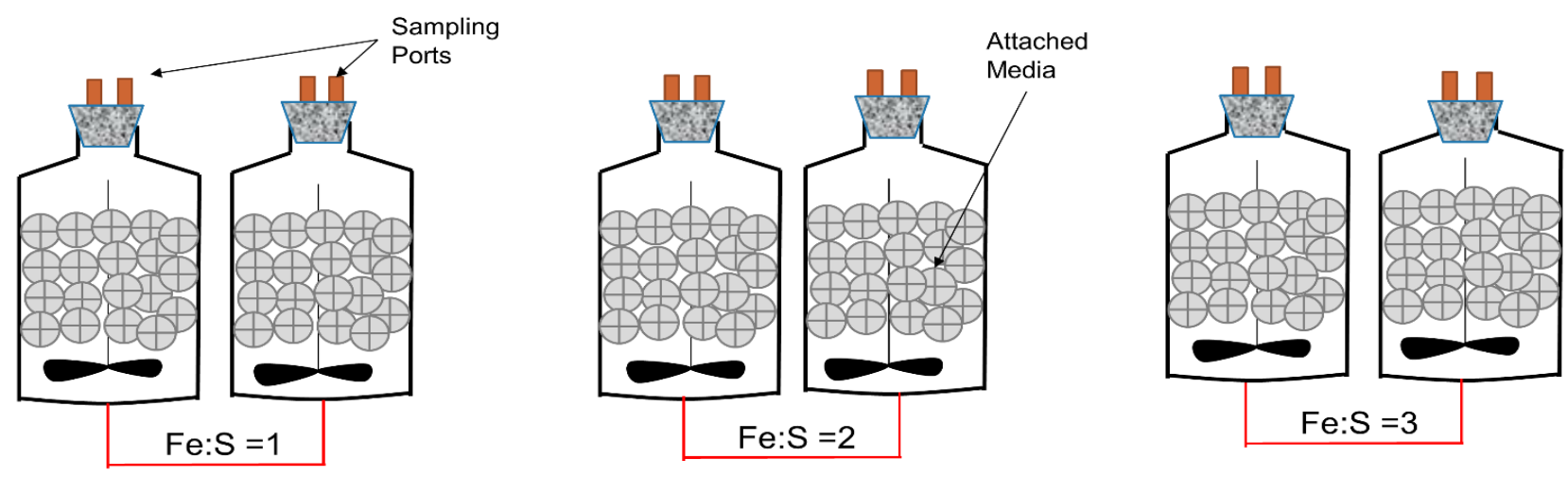

Total equivalent conc. of oxidizing agents $4.68 \mathrm{mN}$

Fig. S1: Experimental Set-up of Batch Reactors 

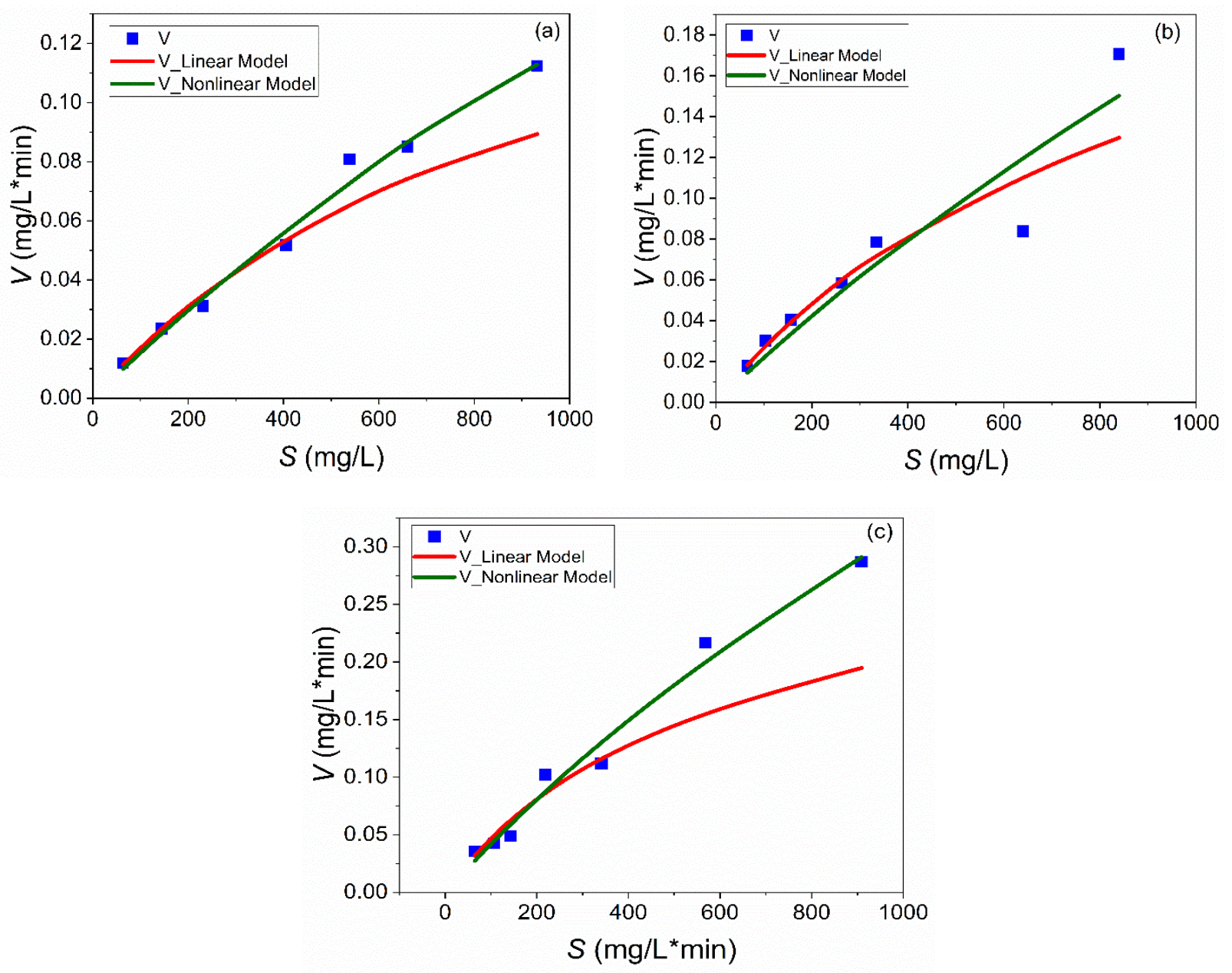

Fig. S2: Linear and Nonlinear Models for three different ratios (a) Fe/S =1 (b) Fe/S =2 (c) $\mathrm{Fe} / \mathrm{S}=3$

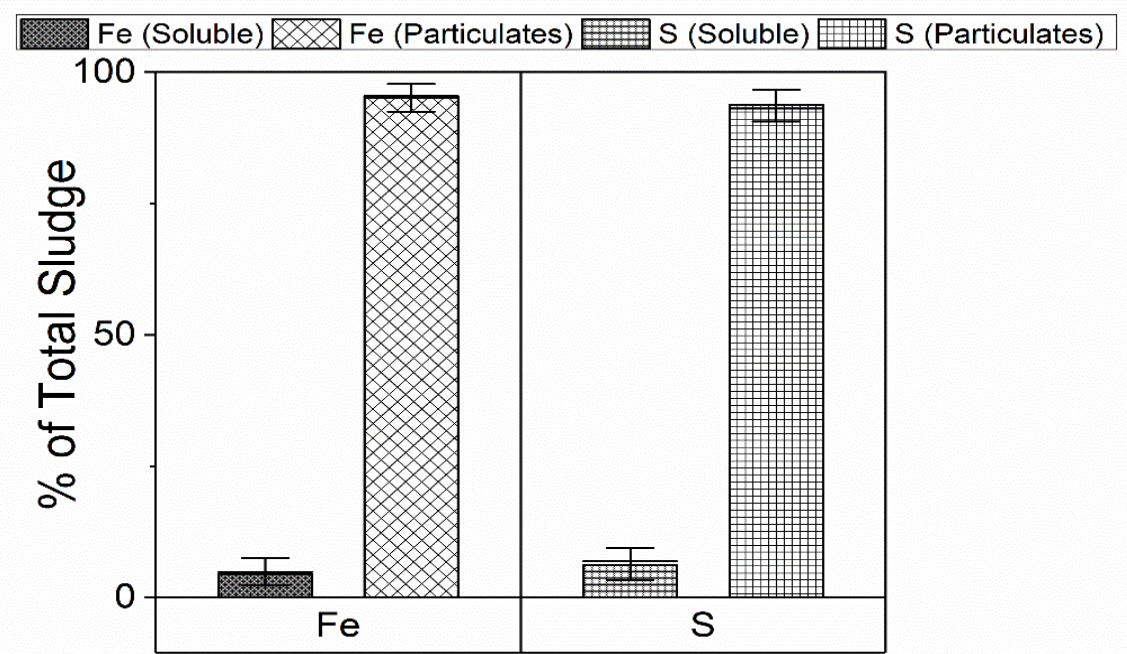

Fig. S3: Fe and S percentages in the sludge materials from the bioreactors 


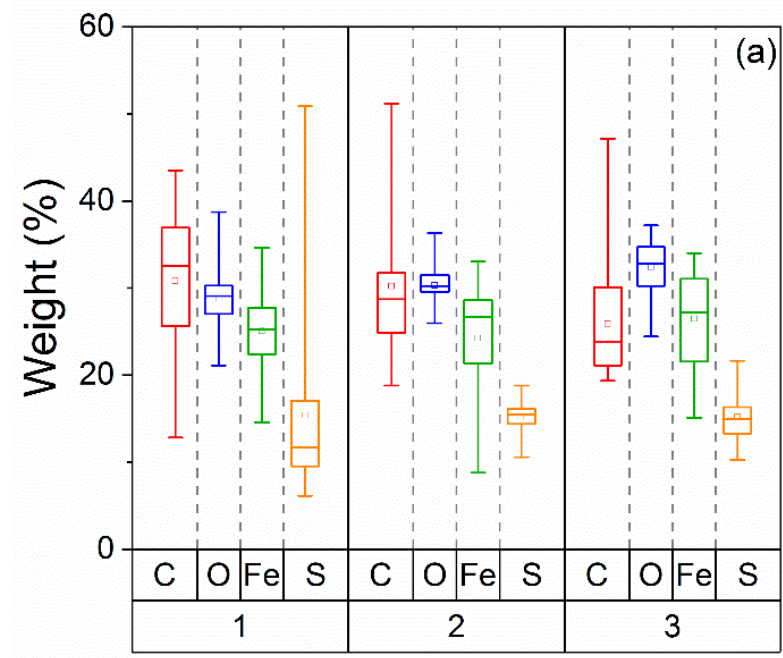

Fe/S Ratio

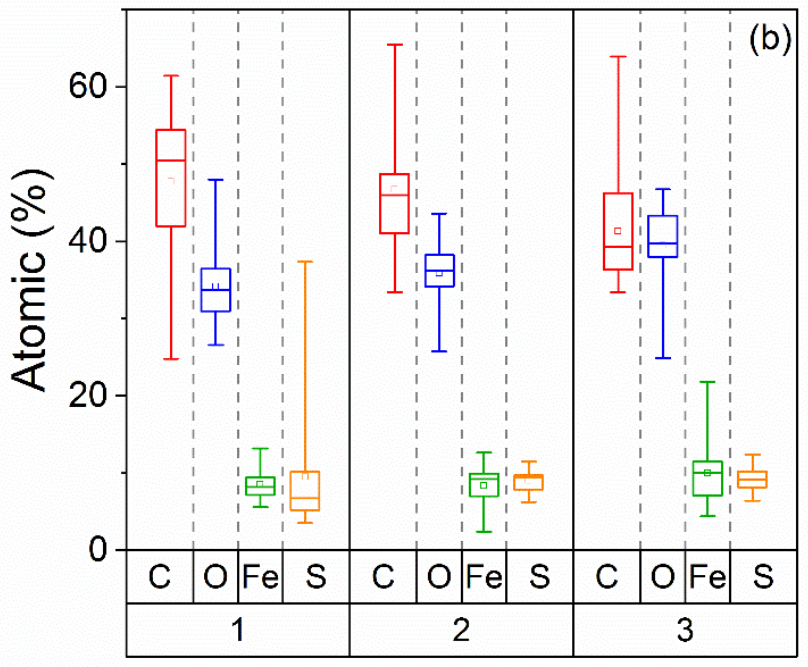

Fe/S Ratio

Fig. S4: (a) Weight and (b) atomic percentages of selected chemical elements in the sludge materials from EDS analysis

\section{References}

Ahmed, M., Lin, L.-S., 2017. Ferric reduction in organic matter oxidation and its applicability for anaerobic wastewater treatment: a review and future aspects. Rev. Environ. Sci. Biotechnol. 16, 273-287. https://doi.org/10.1007/s11157-017-9424-3

Aklujkar, M., Young, N.D., Holmes, D., Chavan, M., Risso, C., Kiss, H.E., Han, C.S., Land, M.L., Lovley, D.R., 2010. The genome of Geobacter bemidjiensis, exemplar for the subsurface clade of Geobacter species that predominate in $\mathrm{Fe}(\mathrm{III})$-reducing subsurface environments. BMC Genomics 11, 1-18. https://doi.org/10.1186/14712164-11-490

APHA, AWWA, WEF, 2005. Standard methods for the examination of water and wastewater, 21st ed. American Public Health Association,American water Works Association, and Water Environment Federation.

Bonneville, S., Behrends, T., Cappellen, P. Van, Hyacinthe, C., Röling, W.F.M., 2006. Reduction of $\mathrm{Fe}$ (III) colloids by Shewanella putrefaciens: A kinetic model. Geochim. Cosmochim. Acta 70, 5842-5854. https://doi.org/10.1016/j.gca.2006.04.029

Bonneville, S., Behrends, T., Van Cappellen, P., 2009. Solubility and dissimilatory reduction kinetics of iron(III) oxyhydroxides: A linear free energy relationship. Geochim. Cosmochim. Acta 73, 5273-5282. https://doi.org/10.1016/j.gca.2009.06.006

Bonneville, S., Van Cappellen, P., Behrends, T., 2004. Microbial reduction of iron(III) oxyhydroxides: Effects of mineral solubility and availability. Chem. Geol. 212, 255268. https://doi.org/10.1016/j.chemgeo.2004.08.015

Bratkova, S., Lavrova, S., Angelov, A., Nikolova, K., Ivanov, R., Koumanova, B., 2018. 
Treatment of wastewaters containing $\mathrm{Fe}, \mathrm{Cu}, \mathrm{Zn}$ and as by microbial hydrogen sulfide and subsequent emoval of COD, N and P. J. Chem. Technol. Metall. 53, 245257.

Cadena, F., Peters, R.W., 1988. Evaluation of Chemical Oxidizers for Hydrogen Sulfide Control. Water Pollut. Control Fed. 60, 1259-1263. https://doi.org/10.2307/25043633

Childers, S.E., Ciufo, S., Lovley, D.R., 2002. Geobacter metallireducens accesses insoluble $\mathrm{Fe}(\mathrm{III})$ oxide by chemotaxis. Nature 416, 767-769. https://doi.org/10.1038/416767a

Cirne, D.G., Van Der Zee, F.P., Fernandez-Polanco, M., Fernandez-Polanco, F., 2008. Control of sulphide during anaerobic treatment of S-containing wastewaters by adding limited amounts of oxygen or nitrate. Rev. Environ. Sci. Biotechnol. 7, 93105. https://doi.org/10.1007/s11157-008-9128-9

Coates, J.D., Bhupathiraju, V.K., Achenbach, L.A., Mcinerney, M.J., Lovley, D.R., 2001. Geobacter hydrogenophilus, Geobacter chapellei and Geobacter grbiciae, three new, strictly anaerobic, dissimilatory Fe(III)-reducers. Int. J. Syst. Evol. Microbiol. 51, 581-588.

Coates, J.D., Ellis, D.J., Gaw, C. V, Lovley, D.R., 1999. Geothrix fermentans gen. nov., sp. nov., a novel $\mathrm{Fe}(\mathrm{III})$-reducing bacterium from a hydrocarbon-contaminated aquifer. Int. J. Syst. Evol. Microbiol. 49, 1615-1622.

Coleman, M.L., Hedrick, D.B., Lovley, D.R., White, D.C., Pye, K., 1993. Reduction of $\mathrm{Fe}(\mathrm{III})$ in sediments by sulphate-reducing bacteria. Nature 361, 436-438. https://doi.org/10.1038/361436a0

Csákberényi-Malasics, D., Rodriguez-Blanco, J.D., Kis, V.K., Rečnik, A., Benning, L.G., Pósfai, M., 2012. Structural properties and transformations of precipitated $\mathrm{FeS}$. Chem. Geol. 294-295, 249-258. https://doi.org/10.1016/j.chemgeo.2011.12.009

Deng, D., Lin, L.S., 2017. Continuous sulfidogenic wastewater treatment with iron sulfide sludge oxidation and recycle. Water Res. 114, 210-217. https://doi.org/10.1016/j.watres.2017.02.048

Deng, D., Lin, O., Rubenstein, A., Weidhaas, J.L., Lin, L.-S., 2019. Elucidating biochemical transformations of $\mathrm{Fe}$ and $\mathrm{S}$ in an innovative $\mathrm{Fe}$ (II)-dosed anaerobic wastewater treatment process using spectroscopic and phylogenetic analyses. Chem. Eng. J. 358, 1208-1217. https://doi.org/10.1016/J.CEJ.2018.10.030

Deng, D., Weidhaas, J.L., Lin, L.-S., 2016. Kinetics and microbial ecology of batch sulfidogenic bioreactors for co-treatment of municipal wastewater and acid mine drainage. J. Hazard. Mater. 305, 200-8. https://doi.org/10.1016/j.jhazmat.2015.11.041

Descostes, M., Mercier, F., Thromat, N., Beaucaire, C., Gautier-Soyer, M., 2000. Use of XPS in the determination of chemical environment and oxidation state of iron and sulfur samples: Constitution of a data basis in binding energies for $\mathrm{Fe}$ and $\mathrm{S}$ reference compounds and applications to the evidence of surface species of an 
oxidized py. Appl. Surf. Sci. 165, 288-302. https://doi.org/10.1016/S01694332(00)00443-8

Dobbin, P.S., Carter, J.P., Juan, C.G.S.S., Von Höbe, M., Powell, A.K., Richardson, D.J., 1999. Dissimilatory $\mathrm{Fe}(\mathrm{III})$ reduction by Clostridium beijerinckii isolated from freshwater sediment using Fe(III) maltol enrichment. FEMS Microbiol. Lett. 176, 131138. https://doi.org/10.1016/S0378-1097(99)00229-3

El Houari, A., Ranchou-Peyruse, M., Ranchou-Peyruse, A., Dakdaki, A., Guignard, M., Idouhammou, L., Bennisse, R., Bouterfass, R., Guyoneaud, R., Qatibi, A.I., 2017. Desulfobulbus oligotrophicus sp. Nov., a sulfate-reducing and propionate-oxidizing bacterium isolated from a municipal anaerobic sewage sludge digester. Int. J. Syst. Evol. Microbiol. 67, 275-281. https://doi.org/10.1099/ijsem.0.001615

Esquivel-Elizondo, S., Maldonado, J., Krajmalnik-Brown, R., 2018. Anaerobic carbon monoxide metabolism by Pleomorphomonas carboxyditropha sp. nov., a new mesophilic hydrogenogenic carboxydotroph. FEMS Microbiol. Ecol. 94, 1-12. https://doi.org/10.1093/femsec/fiy056

Esther, J., Sukla, L.B., Pradhan, N., Panda, S., 2015. Fe (III) reduction strategies of dissimilatory iron reducing bacteria. Korean J. Chem. Eng. 32, 1-14. https://doi.org/10.1007/s11814-014-0286-x

Fortney, N.W., He, S., Kulkarni, A., Friedrich, M.W., Holz, C., Boyd, E.S., Roden, E.E., 2018. Stable isotope probing for microbial iron reduction in Chocolate Pots hot spring, Yellowstone National Park. Appl. Environ. Microbiol. 84. https://doi.org/10.1128/AEM.02894-17

Gerardi, M.H., 2006. Wastewater bacteria. John Wiley \& Sons, New Jersey.

Gramp, J.P., Bigham, J.M., Jones, F.S., Tuovinen, O.H., 2010. Formation of Fe-sulfides in cultures of sulfate-reducing bacteria. J. Hazard. Mater. 175, 1062-1067. https://doi.org/10.1016/j.jhazmat.2009.10.119

Hegyi, G., Kardos, J., Kovács, M., Málnási-Csizmadia, A., Nyitray, L., Pál, G., Radnai, L., Reményi, A., Venekei, I., 2013. Introduction to Practical Biochemistry. Eötvös Loránd University, Hungary.

Herbert, R.B., Benner, S.G., Pratt, A.R., Blowes, D.W., 1998. Surface chemistry and morphology of poorly crystalline iron sulfides precipitated in media containing sulfatereducing bacteria. Chem. Geol. 144, 87-97. https://doi.org/10.1016/S00092541(97)00122-8

Horikawa, M.S., Rossi, F., Gimenes, M.L., Costa, C.M.M., Da Silva, M.G.C., 2004. Chemical absorption of H2S for biogas purification. Brazilian J. Chem. Eng. 21, 415422. https://doi.org/10.1590/S0104-66322004000300006

Jensen, M.M., Thamdrup, B., Rysgaard, S., Holmer, M., Fossing, H., 2003. Rates and Regulation of Microbial Iron Reduction in Sediments of the Baltic-North Sea Transition 65, 295-317.

Jones, J., Davison, W., Gardener, S., 1984. Iron reduction by bacteria: range of 
organisms involved and metals reduced. FEMS Microbiol. Lett. 21, 133-136.

Kaksonen, A.H., Plumb, J.J., Robertson, W.J., Riekkola-Vanhanen, M., Franzmann, P.D., Puhakka, J.A., 2006. The performance, kinetics and microbiology of sulfidogenic fluidized-bed treatment of acidic metal- and sulfate-containing wastewater. Hydrometallurgy 83, 204-213. https://doi.org/10.1016/j.hydromet.2006.03.025

Kapdi, S.S., Vijay, V.K., Rajesh, S.K., Prasad, R., 2005. Biogas scrubbing, compression and storage: Perspective and prospectus in Indian context. Renew. Energy 30, 1195-1202. https://doi.org/10.1016/j.renene.2004.09.012

Khadse, G.K., Patni, P.M., Labhasetwar, P.K., 2015. Removal of Iron and Manganese from drinking water supply. Sustain. Water Resour. Manag. 1, 157-165. https://doi.org/10.1021/ie50297a006

Lennie, A.R., Vaughan, D.J., 1996. Spectroscopic studies of iron sulfide formation and phase relations at low temperatures, in: Dyar, M.D., McCammon, C., Schaefer, M.W. (Eds.), Mineral Spectroscopy: A Tribute to Roger G. Burns. pp. 117-131.

Li, C., Jun, X., Jing, C., 2015. Applications of scanning electron microscopy in earth sciences. Sci. China Earth Sci. 58, 1768-1778. https://doi.org/10.1007/s11430-015$5172-9$

Liu, C., Gorby, Y.A., Zachara, J.M., Fredrickson, J.K., Brown, C.F., 2002. Reduction kinetics of $\mathrm{Fe}(\mathrm{III}), \mathrm{Co}(\mathrm{III}), \mathrm{U}(\mathrm{VI}), \mathrm{Cr}(\mathrm{VI})$, and $\mathrm{Tc}(\mathrm{VII})$ in cultures of dissimilatory metalreducing bacteria. Biotechnol. Bioeng. 80, 637-649. https://doi.org/10.1002/bit.10430

Liu, J., Zhao, Z., Jiang, G., 2008. Coating Fe3O4 Magnetic Nanoparticles with Humic Acid for High Efficient Removal of Heavy Metals in Water. Environ. Sci. Technol. 42, 6949-6954. https://doi.org/10.1021/es800924c

Lovley, D.R., 2000. Fe(III) and Mn(IV) Reduction, in: Lovley, D.R. (Ed.), Environmentai Microbe-Metal Interactions. ASM Press, Washington D.C., pp. 3-30.

Lovley, D.R., 1995. Bioremediation of organic and metal contaminants with dissimilatory metal reduction. J. Ind. Microbiol. 14, 85-93. https://doi.org/10.1007/BF01569889

Lovley, D.R., 1993. Dissimilatory metal reduction. Annu. Rev. Microbiol. 47, 20-29.

Lovley, D.R., 1987. Organic matter mineralization with the reduction of ferric iron: A review. Geomicrobiol. J. 5, 375-399. https://doi.org/10.1080/01490458709385975

Lovley, D.R., Giovannoni, S.J., White, D.C., Champine, J.E., Phillips, E.J.P., Gorby, Y.A., Goodwin, S., 1993. Geobacter metallireducens gen. nov. sp. nov., a microorganism. Arch. Microbiol. 159, 336-344.

Lovley, D.R., Phillips, E.J.P., 1989. Requirement for a microbial consortium to completely oxidize glucose in Fe(III)- reducing sediments. Appl. Environ. Microbiol. 55, 32343236.

Mahadevan, R., Palsson, B., Lovley, D.R., 2011. In situ to in silico and back: Elucidating the physiology and ecology of Geobacter spp. using genome-scale modelling. Nat. Rev. Microbiol. 9, 39-50. https://doi.org/10.1038/nrmicro2456 
Martin, R.B., 1997. Disadvantages of Double Reciprocal Plots. J. Chem. Educ. 74, 1238. https://doi.org/10.1021/ed074p1238

Mosey, F., Swanwick, J., Hughes, D.A., 1971. Factors Affecting the Availability of Heavy Metals to Inhibit Anaerobic Digestion. J. Water Pollut. Control Fed. 71, 668-678.

Myers, J.M., Myers, C.R., 2001. Role for outer membrane cytochromes OmcA and OmcB of Shewanella putrefaciens MR-1 in reduction of manganese dioxide. Appl. Environ. Microbiol. 67, 260-269. https://doi.org/10.1128/AEM.67.1.260-269.2001

Nevin, K.P., Holmes, D.E., Woodard, T.L., Hinlein, E.S., Ostendorf, D.W., Lovley, D.R., 2005. Geobacter bemidjiensis sp. nov. and Geobacter psychrophilus sp. nov., two novel Fe(III)-reducing subsurface isolates. Int. J. Syst. Evol. Microbiol. 55, 16671674. https://doi.org/10.1099/ijs.0.63417-0

Nevin, K.P., Lovley, D.R., 2002. Mechanisms for Fe(III) Oxide Reduction in Sedimentary Environments. Geomicrobiol. J. 19, 141-159.

Perrin, C.L., 2017. Linear or Nonlinear Least-Squares Analysis of Kinetic Data? J. Chem. Educ. 94, 669-672. https://doi.org/10.1021/acs.jchemed.6b00629

Petersson, A., Wellinger, A., 2009. Biogas upgrading technologies - developments and innovations Task 37 -Energy from biogas and landfill gas leA Bioenergy aims to accelerate the use of environmental sound and cost-competitive Bioenergy on a sustainable basis, and thereby achieve a substant. IEA Bioenergy 13.

Podosokorskaya, O.A., Kadnikov, V. V., Gavrilov, S.N., Mardanov, A. V., Merkel, A.Y., Karnachuk, O. V., Ravin, N. V., Bonch-Osmolovskaya, E.A., Kublanov, I. V., 2013. Characterization of Melioribacter roseus gen. nov., sp. nov., a novel facultatively anaerobic thermophilic cellulolytic bacterium from the class Ignavibacteria, and a proposal of a novel bacterial phylum Ignavibacteriae. Environ. Microbiol. 15, 17591771. https://doi.org/10.1111/1462-2920.12067

Postma, D., 1993. The reactivity of iron oxides in sediments: A kinetic approach. Geochim. Cosmochim. Acta 57, 5027-5034. https://doi.org/10.1016/S00167037(05)80015-8

Rabus, R., Venceslau, S.S., Wöhlbrand, L., Voordouw, G., Wall, J.D., Pereira, I.A.C., 2015. A Post-Genomic View of the Ecophysiology, Catabolism and Biotechnological Relevance of Sulphate-Reducing Prokaryotes. Adv. Microb. Physiol. 66, 55-321. https://doi.org/10.1016/bs.ampbs.2015.05.002

Roden, E.E., Wetzel, R.G., 2002. Kinetics of microbial Fe(III) oxide reduction in freshwater wetland sediments. Limnol. Oceanogr. 47, 198-211. https://doi.org/10.4319/lo.2002.47.1.0198

Shah, M., Lin, C.-C., Kukkadapu, R., Engelhard, M.H., Zhao, X., Wang, Y., Barkay, T., Yee, N., 2014. Syntrophic Effects in a Subsurface Clostridial Consortium on Fe(III)(Oxyhydr)oxide Reduction and Secondary Mineralization. Geomicrobiol. J. 31, 101115.

Straub, K.L., Benz, M., Schink, B., 2001. Iron metabolism in anoxic environments at near 
neutral pH. FEMS Microbiol. Ecol. 34, 181-186. https://doi.org/10.1016/S01686496(00)00088-X

Tebo, B.M., Obraztsova, A.Y., 1998. Sulfate-reducing bacterium grows with $\mathrm{Cr}$ ( VI ), U ( VI ), Mn ( IV ), and Fe ( III ) as electron acceptors. Source 162, 193-198. https://doi.org/10.1111/j.1574-6968.1998.tb12998.x

Thamdrup, B., 2000. Bacterial Manganese and Iron Reduction in Aquatic Sediments. Adv. Microb. Ecol. 16, 41-84. https://doi.org/10.1007/978-1-4615-4187-5_2

Thorpe, A.N., Senftle, F.E., Alexander, C.C., Dulong, F.T., 1984. Oxidation of pyrite in coal to magnetite. Fuel 63, 662-668. https://doi.org/10.1016/0016-2361(84)90163-7

Urrutia, M.M., Roden, E.E., Fredrickson, J.K., Zachara, J.M., 1998. Microbial and surface chemistry controls on reduction of synthetic $\mathrm{Fe}$ (III) oxide minerals by the dissimilatory iron-reducing bacterium Shewanella alga. Geomicrobiol. J. 15, 269-291.

Utgikar, V.P., Harmon, S.M., Chaudhary, N., Tabak, H.H., Govind, R., Haines, J.R., 2002. Inhibition of sulfate-reducing bacteria by metal sulfide formation in bioremediation of acid mine drainage. Environ. Toxicol. 17, 40-48. https://doi.org/10.1002/tox.10031

Vaclavkova, S., Jørgensen, C.J., Jacobsen, O.S., Aamand, J., Elberling, B., 2014. The Importance of Microbial Iron Sulfide Oxidation for Nitrate Depletion in Anoxic Danish Sediments. Aquat. Geochemistry 20, 419-435. https://doi.org/10.1007/s10498-0149227-x

Van der Maas, P., 2005. Fe(III) EDTA reduction in BioDeNOx reactors: kinetics and mechanism, in: Chemically Enhanced Biological NOx Removal from Flue Gases. Wageningen University, pp. 109-124.

Van Lier, J.B., 2008. High-rate anaerobic wastewater treatment: Diversifying from endof-the-pipe treatment to resource-oriented conversion techniques. Water Sci. Technol. 57, 1137-1148. https://doi.org/10.2166/wst.2008.040

Van Lier, J.B., Van der Zee, F.P., Frijters, C.T.M.J., Ersahin, M.E., 2015. Celebrating 40 years anaerobic sludge bed reactors for industrial wastewater treatment. Rev. Environ. Sci. Biotechnol. 14, 681-702. https://doi.org/10.1007/s11157-015-9375-5

Waters, K.E., Rowson, N.A., Greenwood, R.W., Williams, A.J., 2008. The effect of heat treatment on the magnetic properties of pyrite 21, 679-682. https://doi.org/10.1016/j.mineng.2008.01.008

Zhang, J., Zhang, Y., Chang, J., Quan, X., Li, Q., 2013. Biological sulfate reduction in the acidogenic phase of anaerobic digestion under dissimilatory Fe (III) - Reducing conditions. Water Res. 47, 2033-2040. https://doi.org/10.1016/j.watres.2013.01.034 


\section{Chapter 4: Continuous Ferric Iron-dosed Anaerobic Wastewater Treatment: Treatment Performance, Sludge Characteristics, and Microbial Composition}

(M. Ahmed, C. M. Saup, M. J. Wilkins, L.-S. Lin, Continuous Ferric Iron-dosed Anaerobic Wastewater Treatment: Organics Removal, Kinetics, Sludge Characteristics, and Microbial Composition, Journal of Environmental Chemical Engineering, 8 (2), 2020)

\subsection{Introduction}

In the efforts of moving towards more sustainable wastewater management, anaerobic treatment is increasing in popularity due to its energy efficiency, cost effectiveness, low sludge production and greenhouse emission, as well as the potential for resource recovery (Chan et al., 2009; Van Lier et al., 2015). Nitrate, sulfate and carbon dioxide are electron acceptors commonly used in anaerobic biological processes to treat wastewater (Damianovic and Foresti, 2007; Hubert and Voordouw, 2007). Due to its highly redoxactive nature, the prospect of using ferric iron as an electron acceptor in wastewater treatment was recently reviewed and demonstrated in a batch study (Ahmed et al., 2019; Ahmed and Lin, 2017). Iron, the second most abundant mineral on earth, is often found in wastes (e.g., acid mine drainage and coal ash) and these wastes can be readily used as a cheap source of iron for wastewater treatment. Iron has been commonly used for coagulation, Fenton's reagent, and sulfide toxicity and odor control in wastewater treatment (Waite, 2002; Wang et al., 2016; Zhang et al., 2015). A recent study found that $\mathrm{Fe}$ (III) dosing in wastewater treatment can also promote removal of organic micropollutants via adsorption of the compounds on iron sulfide (FeS) surface and subsequent biodegradation (Kulandaivelu et al., 2019). In addition, biogenic iron sulfide sludge produced as a byproduct of iron-dosed wastewater treatment has great applications in remediation of soil and groundwater contamination as well as in wastewater treatment. Iron sulfides and nanoparticles synthesized from iron sulfides were found effective in removal of organic contaminants (benzene, chlorinated organic pollutants, aromatic hydrocarbons), toxic metals ( $\mathrm{As}, \mathrm{Pb}, \mathrm{Hg}, \mathrm{Cd}, \mathrm{Cr}$ ), nutrients ( $\mathrm{N}$ and P), and radionuclides ( $U$ and Se) (Gong et al., 2016; Yang et al., 2017). Moreover, this iron sulfide sludge can potentially be converted into useful products with magnetic properties (e.g., magnetite) for phosphorus recovery from wastewater (Thorpe et al., 
1984a; Wang et al., 2008; Waters et al., 2008; Xiang et al., 2014). This iron-based wastewater treatment does not produce biogas as in methanogenic process. However, its multiple potential benefits (use of iron-containing wastes, no aeration, unique reaction mechanisms for coagulation, sulfide control, organic micropollutant removal, and useful sludge byproduct) render this treatment method versatile. It can be tailored to meet treatment needs such as decentralized treatment with low operation and maintenance requirements.

In Fe(III)-dosed anaerobic wastewater treatment, both Iron reducing bacteria (IRB) and sulfate reducing bacteria (SRB) can contribute to microbial oxidation of organics given the prevalent presence of sulfate in wastewater. Under substrate limiting conditions, IRB can outcompete SRB by diverting the electron flow away from SRB (Lovley and Phillips, 1989). However, for treatment applications of wastewaters, in which substrate limiting is unlikely (Chemical Oxygen Demand, COD, 339-1,016 mg/L, (Metcalf \& Eddy et al., 2014)), the symbiotic relationship between IRB and SRB is currently unknown. In such a treatment system, availability of ferric iron and sulfate is expected to regulate the microbial activities of IRB and SRB, and the overall treatment performance. In addition, the treatment effectiveness also depends on the types of ferric compound, $\mathrm{pH}$, organic compounds and their concentrations as well as reactor configuration (Azam and Finneran, 2013; Lovley, 1987).

Geobacter sp. and Shewanella sp. are two of the most well-studied iron-reducing taxa in the natural environment (Weber et al., 2006). The interactions of these iron reducers with insoluble ferric surface are quite dissimilar from each other. Shewanella sp. was observed to have direct and indirect (ligand, electron shuttle) electron transfer to insoluble ferric surface, whereas Geobacter sp. was often found to rely on pilin filaments for electron transfer (Esther et al., 2015; Weber et al., 2006). Some of the IRB were observed to be closely linked with SRB belonging to the same taxa and utilizing same electron acceptor for growth. For example, Desulfovibrio sp., a common SRB, was observed to perform ferric reduction and organic compound oxidation in an iron reducing environment (Lovley, 1993). In an engineering treatment system, the abundances of these reducers and other microorganisms are dependent on the concentrations and bioavailability of the electron 
acceptors (i.e., ferric iron vs. sulfate) and organic compounds. The respective populations of IRB and SRB in turn affect the treatment performance of organics oxidation kinetics (Ahmed et al., 2019).

Building upon a previous fed-batch study of reaction kinetics (Ahmed et al., 2019), the objective of this study was to investigate the long-term performance of continuous $\mathrm{Fe}(\mathrm{III})$ dosed anaerobic biological treatment of sulfate-containing wastewater under varied ferric and sulfate concentrations (expressed as Fe/S ratios). Specifically, the study focused on how $\mathrm{Fe} / \mathrm{S}$ ratio affects treatment performance, sludge production, and microbial composition. The treatment performance was characterized in terms of organics removal efficiency, removal rate, and effluent quality. In addition, mass flow rates of $\mathrm{Fe}$ and $\mathrm{S}$ were estimated for understanding the biogeochemical transformations of the elements throughout the treatment system. Microbiological analyses were performed to elucidate the relationship between microbial communities and both treatment performance and sludge production.

\subsection{Materials and Methods}

\subsubsection{Bench-scale iron-dosed treatment system}

The treatment system consists of a wastewater tank, a ferric iron solution reservoir, a bioreactor and an effluent collection tank (Supplementary Material, Fig. S5).

\subsubsection{Wastewater Tank}

A 4-L tank was used to feed wastewater in the bioreactor of the treatment system. A solution containing sodium acetate anhydrous $\left(\mathrm{C}_{2} \mathrm{H}_{3} \mathrm{NaO}_{2}, 3 \mathrm{mM}\right), 1.54 \mathrm{mM}$ ethanol $\left(\mathrm{C}_{2} \mathrm{H}_{6} \mathrm{O}, 1.54 \mathrm{mM}\right)$, lactose monohydrate $\left(\mathrm{C}_{12} \mathrm{H}_{22} \mathrm{O}_{11} . \mathrm{H}_{2} \mathrm{O}, 0.32 \mathrm{mM}\right)$, sodium bicarbonate $\left(\mathrm{NaHCO}_{3}, 1.57 \mathrm{mM}\right)$, and trace elements $(4.75 \mathrm{~mL} / \mathrm{L})$ (Deng and Lin, 2017) was prepared as a synthetic wastewater in this study. This synthetic wastewater was used as a base solution to maintain a consistent level of organics (COD=420 mg/L). A sodium sulfate solution $\left(\mathrm{Na}_{2} \mathrm{SO}_{4}\right)$ was used to adjust the sulfate concentration in the wastewater for different $\mathrm{Fe} / \mathrm{S}$ ratios. 


\subsubsection{Ferric Chloride Reservoir}

A 2-L tank containing a ferric chloride solution $\left(\mathrm{FeCl}_{3} \cdot 6 \mathrm{H}_{2} \mathrm{O}, 1.32 \mathrm{mM}, 2.50 \mathrm{mM}\right.$ and 4.50 $\mathrm{mM}$ ) was used to feed ferric iron to the bioreactor to obtain Fe/S molar ratio $0.5,1$ and 2 respectively. The ferric solution $\mathrm{pH}$ was adjusted to 4-4.2 using a sodium hydroxide solution $(\mathrm{NaOH}, 5 \mathrm{~N})$.

\subsubsection{Bioreactor}

The bioreactor $(1.4 \mathrm{~L})$ was made of acrylic cylinder with ports on the top for wastewater and ferric iron inflows. Two ports on the side of the reactor were used for internal recirculation to enhance hydraulic mixing in the reactor. The reactor was packed with five hundred plastic media (Evolution Aqua Ltd., UK, Kaldness K1 Biomedia, specific surface area $=500 \mathrm{~m}^{2} / \mathrm{m}^{3}$ ) for attached growth of microorganisms. This resulted in a working volume of $0.9 \mathrm{~L}$ in the reactor. A perforated acrylic plate was used to support the packing media and a cone-shaped bottom was used for sludge settling and collection. The reactor was first inoculated with anaerobic sludge from a wastewater treatment plant (Star City, West Virginia) and acid mine drainage (St. Thomas, Morgantown, West Virginia) at 1:1 volume ratio. The bioreactor was purged with $\mathrm{N}_{2}$ gas regularly prior to the operation and sealed airtight to maintain an anaerobic condition. The bioreactor was operated at room temperature and given three-month enrichment period with continuous feeding of the synthetic wastewater containing a Fe/S molar ratio of 0.5 .

\subsubsection{Treatment Experiments}

The treatment performance was evaluated under three different Fe/S molar ratios $(0.5,1$, and 2) while maintaining the same total equivalent concentration of $\mathrm{Fe}(\mathrm{III})$ and sulfate (Table 3). The bioreactor was operated continuously for 500 days, during which the flow rates of influent $(0.67 \mathrm{~L} / \mathrm{d})$, ferric solution $(0.53 \mathrm{~L} / \mathrm{d})$, and internal recirculation $(3.4 \mathrm{~L} / \mathrm{d})$ were kept constant. During the treatment, the ferric chloride and sulfate loadings to the bioreactor were varied to obtain the three target Fe/S molar ratios. The total equivalent concentration of the electron acceptors was maintained the same for all three Fe/S molar ratios $(11.9 \mathrm{mN} / \mathrm{d})$ to have the same total reducing capacity for organic matter oxidation. 
Table 3: Daily loads of Fe and S for three target Fe/S molar ratios

\begin{tabular}{|l|l|l|}
\hline Fe/S molar ratio & Fe loading (mmol/d) & S loading $(\mathbf{m m o l} / \mathbf{d})$ \\
\hline $\mathbf{0 . 5}$ & 0.70 & 1.40 \\
\hline $\mathbf{1}$ & 1.32 & 1.32 \\
\hline $\mathbf{2}$ & 2.38 & 1.19 \\
\hline
\end{tabular}

Before changing the ratio of $\mathrm{Fe} / \mathrm{S}$, all solutions and sludges were removed from the bioreactor and replaced with fresh synthetic wastewater. Under each Fe/S ratio, the first month was allowed for microorganisms to adapt to the chemical condition and to reach a steady state and treatment in the following three months was considered under the steady state condition. The influent and effluent samples were collected daily and later intermittently for COD, sulfate, total iron, sulfide and ferrous iron analyses. All samples were stored at $4^{\circ} \mathrm{C}$ until analysis except sulfide and ferrous iron samples which were analyzed immediately to avoid oxidation. Influent and effluent COD, sulfate and total iron concentrations were used to estimate the COD removal efficiency, sulfate reduction and total iron retention. In this study, iron retention is referred to iron retained in the bioreactor and the sludge. COD removal rate was calculated using the influent and effluent COD concentrations under the steady-state condition (Deng and Lin, 2017). The sludge samples were collected monthly for solid measurements, microscopic and microbiological analyses.

\subsubsection{Analytical Methods}

Standard methods were used for all the chemical analyses (APHA et al., 2005). A pH meter (AB15 Plus, Fisher Scientific) was used to measure the $\mathrm{pH}$ of wastewater and ferric solution. COD concentration was measured by following a closed reflux, colorimetric method (Standard Method 5220 D) using a spectrophotometer (HACH, DR 2800). Soluble sulfate concentration was measured by a turbidimetric method (USEPA method 375.4) using a spectrophotometer (Thermo Scientific, GENESYS 10UV). Total iron concentration was measured with an atomic absorption spectrophotometer (Perkin Elmer $3100)$ after the samples were acidified with a $70 \%$ nitric acid $\left(\mathrm{HNO}_{3}\right)$ solution. Ferrous iron concentration was determined using 1, 10 phenanthroline method (Standard Method 
3500 B) and ferric iron concentration was calculated by the differences between the total and ferrous iron concentrations. Sulfide concentrations were measured by a methylene blue method (Standard Method 4500 D) using a HACH spectrophotometer (DR 2800). An optical emission spectrometer (Optima 2100 DV) was used to estimate the total sulfur in the sludge sample after acidified with a $70 \% \mathrm{HNO}_{3}$ solution.

\subsubsection{Sludge Characterization}

After running the experiment under each $\mathrm{Fe} / \mathrm{S}$ ratio, the accumulated sludge sample was collected from the bioreactor for physical, chemical and biological characterization. Total suspended solid (TSS), volatile suspended solid (VSS), and non-volatile suspended solid (NVSS) in the sludge samples were measured (Standard Method 2540). A scanning electron microscope (SEM) equipped with an energy dispersion spectroscopy (SEMEDS, Hitachi S 4700) was used to study the morphological and elemental composition of the sludge. The sludge samples were dried in a closed desiccator filled with calcium sulfate and flushed with $\mathrm{N}_{2}$ gas to prevent sludge oxidation. After grinding the dried sludge, the powdered samples were mounted on aluminum stubs and coated with Au-Pd by using a sputter (Denton Desk $V$ ) to avoid surface charging. The SEM scanning was performed under an accelerating voltage of $10-20 \mathrm{kV}$ and qualitative elemental analysis of the sludge samples was conducted by EDS spectrometry under an accelerating voltage of $10 \mathrm{kV}$. Biological fixation of the sludge sample was done to take SEM images of the microorganisms (Supplementary material).

The powdered sludge samples were also used to determine the chemical states of Fe and S by X-ray photoelectron spectroscopy (XPS) analysis (PHI 5000 Versaprobe). The sample powder was mounted on a sample holder with a zero reflective quartz plate (MTI corporation, CA) located underneath. XPS spectra were obtained with a monochromatized Al Ka X-ray source $(1487 \mathrm{eV})$ while base pressure of the analytical chamber was on the order of $10^{-7} \mathrm{~Pa}$. A pass energy of $23.5 \mathrm{eV}$ was used to conduct elemental scans of $\mathrm{Fe}$ and $\mathrm{S}$. X-ray diffraction (XRD) analysis was conducted to determine the crystallinity of the sludge samples using an X-ray diffractometer (PANalytical X'Pert Pro). The samples were prepared by separating the sludge particles 
from the solution using high-speed centrifugation $(5000 \times \mathrm{g})$ for 10 minutes. The XRD analysis was performed with a $\mathrm{Cu} \mathrm{Ka} \mathrm{X}$-ray source operated under $45 \mathrm{kV}$ and $40 \mathrm{~mA}$.

\subsubsection{Microbiological Analysis}

A DNeasy Powersoil DNA extraction kit (Qiagen, Maryland, USA) was used to extract the DNA from sludge samples and a Qubit fluorometer (Invitrogen, Carlsbad, CA, USA) was used for quantification. The bacterial/archaeal primer set 515F/806R that targets the V4 region of the gene was used to sequence the 16S rRNA genes in the extracted DNA at Argonne National Laboratory. Resulting reads were checked for chimeras (DADA2) and subsequently clustered into exact sequence variant (ESV) classifications at $100 \%$ similarities using the DADA2 tool in the QIIME2 pipeline (Qiime2-2018.4) and SILVA 16S rRNA gene database. Sequences used in this study have been deposited in the NCBI Sequence Read Archive under accession number PRJNA528092.

\subsection{Results and Discussion}

\subsubsection{Treatment performance}

\subsubsection{Acclimation to new $\mathrm{Fe} / \mathrm{S}$ ratios}

Acclimation of the bioreactor to a new Fe/S ratio was evaluated by monitoring COD concentration periodically to determine when a steady state could be reached. COD concentration was observed to stabilize after approximately 23 days (Supplementary material, Fig. S6). A one-month acclimation period was therefore given before regular sampling of the influent and effluent to evaluate the treatment performance under each $\mathrm{Fe} / \mathrm{S}$ ratio.

\subsubsection{COD removal, sulfate reduction and iron retention}

The bioreactor was found to provide fairly consistent treatment for COD removal during the study (Supplementary material, Fig. S7). The average COD removal efficiencies were $84 \pm 4 \%, 86 \pm 4 \%$ and $89 \pm 2 \%$ for Fe/S ratios of $0.5,1$ and 2 , respectively (Fig. 1). The $\mathrm{COD}$ removal increased slightly with $\mathrm{Fe} / \mathrm{S}$ ratio showing the effect of increasing $\mathrm{Fe}(\mathrm{III})$ dosing on the organics oxidation. Sulfate reduction and iron retention also followed an increasing trend with the Fe/S ratio (Fig. 13a). Higher than 90\% sulfate reduction and 
close to $100 \%$ iron retention under all the $\mathrm{Fe} / \mathrm{S}$ ratios indicated that both ferric iron and sulfate reduction played a significant role in COD oxidation.

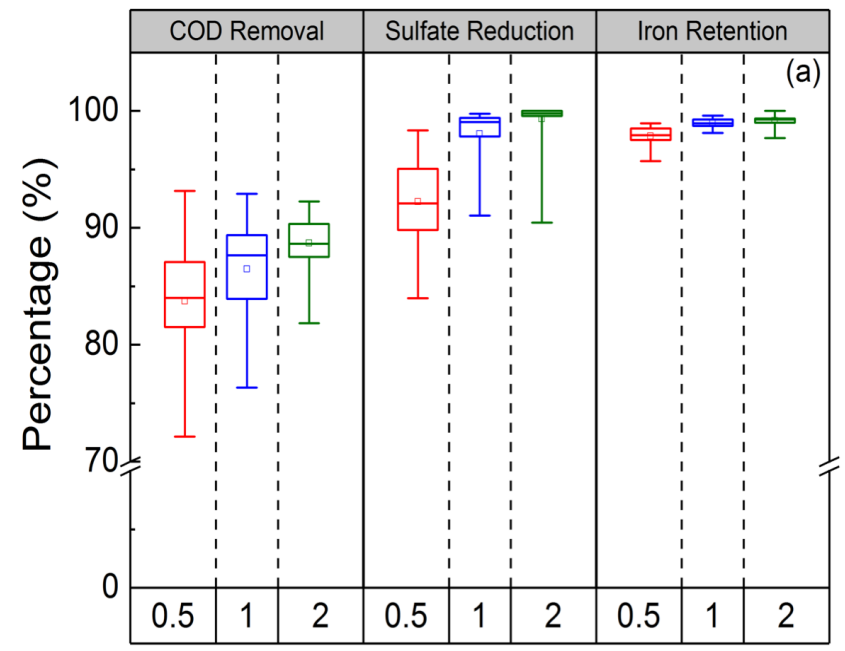

$\mathrm{Fe} / \mathrm{S}$ Ratio

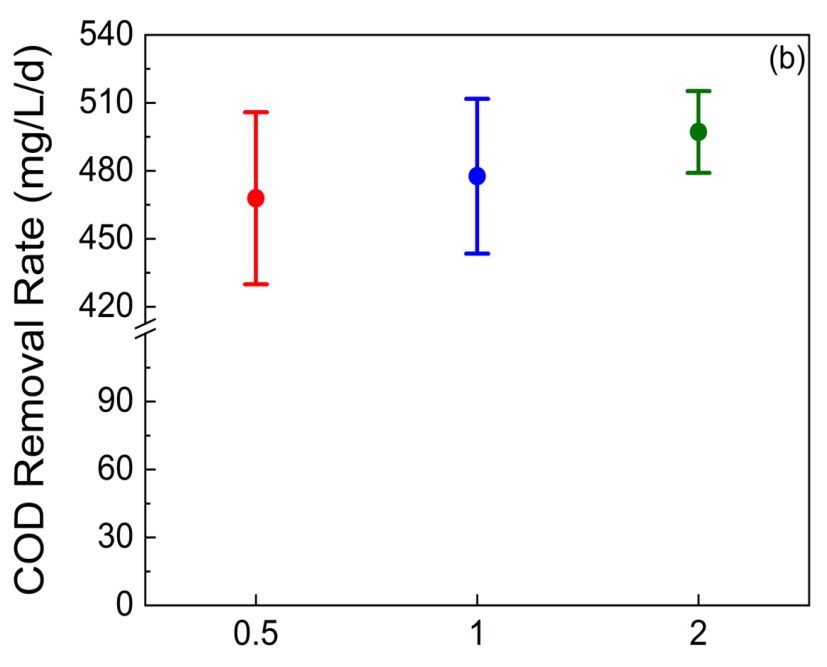

$\mathrm{Fe} / \mathrm{S}$ Ratio

Fig. 13: (a) COD removal, sulfate reduction and iron retention and (b) COD removal rates under different $\mathrm{Fe} / \mathrm{S}$ molar ratios

\subsubsection{COD Removal Rate}

The COD removal rates were calculated as $468 \pm 25 \mathrm{mg} / \mathrm{L} / \mathrm{d}, 478 \pm 23 \mathrm{mg} / \mathrm{L} / \mathrm{d}$ and $497 \pm$ $12 \mathrm{mg} / \mathrm{L} / \mathrm{d}$ for Fe/S ratio $0.5,1$ and 2 respectively (Fig. 13b). The increasing removal rate was attributed to evolving microbial community in the bioreactor that facilitated faster organics oxidation resulting from the increased ferric loadings. The result shows how $\mathrm{Fe} / \mathrm{S}$ ratio can be used to regulate organic oxidation rates in the $\mathrm{Fe}(\mathrm{III})$-dosed treatment system.

\subsubsection{Effluent Quality}

Mean total iron concentrations of the 200 effluent samples were observed as $1.6 \pm 0.6$, $1.6 \pm 0.5$ and $2.2 \pm 0.8 \mathrm{mg} / \mathrm{L}$ under $\mathrm{Fe} / \mathrm{S}$ ratio $0.5,1$ and 2 , respectively. Soluble ferrous iron was consistently low under all Fe/S ratios with mean concentrations ranging from 0.02-0.05 mg/L. Sulfide concentrations were higher under Fe/S ratio $0.5(0.42 \pm 0.3 \mathrm{mg} / \mathrm{L})$ and decreased to $0.04 \pm 0.1$ and $0.03 \pm 0.02 \mathrm{mg} / \mathrm{L}$ as the ratio increased to 1 and 2 , respectively (Fig. 14a). These results indicated that under Fe/S ratio 0.5, ferrous iron 
produced from ferric reduction was insufficient to precipitate out all the biogenic sulfide. Under the two higher Fe/S ratios (1 and 2), sufficient amounts of ferrous iron were produced to precipitate out soluble sulfide. The residual iron represented a small fraction ( $2 \%, 1 \%$, and $0.8 \%$ for $\mathrm{Fe} / \mathrm{S}$ ratios $0.5,1$ and 2 respectively) of the iron dose, and mostly was in the form of ferric iron. The residual ferrous iron and sulfide in the effluent represent an oxygen demand and can be oxidized by chlorine in a disinfection unit (Cadena and Peters, 1988; Khadse et al., 2015). The resultant ferric iron is expected to form a hydroxide solid which can be removed by sedimentation or filtration before discharge of the effluent to the environment.

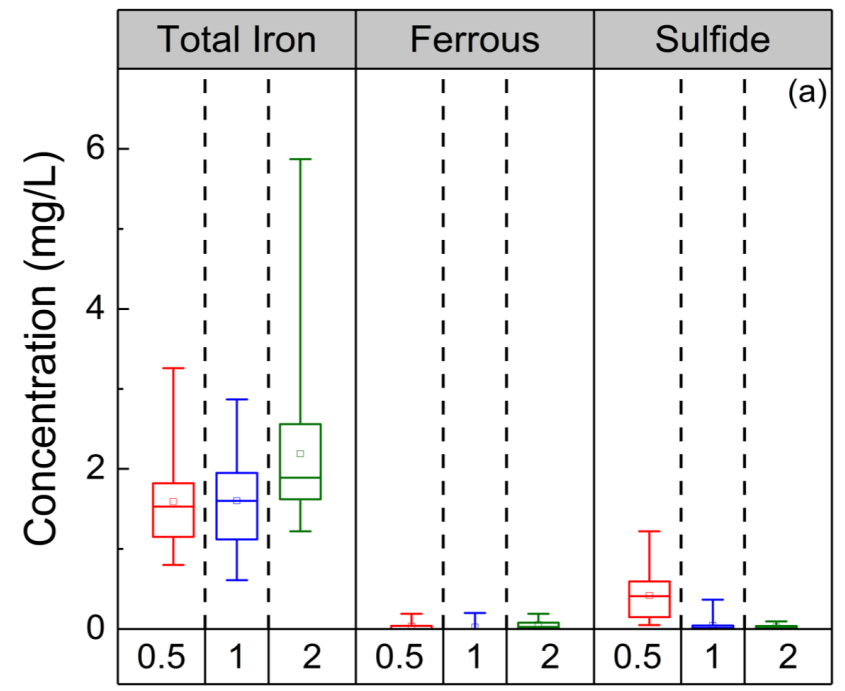

$\mathrm{Fe} / \mathrm{S}$ Ratio

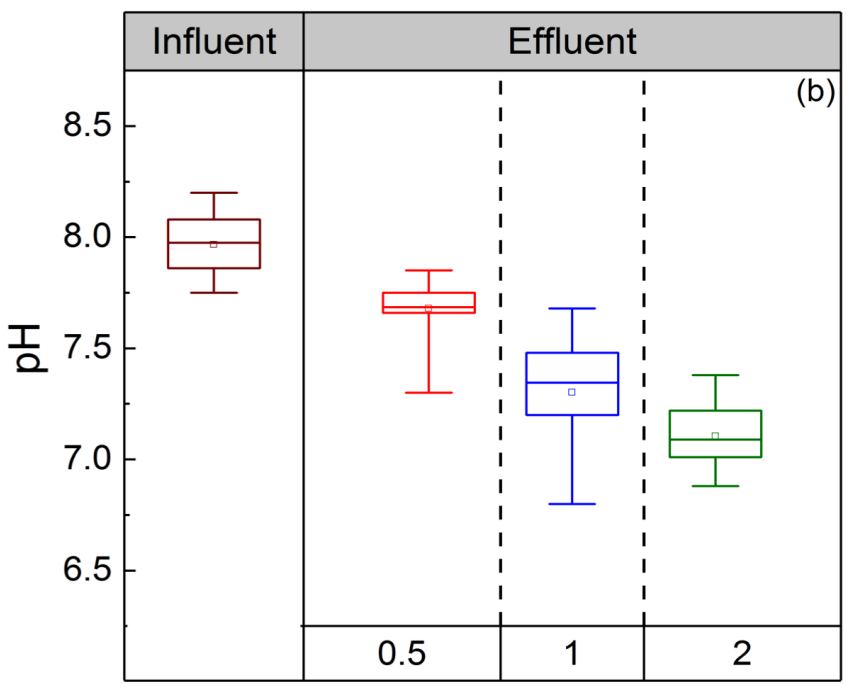

Fe/S Ratio

Fig. 14: (a) Effluent total iron, ferrous and sulfide concentration and (b) Influent and effluent $\mathrm{pHs}$ at different $\mathrm{Fe} / \mathrm{S}$ molar ratios

The influent $\mathrm{pH}(8.0 \pm 0.1)$ was consistently lowered to those in the effluent as a result of the biological treatment (Fig. 14b), which was attributed partly to addition of the ferric iron solution ( $\mathrm{pH} 4-4.2)$ to the bioreactor. The $\mathrm{pH}$ trend also suggests a positive correlation between net acidity production and the Fe/S ratio. This is supported by previous studies that showed production of acidity from organic carbon oxidation was higher than alkalinity generation by ferric iron reduction (Deng et al., 2016; Lovley and Lonergan, 1990; Lovley and Phillips, 1988). 


\subsubsection{Mass balance of Fe and $S$ in the bioreactor}

A mass balance was performed on $\mathrm{Fe}$ and $\mathrm{S}$ under $\mathrm{Fe} / \mathrm{S}$ ratio 2 to understand the chemical flows throughout the biological treatment. In the influent, sulfur (S) was in the dissolved form (38.2 mg/d) and iron (Fe, $134.3 \mathrm{mg} / \mathrm{d})$ was in suspended flocs $(\mathrm{pH} 4$ 4.2). During this operation, total 50 samples used for mass balance calculations showed that only $1.3 \%$ of the total S load and $2 \%$ of the total Fe load were discharged through the effluent. On the other hand, $69 \%$ of the total S load and $48 \%$ of the total Fe load was accounted as particulates in the sludge sample (Fig. 15). This high Fe and S content of sludge samples were due to ferrous sulfide precipitation. The remaining chemical masses were calculated as unaccounted fractions that can be recognized by several possible mechanisms, including iron sulfide precipitation retained in the bioreactor, evaporative loss of sulfide or some loss during sampling and sample preparation for chemical analyses (Deng and Lin, 2017). This mass balance of Fe and S revealed that, most of the fed $\mathrm{Fe}$ and $\mathrm{S}$ formed chemical precipitates as a result of the biogeochemical transformations occurring in the bioreactor and only a small fraction of the elements was discharged in the effluent.

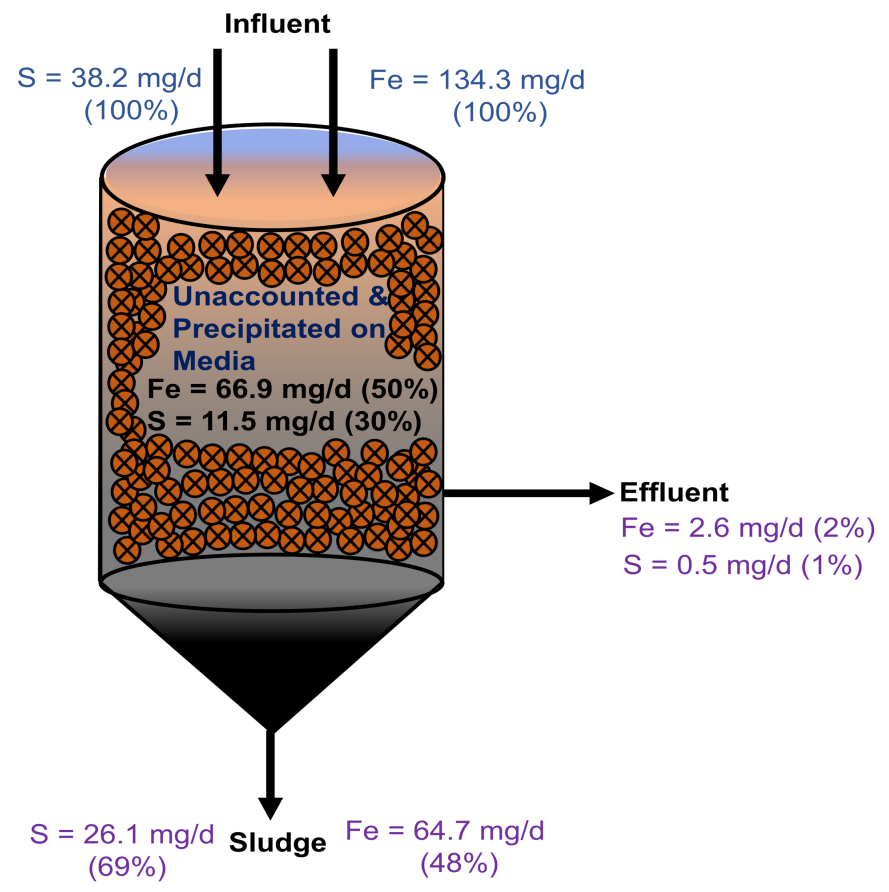

Fig. 15: Mass flow rates of $\mathrm{Fe}$ and $\mathrm{S}$ throughout the biological treatment under $\mathrm{Fe} / \mathrm{S}$ molar ratio 2 


\subsubsection{Sludge Characterization}

\subsubsection{Solid Concentrations}

Mean TSS concentration of the sludge samples ranged from 1,341-21,946 mg/L. The mean TSS concentration increased with the $\mathrm{Fe} / \mathrm{S}$ ratio, indicating an increase in the sludge production under the higher $\mathrm{Fe} / \mathrm{S}$ ratios compared to $\mathrm{Fe} / \mathrm{S}$ ratio 0.5 . The solid analyses showed that the mean VSS/TSS decreased from $40 \%$ to $20 \%$ and correspondingly the mean NVSS/TSS increased from $60 \%$ to $80 \%$ as $\mathrm{Fe} / \mathrm{S}$ ratio increased from 0.5 to 2 (Fig. 16). This revealed that most of the solids were inorganic materials and the inorganic fraction of the solids increased with the Fe/S ratio. These results showed the range of volatile fractions of the sludge samples $(0.2-0.4)$ and their corresponding nonvolatile fractions $(0.8-0.6)$ resulting from this treatment and their fluctuations under different dosing scenarios. The increasing inorganic fraction of the sludge solid with the $\mathrm{Fe} / \mathrm{S}$ ratio indicated more iron sulfide production with increasing iron dosing.

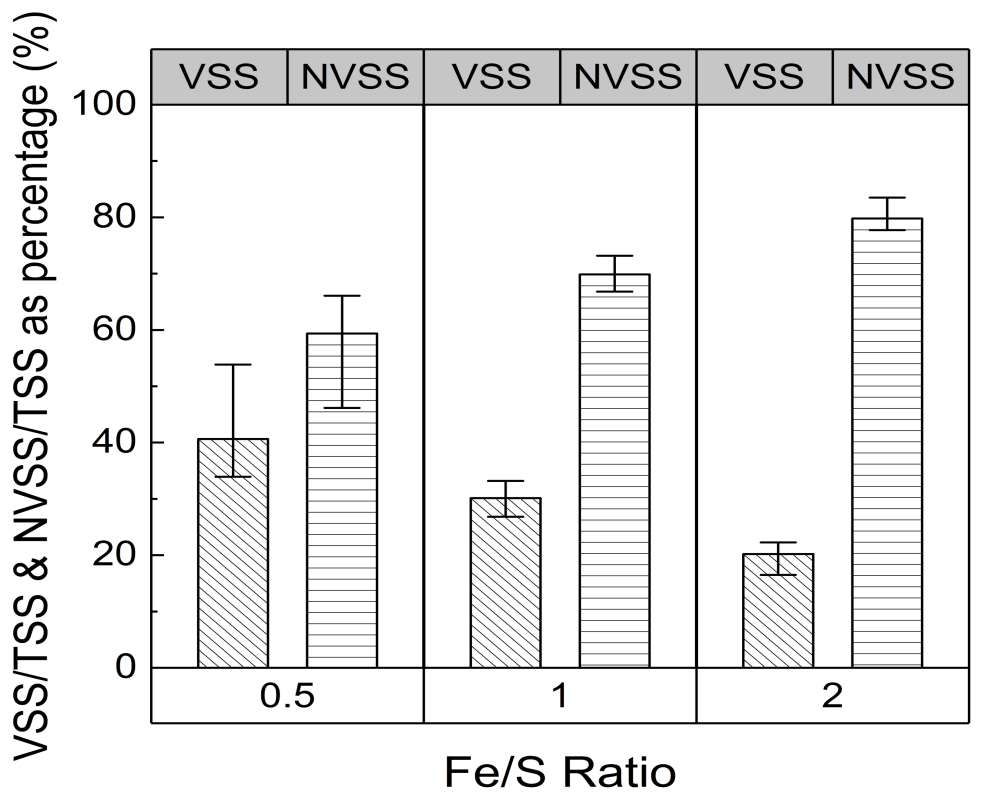

Fig. 16: VSS/TSS and NVSS/TSS as percentage (\%) of sludge samples under different $\mathrm{Fe} / \mathrm{S}$ ratios 


\subsubsection{Sludge Morphology}

SEM-EDS analysis in this study revealed major elements of the sludge sample as carbon (C), oxygen (O), Fe, and S (Supplementary material, Fig. 17a and b). The small grains observed in the SEM image (Fig. 17a) were recognized as the precipitate particles which had a very disordered morphology with no specific pattern. The small sizes $(\approx 1-2 \mu \mathrm{m})$ of the sludge particles as spherical aggregates were in line with the structural descriptions of iron sulfide presented in previous studies (Bratkova et al., 2018; Csákberényi-Malasics et al., 2012; Vaclavkova et al., 2014).

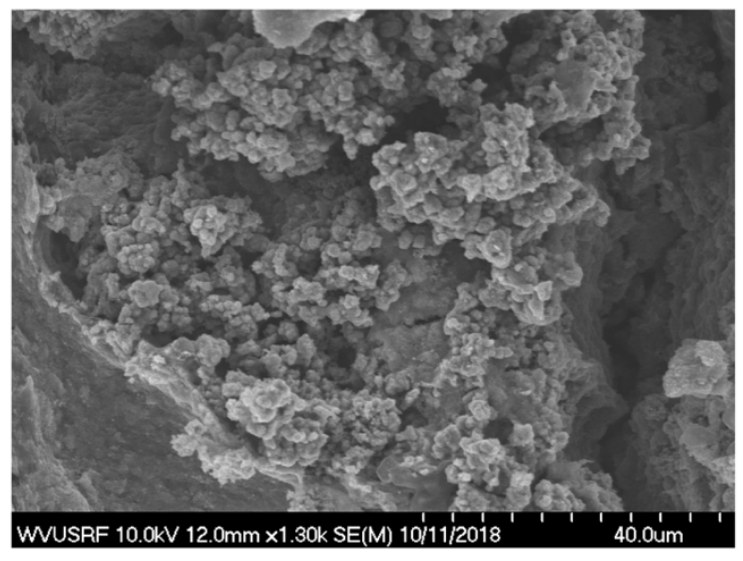

(a)

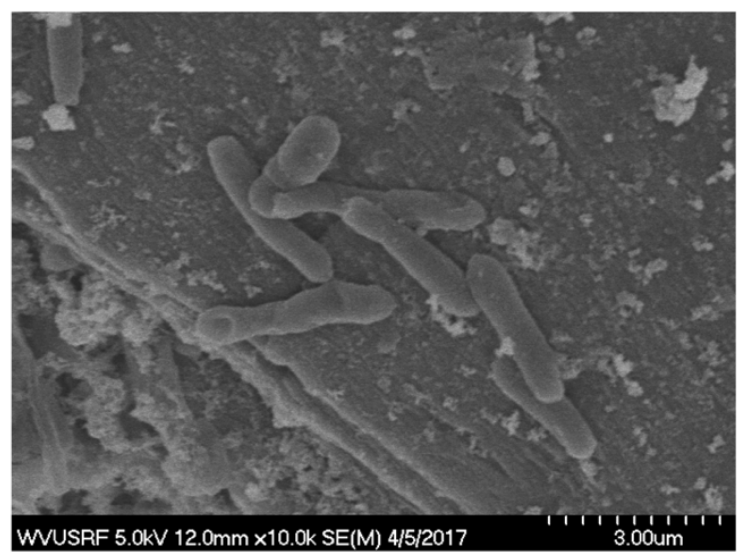

(c)

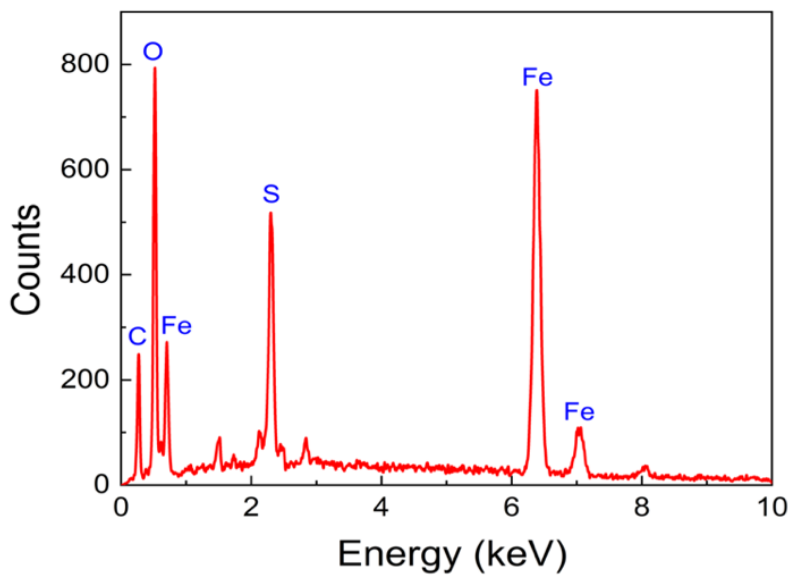

(b)

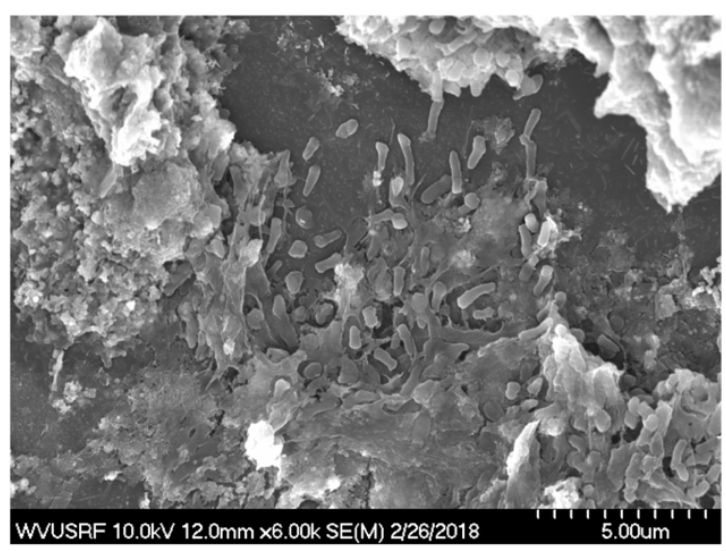

(d)

Fig. 17: (a) SEM micrograph and (b) EDS spectrum for sludge sample under Fe/S molar ratio 2; (c) \& (d): SEM images of cells present in anaerobic sludge

SEM images taken after the biological fixation of sludge samples revealed the presence of various microbial cells in the sludge. Majority of the observed microorganisms were rod 
shaped and curved, and had an approximate length of 2-3 $\mu \mathrm{m}$ (Supplementary Material, Fig. 17c). The size and shape observed in these images were similar to those in the previous studies describing the physical characteristics of Geobacter sp. (Caccavo Jr et al., 1994; Nevin et al., 2005) and Desulfovibrio sp. (Zellner et al., 1989). Cells were observed to be in high density (Fig. 17d).

\subsubsection{Sludge Composition}

XPS analysis showed that two different iron sulfide forms, FeS and $\mathrm{FeS}_{2}$, were the major inorganic constituents of the sludge samples. The narrow region in the spectrum of $\mathrm{Fe} 2 p$ revealed a major peak at $707.4 \mathrm{eV}$ (Fig. 18a), which represents both $\mathrm{FeS}$ and $\mathrm{FeS}_{2}$. As the binding energies of $\mathrm{FeS}$ and $\mathrm{FeS}_{2}$ are very similar, it is often difficult to separate the peaks of these two different forms in an Fe2p spectrum (Descostes et al., 2000; Han et al., 2013). However, the S2p spectrum was fit with two distinct peaks at $160.9 \mathrm{eV}$ and $162.3 \mathrm{eV}$, in agreement with the typical binding energies of $\mathrm{FeS}$ and $\mathrm{FeS}_{2}$ respectively (Fig. 18b) (Lennie and Vaughan, 1996; Naumkin et al., 2012).
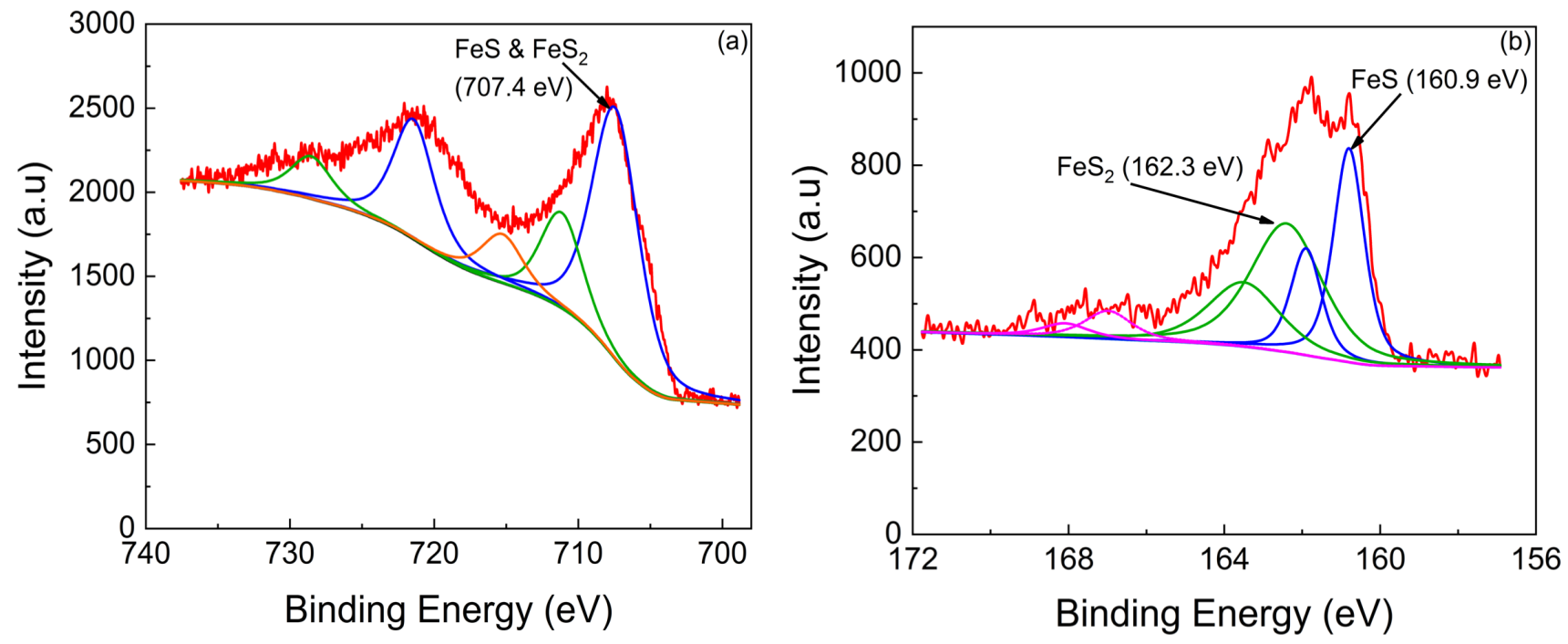

Fig. 18: XPS spectrum of (a) Fe2p and (b) S2p region of a sludge sample

\subsubsection{Sludge Crystallinity}

An XRD spectrum of the sludge samples showed sharp peaks representing crystalline forms of $\mathrm{FeS}$ (mackinawite), $\mathrm{FeS}_{2}$ (pyrite), $\mathrm{Fe}_{3} \mathrm{~S}_{4}$ (greigite), $\mathrm{FeOOH}$ (goethite), and $\mathrm{Fe}_{3} \mathrm{O}_{4}$ (magnetite) (Supplementary Material, Fig. S8). However, the low intensity of the sharp 
peaks and dominant presence of broad hump peaks suggest that most of the sludge samples were in an amorphous form. Biogenic sludge generally precipitates as amorphous $\mathrm{FeS}$, which may be transformed to stable crystalline form of $\mathrm{FeS}$ and $\mathrm{FeS}_{2}$ under a long-term operation. Greigite $\left(\mathrm{Fe}_{3} \mathrm{~S}_{4}\right)$ was considered an intermediate iron sulfide form between the transformation of amorphous $\mathrm{FeS}$ to well crystallized $\mathrm{FeS}_{2}$ in anaerobic environments (Csákberényi-Malasics et al., 2012; Gramp et al., 2010). Therefore, the sludge precipitates can be described as a mixture of both amorphous and crystalline iron sulfides with amorphous phases being prevailing. Crystallographic information of the obtained peaks revealed tetragonal crystal structure of $\mathrm{FeS}$ and cubic structure of $\mathrm{FeS}_{2}$ and $\mathrm{Fe}_{3} \mathrm{~S}_{4}$.

Sharp peaks of $\mathrm{FeOOH}$ represent crystalline ferric oxyhydroxides that occurred due to the surface oxidation of ferrous sulfide. The presence of $\mathrm{Fe}_{3} \mathrm{O}_{4}$ (magnetite) can be attributed to biologically-induced mineralization (BIM) in which microbes sorb solutes onto their cell surface or extrude organic polymers resulting in mineral formation (Bazylinski et al., 2007). Geobacter sp. has been reported to produce magnetite extracellularly through BIM during FeOOH reduction (Moskowitz et al., 1989). Magnetite can be a very useful element because of its physical properties and various heat treatments have been investigated for generating magnetite from iron sulfide (Thorpe et al., 1984b; Waters et al., 2008). These results suggest the sludge produced in this Fe(III)-dosed biological treatment can potentially be further processed for beneficial applications.

\subsubsection{Microbiological Composition}

Dominant ESVs identified in the sludge samples belonged to ten different phyla, including members of the Alphaproteobacteria, Deltaproteobacteria, Gammaproteobacteria, Acidobacteria, Bacteroidetes, Chloroflexi, Firmicutes, Spirochaetes, Actinobacteria and Euryarchaeota. The average relative abundances of these phyla are listed in Table 4. 
Table 4: Major bacteria and their phylum identified in the bioreactor

\begin{tabular}{|c|c|c|c|c|}
\hline Deltaproteobacteria & Acidobacteria & Bacteroidetes & Gammaproteobacteria & Actinobacteria \\
\hline $\begin{array}{l}\text { Geobacter sp. (22\%) } \\
\text { Desulfobulbus sp. } \\
(4 \%) \\
\text { Desulfovibrio sp. } \\
(5 \%) \\
\text { Desulfatirhabdium } \\
\text { sp. (3\%) } \\
\text { Desulforhabdus sp. } \\
(1 \%) \\
\text { Desulfomonile sp. } \\
\text { (0.2\%) } \\
\text { Syntrophobacter sp. } \\
(2 \%) \\
\text { Smithella sp. (0.2\%) }\end{array}$ & $\begin{array}{l}\text { Geothrix sp. } \\
(0.5 \%)\end{array}$ & $\begin{array}{l}\text { Ignavibacteria sp. } \\
(4 \%) \\
\text { Paludibacter sp. (2\%) }\end{array}$ & $\begin{array}{l}\text { Methylomonas sp. } \\
(0.2 \%) \\
\text { Azospira sp. }(0.04 \%) \\
\text { Azobacter sp. }(0.1 \%)\end{array}$ & $\begin{array}{l}\text { Cellulomonas } \\
\text { sp. }(0.1 \%)\end{array}$ \\
\hline Firmicutes & Chloroflexi & Alphaproteobacteria & Spirochaetes & Euryarchaeota \\
\hline $\begin{array}{l}\text { Clostridium sp. (4\%) } \\
\text { Ruminiclostridium } 1 \\
(0.04 \%) \\
\text { Veillonellaceae sp. } \\
(1 \%)\end{array}$ & $\begin{array}{l}\text { Anaerolineae } \\
\text { sp. }(4 \%)\end{array}$ & $\begin{array}{l}\text { Pleomorphomonas } \\
\text { sp. }(7 \%)\end{array}$ & Treponema sp. (6\%) & $\begin{array}{l}\text { Methanosaeta } \\
\text { sp. }(2 \%)\end{array}$ \\
\hline
\end{tabular}

Although caution must be taken when assigning functional roles to identified taxa from 16S rRNA gene data, some inferred conserved functions may be assigned based on laboratory studies of model microorganisms within specific taxonomic groups. Geobacter sp., Geothrix sp. and Ignavibacteria sp. were classified as IRB, and Desulfovibrio sp., Desulfobulbus sp., Desulfatirhabdium sp., Desulforhabdus sp. and Desulfomonile sp. were classified as SRB based on this concept. The ability of Geobacter sp. and Geothrix 
sp. to perform ferric reduction has been observed in laboratory studies (Childers et al., 2002; Coates et al., 2001; Nevin et al., 2005; Nevin and Lovley, 2002). Ignavibacteria sp. was recently identified to facilitate iron reduction as well (Fortney et al., 2018; Podosokorskaya et al., 2013). With $83 \%$ relative abundance of the total identified IRB, Geobacter sp. was inferred to perform the majority of iron reduction in the bioreactor (Fig. 19a). The dominancy of Geobacter sp. can be linked with presence of acetate as one of the major organic compounds in synthetic wastewater. Geobacter sp. typically oxidize small organic substrates such as acetate to $\mathrm{CO}_{2}$, coupled to iron reduction (Esther et al., 2015; Lovley, 1993; Lovley et al., 1993). Ignavibacteria sp. and Geothrix sp. comprised $15 \%$ and $2 \%$ relative abundance of the total IRB respectively, and likely contributed to the ferric reduction in the bioreactor (Fig. 19a). Similar to Geobacter, Ignavibacteria has been observed to grow well in acetate-amended incubations (Fortney et al., 2018). Due to the insolubility of ferric compounds at the $\mathrm{pH}$ range 7-8 in the bioreactor, these IRBs perform the ferric reduction either by direct contact with outer-membrane cytochromes or via conductive pili structures. In addition, Geothrix is able to produce chelators that solubilize $\mathrm{Fe}(\mathrm{III})$ and release electron-shuttling compounds for the microbial interaction of $\mathrm{Fe}(\mathrm{III})$ surface with cell structure (Nevin and Lovley, 2002).
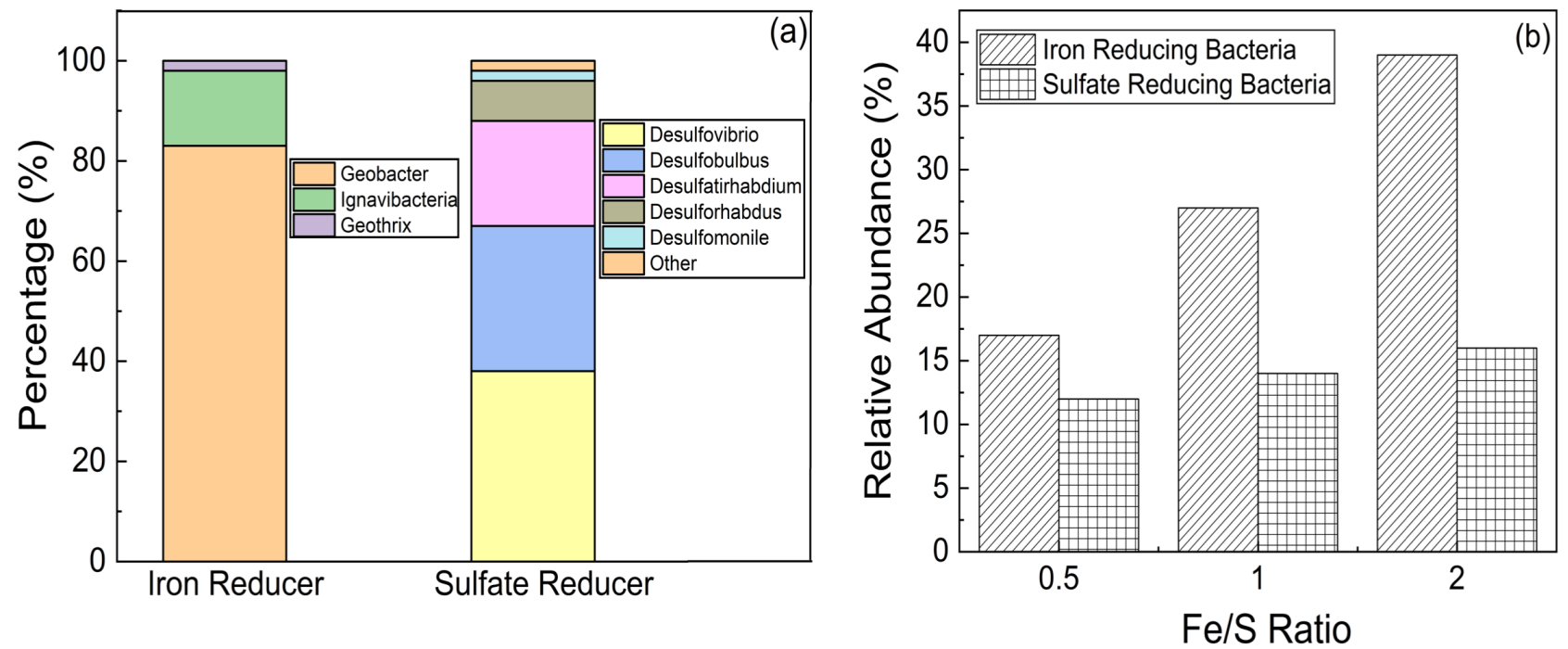

Fig. 19: (a) Microbial distribution and (b) relative abundances of putative IRB and SRB 
Desulfovibrio sp., Desulfobulbus sp., Desulfatirhabdium sp., Desulforhabdus sp., Desulfomonile sp. were the major putative SRB observed in the bioreactor and comprised $38 \%, 30 \%, 21 \%, 8 \%$ and $2 \%$ relative abundance of the total SRB respectively (Fig. 19a). All these gram-negative SRB belong to the Deltaproteobacteria phyla, and previously have been shown to use sulfate as electron acceptor, which is subsequently reduced to sulfide (Balk et al., 2008; DeWeerd et al., 1990; El Houari et al., 2017; Elferink et al., 1995; Rabus et al., 2015). Desulfovibrio sp. and Desulfobulbus sp. can catalyze incomplete oxidation of larger organic substrates such as lactate, yielding acetate which can subsequently be used by other IRB and SRB (i.e. Desulfatirhabdium sp. and Desulforhabdus sp.) as an electron donor (El Houari et al., 2017; Rabus et al., 2015). Characterized representatives of the putative SRB identified here are mesophilic, growing well under moderate temperatures $\left(20-45^{\circ} \mathrm{C}\right)$ and circumneutral $\mathrm{pH}$.

In terms of relative abundances, IRB were observed to be the dominant functional group over SRB under all the Fe/S ratios. In general, IRB have a competitive edge over SRB for organic substrate utilization due to the thermodynamically favorable redox reactions with ferric iron. The relative abundance of putative IRB was $17 \%, 27 \%$ and $39 \%$ for $\mathrm{Fe} / \mathrm{S}$ $0.5,1$ and 2 respectively (Fig. 19b), indicating a positive correlation of IRB with COD removal as organic oxidation was also improved with increasing $\mathrm{Fe} / \mathrm{S}$ ratio. Although sulfate concentrations decreased slightly with the increasing $\mathrm{Fe} / \mathrm{S}$ ratio, the relative abundances of putative SRB increased from $12 \%$ to $16 \%$. A major reason may be the presence of both Desulfovibrio sp. and Desulfobulbus sp. as the dominant SRB in the bioreactor. Both of the taxonomic groups have been observed to grow well under iron reducing conditions, and perform enzymatic Fe(III) reduction (Coleman et al., 1993; Holmes et al., 2004; Tebo and Obraztsova, 1998). Therefore, the possibility exists that these SRB were also performing ferric reduction under higher $\mathrm{Fe} / \mathrm{S}$ ratios, and concurrently increasing in relative abundance.

In addition to IRB and SRB, many other bacteria were also detected in the bioreactor. Comparatively low abundance of methanogens, Methanosaeta sp. (2\%) in the bioreactor suggests that IRB and SRB outcompeted methanogens for substrate utilization. Bacteria previously characterized as fermenters, such as Clostridium sp., Treponema sp., and 
Paludibacter sp. were present with average relative abundance of $4 \%, 6 \%$ and $2 \%$ respectively. These fermentative bacteria can break the complex organic compounds into small organic substrates that can be easily utilized by IRB and SRB (Chen et al., 2005; Dröge et al., 2008; Ueki et al., 2006). Some strains of Clostridium have previously been found to indirectly participate in dissimilatory $\mathrm{Fe}(\mathrm{III})$ reduction by disposing of reducing equivalents (Dobbin et al., 1999; Shah et al., 2014). Anaerolineae ESVs were also identified within the bioreactor; members of this group are generally found in the anaerobic sludge granules of bioreactors (Yamada et al., 2005).

Shannon's diversity index $(\mathrm{H})$ was calculated as $3.26,3.36$ and 3.34 for Fe/S ratio $0.5,1$ and 2 respectively and Simpson's diversity index was measured as $0.88,0.92$ and 0.92 for the same ratio values. These high values of diversity indices (higher than 2 for Shanonn's $\mathrm{H}$ and close to 1 for Simpson's index) reflect the diverse microbial community in the bioreactor (Grabchak et al., 2017; Ifo et al., 2016). Higher microbial diversity of the bioreactor at higher ratios may also support increase in functionality and tolerance level against environmental and chemical disturbances (e.g. temperature, electron donors) (Hiibel et al., 2011; Koschorreck et al., 2010).

\subsection{Conclusion}

The long-term operation of a continuous $\mathrm{Fe}$ (III)-dosed anaerobic biological treatment was investigated in this study to understand the $\mathrm{Fe}$ and $\mathrm{S}$ biogeochemical transformations in the context of wastewater treatment. The $\mathrm{Fe} / \mathrm{S}$ ratio was found to play a significant role in regulating major treatment aspects of the biological system including organics removal rate and efficiency, effluent quality, sludge production and microbial composition. For practical implementation of this treatment method, the iron dosing requirement is primarily to be determined by the organics and sulfate loads of the wastewater to provide sufficient electron acceptors for organics oxidation. The results showed increasing $\mathrm{Fe}(\mathrm{III})$ dosing resulted in enhanced organics removal rates and efficiency. Another beneficial outcome of higher iron dosing is that excessive quantity of ferrous iron can lower the sulfide level in the effluent through forming iron sulfide precipitates. This precipitation mechanism is significant because it eliminates toxicity and oxygen demand possibly caused by sulfide in the receiving water. The biogenic ferrous iron and sulfide primarily precipitated as 
amorphous FeS, which may undergo long-term transformations to crystalline $\mathrm{FeS}$ and $\mathrm{FeS}_{2}$. These sludge byproducts can directly be used for environmental remediation and wastewater treatment or for recovering valuable materials (e.g magnetite). The microbiological analyses indicated the presence of putative IRB and SRB along with fermentative bacteria in the bioreactor. Their known functional activities suggest synergistic relationships among these bacterial species in organics degradation.

\section{Acknowledgements}

The authors wish to thank Dr. Eugenia Pena-Yewtukhiw, Associate Professor of Davis college of Agriculture, Natural Resources and Design of West Virginia University during the total sulfur analysis with optical emission spectrometer. The authors also appreciate the help from Dr. Marcela Redigolo and Dr. Qiang Wang of West Virginia University Shared Research Facility (SRF) for assistance in SEM, XPS and XRD analysis of the sludge samples. This research is supported by the National Science Foundation [grant number OIA-1458952]. The authors are thankful for the support.

\subsection{Supplementary Materials}

\section{Biological fixation of sludge samples for SEM photographs}

The $6 \mathrm{ml}$ sludge sample was taken on a Microscope cover glass (Fisherbrand) and processes several steps of biological fixation to preserve the integrity of bacterial cell walls. The sample was washed with $2.5 \%$ Glutaraldehyde for one hour and rinsed three times with phosphate buffer saline (PBS) at 15-minute intervals. Then the sample was dehydrated with a series of ethanol solution at different concentrations $(30 \%, 50 \%, 70 \%$, $90 \%, 100 \%)$. This dehydration procedure was executed with gentle agitation for 15 minutes in each step. Then the ethanol was removed from the sample and dried with hexamethyldisilazane (HMDS) for another 15 minutes. This technique was applied to

eliminate surface tension effects by raising the temperature of the sample above the critical temperature for $\mathrm{CO}_{2}$ and reducing the distortion of morphology and surface structure. 


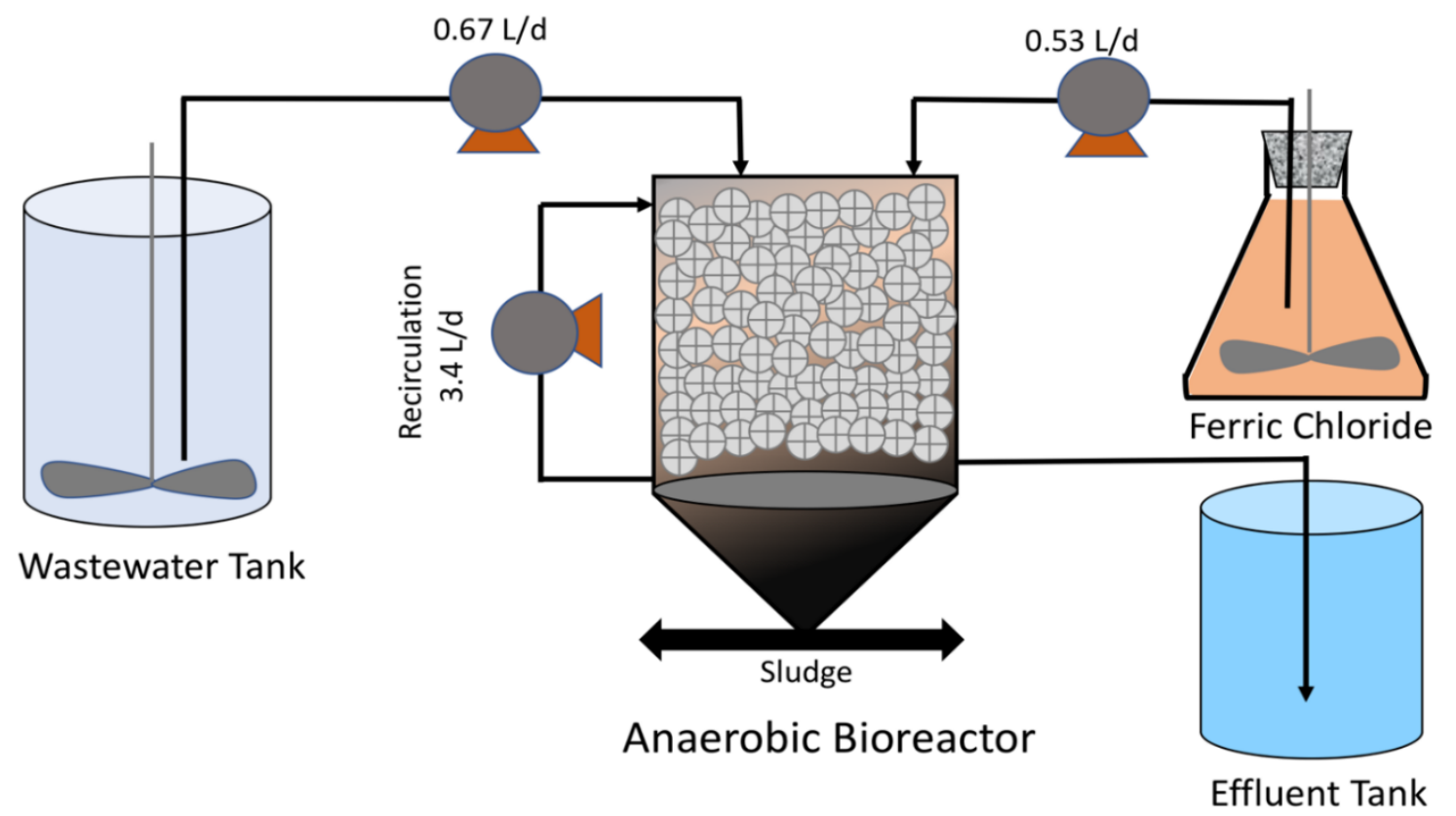

Fig. S5: Experimental setup of the Fe(III)-dosed treatment system

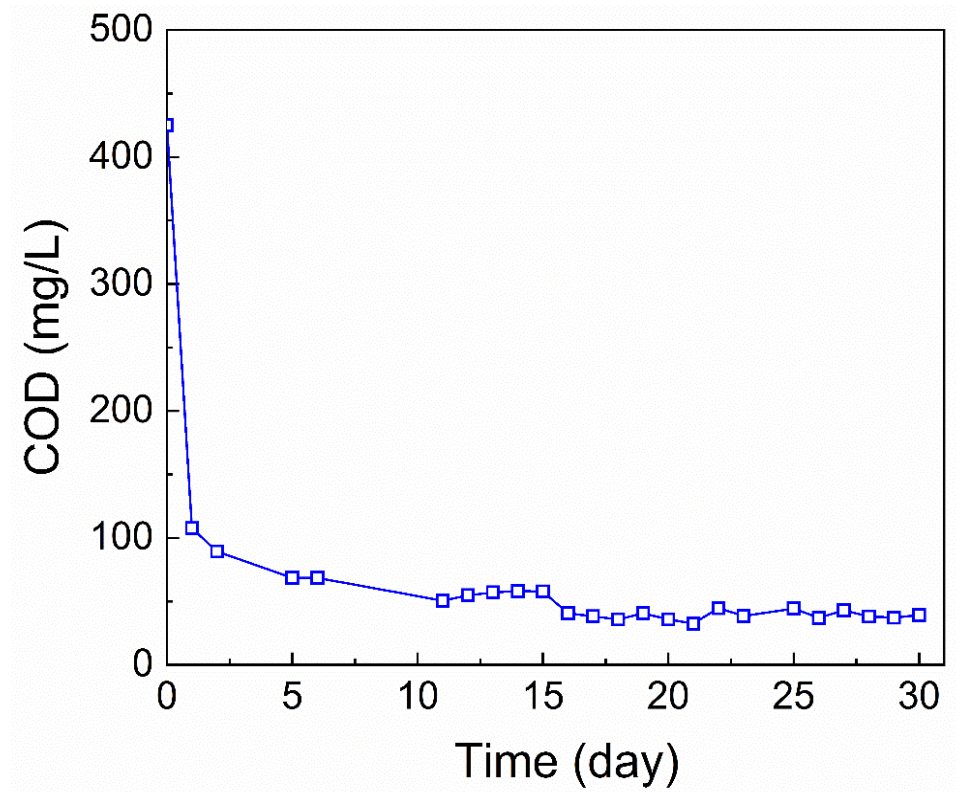

Fig. S6: COD concentration of the effluent under Fe/S ratio 2 for microbial acclimation evaluation 


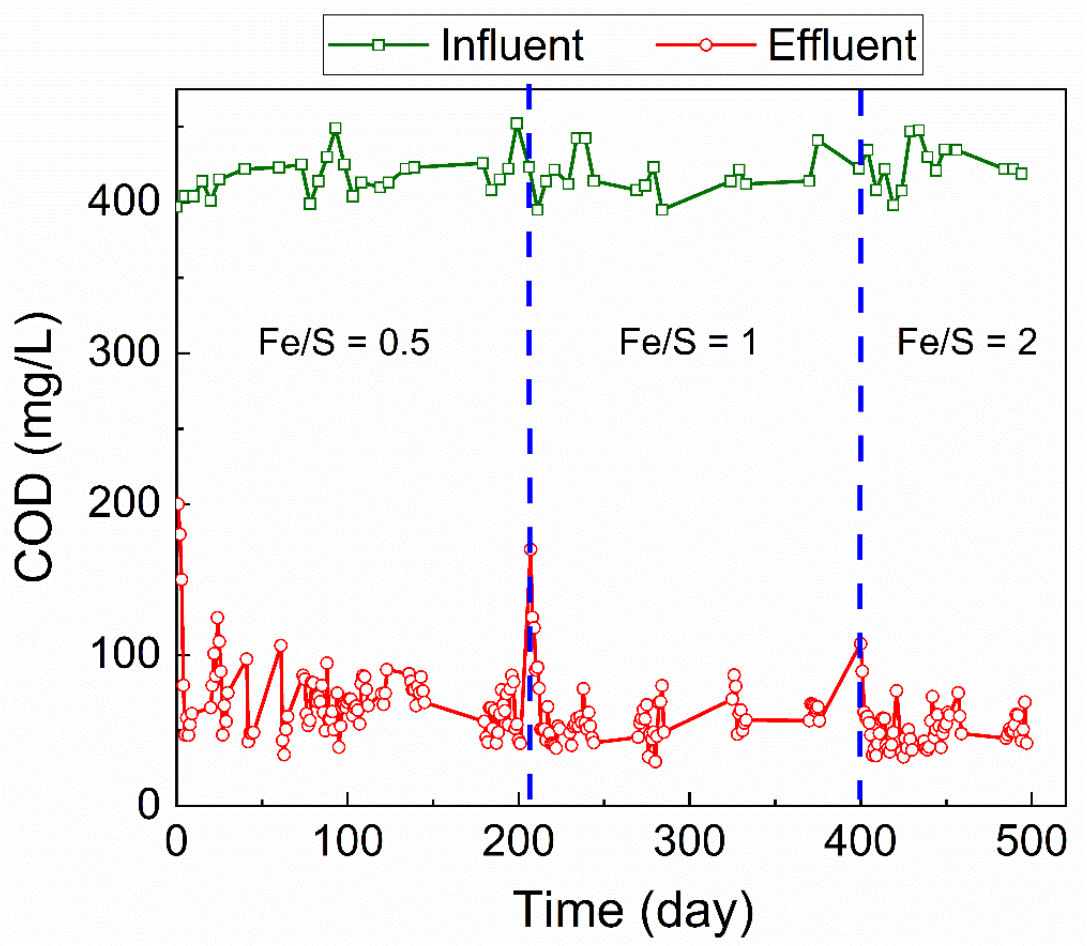

Fig. S7: COD concentration of effluent from the Fe(III)-dosed biological treatment

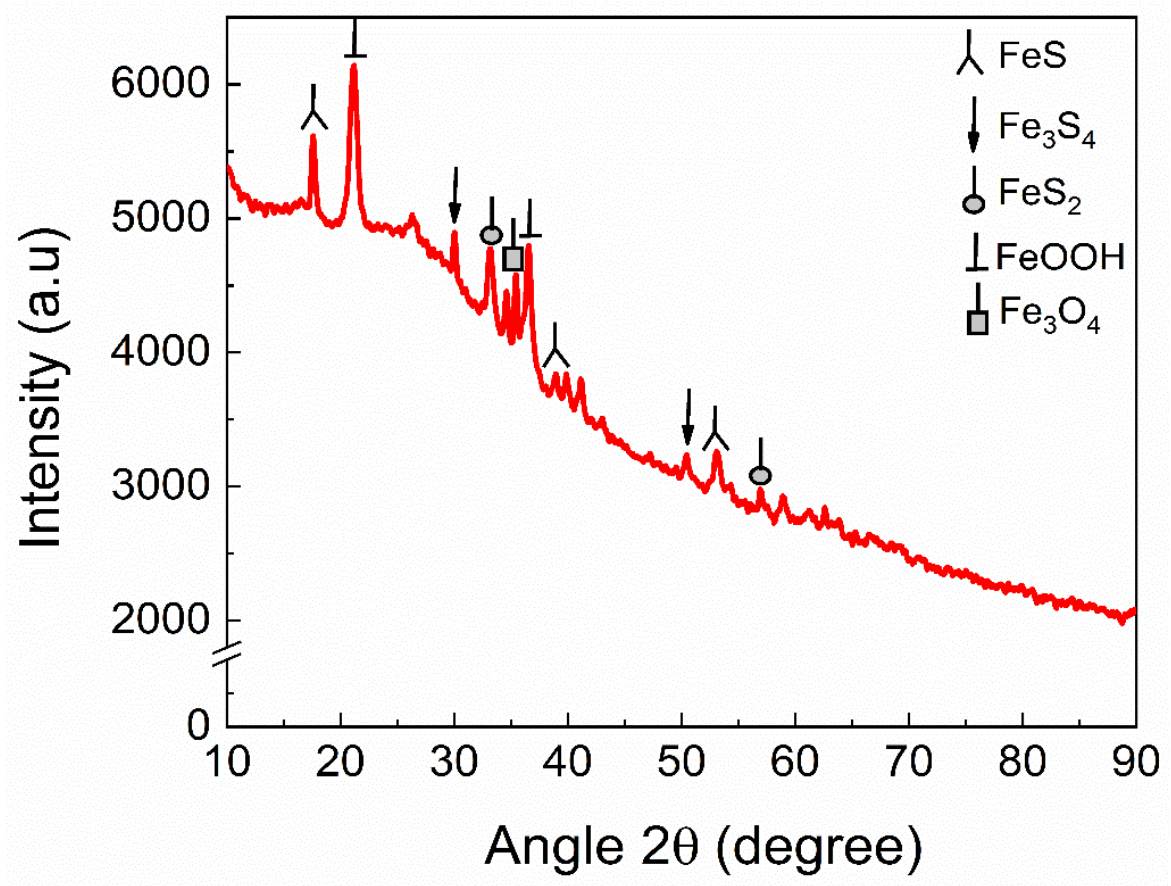

Fig. S8: XRD spectrum of the anaerobic sludge sample $(\mathrm{Fe} / \mathrm{S}=2)$ 


\section{References}

Ahmed, M., Lin, L.-S., 2017. Ferric reduction in organic matter oxidation and its applicability for anaerobic wastewater treatment: a review and future aspects. Rev. Environ. Sci. Biotechnol. 16, 273-287. https://doi.org/10.1007/s11157-017-9424-3

Ahmed, M., Lin, O., Saup, C.M., Wilkins, M.J., Lin, L.S., 2019. Effects of Fe/S ratio on the kinetics and microbial ecology of an $\mathrm{Fe}(\mathrm{III})$-dosed anaerobic wastewater treatment system. J. Hazard. Mater. 369, 593-600. https://doi.org/10.1016/j.jhazmat.2019.02.062

APHA, AWWA, WEF, 2005. Standard methods for the examination of water and wastewater, 21st ed. American Public Health Association,American water Works Association, and Water Environment Federation.

Azam, H.M., Finneran, K.T., 2013. Ferric iron amendment increases Fe(III)-reducing microbial diversity and carbon oxidation in on-site wastewater systems. Chemosphere 90, 1435-1443. https://doi.org/10.1016/j.chemosphere.2012.09.002

Balk, M., Altinbaş, M., Rijpstra, W.I.C., Damsté, J.S.S., Stams, A.J.M., 2008. Desulfatirhabdium butyrativorans gen. nov., sp. nov., a butyrate-oxidizing, sulfatereducing bacterium isolated from an anaerobic bioreactor. Int. J. Syst. Evol. Microbiol. 58, 110-115. https://doi.org/10.1099/ijs.0.65396-0

Bazylinski, D.A., Frankel, R.B., Konhauser, K.O., 2007. Modes of biomineralization of magnetite by microbes. Geomicrobiol. J. 24, 465-475. https://doi.org/10.1080/01490450701572259

Bratkova, S., Lavrova, S., Angelov, A., Nikolova, K., Ivanov, R., Koumanova, B., 2018. Treatment of wastewaters containing $\mathrm{Fe}, \mathrm{Cu}, \mathrm{Zn}$ and as by microbial hydrogen sulfide and subsequent emoval of COD, N and P. J. Chem. Technol. Metall. 53, 245257.

Caccavo Jr, F., Lonergan, D.J., Lovley, D.R., Davis, M., Stolz, J.F., Mclnerney, M.J., 1994. Geobacter sulfurreducens sp. nov., a Hydrogen- and Acetate- Oxidizing Dissimilatory Metal-Reducing Microorganism. Appl. Environ. Microbiol. 60, 37523759. https://doi.org/10.1111/j.1758-2229.2009.00055.x

Cadena, F., Peters, R.W., 1988. Evaluation of Chemical Oxidizers for Hydrogen Sulfide Control. Water Pollut. Control Fed. 60, 1259-1263. https://doi.org/10.2307/25043633

Chan, Y.J., Chong, M.F., Law, C.L., Hassell, D.G., 2009. A review on anaerobic-aerobic treatment of industrial and municipal wastewater. Chem. Eng. J. 155, 1-18. https://doi.org/10.1016/j.cej.2009.06.041

Chen, W.M., Tseng, Z.J., Lee, K.S., Chang, J.S., 2005. Fermentative hydrogen production with Clostridium butyricum CGS5 isolated from anaerobic sewage sludge. Int. J. Hydrogen Energy 30, 1063-1070. https://doi.org/10.1016/j.ijhydene.2004.09.008

Childers, S.E., Ciufo, S., Lovley, D.R., 2002. Geobacter metallireducens accesses insoluble $\mathrm{Fe}(\mathrm{III})$ oxide by chemotaxis. Nature 416, 767-769. 
https://doi.org/10.1038/416767a

Coates, J.D., Bhupathiraju, V.K., Achenbach, L.A., Mcinerney, M.J., Lovley, D.R., 2001. Geobacter hydrogenophilus, Geobacter chapellei and Geobacter grbiciae, three new, strictly anaerobic, dissimilatory Fe(III)-reducers. Int. J. Syst. Evol. Microbiol. 51, 581-588.

Coleman, M.L., Hedrick, D.B., Lovley, D.R., White, D.C., Pye, K., 1993. Reduction of $\mathrm{Fe}(\mathrm{III})$ in sediments by sulphate-reducing bacteria. Nature $361,436-438$. https://doi.org/10.1038/361436a0

Csákberényi-Malasics, D., Rodriguez-Blanco, J.D., Kis, V.K., Rečnik, A., Benning, L.G., Pósfai, M., 2012. Structural properties and transformations of precipitated FeS. Chem. Geol. 294-295, 249-258. https://doi.org/10.1016/j.chemgeo.2011.12.009

Damianovic, M.H.R.Z., Foresti, E., 2007. Anaerobic degradation of synthetic wastewaters at different levels of sulfate and $\mathrm{COD} /$ sulfate ratios in horizontal-flow anaerobic reactors (HAIB). Environ. Eng. Sci. 24, 383-393.

Deng, D., Lin, L.S., 2017. Continuous sulfidogenic wastewater treatment with iron sulfide sludge oxidation and recycle. Water Res. 114, 210-217. https://doi.org/10.1016/j.watres.2017.02.048

Deng, D., Weidhaas, J.L., Lin, L.-S., 2016. Kinetics and microbial ecology of batch sulfidogenic bioreactors for co-treatment of municipal wastewater and acid mine drainage. J. Hazard. Mater. 305, 200-8. https://doi.org/10.1016/j.jhazmat.2015.11.041

Descostes, M., Mercier, F., Thromat, N., Beaucaire, C., Gautier-Soyer, M., 2000. Use of XPS in the determination of chemical environment and oxidation state of iron and sulfur samples: Constitution of a data basis in binding energies for $\mathrm{Fe}$ and $\mathrm{S}$ reference compounds and applications to the evidence of surface species of an oxidized py. Appl. Surf. Sci. 165, 288-302. https://doi.org/10.1016/S01694332(00)00443-8

DeWeerd, K.A., Mandelco, L., Tanner, R.S., Woese, C.R., Suflita, J.M., 1990. Desulfomonile tiedjei gen. nov. and sp. nov., a novel anaerobic, dehalogenating, sulfate-reducing bacterium. Arch. Microbiol. 154, 23-30. https://doi.org/10.1103/PhysRev.85.816

Dobbin, P.S., Carter, J.P., Juan, C.G.S.S., Von Höbe, M., Powell, A.K., Richardson, D.J., 1999. Dissimilatory $\mathrm{Fe}(\mathrm{III})$ reduction by Clostridium beijerinckii isolated from freshwater sediment using Fe(III) maltol enrichment. FEMS Microbiol. Lett. 176, 131138. https://doi.org/10.1016/S0378-1097(99)00229-3

Dröge, S., Rachel, R., Radek, R., König, H., 2008. Treponema isoptericolens sp. nov., a novel spirochaete from the hindgut of the termite Incisitermes tabogae. Int. J. Syst. Evol. Microbiol. 58, 1079-1083. https://doi.org/10.1099/ijs.0.64699-0

El Houari, A., Ranchou-Peyruse, M., Ranchou-Peyruse, A., Dakdaki, A., Guignard, M., Idouhammou, L., Bennisse, R., Bouterfass, R., Guyoneaud, R., Qatibi, A.I., 2017. 
Desulfobulbus oligotrophicus sp. Nov., a sulfate-reducing and propionate-oxidizing bacterium isolated from a municipal anaerobic sewage sludge digester. Int. J. Syst. Evol. Microbiol. 67, 275-281. https://doi.org/10.1099/ijsem.0.001615

Elferink, S.J.W.H.O., Maas, R.N., Harmsen, H.J.M., Stams, A.J.M., 1995. Desulforhabdus amnigenus gen. nov. sp. nov., a sulfate reducer isolated from anaerobic granular sludge. Arch. Microbiol. 164, 119-124.

Esther, J., Sukla, L.B., Pradhan, N., Panda, S., 2015. Fe (III) reduction strategies of dissimilatory iron reducing bacteria. Korean J. Chem. Eng. 32, 1-14. https://doi.org/10.1007/s11814-014-0286-x

Fortney, N.W., He, S., Kulkarni, A., Friedrich, M.W., Holz, C., Boyd, E.S., Roden, E.E., 2018. Stable isotope probing for microbial iron reduction in Chocolate Pots hot spring, Yellowstone National Park. Appl. Environ. Microbiol. 84. https://doi.org/10.1128/AEM.02894-17

Gong, Y., Tang, J., Zhao, D., 2016. Application of iron sulfide particles for groundwater and soil remediation: A review. Water Res. 89, 309-320. https://doi.org/10.1016/j.watres.2015.11.063

Grabchak, M., Marcon, E., Lang, G., Zhang, Z., 2017. The generalized Simpson's entropy is a measure of biodiversity. PLoS One 12, 1-11. https://doi.org/10.1371/journal.pone.0173305

Gramp, J.P., Bigham, J.M., Jones, F.S., Tuovinen, O.H., 2010. Formation of Fe-sulfides in cultures of sulfate-reducing bacteria. J. Hazard. Mater. 175, 1062-1067. https://doi.org/10.1016/j.jhazmat.2009.10.119

Han, D.S., Batchelor, B., Abdel-Wahaba, A., 2013. XPS Analysis of Sorption of Selenium(IV) and Selenium(VI) to Mackinawite (FeS). Environ. Prog. Sustain. Energy 32, 84-93. https://doi.org/10.1002/ep

Hiibel, S.R., Pereyra, L.P., Breazeal, M.V.R., Reisman, D.J., Reardon, K.F., Pruden, A., 2011. Effect of Organic Substrate on the Microbial Community Structure in PilotScale Sulfate-Reducing Biochemical Reactors Treating Mine Drainage. Environ. Eng. Sci. 28, 563-572. https://doi.org/10.1089/ees.2010.0237

Holmes, D.E., Bond, D.R., Lovley, D.R., 2004. Electron Transfer by Desulfobulbus propionicus to Fe (III) and Graphite Electrodes Electron Transfer by Desulfobulbus propionicus to Fe (III) and Graphite Electrodes. Appl. Environ. Microbiol. 70, 12341237. https://doi.org/10.1128/AEM.70.2.1234

Hubert, C., Voordouw, G., 2007. Oil field souring control by nitrate-reducing Sulfurospirillum spp. that outcompete sulfate-reducing bacteria for organic electron donors. Appl. Environ. Microbiol. 73, 2644-2652. https://doi.org/10.1128/AEM.02332-06

Ifo, S.A., Moutsambote, J.M., Koubouana, F., Yoka, J., Ndzai, S.F., Bouetou-Kadilamio, L.N.O., Mampouya, H., Jourdain, C., Bocko, Y., Mantota, A.B., Mbemba, M., Mouanga-Sokath, D., Odende, R., Mondzali, L.R., Wenina, Y.E.M., Ouissika, B.C., 
Joel, L.J., 2016. Tree Species Diversity, Richness, and Similarity in Intact and Degraded Forest in the Tropical Rainforest of the Congo Basin: Case of the Forest of Likouala in the Republic of Congo. Int. J. For. Res. 2016. https://doi.org/10.1155/2016/7593681

Khadse, G.K., Patni, P.M., Labhasetwar, P.K., 2015. Removal of Iron and Manganese from drinking water supply. Sustain. Water Resour. Manag. 1, 157-165. https://doi.org/10.1021/ie50297a006

Koschorreck, M., Geller, W., Neu, T., Kleinsteuber, S., Kunze, T., Trosiener, A., WendtPotthoff, K., 2010. Structure and function of the microbial community in an in situ reactor to treat an acidic mine pit lake. FEMS Microbiol. Ecol. 73, 385-395. https://doi.org/10.1111/j.1574-6941.2010.00886.x

Kulandaivelu, J., Gao, J., Song, Y., Shrestha, S., Li, X., Li, J., Doederer, K., Keller, J., Yuan, Z., Mueller, J.F., Jiang, G., 2019. Removal of Pharmaceuticals and Illicit Drugs from Wastewater Due to Ferric Dosing in Sewers. Environ. Sci. Technol. 53, 62456254. https://doi.org/10.1021/acs.est.8b07155

Lennie, A.R., Vaughan, D.J., 1996. Spectroscopic studies of iron sulfide formation and phase relations at low temperatures, in: Dyar, M.D., McCammon, C., Schaefer, M.W. (Eds.), Mineral Spectroscopy: A Tribute to Roger G. Burns. pp. 117-131.

Lovley, D.R., 1993. Dissimilatory metal reduction. Annu. Rev. Microbiol. 47, 20-29.

Lovley, D.R., 1987. Organic matter mineralization with the reduction of ferric iron: A review. Geomicrobiol. J. 5, 375-399. https://doi.org/10.1080/01490458709385975

Lovley, D.R., Giovannoni, S.J., White, D.C., Champine, J.E., Phillips, E.J.P., Gorby, Y.A., Goodwin, S., 1993. Geobacter metallireducens gen. nov. sp. nov., a microorganism. Arch. Microbiol. 159, 336-344.

Lovley, D.R., Lonergan, D.J., 1990. Anaerobic oxidation of toluene, phenol, and p-cresol by the dissimilatory iron-reducing organism, GS-15. Appl. Environ. Microbiol. 56, 1858-1864. https://doi.org/10.1128/aem.72.5.3236-3244.2006

Lovley, D.R., Phillips, E.J.P., 1989. Requirement for a microbial consortium to completely oxidize glucose in Fe(III)- reducing sediments. Appl. Environ. Microbiol. 55, 32343236.

Lovley, D.R., Phillips, E.J.P., 1988. Novel Mode of Microbial Energy Metabolism: Organic Carbon Oxidation Coupled to Dissimilatory Reduction of Iron or Manganese. Appl. Environ. Microbiol. 54, 1472-1480. https://doi.org/10.1103/PhysRevLett.50.1998

Metcalf \& Eddy, I., Tchobanoglous, G., Stensel, H.D., Tsuchihashi, R., Burton, F., 2014. Wastewater Engineering: Treatment and Resorce Recovery. McGraw-Hill, New York.

Moskowitz, B.M., Frankel, R.B., Bazylinski, D.A., Jannasch, H.W., Lovley, D.R., 1989. A comparison of magnetite particles produced anaerobically by magnetotactic and dissimilatory iron-reducing bacteria. Geophys. Reseaerch Lett. 16, 665-668.

Naumkin, A. V., Kraut-Vass, A., Gaarenstroom, S.W., Powell, C.J., 2012. NIST X-ray 
Photoelectron Spectroscopy Database [WWW Document]. https://doi.org/http://dx.doi.org/10.18434/T4T88K

Nevin, K.P., Holmes, D.E., Woodard, T.L., Hinlein, E.S., Ostendorf, D.W., Lovley, D.R., 2005. Geobacter bemidjiensis sp. nov. and Geobacter psychrophilus sp. nov., two novel $\mathrm{Fe}(\mathrm{III})$-reducing subsurface isolates. Int. J. Syst. Evol. Microbiol. 55, 16671674. https://doi.org/10.1099/ijs.0.63417-0

Nevin, K.P., Lovley, D.R., 2002. Mechanisms for accessing insoluble Fe(III) oxide during dissimilatory Fe(III) reduction by Geothrix fermentans. Appl. Environ. Microbiol. 68, 2294-2299. https://doi.org/10.1128/AEM.68.5.2294-2299.2002

Podosokorskaya, O.A., Kadnikov, V. V., Gavrilov, S.N., Mardanov, A. V., Merkel, A.Y., Karnachuk, O. V., Ravin, N. V., Bonch-Osmolovskaya, E.A., Kublanov, I. V., 2013. Characterization of Melioribacter roseus gen. nov., sp. nov., a novel facultatively anaerobic thermophilic cellulolytic bacterium from the class Ignavibacteria, and a proposal of a novel bacterial phylum Ignavibacteriae. Environ. Microbiol. 15, 17591771. https://doi.org/10.1111/1462-2920.12067

Rabus, R., Venceslau, S.S., Wöhlbrand, L., Voordouw, G., Wall, J.D., Pereira, I.A.C., 2015. A Post-Genomic View of the Ecophysiology, Catabolism and Biotechnological Relevance of Sulphate-Reducing Prokaryotes. Adv. Microb. Physiol. 66, 55-321. https://doi.org/10.1016/bs.ampbs.2015.05.002

Shah, M., Lin, C.-C., Kukkadapu, R., Engelhard, M.H., Zhao, X., Wang, Y., Barkay, T., Yee, N., 2014. Syntrophic Effects in a Subsurface Clostridial Consortium on Fe(III)(Oxyhydr)oxide Reduction and Secondary Mineralization. Geomicrobiol. J. 31, 101115.

Tebo, B.M., Obraztsova, A.Y., 1998. Sulfate-reducing bacterium grows with $\mathrm{Cr}$ ( VI ), U ( VI ), Mn ( IV ), and Fe ( III ) as electron acceptors. Source 162, 193-198. https://doi.org/10.1111/j.1574-6968.1998.tb12998.x

Thorpe, A.N., Senftle, F.E., Alexander, C.C., Dulong, F.T., 1984a. Oxidation of pyrite in coal to magnetite. Fuel 63, 662-668. https://doi.org/10.1016/0016-2361(84)90163-7

Thorpe, A.N., Senftle, F.E., Alexander, C.C., Dulong, F.T., 1984b. Oxidation of pyrite in coal to magnetite. Fuel 63, 662-668. https://doi.org/10.1016/0016-2361(84)90163-7

Ueki, A., Akasaka, H., Suzuki, D., Ueki, K., 2006. Paludibacter propionicigenes gen. nov., sp. nov., a novel strictly anaerobic, Gram-negative, propionate-producing bacterium isolated from plant residue in irrigated rice-field soil in Japan. Int. J. Syst. Evol. Microbiol. 56, 39-44. https://doi.org/10.1099/ijs.0.63896-0

Vaclavkova, S., Jørgensen, C.J., Jacobsen, O.S., Aamand, J., Elberling, B., 2014. The Importance of Microbial Iron Sulfide Oxidation for Nitrate Depletion in Anoxic Danish Sediments. Aquat. Geochemistry 20, 419-435. https://doi.org/10.1007/s10498-0149227-x

Van Lier, J.B., Van der Zee, F.P., Frijters, C.T.M.J., Ersahin, M.E., 2015. Celebrating 40 years anaerobic sludge bed reactors for industrial wastewater treatment. Rev. 
Environ. Sci. Biotechnol. 14, 681-702. https://doi.org/10.1007/s11157-015-9375-5

Waite, T.D., 2002. Challenges and opportunities in the use of iron in water and wastewater treatment. Rev. Environ. Sci. Biotechnol. 1, 9-15. https://doi.org/10.1023/A:1015131528247

Wang, L., Pan, Y.X., Li, J.H., Qin, H.F., 2008. Magnetic properties related to thermal treatment of pyrite. Sci. China, Ser. D Earth Sci. 51, 1144-1153. https://doi.org/10.1007/s11430-008-0083-7

Wang, N., Zheng, T., Zhang, G., Wang, P., 2016. A review on Fenton-like processes for organic wastewater treatment. J. Environ. Chem. Eng. 4, 762-787. https://doi.org/10.1016/j.jece.2015.12.016

Waters, K.E., Rowson, N.A., Greenwood, R.W., Williams, A.J., 2008. The effect of heat treatment on the magnetic properties of pyrite. Miner. Eng. 21, 679-682. https://doi.org/10.1016/j.mineng.2008.01.008

Weber, K.A., Achenbach, L.A., Coates, J.D., 2006. Microorganisms pumping iron: Anaerobic microbial iron oxidation and reduction. Nat. Rev. Microbiol. 4, 752-764. https://doi.org/10.1038/nrmicro1490

Xiang, H., Liu, C., Pan, R., Han, Y., Cao, J., 2014. Magnetite for phosphorus removal in low concentration phosphorus-contained water body. Adv. Environ. Res. 3, 163-172.

Yamada, T., Sekiguchi, Y., Imachi, H., Kamagata, Y., Ohashi, A., Harada, H., 2005. Diversity, Localization, and Physiological Properties of Filamentous Microbes Belonging to. Microbiology 71, 7493-7503. https://doi.org/10.1128/AEM.71.11.7493

Yang, Y., Chen, T., Sumona, M., Gupta, B. Sen, Sun, Y., Hu, Z., Zhan, X., 2017. Utilization of iron sulfides for wastewater treatment: a critical review. Rev. Environ. Sci. Biotechnol. 16, 289-308. https://doi.org/10.1007/s11157-017-9432-3

Zellner, G., Messner, P., Kneifel, H., Winter, J., 1989. Desulfovibrio simplex spec. nov., a new sulfate-reducing bacterium from a sour whey digester. Arch. Microbiol. 152, 329-334. https://doi.org/10.1007/BF00425169

Zhang, Z., Wang, Y., Leslie, G.L., Waite, T.D., 2015. Effect of ferric and ferrous iron addition on phosphorus removal and fouling in submerged membrane bioreactors. Water Res. 69, 210-222. https://doi.org/10.1016/j.watres.2014.11.011 


\section{Chapter 5: Magnetic Sludge Byproducts for Adsorptive Removal of Phosphorus: Resource Recovery from Iron-based Anaerobic Sewage Sludge}

(M. Ahmed, M. Azizah, R. Anwar, M. Johnson, L.-S. Lin, Magnetic Sludge Byproducts for Adsorptive Removal of Phosphorus: Resource Recovery from Iron-based Anaerobic Sewage Sludge, Manuscript under review in Waste Management Journal)

\subsection{Introduction}

Sludge management is an important aspect of biological wastewater treatment as it represents a difficult and expensive issue in wastewater engineering (Cies̈lik et al., 2015; Uggetti et al., 2010; Yang et al., 2015). Worldwide, sludge management strategies mostly fall in three categories: land application, landfill disposal and incineration or thermal technologies (Campbell, 2000). In many instances, sludge is applied for land application at a high loading rate which exceeds the nutrient requirements of the vegetation. Excess nutrients from the sludge can contaminate groundwater and surface water through leaching from soil and via runoff generating from rainfall respectively (EPA, 2000). Severe environmental impact was observed by landfill gas and leachate emitted from landfill disposal, and local soil contamination with metals and pathogens due to land application. Incineration has a major drawback of air pollution due to the emission of contaminants, that can cause severe health and environmental risk (Hu et al., 2015; Roberts and Chen, 2006). Anaerobic digestion and pyrolysis are among the most promising processes practiced for energy generation from sewage sludge (Cao and Pawłowski, 2012). However, energy generation through these processes is highly dependent on the amount of organic matters present in the sludge. Biogas production using anaerobic digestion is a complex process as several parameters (e.g. pH, temperature, reactor type, retention time, organic loading rate) are needed to be controlled for an efficient process (Van et al., 2019). Moreover, the presence of incombustible gases like carbon dioxide $\left(\mathrm{CO}_{2}\right)$, hydrogen sulfide $\left(\mathrm{H}_{2} \mathrm{~S}\right)$ and water vapor reduce the calorific value of biogas and make the compression, transportation and energy generation expensive (Olugasa et al., 2014). Therefore, it is important to develop simple and cost-effective methods to extract valuable resources from the sludge. Various chemical and biological treatment approaches (e.g. stripping/absorption of ammonium, partial nitrification/anammox, struvite precipitation) 
have been employed for nutrient recovery from sewage sludge (Ahmed et al., 2015; Antakyali et al., 2013; Booker et al., 1999; Vrieze et al., 2016). These approaches create new avenues of valuable resource recovery from sludge.

A novel, energy-efficient Fe(III)-dosed anaerobic biological wastewater treatment system was recently developed and showed effective treatment performance (Ahmed et al., $2020,2019)$. In this biological treatment, organics oxidation is coupled to both iron- and sulfate-reduction facilitated by iron- and sulfate-reducing bacteria. The sludge materials produced from this treatment mostly contained inorganic precipitates and smaller amounts of biomass. Electronic microscopic and spectroscopic analyses of the sludge materials revealed that the inorganic precipitates are iron sulfide ( $\mathrm{FeS}$ and $\mathrm{FeS}_{2}$, Ahmed et al., 2020, 2019). Although sludge production rate in this anaerobic treatment system is lower than those of typical aerobic treatment processes, beneficial applications of the sludge materials can significantly improve the sustainability of the treatment method. Valuable resource recovery from the iron sulfide sludge with simple treatment approach can reduce the sludge management problem and minimize environmental footprint.

Different forms of iron sulfides $\left(\mathrm{FeS}, \mathrm{FeS}_{2}, \mathrm{Fe}_{1-\mathrm{x}} \mathrm{S}\right)$ and synthesized nanoparticles from iron sulfides were found effective for removing organic compounds (e.g., trichloroethylene, tetrachloroethylene, nitroaromatic compounds), heavy metals (e.g., $\mathrm{Hg}$, $\mathrm{Cd}, \mathrm{Cr}$ ), oxyanions (arsenite/arsenate, selenite/selenite), nutrients ( $\mathrm{N}$ and $\mathrm{P}$ ), radionuclides (e.g., $\mathrm{U}, \mathrm{Tc}, \mathrm{Np}$ ) through chemical precipitation, chemical reduction, surface sorption, and complexation from aqueous solutions (Gong et al., 2016; Yang et al., 2017). These iron sulfides known as weakly paramagnetic with very small and positive susceptibility (Waters et al., 2008), can be transformed into iron oxides with high magnetic properties. Iron oxides such as magnetite- and maghemite-based nanoparticles have been recognized as useful materials due to their technological and industrial applications (Khan et al., 2015; Teja and Koh, 2009). Their unique properties such as superparamagnetism, higher surface area to volume ratio, morphology and chemical composition, lead to broad applications in the field of environment, agriculture and biomedicine (Ali et al., 2016; Farhanian et al., 2018). Magnetite is identified to have major potential in biomedicine sector, especially in phototherapy, bacterial detection, drug 
delivery, and bioimaging agents (Ansar et al., 2015; Ansari et al., 2019; Saeed et al., 2018; Xu et al., 2019). In the field of wastewater treatment and pollution control, iron oxide-based particles have been used as a coagulant for rapid sludge clarification and process intensification (Anderson et al., 1987; Booker et al., 1991), and as an effective adsorbent for contaminant removal from aqueous wastes due to their smaller size, and higher surface area (Nassar, 2012; Oliveira et al., 2002). Their magnetic properties allow separation of the adsorbents from the aqueous phase for further applications (Dave and Chopda, 2014). In particular, iron oxide particles (e.g., magnetite, maghemite, and hematite) have been extensively used for phosphate removal from aqueous system (Ajmal et al., 2018; Berner, 1973; Shahid et al., 2019). Magnetite particles were found effective for removing heavy metals such as lead, copper, zinc, manganese, and cadmium (El-Dib et al., 2019; Giraldo et al., 2013). More than $90 \%$ adsorptive removal of lead, zinc, cadmium, chromium, copper, and nickel from aqueous system by maghemite were also reported (Ahmadi et al., 2014; Hu et al., 2006). A synthesized magnetitehematite mixture was also observed as a proficient adsorbent with maximum adsorption efficiency of $98,99.50$, and $99.84 \%$ for removal of lead (II), chromium (III) and cadmium (II) respectively from water (Ahmed et al., 2013).

Thermal treatment has been used to convert iron sulfide $\left(\mathrm{FeS}_{2}\right)$ into strong ferrimagnetic substances such as magnetite and maghemite (Thorpe et al., 1984; Wang et al., 2008; Waters et al., 2008). Weakly antiferromagnetic hematite $\left(\alpha-\mathrm{Fe}_{2} \mathrm{O}_{3}\right)$ and strongly ferrimagnetic maghemite $\left(\gamma-\mathrm{Fe}_{2} \mathrm{O}_{3}\right)$ were observed as the oxidation products of pyrite in coal treated at dry temperatures, as high as $600^{\circ} \mathrm{C}$ (Marusak et al., 1976). Another study by Nishihara and Kondo, (1959) revealed that at low partial pressure of oxygen, $\mathrm{FeS}_{2}$ was converted stepwise to pyrrhotite $\left(\mathrm{Fe}_{1-\mathrm{x}} \mathrm{S}\right), \mathrm{FeO}, \mathrm{Fe}_{3} \mathrm{O}_{4}$ and finally to $\alpha-\mathrm{Fe}_{2} \mathrm{O}_{3}$ when treated at high temperature $\left(700-900^{\circ} \mathrm{C}\right)$. In another study, pyrite of bituminous coal was partially converted to magnetite when baked at $393-455^{\circ} \mathrm{C}$ at low oxygen atmosphere (Thorpe et al., 1984). At low oxygen concentration, $\mathrm{FeS}_{2}$ was observed to oxidize to $\mathrm{Fe}_{3} \mathrm{O}_{4}$ and $\alpha$ $\mathrm{Fe}_{2} \mathrm{O}_{3}$, but no magnetite phase was observed when temperature and oxygen concentration were too high, and only $\alpha-\mathrm{Fe}_{2} \mathrm{O}_{3}$ phase prevailed. Thus, temperature and partial pressure of oxygen both act as regulating factors for thermal conversion of pyrite 
into magnetic particles. However, controlling the partial pressure of oxygen at high temperature is a complex task compared to baking samples with a simple muffle furnace.

The objective of this study was to improve sustainability of the newly developed $\mathrm{Fe}$ (III)dosed anaerobic biological wastewater treatment system (Ahmed et al., 2020) by generating useful products from its sludge materials. A thermal method was applied to transform the sludge materials to products that have magnetic properties for beneficial uses (Supplementary Material, Fig. S9). Spectroscopic and magnetization analyses were conducted to characterize the chemical structures and magnetic properties of the sludge byproducts. Adsorptive removal of phosphate using the magnetic materials was examined as one of the beneficial applications of the sludge byproducts.

\subsection{Materials and methods}

\subsubsection{Sample collection and preparation}

Sludge samples were collected from a Fe(III)-dosed anaerobic bioreactor that was used for treatment of synthetic wastewaters for more than three years. Details of the bioreactor and experimental conditions were previously described (Ahmed et al., 2020). Sludge samples were collected every two months from the bioreactor under mass loading to COD $281 \mathrm{mg} / \mathrm{d}, \mathrm{Fe}$ (III) $134.3 \mathrm{mg} / \mathrm{d}$, and sulfur $38.2 \mathrm{mg} / \mathrm{d}$ (Fe/S molar ratio 2). The sludge solids were first separated from the solution using high-speed centrifugation $(5000 \times \mathrm{g})$ for 10 $\min$. The solid samples were then heated for an hour in a muffle furnace (Lindberg Blue $\mathrm{M}$, Thermo Scientific) at five different temperatures $\left(300^{\circ} \mathrm{C}, 350^{\circ} \mathrm{C}, 400^{\circ} \mathrm{C}, 450^{\circ} \mathrm{C}\right.$, $500^{\circ} \mathrm{C}$ ). After the thermal treatment, the products were crushed and milled to obtain a uniform size and denoted by S300, S350, S400, S450 and S500, respectively.

\subsubsection{Material Characterization}

The thermally transformed sludge byproducts were characterized for their composition using PANalytical X'Pert Pro X-ray Diffractometer (XRD) with a Cu-Ka source $(\lambda=1.542$ $\left.A^{\circ}\right)$. Rietveld refinement for phase quantification was done by HighScore Pro software (Bish and Howard, 1988; De La Torre et al., 2001) for four different phases: magnetite $\left(\mathrm{Fe}_{3} \mathrm{O}_{4}\right)$, hematite $\left(\mathrm{\alpha}-\mathrm{Fe}_{2} \mathrm{O}_{3}\right)$, maghemite $\left(\mathrm{\gamma}-\mathrm{Fe}_{2} \mathrm{O}_{3}\right)$ and pyrite $\left(\mathrm{FeS}_{2}\right)$. Rietveld refinement for powder-diffraction data is a multi-parameter curve-fitting procedure used to quantify 
the weight percentage (\%) of the different crystalline phases present in a sample. Many diffraction peaks or lines of the diffraction pattern for each phase were considered to reduce the discrepancies of overlapping lines from different patterns. A fitted spectrum was determined by minimizing the $\chi$-squared difference between the fit and experimental spectra, based on the known crystal structure parameters and fitting parameters (weight percent, crystallite size and strain) for each phase. This calculated spectrum includes the contributions from the sharp Bragg peaks from the crystalline components of the sample and the contribution of the smooth background that underlies the peaks. The observed, refined, background, and difference between observed and refined data are labeled $I_{O}$, $I_{C}, I_{B G}$ and $I_{O}-I_{C}$ respectively. The $\chi$-squared, goodness of fit (GOF) values are also presented for each spectrum. The particle size was calculated by Scherrer equation $L=K \lambda / \beta \cos \theta$ (Aziziha et al., 2019a; Patterson, 1939; Scherrer, 1912) where $L$ is the particle size, $K$ is a constant equal to 0.9 for spherical particles, $\lambda$ is the $X$-ray wavelength, $\beta$ is the full-width at half-maximum of the peak, and $\theta$ is the peak position.

\subsubsection{Magnetic Measurements}

A Physical Property Measurement System (PPMS ${ }^{\odot}$ ) Evercool II (Quantum Design) was used for the magnetic measurements of the sludge byproducts. This system allows the sample temperature to be varied from 1.8 to $400 \mathrm{~K}$ (with $1 \%$ accuracy) and the magnetic field $(\mathrm{H})$ from -90 to $90 \mathrm{kOe}$ (with an accuracy of $0.2 \mathrm{Oe}$ ). The estimated error in $\mathrm{M} / \mathrm{m}$ (emu/g) was less than $0.1 \%$ for the samples used in this study. For the vibrating sample magnetometer (VSM) magnetic measurements, $10 \mathrm{mg}$ of each powder sample was used. For each sample, the powder was compressed and sealed in a plastic tube sample holder (P/N 4096-388) and the sample holder was snapped into a brass half tube, which was appropriately positioned in the magnetic field. The small diamagnetic background related to the sample holder and the brass piece was measured (without the powder sample) and subtracted from the measured data associated with the powder samples. 


\subsubsection{Adsorption Experiments}

Batch adsorption experiments were conducted on sludge byproducts baked at $350^{\circ} \mathrm{C}$ and $500^{\circ} \mathrm{C}$ using synthetic phosphate $\left(\mathrm{PO}_{4}{ }^{3-}\right)$ solutions that were prepared at $\mathrm{pH} 7.0 \pm 0.1$ using sodium phosphate dibasic $\left(\mathrm{Na}_{2} \mathrm{HPO}_{4}\right)$ and sodium phosphate monobasic $\left(\mathrm{NaH}_{2} \mathrm{PO}_{4} \cdot 2 \mathrm{H}_{2} \mathrm{O}\right)$. Phosphorous $(\mathrm{P})$ concentrations were monitored during a 24 -hr period to examine the adsorption kinetics. A range of $\mathrm{PO}_{4}{ }^{3-}-\mathrm{P}$ concentrations $(20,50,100,200$, $300,500,800$ and $1000 \mathrm{mg} / \mathrm{L}$ ) were used to develop adsorption isotherms by letting the reaction reach equilibrium. For each batch, a predetermined amount of adsorbent $(0.01$ g) was added into a $50 \mathrm{ml}$ Erlenmeyer flask, followed by the addition of $15 \mathrm{~mL}$ of the $\mathrm{PO}_{4}{ }^{3-}$ solution resulting in an adsorbent loading rate of $0.67 \mathrm{~g} / \mathrm{L}$. The flasks were covered with parafilm and placed in an incubator shaker (MaxQ 4000, Thermo Scientific) at $150 \mathrm{rpm}$ for mixing. After adsorption, the suspension samples were filtered through a $0.45 \mu \mathrm{m}$ membrane to remove the solids and the $P$ concentrations in the filtrate samples were measured by the Ascorbic Acid method (Standard Method 4500 E, APHA et al., 2005). An experiment was also conducted to study the effects of $\mathrm{pH}$ on the adsorption by using $0.1 \mathrm{~N} \mathrm{HCl}$ and $0.02 \mathrm{~N} \mathrm{NaOH}$ solutions to control the $\mathrm{pH}$.

\subsubsection{Adsorption Kinetics and Isotherm Modeling}

A pseudo-second-order kinetic model was applied on the kinetic data to gain a better insight into the adsorption kinetics. This model takes the form

$$
\frac{t}{q}=\frac{1}{k q_{e}^{2}}+\frac{t}{q_{e}}
$$

where $q_{e}$ and $q$ (mg $\mathrm{PO}_{4}{ }^{3-}-\mathrm{P} / \mathrm{g}$-adsorbent) are the amount of $\mathrm{PO}_{4}{ }^{3-}-\mathrm{P}$ adsorbed by the adsorbent at equilibrium and at given time $t(\mathrm{~min})$, respectively. Adsorption rate constant $k[\mathrm{~g} /(\mathrm{mg} \times \mathrm{min})]$ and adsorption capacity $q_{e}\left(\mathrm{mg}-\mathrm{PO}_{4}{ }^{3}-\mathrm{P} / \mathrm{g}\right.$-adsorbent) were calculated from the slope and intercept of the linear regression line.

Non-linear Langmuir (Eq. 2) and Freundlich (Eq. 3) models were used to characterize the adsorption isotherms (Ajmal et al., 2018; Desta, 2013; Krishna and Swamy, 2012). Langmuir model is based on the assumption that adsorption can occur only at a finite number of surface sites and maximum adsorption corresponds to a saturated monolayer 
of adsorbate molecules on the adsorbent surface (Dada et al., 2012). The Freundlich model can be applied to the multilayer adsorption, based on an assumption of heterogenous surface energies (Krishna and Swamy, 2012). The Langmuir and Freundlich equations used are

$$
\begin{gathered}
q_{e}=q_{m} K_{L} \frac{C_{e}}{1+K_{L} C_{e}} \quad \text { and } \\
q_{e}=K_{F} C_{e}^{1 / n},
\end{gathered}
$$

where, $C_{e}(\mathrm{mg} / \mathrm{L}), q_{m}\left(\mathrm{mg} \mathrm{PO}{ }_{4}^{3-}-\mathrm{P} / \mathrm{g}\right.$-adsorbent) and $K_{L}(\mathrm{~L} / \mathrm{mg})$ represent the equilibrium aqueous $\mathrm{P}$ concentration, the maximum adsorption capacity, and Langmuir adsorption constant, respectively. The Freundlich parameter $K_{F}\left((\mathrm{mg} / \mathrm{g})(\mathrm{L} / \mathrm{mg})^{1 / n}\right)$ quantifies the adsorption capacity and $1 / n$ (dimensionless) is indicative of adsorption intensity. Nonlinear fitting of both the models were done using Microsoft Excel Solver.

\subsection{Results and Discussion}

\subsubsection{Material Characterization}

\subsubsection{Material size and structure}

The X-ray diffraction spectra of the sludge byproducts baked at 300, 350, 400, 450, and $500{ }^{\circ} \mathrm{C}$ indicate that the samples were a mixture of amorphous and crystalline structures (Fig. 20). Sharp peaks and broad hump peaks of the spectra represent the crystalline and amorphous from of the samples respectively. The intensity of the sharp peaks increased with the temperature, which indicates the increase of the sample's crystallinity with temperature. The crystallite size of the materials ranged from 7 to $15 \mathrm{~nm}$, where size was observed to increase with the baking temperature (data not shown). These sizes are comparable to the size of the iron oxide nanocrystals reported in previous studies (Demortière et al., 2011). Magnetic iron oxide nanocrystals have many technological and industrial applications due to their unique physical and chemical properties (Demortière et al., 2011; Liu et al., 2016; Tian et al., 2015; Willis et al., 2005). Particularly, they have significant contribution in the field of biomedicine such as drug delivery, DNA detection, magnetic resonance imaging (MRI), cell separation technique etc. (Hogemann et al., 2000; Josephson et al., 2001; Willis et al., 2005). There is an enormous scope for using 
magnetic nanocrystals for development of magnetic or optical devices, including permanent magnets, recording media (Chaubey et al., 2008; Weller and McDaniel, 2006). Moreover, these particles can also be used as adsorptive material for pollutant removal for air emission and wastewater treatment due to their high surface area to size ratio (Chiavola et al., 2016; Karatza et al., 2013; Molino et al., 2013).

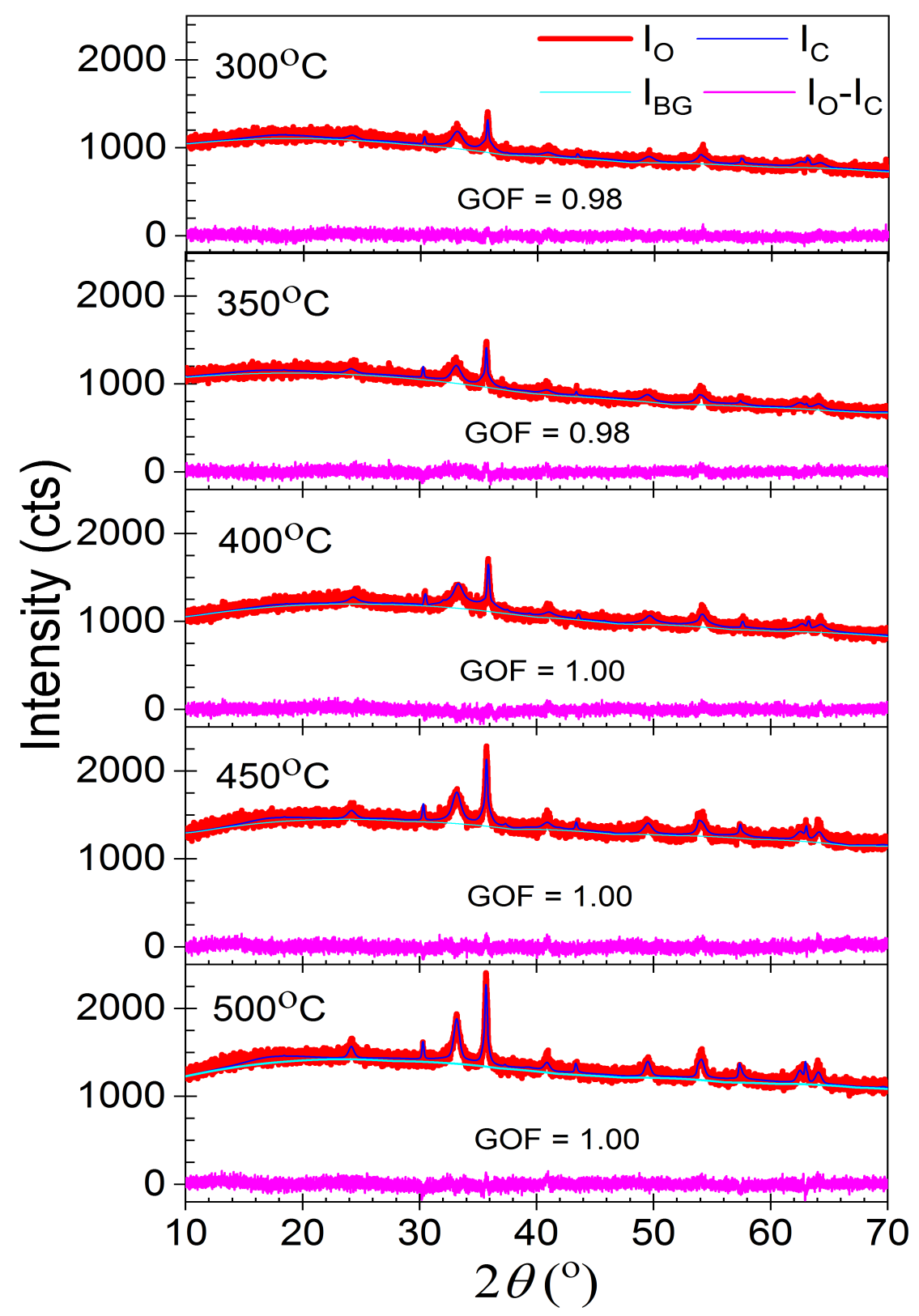

Fig. 20: XRD spectra of the sludge byproducts derived from the thermal treatment. Red: XRD spectrum, Blue: Rietveld fit, Cyan: Background, Pink: Difference between the experimental and Rietveld refinement 


\subsubsection{Material phase analysis}

The Rietveld refinement was performed on the XRD spectrum by considering four phases of iron minerals $\alpha-\mathrm{Fe}_{2} \mathrm{O}_{3}$ (hematite), $\mathrm{\gamma}-\mathrm{Fe}_{2} \mathrm{O}_{3}$ (maghemite), $\mathrm{Fe}_{3} \mathrm{O}_{4}$ (magnetite), and $\mathrm{FeS}_{2}$ (pyrite). The phase weight percentages (\%) did not show any particular trend with the temperature (Fig. 21). In all cases, magnetite and hematite were found to be the most dominant phases in the materials (Fig. 21). Magnetite phase ranged from 14 to $39 \%$, with the highest percentage observed at $350^{\circ} \mathrm{C}$. The weight percentage of the hematite phase ranged from 41 to $76 \%$, with its highest percentage, observed at $400^{\circ} \mathrm{C}$. Another, ferromagnetic phase observed in this study was maghemite $\left(\mathrm{\gamma}-\mathrm{Fe}_{2} \mathrm{O}_{3}\right)$. Maghemite is likely an intermediate phase between the transformation of magnetite to hematite and has a structure and ferromagnetic properties similar to magnetite (Khan et al., 2015; Nikiforov et al., 2014). The presence of both magnetite and maghemite phases in the byproducts indicates successful conversion of the sludge materials to magnetic particles. More magnetite extraction might have been possible if the thermal treatment was conducted at low oxygen concentrations (1.0-3.0 kPa) (Thorpe et al., 1984), as the magnetite phase has lower stability at high oxygen concentrations. In this study, strict partial pressure or low oxygen concentration were not maintained, only a simple way of thermal treatment process was used. 


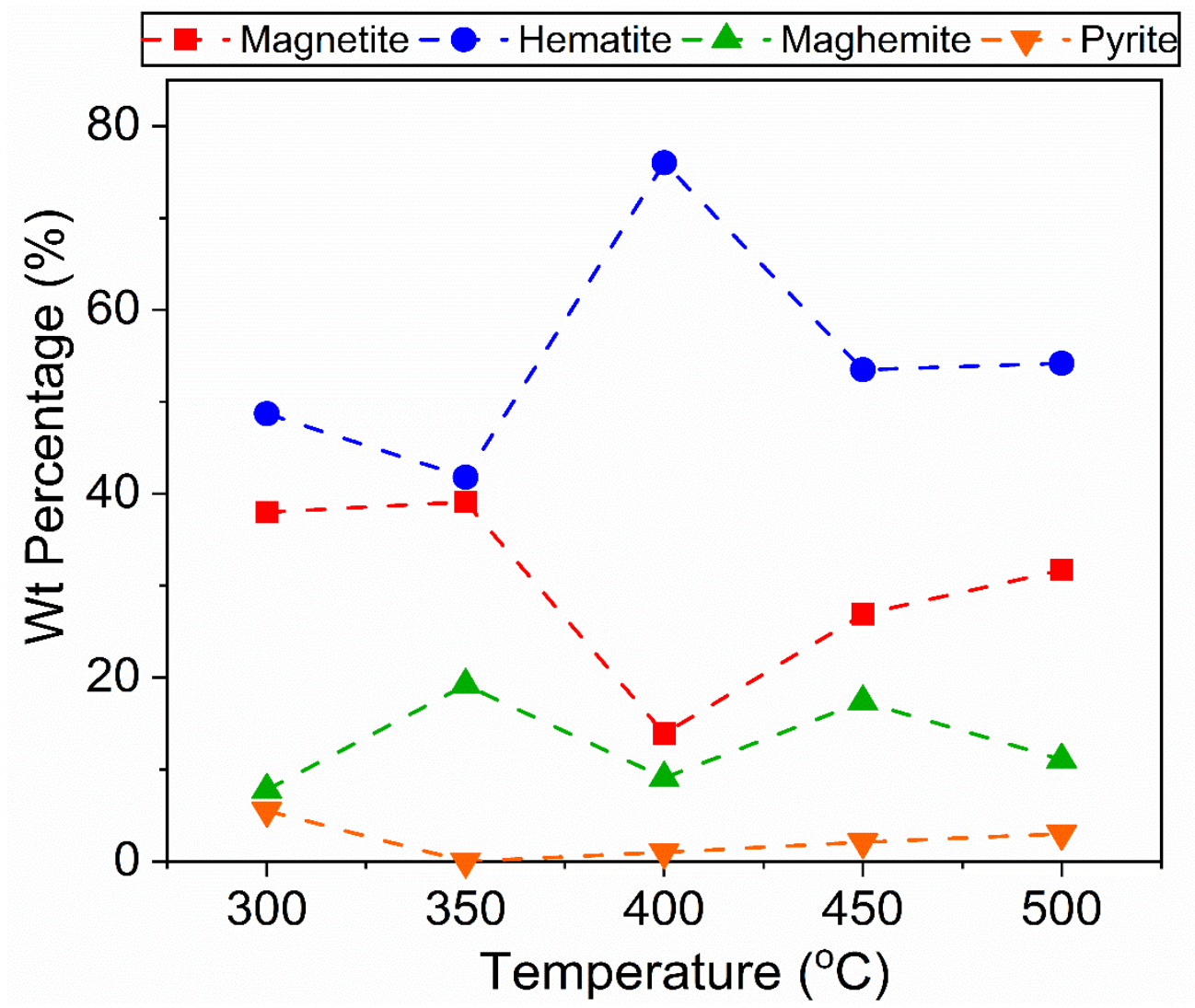

Fig. 21: Weight percentages of different phases of iron minerals derived from the sludge materials at different temperatures

\subsubsection{Magnetic Measurements}

High-resolution hysteresis measurements on the sludge byproducts taken at room temperature for magnetic field $H=-20$ to $20 \mathrm{kOe}$ are shown in Fig. 22. The coercivity, $H_{c}$ (field necessary to completely demagnetize a fully magnetized ferromagnet), remanent magnetization, $M_{r}$ (residual magnetization in a ferromagnetic material after the external magnetic field is removed), and saturation magnetization, $M_{s}$ (highest magnetization in a ferromagnetic material) were estimated from these hysteresis measurements. The values of $M_{\mathrm{s}}$ ranged from 6.3 to $10.9 \mathrm{emu} / \mathrm{g}$ and $M_{\mathrm{r}}$ ranged from 0.7 to $2.0 \mathrm{emu} / \mathrm{g}$ (Supplementary Materials, Table 1), which are lower than the reported magnetization values for pure magnetite and maghemite (Aziziha et al., 2019b; Bao et al., 2011; Dar and Shivashankar, 2014; Lee et al., 2005; Özdemir and Dunlop, 2014). These smaller values are not 
surprising because these magnetic properties vary considerably depending on many details, such as crystallite size, strain, purity, and defects.

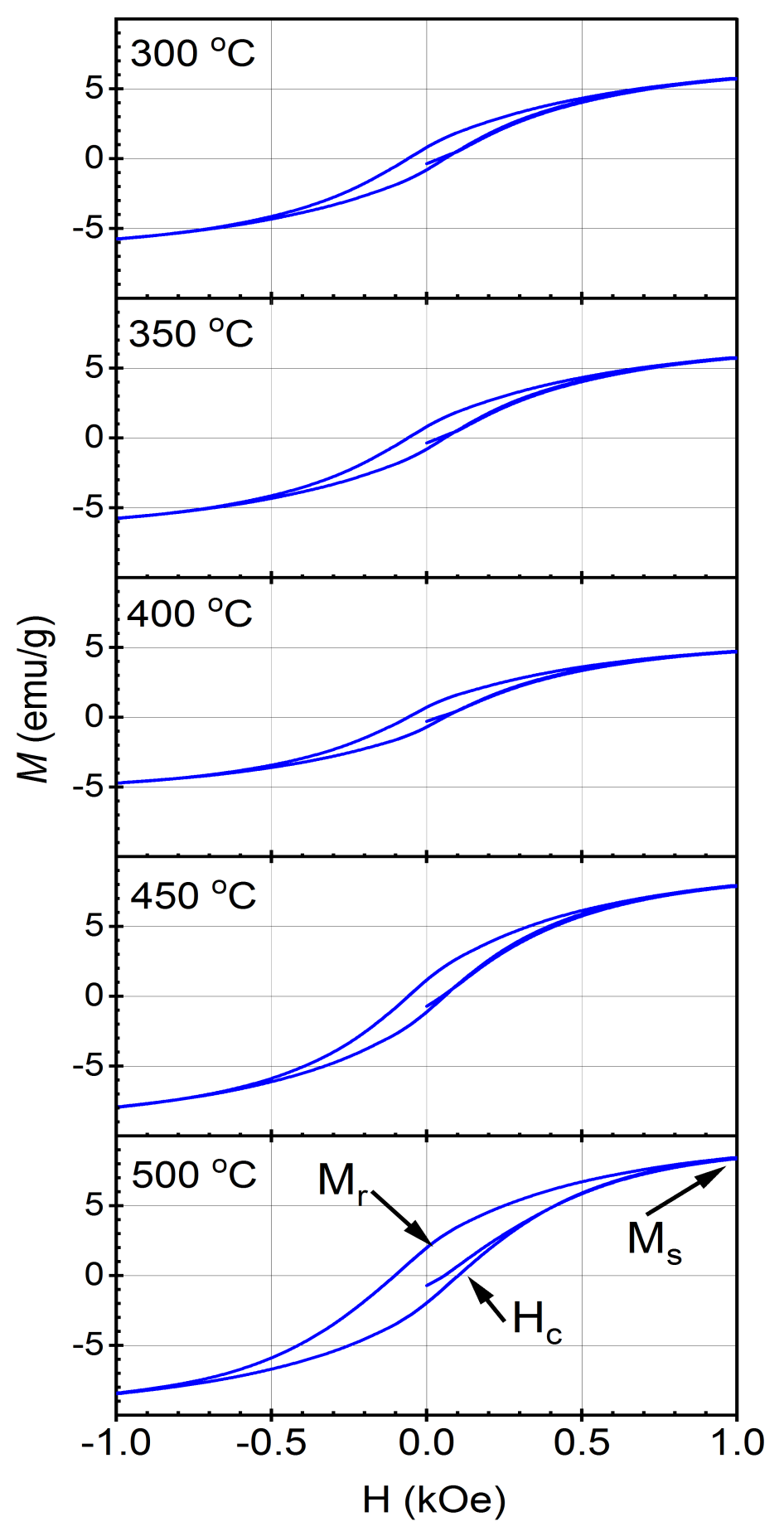

Fig. 22: High-resolution hysteresis measurements of the sludge byproducts derived at different temperatures 
There was no significant change in remanent magnetization $\left(M_{r}\right)$ for bake temperatures from 300 to $400^{\circ} \mathrm{C}$, but $M_{r}$ increased significantly above $400^{\circ} \mathrm{C}$ (Fig. 23). The highest magnetization (both remanent and saturation) was observed for the $500^{\circ} \mathrm{C}$ baked sample. This increased magnetization is probably due to the change in particle size. The magnetic properties of nanocrystals were reported to be dependent on the shape and size of the particles with magnetization increasing with the crystallite size (Bao et al., 2011; Byrne et al., 2011; Lee et al., 2005; Wu et al., 2008; Xu et al., 2007). With the increasing bake temperatures, the crystallite size is observed to increase, which is consistent with the observed increased magnetization. The substantial magnetite phase $(32 \%)$ observed for the $500^{\circ} \mathrm{C}$ sample in large part explains the high magnetization for this $\mathrm{S} 500$ sample. Given the highest $\%$ of magnetite was observed at $350^{\circ} \mathrm{C}$ whereas highest magnetization was observed at $500^{\circ} \mathrm{C}$, for this study, we used both the $\mathrm{S} 350$ and $\mathrm{S} 500$ samples to evaluate the adsorption capabilities.

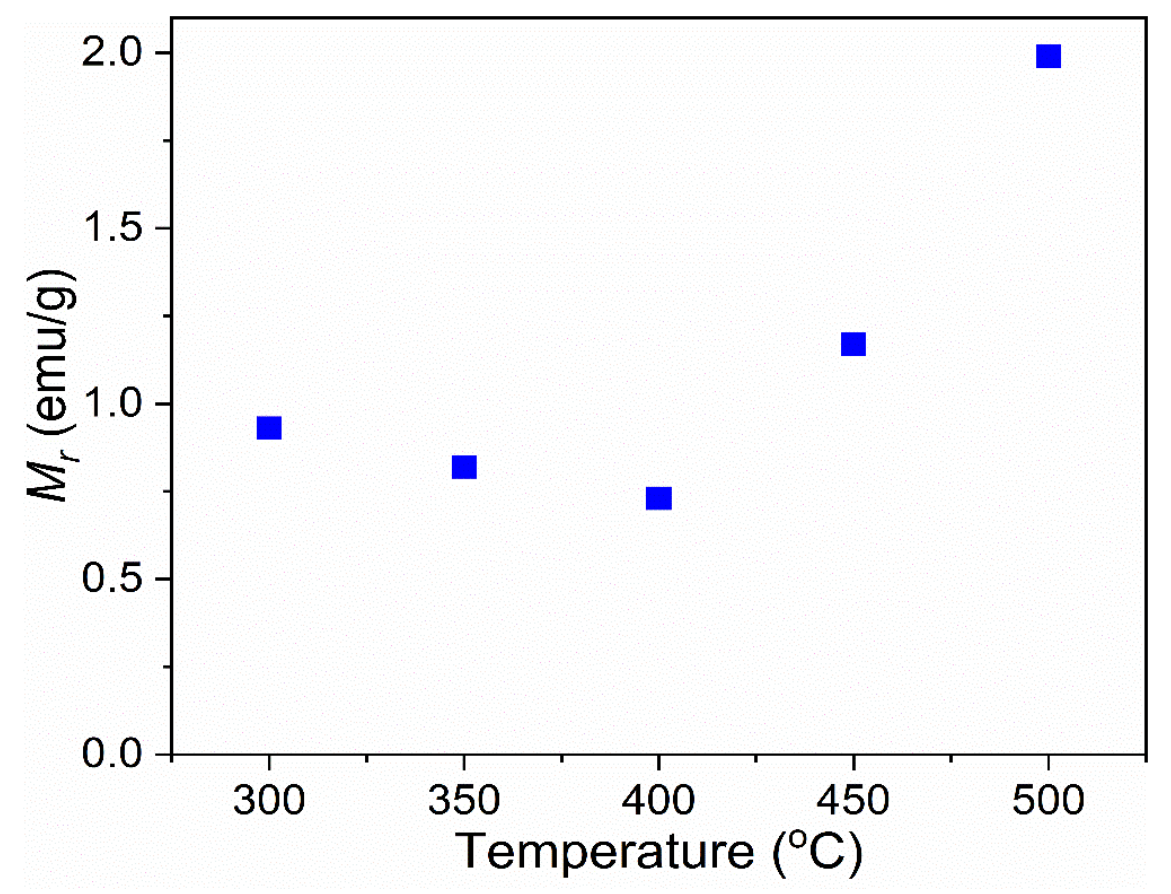

Fig. 23: Remanent magnetization (Mr) of the sludge byproducts derived at different temperatures

\subsubsection{Adsorption Performance}

\subsubsection{Adsorption Kinetics}


Adsorption kinetics of $\mathrm{S} 350$ and $\mathrm{S} 500$ for $\mathrm{PO}_{4}{ }^{3-}-\mathrm{P}$ showed rapid adsorption that reached $98 \%$ and $90 \%$ of the equilibrium capacities at $\mathrm{pH} 7.0$ within 3 hours for S350 and S500 respectively (Fig. 24). Adsorption equilibrium was reached within 24 hours for both samples. For both the adsorbents, pseudo-second-order model characterized the adsorption kinetics well $\left(R^{2}=0.9999\right.$ for $\mathrm{S} 350$ and $R^{2}=0.9982$ for S500). The estimated equilibrium adsorption capacity $\left(q_{e}\right)$ was lower for $\mathrm{S} 500$ than for $\mathrm{S} 350$ (40 vs. $44 \mathrm{mg} \mathrm{PO}_{4}{ }^{3-}$ -P/g-adsorbent), similarly the rate constant was also lower for S500 than S350 (0.001 vs. $0.006 \mathrm{~g} /(\mathrm{mg} \times \mathrm{min}))$. With increasing temperature, samples became more crystalline with larger particle size and thus less specific surface area available for adsorption. This reduction in specific surface area probably leads to the lower equilibrium adsorption capacity for S500. The higher rate constant of S350 than S500 indicates S350 sample reached to equilibrium adsorption capacity faster. The rate constants observed in this study are slightly better than the rate constants observed for pure iron oxide particles, which indicate good adsorption capacity of the treated sludge materials (Ajmal et al., 2018; Yoon et al., 2014).
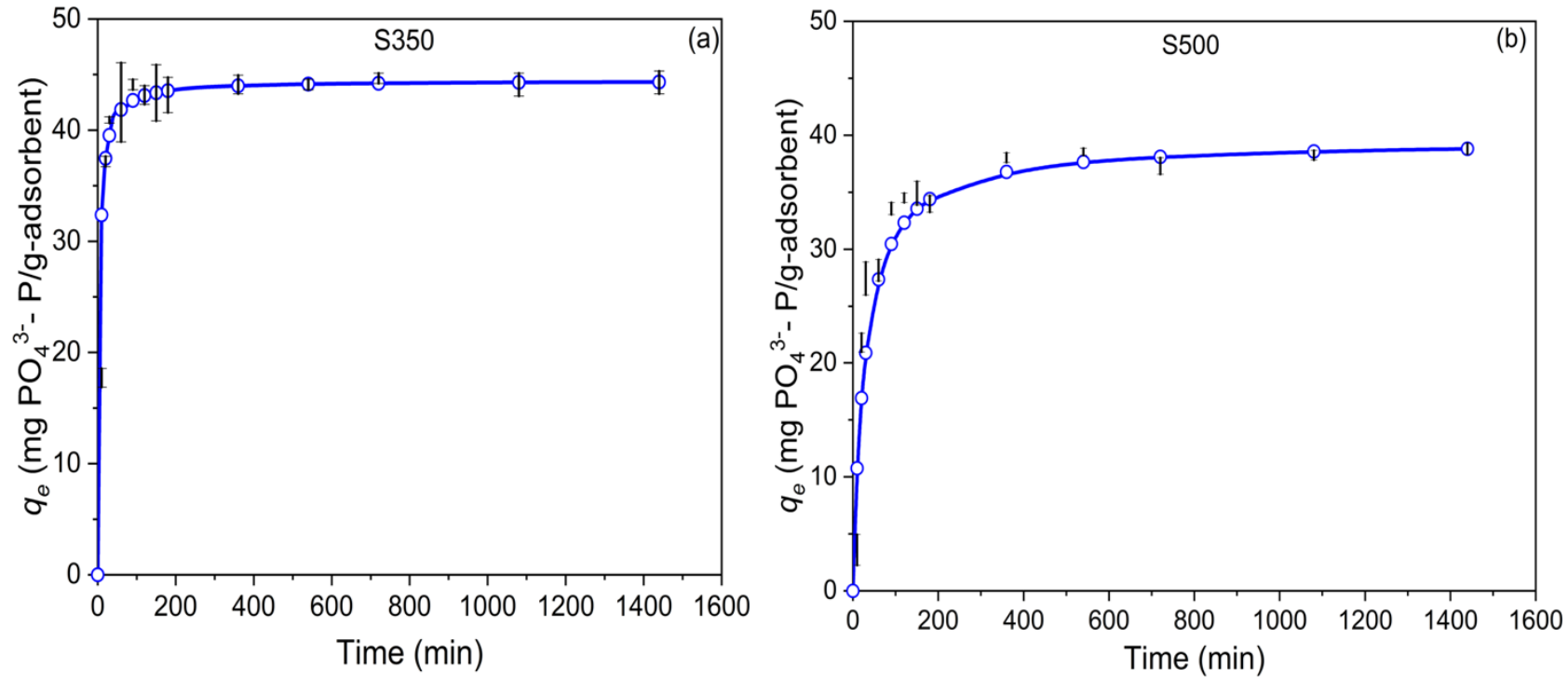

Fig. 24: Adsorption kinetic data and pseudo-second-order kinetic models for (a) S350 and (b) S500 


\subsubsection{Effects of $\mathrm{pH}$}

The effects of $\mathrm{pH}$ on $\mathrm{S} 350$ was examined using initial $\mathrm{PO}_{4}{ }^{3-}-\mathrm{P}$ concentration of $100 \mathrm{mg} / \mathrm{L}$. The adsorption capacity ranged from 31 to $35 \mathrm{mg} \mathrm{PO}{ }_{4}^{3-}-\mathrm{P} / \mathrm{g}$ adsorbent for $\mathrm{pH}$ from 3 to 6. The adsorption capacity decreased considerably at pHs above 6 , leading to about $50 \%$ reduction at $\mathrm{pH} 10.5$ from the acidic conditions (Fig. 25). This pH dependent adsorption of $P$ can be explained by the point of zero charges $\left(\mathrm{pH}_{\mathrm{PZC}}\right.$ ) of magnetite and hematite, which were the dominant minerals in the sludge byproduct. The $\mathrm{pH}$ PzC values of magnetite and hematite were reported to be from 6.5 to 7 in different studies (Čerović et al., 2009; Milonjić et al., 1983; Preočanin et al., 2011). At low pHs (3-6), the adsorbent surface was dominated by positive charges, exhibiting higher electrostatic interactions with anionic phosphate $\left(\mathrm{H}_{2} \mathrm{PO}_{4}{ }^{-}\right.$and $\left.\mathrm{HPO}_{4}{ }^{2-}\right)$ and resulting in better adsorption performance. At $\mathrm{pH}$ above $\mathrm{pH}_{\mathrm{PZC}}$, overall negative surface charges caused adsorption to decline.

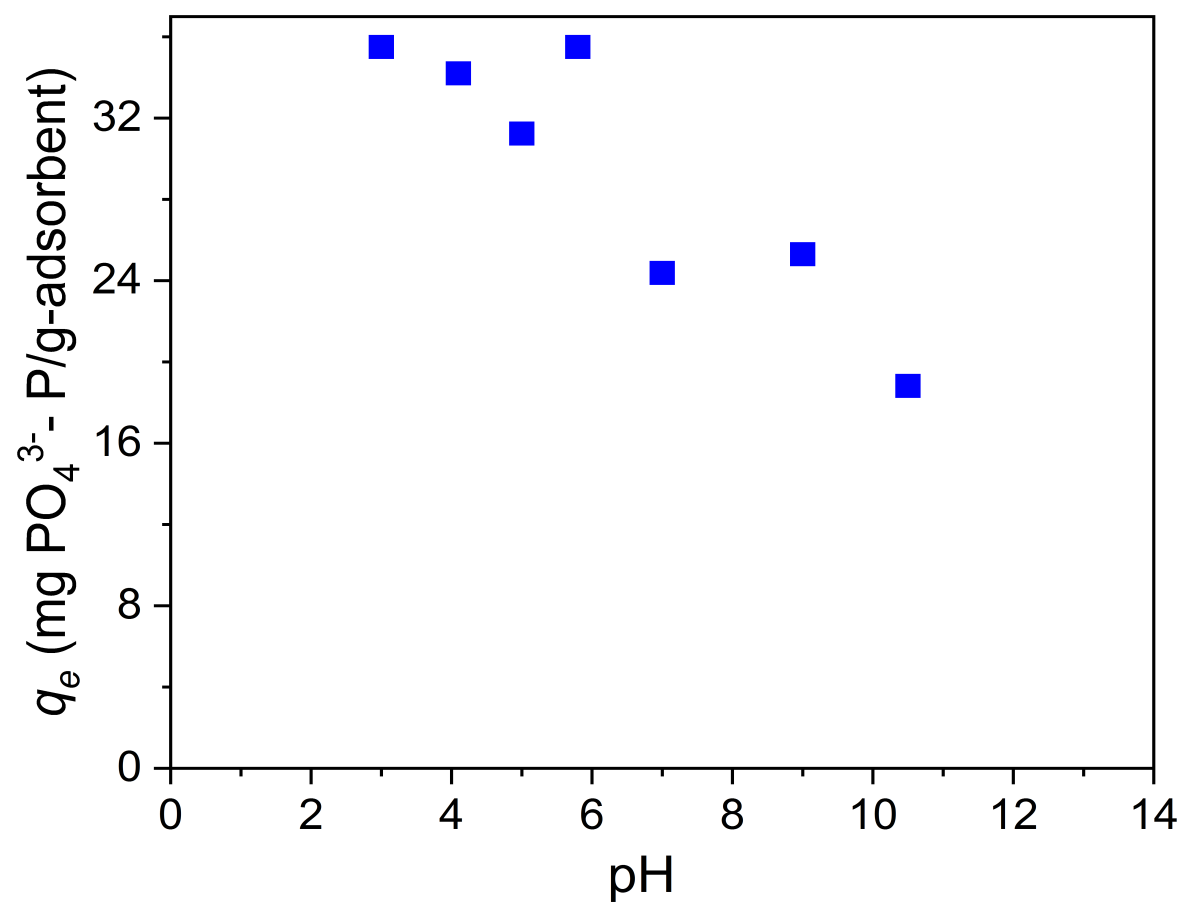

Fig. 25: Adsorption capacity of S350 for phosphate ions

\subsubsection{Adsorption Isotherms}

The adsorption capacities were higher for S350 than S500 at different equilibrium concentrations $(\mathrm{Ce})$. High crystallinity, larger crystals in S500 resulted in lower surface area for adsorption versus low crystalline, smaller crystals in S350. For S350 and S500, 
the adsorption capacities were similar at lower equilibrium concentrations, but showed significant differences at high equilibrium concentrations (Fig. 26). The high adsorption capacities of $\mathrm{S} 350$ and $\mathrm{S} 500$ at high $\mathrm{PO}_{4}{ }^{3-}-\mathrm{P}$ concentrations suggest that these treated sludge materials can be excellent adsorbent for $\mathrm{PO}_{4}{ }^{3-}-\mathrm{P}$ removal from nutrient rich wastewater, e.g., agricultural drainage, urban runoff, industrial wastewater.

According to the $\mathrm{R}^{2}$ values in Table 5, the Langmuir and Freundlich models characterize the isotherm data well for S350. But, for S500, the Freundlich model $\left(R^{2}=0.89\right)$ does not fit as well as Langmuir model $\left(R^{2}=0.95\right)$. For the Langmuir model, the maximum adsorption capacity at $\mathrm{pH} 7.0$ was estimated as 310 and $190 \mathrm{mg} \mathrm{PO}_{4}{ }^{3-}-\mathrm{P} / \mathrm{g}$-adsorbent for S350 and S500, respectively (Fig. 26a). These adsorption capacities are slightly higher than the reported values of iron oxides used as an adsorbent in previous studies (Ajmal et al., 2018; Sousa et al., 2012; Trazzi et al., 2016). The feasibility of $\mathrm{PO}_{4}{ }^{3-}$ adsorption can also be measured with a dimensionless parameter $R_{L}$, expressed as $1 /\left(1+K_{L}{ }^{*} C_{o}\right)$. Adsorption is considered favorable if $R_{L}$ is between 0 and 1 , unfavorable if greater than 1. The average $R_{L}$ was 0.55 and 0.52 for $S 350$ and $S 500$, respectively, indicating their favorable adsorption of $\mathrm{PO}_{4}{ }^{3-}-\mathrm{P}$ from the aqueous solution.

Table 5: Langmuir and Freundlich Isotherm model parameters for S350 and S500

\begin{tabular}{|c|c|c|c|c|c|c|}
\hline \multicolumn{6}{|c|}{ Isotherm Model } \\
\hline \multirow{2}{*}{$\begin{array}{c}\text { Temp. } \\
\left({ }^{\circ} \mathrm{C}\right)\end{array}$} & $\begin{array}{c}q_{\max } \\
\left(\mathrm{mg} \mathrm{PO} 4^{3-}-\mathrm{P} / \mathrm{g}\right. \\
\text { adsorbed })\end{array}$ & $\begin{array}{c}K_{L} \\
(\mathrm{~L} / \mathrm{mg})\end{array}$ & $R^{2}$ & $\begin{array}{c}K_{f} \\
(\mathrm{mg} / \mathrm{g}) \\
(\mathrm{L} / \mathrm{mg})^{1 / n}\end{array}$ & $n$ & $R^{2}$ \\
\hline 350 & 310 & 0.004 & 0.94 & 9.8 & 2.09 & 0.97 \\
\hline 500 & 190 & 0.004 & 0.95 & 5.7 & 2.04 & 0.89 \\
\hline
\end{tabular}

$K_{F}$ values were estimated to be 9.8 and $5.7(\mathrm{mg} / \mathrm{g})(\mathrm{L} / \mathrm{mg})^{1 / \mathrm{n}}$ for $\mathrm{S} 350$ and $\mathrm{S} 500$, respectively. These values are relatively higher than the reported values of iron oxide and iron coated adsorbents (Ajmal et al., 2018; Boujelben et al., 2008) . The high $K_{F}$ values suggest easy uptake of $\mathrm{PO}_{4}{ }^{3-}$ from solution with a high adsorptive capacity of the 
adsorbent. The $K_{F}$ value decreased with increasing baking temperature, which is consistent with results obtained from the Langmuir model fitting. The $n$ values obtained from the Freundlich models lie between one and ten, indicating a favorable sorption process (Krishna and Swamy, 2012). The results obtained from both isotherm models suggest that both the sludge byproducts derived from 350 and $500^{\circ} \mathrm{C}$ thermal treatment can be used to efficiently remove $\mathrm{PO}_{4}{ }^{3-}-\mathrm{P}$ from aqueous solutions.
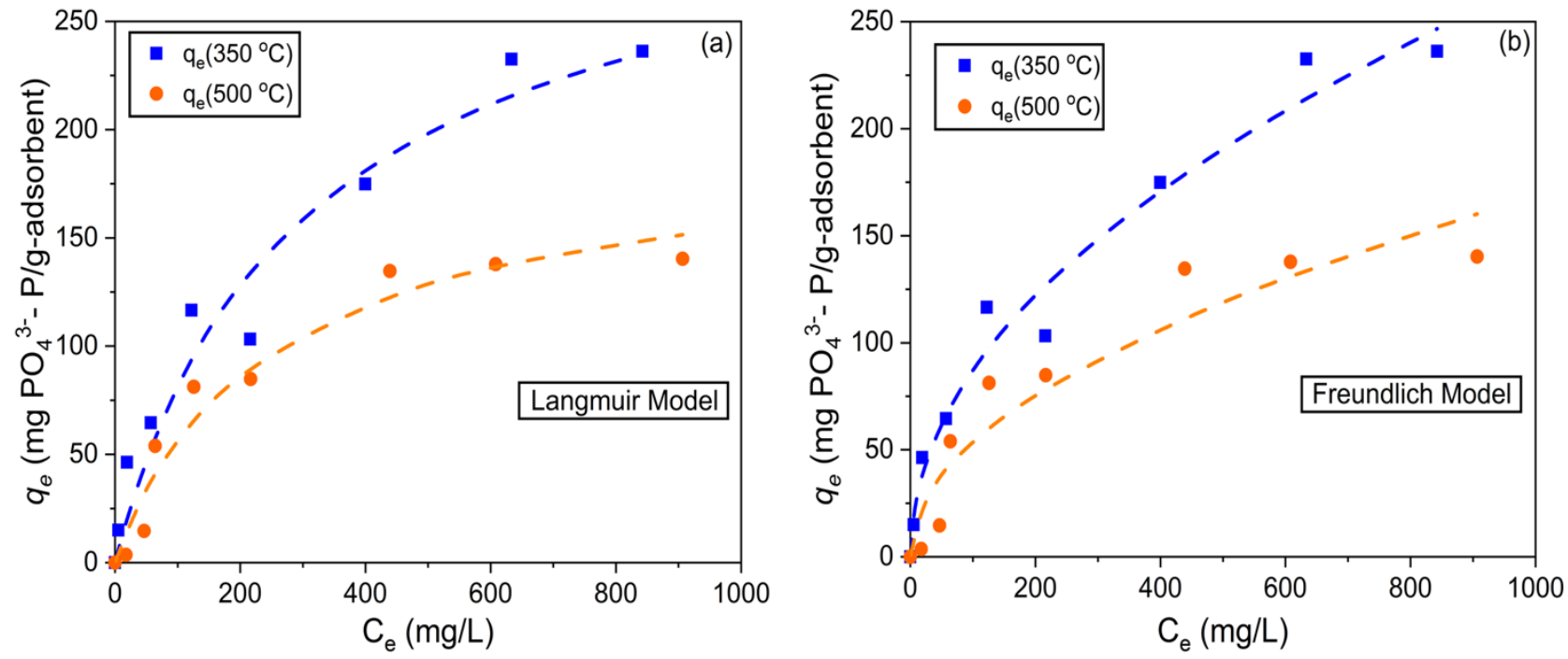

Fig. 26: Adsorption isotherm data, and (a) Langmuir and (b) Freundlich models for S350 and $\mathrm{S} 500$ at $\mathrm{pH} 7.0$

\subsection{Conclusion}

In this study, a simple thermal treatment method was developed to produce magnetic particles from the iron sulfide sludge of a newly developed iron-dosed anaerobic biological treatment system. This innovative approach has demonstrated a potential pathway of recovering useful sludge byproducts while alleviating sludge disposal or management. Extracting sludge and its conversion to magnetic byproducts, and using them for beneficial applications can improve the sustainability of the wastewater treatment system. For practical applications, dewatering of the sludge before the thermal treatment would significantly reduce the energy required for generating the byproducts. There are opportunities of using the magnetic iron oxides (magnetite, maghemite) within the $\mathrm{Fe}$ (III)dosed treatment system for process intensification. For examples, they can be used as a 
coagulant in the primary clarifier or adsorptive phosphate removal from wastewater effluent as a polishing treatment. Alternatively, they can be used as a supplement for iron dosing as an electron acceptor for organics oxidation facilitated by iron reducers. This will reduce the demand of external iron source as well as reduce the environmental footprint of the treatment system. Further studies are also warranted to transform the sludge under controlled conditions (e.g., $\mathrm{O}_{2}$ partial pressure) for better control of the byproduct characteristics (e.g., size, surface magnetic phases) and purification to generate products for targeted applications, such as those in the biomedical field.

\subsection{Supplementary Materials}

Table S1: Saturation magnetization $\left(M_{s}\right)$, Remanent magnetization $\left(M_{r}\right)$ and Coercive field $\left(H_{c}\right)$ at each temperature

\begin{tabular}{|c|c|c|c|}
\hline $\begin{array}{c}\text { Baking } \\
\text { Temperature, } \mathrm{T} \\
\left({ }^{\circ} \mathrm{C}\right)\end{array}$ & $\begin{array}{c}\text { Coercive } \\
\text { Field, } \\
\mathrm{H}_{\mathrm{c}}(\mathrm{Oe})\end{array}$ & $\begin{array}{c}\text { Remanent } \\
\text { Magnetization, } \mathrm{M}_{\mathrm{r}} \\
(\mathrm{emu} / \mathrm{g})\end{array}$ & $\begin{array}{c}\text { Saturation } \\
\text { Magnetization, } \mathrm{M}_{\mathrm{s}} \\
(\mathrm{emu} / \mathrm{g})\end{array}$ \\
\hline 300 & 75 & 0.9 & 7.2 \\
\hline 350 & 50 & 0.8 & 7.8 \\
\hline 400 & 50 & 0.7 & 6.3 \\
\hline 450 & 50 & 1.2 & 10.4 \\
\hline 500 & 100 & 2.0 & 10.9 \\
\hline
\end{tabular}




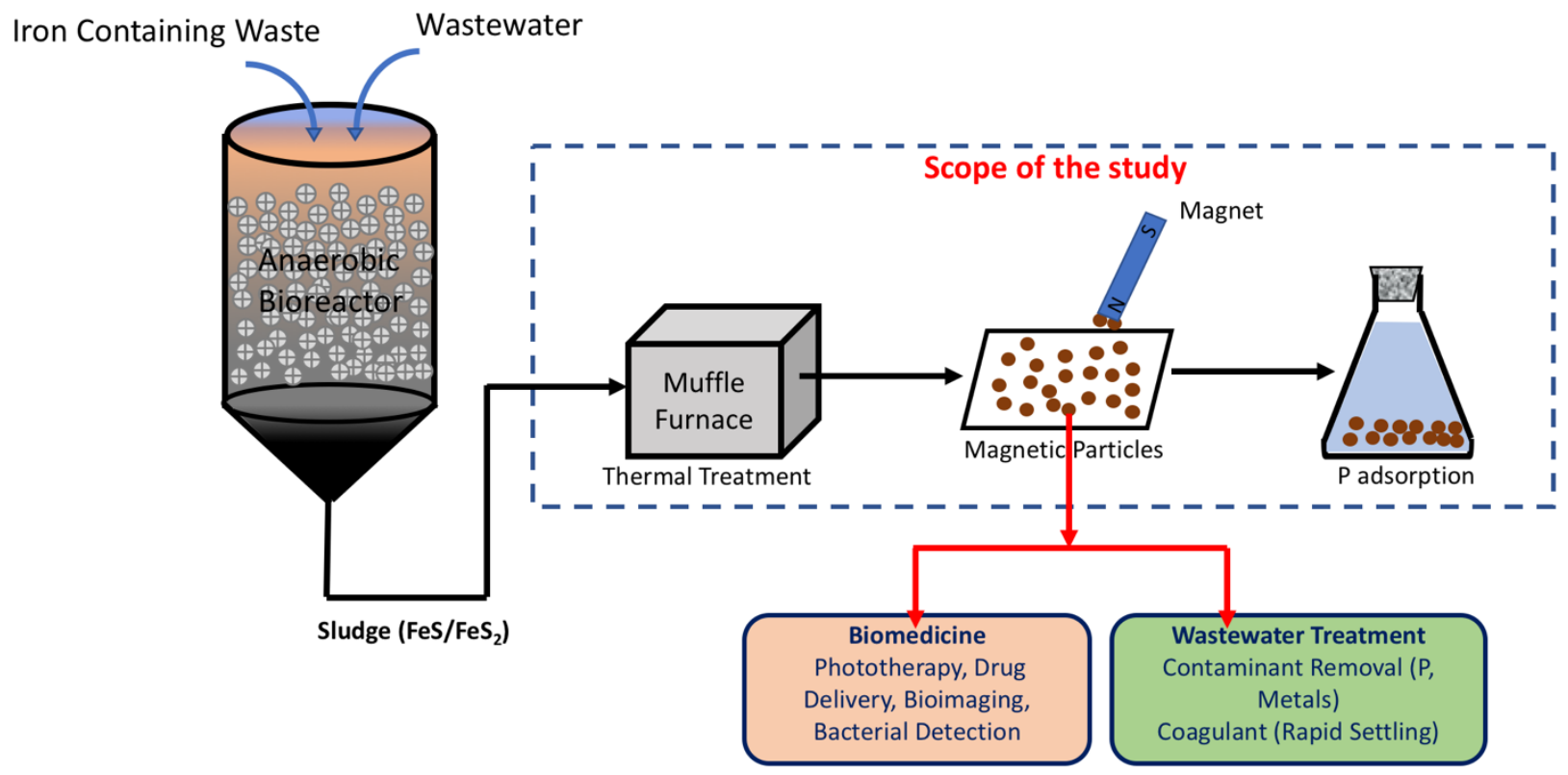

Fig. S9: Schematic diagram depicting the scope of this study

\section{References}

Ahmadi, A., Heidarzadeh, S., Mokhtari, A.R., Darezereshki, E., Harouni, H.A., 2014. Optimization of heavy metal removal from aqueous solutions by maghemite $(\mathrm{y}-$ Fe2O3) nanoparticles using response surface methodology. J. Geochemical Explor. 147, 151-158.

Ahmed, M., Hasan, C.K., Rahman, H., Ali Hossain, M., Uddin, S.A., 2015. Prospects of using wastewater as a resource-nutrient recovery and energy generation. Am. J. Environ. Sci. https://doi.org/10.3844/ajessp.2015.99.114

Ahmed, M., Lin, O., Saup, C.M., Wilkins, M.J., Lin, L.S., 2019. Effects of Fe/S ratio on the kinetics and microbial ecology of an Fe(III)-dosed anaerobic wastewater treatment system. J. Hazard. Mater. 369, 593-600. https://doi.org/10.1016/j.jhazmat.2019.02.062

Ahmed, M., Saup, C.M., Wilkins, M.J., Lin, L.-S., 2020. Continuous ferric iron-dosed anaerobic wastewater treatment: treatment perfromance, sludge characteristics, and mirobial composition. J. Environ. Chem. Eng. 8. https://doi.org/10.1016/j.jece.2019.103537

Ahmed, M.A., Ali, S.M., El-Dek, S.I., Galal, A., 2013. Magnetite-hematite nanoparticles prepared by green methods for heavy metal ions removal from water. Mater. Sci. Eng. B 178, 744-751. https://doi.org/10.1016/j.mseb.2013.03.011

Ajmal, Z., Muhmood, A., Usman, M., Kizito, S., Lu, J., Dong, R., Wu, S., 2018. Phosphate removal from aqueous solution using iron oxides: Adsorption, desorption and regeneration characteristics. J. Colloid Interface Sci. 528, 145-155. https://doi.org/10.1016/j.jcis.2018.05.084

Ali, A., Zafar, H., Zia, M., ul Haq, I., Phull, A.R., Ali, J.S., Hussain, A., 2016. Synthesis, characterization, applications, and challenges of iron oxide nanoparticles. 
Nanotechnol. Sci. Appl. 9, 49-67. https://doi.org/10.2147/NSA.S99986

Anderson, N.J., Blesing, N. V., Bolto, B.A., Jackson, M.B., 1987. The role of polyelectrolytes in a magnetic process for water clarification. React. Polym. ion Exch. Sorbents 7, 47-55.

Ansar, M.Z., Atiq, S., Riaz, S., Naseem, S., 2015. Magnetite Nano-crystallites for Anticancer Drug Delivery, in: International Conference on Solid State Physics 2013. Elsevier Ltd., pp. 5410-5414. https://doi.org/10.1016/j.matpr.2015.11.060

Ansari, S.A.M.K., Ficiarà, E., Ruffinatti, F.A., Stura, I., Argenziano, M., Abollino, O., Cavalli, R., Guiot, C., D'Agata, F., 2019. Magnetic iron oxide nanoparticles: Synthesis, characterization and functionalization for biomedical applications in the Central Nervous System. Materials (Basel). 12, 1-24. https://doi.org/10.3390/ma12030465

Antakyali, D., Meyer, C., Preyl, V., Maier, W., Steinmetz, H., 2013. Large-scale application of nutrient recovery from digested sludge as struvite. Water Pract. Technol. 8, 256-262. https://doi.org/10.2166/wpt.2013.027

APHA, AWWA, WEF, 2005. Standard methods for the examination of water and wastewater, 21st ed. American Public Health Association,American water Works Association, and Water Environment Federation.

Aziziha, M., Beesley, R., Magers, J.R., Mottaghi, N., Holcomb, M.B., Lewis, J.P., Seehra, M.S., Johnson, M.B., 2019a. Electronic state and concentration of $\mathrm{Fe}^{3+}$ in $\mathrm{CuAl} 1-\mathrm{xFexO}{ }_{2}$ determined by magnetic measurements. J. Magn. Magn. Mater. 471, 495-500.

Aziziha, M., Byard, S.A., Beesely, R., Lewis, J.P., Seehra, M.S., Johnson, M.B., 2019b. Magnetic properties of $\mathrm{Fe}$-doped $\mathrm{CuAlO}_{2}$ and role of impurities. AlP Adv. 9. https://doi.org/10.1063/1.5080099

Bao, L., Yang, H., Wang, X., Zhang, F., Shi, R., Liu, B., Wang, L., Zhao, H., 2011. Synthesis and size-dependent magnetic properties of single-crystalline hematite nanodiscs. J. Cryst. Growth 328, 62-69. https://doi.org/10.1016/j.jcrysgro.2011.05.030

Berner, R.A., 1973. Phosphate removal from sea water by adsorption on volcanogenic ferric oxides. Earth Planet. Sci. Lett. 18, 77-86. https://doi.org/10.1016/0012821X(73)90037-X

Bish, D.L., Howard, S.A., 1988. Quantitative phase analysis using the Rietveld method. J. Appl. Crystallogr. 21, 86-91. https://doi.org/10.1107/S0021889887009415

Booker, N.A., Keir, D., Priestley, A.J., Ritchie, C.B., Sudarmana, D.L., Woods, M.A., 1991. Sewage clarification with magnetite particles. Water Sci. Technol. 23, 1703-1712. https://doi.org/10.2166/wst.1991.0625

Booker, N.A., Priestley, A.J., Fraser, I.H., 1999. Struvite formation in wastewater treatment plants: Opportunities for nutrient recovery. Environ. Technol. 20, 777-782.

Boujelben, N., Bouzid, J., Elouear, Z., Feki, M., Jamoussi, F., Montiel, A., 2008. Phosphorus removal from aqueous solution using iron coated natural and engineered sorbents. J. Hazard. Mater. 151, 103-110. https://doi.org/10.1016/j.jhazmat.2007.05.057

Byrne, J.M., Telling, N.D., Coker, V.S., Pattrick, R.A.D., Van Der Laan, G., Arenholz, E., Tuna, F., Lloyd, J.R., 2011. Control of nanoparticle size, reactivity and magnetic properties during the bioproduction of magnetite by Geobacter sulfurreducens. 
Nanotechnology 22. https://doi.org/10.1088/0957-4484/22/45/455709

Campbell, H.W., 2000. Sludge management - Future issues and trends. Water Sci. Technol. 41, 1-8.

Cao, Y., Pawłowski, A., 2012. Sewage sludge-to-energy approaches based on anaerobic digestion and pyrolysis: Brief overview and energy efficiency assessment. Renew. Sustain. Energy Rev. 16, 1657-1665. https://doi.org/10.1016/j.rser.2011.12.014

Čerović, L., Lefèvre, G., Jaubertie, A., Fédoroff, M., Milonjić, S., 2009. Deposition of hematite particles on polypropylene walls in dynamic conditions. J. Colloid Interface Sci. 330, 284-291. https://doi.org/10.1016/j.jcis.2008.10.079

Chaubey, G.S., Nandwana, V., Poudyal, N., Rong, C.B., Ping Liu, J., 2008. Synthesis and characterization of bimagnetic bricklike nanoparticles. Chem. Mater. 20, 475478. https://doi.org/10.1021/cm7028068

Chiavola, A., D'Amato, E., Stoller, M., Chianese, A., Boni, M.R., 2016. Application of iron based nanoparticles as adsorbents for Arsenic removal from water. Chem. Eng. Trans. 47, 325-330. https://doi.org/10.3303/CET1647055

Cies̈lik, B.M., Namies̈nik, J., Konieczka, P., 2015. Review of sewage sludge management: Standards, regulations and analytical methods. J. Clean. Prod. 90, 115. https://doi.org/10.1016/j.jclepro.2014.11.031

Dada, A.O., Olalekan, A.P., Olatunya, A.M., Dada, O., 2012. Langmuir, Freundlich, Temkin and Dubinin-Radushkevich Isotherms Studies of Equilibrium Sorption of $\mathrm{Zn}$ 2+ Unto Phosphoric Acid Modified Rice Husk. IOSR J. Appl. Chem. 3, 38-45. https://doi.org/10.9790/5736-0313845

Dar, M.I., Shivashankar, S.A., 2014. Single crystalline magnetite, maghemite, and hematite nanoparticles with rich coercivity. RSC Adv. 4, 4105-4113. https://doi.org/10.1039/c3ra45457f

Dave, P.N., Chopda, L. V., 2014. Application of iron oxide nanomaterials for the removal of heavy metals. J. Nanotechnol. 2014. https://doi.org/10.1155/2014/398569

De La Torre, A.G., Bruque, S., Aranda, M.A.G., 2001. Rietveld quantitative amorphous content analysis. J. Appl. Crystallogr. 34, 196-202. https://doi.org/10.1107/S0021889801002485

Demortière, A., Panissod, P., Pichon, B.P., Pourroy, G., Guillon, D., Donnio, B., BéginColin, S., 2011. Size-dependent properties of magnetic iron oxide nanocrystals. Nanoscale 3, 225-232. https://doi.org/10.1039/c0nr00521e

Desta, M.B., 2013. Batch Sorption Experiments: Langmuir and Freundlich Isotherm Studies for the Adsorption of Textile Metal Ions onto Teff Straw (Eragrostis tef) Agricultural Waste Mulu. J. Thermodyn. 61, 1-6. https://doi.org/10.1080/00380768.2015.1020506

El-Dib, F.I., Mohamed, D.E., El-Shamy, O.A.A., Mishrif, M.R., 2019. Study the adsorption properties of magnetite nanoparticles in the presence of different synthesized surfactants for heavy metal ions removal. Egypt. J. Pet. 0-6. https://doi.org/10.1016/j.ejpe.2019.08.004

EPA, 2000. Land Application of Biosolids, in: Biosolids Technology Fact Sheet. pp. 1-9.

Farhanian, D., De Crescenzo, G., Tavares, J.R., 2018. Large-Scale Encapsulation of Magnetic Iron Oxide Nanoparticles via Syngas Photo-Initiated Chemical Vapor Deposition. Sci. Rep. 8, 1-11. https://doi.org/10.1038/s41598-018-30802-1

Giraldo, L., Erto, A., Moreno-Piraján, J.C., 2013. Magnetite nanoparticles for removal of 
heavy metals from aqueous solutions: Synthesis and characterization. Adsorption 19, 465-474. https://doi.org/10.1007/s10450-012-9468-1

Gong, Y., Tang, J., Zhao, D., 2016. Application of iron sulfide particles for groundwater and soil remediation: A review. Water Res. 89, 309-320. https://doi.org/10.1016/j.watres.2015.11.063

Hogemann, D., Josephson, L., Weissleder, R., Basilion, J.P., 2000. Improvement of MRI probes to allow efficient detection of gene expression. Bioconjug. Chem. 11, 941946. https://doi.org/10.1021/bc000079x

$\mathrm{Hu}, \mathrm{H}$. , Li, X., Nguyen, A.D., Kavan, P., 2015. A critical evaluation of waste incineration plants in Wuhan (China) based on site selection, environmental influence, public health and public participation. Int. J. Environ. Res. Public Health 12, 7593-7614. https://doi.org/10.3390/ijerph120707593

Hu, J., Chen, G., Lo, I.M.C., 2006. Selective Removal of Heavy Metals from Industrial Wastewater Using Maghemite Nanoparticle: Performance and Mechanisms. J. Environ. Eng. 132, 709-715. https://doi.org/10.1061/(ASCE)0733-9372(2006)132

Josephson, L., Perez, J.M., Weissleder, R., 2001. Magnetic Nanosensors for the Detection of Oligonucleotide Sequences. Angew. Chemie 113, 3204-3206.

Karatza, D., Lancia, A., Prisciandaro, M., Musmarra, D., Mazziotti Di Celso, G., 2013. Influence of oxygen on adsorption of elemental mercury vapors onto activated carbon. Fuel 111, 485-491. https://doi.org/10.1016/j.fuel.2013.03.068

Khan, U.S., Amanullah, Manan, A., Khan, N., Mahmood, A., Rahim, A., 2015. Transformation mechanism of magnetite nanoparticles. Mater. Sci. Pol. 33, 278-285. https://doi.org/10.1515/msp-2015-0037

Krishna, R.H., Swamy, A.V.V.S., 2012. Physico-Chemical Key Parameters, Langmuir and Freundlich isotherm and Lagergren Rate Constant Studies on the removal of divalent nickel from the aqueous solutions onto powder of calcined brick. Int. J. Eng. Res. Dev. 4, 2278-67.

Lee, Y., Lee, J., Bae, C.J., Park, J.G., Noh, H.J., Park, J.H., Hyeon, T., 2005. Large-scale synthesis of uniform and crystalline magnetite nanoparticles using reverse micelles as nanoreactors under reflux conditions. Adv. Funct. Mater. 15, 503-509. https://doi.org/10.1002/adfm.200400187

Liu, J., Wu, Z., Tian, Q., Wu, W., Xiao, X., 2016. Shape-controlled iron oxide nanocrystals: Synthesis, magnetic properties and energy conversion applications. CrystEngComm 18, 6303-6326. https://doi.org/10.1039/c6ce01307d

Marusak, L., Walker, P., Mulay, L., 1976. The magnetokinetics of oxidation of pyrite $\left(\mathrm{FeS}_{2}\right)$. IEEE Trans. Magn. 12, 889-891.

Milonjić, S.K., Kopečni, M.M., Ilić, Z.E., 1983. The point of zero charge and adsorption properties of natural magnetite. J. Radioanal. Chem. 78, 15-24. https://doi.org/10.1007/BF02519745

Molino, A., Erto, A., Natale, F. Di, Donatelli, A., lovane, P., Musmarra, D., 2013. Gasification of Granulated Scrap Tires for the Production of Syngas and a Low-Cost Adsorbent for Cd(II) Removal from Wastewaters. Ind. Eng. Chem. Res. 52, 1215412160.

Nassar, N.N., 2012. Iron Oxide Nanoadsorbents for Removal of Various Pollutants from Wastewater: An Overview. Appl. Adsorbents Water Pollut. Control 81-118. https://doi.org/10.2174/978160805269111201010081 
Nikiforov, V.N., Goldt, A.E., Gudilin, E.A., Sredin, V.G., Irhin, V.Y., 2014. Magnetic properties of maghemite nanoparticles. Bull. Russ. Acad. Sci. Phys. 78, 1075-1080. https://doi.org/10.3103/S1062873814100141

Nishihara, K., Kondo, Y., 1959. Studies of the oxidation of Pyrite I. Mem. Fac. Eng. Kyoto Univ. 20, 285-306.

Oliveira, L.C.A., Rios, R.V.R.A., Fabris, J.D., Garg, V., Sapag, K., Lago, R.M., 2002. Activated carbon/iron oxide magnetic composites for the adsorption of contaminants in water. Carbon N. Y. 40, 2177-2183. https://doi.org/10.1016/S00086223(02)00076-3

Olugasa, T.T., Odesola, I.F., Oyewola, M.O., 2014. Energy production from biogas: A conceptual review for use in Nigeria. Renew. Sustain. Energy Rev. 32, 770-776. https://doi.org/10.1016/j.rser.2013.12.013

Özdemir, Ö., Dunlop, D.J., 2014. Hysteresis and coercivity of hematite. J. Geophys. Res. Solid Earth 119, 2582-2594. https://doi.org/10.1002/2014JB011376.Received

Patterson, A.L., 1939. The scherrer formula for X-ray particle size determination. Phys. Rev. 56, 978-982. https://doi.org/10.1103/PhysRev.56.978

Preočanin, T., Stipić, F., Selmani, A., Kallay, N., 2011. Surface Potential of Polycrystalline Hematite in Aqueous Medium. Int. J. Electrochem. 2011, 1-6. https://doi.org/10.4061/2011/412731

Roberts, R.J., Chen, M., 2006. Waste incineration - How big is the health risk? A quantitative method to allow comparison with other health risks. J. Public Health (Bangkok). 28, 261-266. https://doi.org/10.1093/pubmed/fdl037

Saeed, M., Ren, W., Wu, A., 2018. Therapeutic applications of iron oxide based nanoparticles in cancer: basic concepts and recent advances. Biomater. Sci. 6, 708725.

Scherrer, P., 1912. Determination of the internal structure and size of colloid particles using X-rays, in: Colloid Chemistry A Textbook. Springer, Berlin, Heidelberg. https://doi.org///doi.org/10.1007/978-3-662-33915-2_7

Shahid, M.K., Kim, Y., Choi, Y.-G., 2019. Adsorption of phosphate on magnetite-enriched particles (MEP) separated from the mill scale. Front. Environ. Sci. Eng. 13.

Sousa, A.F. de, Braga, T.P., Gomes, E.C.C., Valentini, A., Longhinotti, E., 2012. Adsorption of phosphate using mesoporous spheres containing iron and aluminum oxide. Chem. Eng. J. 210, 143-149. https://doi.org/10.1016/j.cej.2012.08.080

Teja, A.S., Koh, P.-Y., 2009. Synthesis, properties, and applications of magnetic iron oxide nanoparticles. Prog. Cryst. Growth Charact. Mater. 55, 22-45.

Thorpe, A.N., Senftle, F.E., Alexander, C.C., Dulong, F.T., 1984. Oxidation of pyrite in coal to magnetite. Fuel 63, 662-668. https://doi.org/10.1016/0016-2361(84)90163-7

Tian, N., Tian, X., Ma, L., Yang, C., Wang, Y., Wang, Z., Zhang, L., 2015. Well-dispersed magnetic iron oxide nanocrystals on sepiolite nanofibers for arsenic removal. RSC Adv. 5, 25236-25243.

Trazzi, P.A., Leahy, J.J., Hayes, M.H.B., Kwapinski, W., 2016. Adsorption and desorption of phosphate on biochars. J. Environ. Chem. Eng. 4, 37-46. https://doi.org/10.1016/J.JECE.2015.11.005

Uggetti, E., Ferrer, I., Llorens, E., García, J., 2010. Sludge treatment wetlands: A review on the state of the art. Bioresour. Technol. 101, 2905-2912. https://doi.org/10.1016/j.biortech.2009.11.102 
Van, D.P., Fujiwara, T., Leu Tho, B., Song Toan, P.P., Hoang Minh, G., 2019. A review of anaerobic digestion systems for biodegradable waste: Configurations, operating parameters, and current trends. Environ. Eng. Res. 25, 1-17. https://doi.org/10.4491/eer.2018.334

Vrieze, J. De, Smet, D., Klok, J., Colsen, J., Angenent, L.T., Vlaemnick, S.E., 2016. Thermophilic sludge digestion improves energy balance and nutrient recovery potential in full-scale municipal wastewater treatment plants. Bioresour. Technol. 218, 1237-1245.

Wang, L., Pan, Y.X., Li, J.H., Qin, H.F., 2008. Magnetic properties related to thermal treatment of pyrite. Sci. China, Ser. D Earth Sci. 51, 1144-1153. https://doi.org/10.1007/s11430-008-0083-7

Waters, K.E., Rowson, N.A., Greenwood, R.W., Williams, A.J., 2008. The effect of heat treatment on the magnetic properties of pyrite. Miner. Eng. 21, 679-682. https://doi.org/10.1016/j.mineng.2008.01.008

Weller, D., McDaniel, T., 2006. Media for Extremely High Density Recording, in: Sellmyer, D., Skomski, R. (Eds.), Advanced Magnetic Nanostructures. Springer, Boston, MA.

Willis, A.L., Turro, N.J., O'Brien, S., 2005. Spectroscopic characterization of the surface of iron oxide nanocrystals. Chem. Mater. 17, 5970-5975. https://doi.org/10.1021/cm051370v

Wu, W., He, Q., Jiang, C., 2008. Magnetic iron oxide nanoparticles: Synthesis and surface functionalization strategies. Nanoscale Res. Lett. 3, 397-415. https://doi.org/10.1007/s11671-008-9174-9

Xu, C., Akakuru, O.U., Zheng, J., Wu, A., 2019. Applications of iron oxide-based magnetic nanoparticles in the diagnosis and treatment of bacterial infections. Front. Bioeng. Biotechnol. 7, 1-15. https://doi.org/10.3389/fbioe.2019.00141

Xu, J., Yang, H., Fu, W., Du, K., Sui, Y., Chen, J., Zeng, Y., Li, M., Zou, G., 2007. Preparation and magnetic properties of magnetite nanoparticles by sol-gel method. J. Magn. Magn. Mater. 309, 307-311. https://doi.org/10.1016/j.jmmm.2006.07.037

Yang, G., Zhang, G., Wang, H., 2015. Current state of sludge production, management, treatment and disposal in China. Water Res. 78, 60-73. https://doi.org/10.1016/j.watres.2015.04.002

Yang, Y., Chen, T., Sumona, M., Gupta, B. Sen, Sun, Y., Hu, Z., Zhan, X., 2017. Utilization of iron sulfides for wastewater treatment: a critical review. Rev. Environ. Sci. Biotechnol. 16, 289-308. https://doi.org/10.1007/s11157-017-9432-3

Yoon, S.Y., Lee, C.G., Park, J.A., Kim, J.H., Kim, S.B., Lee, S.H., Choi, J.W., 2014. Kinetic, equilibrium and thermodynamic studies for phosphate adsorption to magnetic iron oxide nanoparticles. Chem. Eng. J. 236, 341-347. https://doi.org/10.1016/j.cej.2013.09.053 


\section{Chapter 6: Chemical Fate of Nutrients and Their Recovery Potential Through the Fe(III)-dosed Wastewater Treatment}

\subsection{Introduction}

The previous studies have demonstrated feasibility of organics removal from wastewater using ferric iron, $\mathrm{Fe}(\mathrm{III})$ as an electron acceptor in an innovative anaerobic wastewater treatment (Ahmed et al., 2020; 2019). This has opened a new avenue for value creation through using iron containing wastes in managing wastewater. Given that iron is a redox active element and its wide range of biogeochemical reactions, this iron-dosed treatment method has also potential benefits of removing and recovering nutrients from wastewater. Nitrogen $(\mathrm{N})$ and phosphorus $(\mathrm{P})$ are critical pollutants to the environment and their excess loadings have caused widespread eutrophication in receiving waterbodies worldwide (Ærtebjerg et al., 2003; De Jonge et al., 2002). Excessive amount of $\mathrm{N}$ and $\mathrm{P}$ can cause serious impact on biodiversity, species composition and water as well as air quality (Olajire and Imeokparia, 2001; Wang et al., 2016).

Typically, wastewater contains $\mathrm{N}$ as primarily ammonium $\left(\mathrm{NH}_{4}{ }^{+}\right)$form with concentration ranging from 12 to $50 \mathrm{mg} / \mathrm{L}$, and $\mathrm{P}$ as phosphate $\left(\mathrm{PO}_{4}{ }^{3-}\right)$ form with concentration ranging from 4 to $12 \mathrm{mg} / \mathrm{L}$ (Metcalf \& Eddy et al., 2014). Various chemical and biological methods have been established for nutrient removal from wastewater. Ammonium stripping and ion-exchange were the most common physiochemical methods for $\mathrm{N}$ removal, but have not gained much attention due to higher sludge production than biological method and low efficiency in $\mathrm{N}$ removal (Cooper et al., 1994; Lahav and Green, 2000). Biological nitrification/denitrification method has shown comparatively better ammonium removal efficiency. However, maintaining enough presence of organics in the denitrification step, recirculation of sewage sludge or addition of synthetic carbon is required, which makes it an expensive approach (Farazaki and Gikas, 2019; Reboleiro-Rivas et al., 2015). Application of soluble salts (e.g. aluminum sulfate, ferric chloride, calcium hydroxide) were found effective in $\mathrm{P}$ removal, but the approach is not feasible due to expensive chemical dosing and P-rich sludge management (Pratt et al., 2012). Enhanced biological phosphorous removal (EBPR) requires an additional anaerobic stage prior to the aeration tank of the wastewater treatment plant. In this process, selective strains of bacteria such 
as Acinetobacter store large amount of $\mathrm{P}$ as polyphosphate within the bacteria cell. These bacteria are responsible for the high $\mathrm{P}$ content of EBPR sludge. Due to the fluctuating performance and high dependency on skilled operators, EBPR is also recognized as a complex process and unreliable at community level (Blackall et al., 2002; Bunce et al., 2018).

Nutrients can be recovered from wastewater and sewage sludge by various physiochemical, chemical and biological techniques which include ammonia stripping, ion exchange, bioelectrochemical systems, struvite precipitation, constructed wetlands, nanofiltration, and chemical reduction (Cornel and Schaum, 2009; Miles and Ellis, 2001; Sengupta et al., 2015). Some of these methods (e.g. struvite precipitation, ammonia stripping and adsorption, air scrubbing, membrane filtration) were used for nutrient recovery from anaerobic digestate to be used as fertilizers (Vaneeckhaute et al., 2017). Using digestate for nutrient recovery has high potential in nutrient-rich regions, but, in most of the cases, they cannot ensure high quality end-product that can be used as fertilizers. Due to this reason, the use of recovered bio-based fertilizers are not encouraged by the environmental legislators. Moreover, these nutrient recovery techniques have several limitations which include scale formation for struvite precipitation, low recovery efficiency for ammonia adsorption and bioelectrochemical systems, and high operational costs for air stripping (Ahmed et al., 2015; Vaneeckhaute et al., 2017). Thus, novel technologies with better applicability need to be explored for nutrient recovery from wastewater.

A few previous studies have investigated $\mathrm{NH}_{4}{ }^{+}$oxidation under iron reducing condition by a bacterial-mediated process, in which ferric reduction is coupled to ammonium $\left(\mathrm{NH}_{4}{ }^{+}\right)$ oxidation (denoted as Feammox). In this process, $\mathrm{NH}_{4}{ }^{+}$was oxidized to either nitrite $\left(\mathrm{NO}_{2}{ }^{-}\right)$, nitrate $\left(\mathrm{NO}_{3}{ }^{-}\right)$or nitrogen $\left(\mathrm{N}_{2}\right)$ when ferric, $\mathrm{Fe}(\mathrm{III})$ is reduced to ferrous, $\mathrm{Fe}(\mathrm{II})$ (Clément et al., 2005; Huang and Jaffé, 2015; Yang et al., 2012) (Fig. 27). Until now, most of the studies related to Feammox were reported in wetland soils (Li et al., 2015; Shrestha et al., 2009), tropical forest soil (Yang et al., 2012), paddy soil (Ding et al., 2014), and sediments (Yao et al., 2019). In the Fe(III)-dosed anaerobic biological treatment of wastewater, Feammox could be a microbial process for $\mathrm{N}$ removal. Such a nitrogen 
removal mechanism is expected to be greatly affected by competition between heterotrophic iron reducing bacteria (IRB) and autotrophic Feammox bacteria. Heterotrophic IRB can outcompete Feammox bacteria for ferric iron and suppress the autotrophs when organics is not limited given that organic carbon is thermodynamically more favorable than $\mathrm{NH}_{4}{ }^{+}$as an electron donor. This is supported by a previous study showing decreasing Feammox rate with increasing organic carbon in a soil system (Clément et al., 2005). In a previous study on riparian wetland soils, Acidimicrobiaceae bacterium A6, an autotrophic bacterium utilizing inorganic carbon as carbon source, was found to be the predominant bacterial species responsible for Feammox reaction with continuous $\mathrm{NH}_{4}{ }^{+}$supply (Huang and Jaffé, 2018, 2015). Presence of Geobacter, a known IRB, was observed in these studies at the initial inoculation period, but their abundance gradually decreased without additional supply of organic carbon. In the Fe(III)-dosed anaerobic wastewater treatment, enough $\mathrm{Fe}^{3+}$ concentration would be a crucial factor so that $\mathrm{NH}_{4}{ }^{+}$oxidation can occur after sufficient organics removal by heterotrophic IRB.

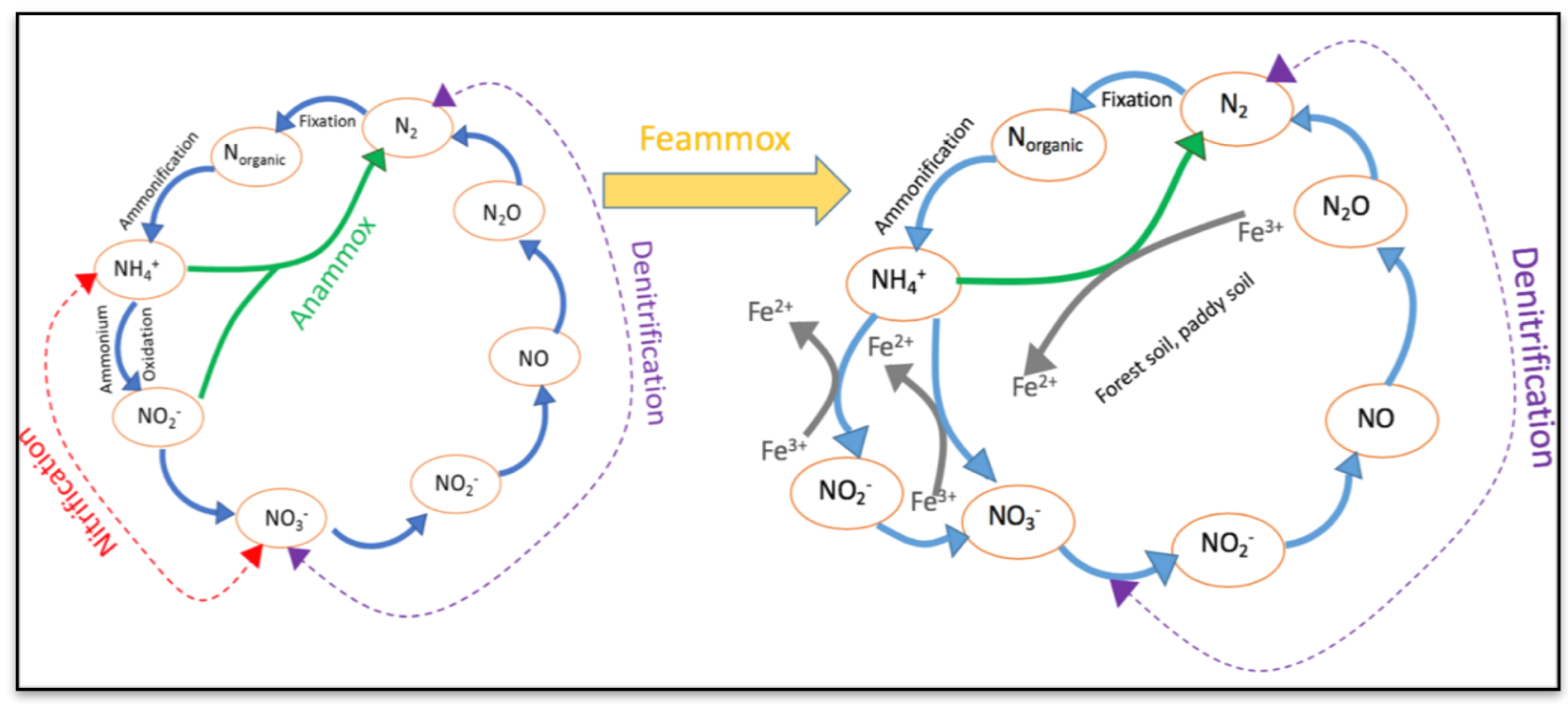

Fig. 27: Adaptation of the $\mathrm{N}$ - cycle in the Feammox reaction for $\mathrm{NH}_{4}{ }^{+}$oxidation Iron has commonly been used as a coagulant for $\mathrm{P}$ removal. Continuous ferric iron dosing in the bioreactor, $\mathrm{P}$ is expected to form $\mathrm{FePO}_{4}$ precipitate as a mechanism of $\mathrm{P}$ removal from wastewater. A potential mechanism in the bioreactor is the formation of ferrous ammonium phosphate (FAP) given the presence of biogenic ferrous ion, ammonium, and 
phosphate. FAP, an insoluble compound at circumneutral $\mathrm{pH}$, is mainly used as food fortificant (Walczyk et al., 2013), and has the potential to use as a form of fertilizer given its nutrient content. The main objective of this study is to investigate the chemical fate of nutrients $\left(\mathrm{N}\right.$ and $\mathrm{P}$ ) along with organics and sulfate $\left(\mathrm{SO}_{4}{ }^{2-}\right)$ transformations in the $\mathrm{Fe}(\mathrm{III})$ dosed anaerobic bioreactor used for wastewater treatment. This study is very relevant to developing innovative and energy-efficient treatment option for nutrients and their recovery.

\subsection{Material and Methods}

\subsubsection{Experimental Set-up}

In this study, a $2.5 \mathrm{~L}$ bioreactor was used to treat a synthetic wastewater with continuous feeding of a ferric chloride solution. A 4-L tank was used as wastewater reservoir and a solution containing sodium acetate anhydrous $\left(\mathrm{C}_{2} \mathrm{H}_{3} \mathrm{NaO}_{2}, 3.2 \mathrm{mM}\right)$, ethanol $\left(\mathrm{C}_{2} \mathrm{H}_{6} \mathrm{O}, 1.93\right.$ $\mathrm{mM})$, lactose monohydrate $\left(\mathrm{C}_{12} \mathrm{H}_{22} \mathrm{O}_{11} \cdot \mathrm{H}_{2} \mathrm{O}, 0.36 \mathrm{mM}\right)$, sodium sulfate $\left(\mathrm{Na}_{2} \mathrm{SO}_{4}, 0.55 \mathrm{M}\right)$, sodium bicarbonate $\left(\mathrm{NaHCO}_{3}, 1.67 \mathrm{mM}\right)$, ammonium chloride $\left(\mathrm{NH}_{4} \mathrm{Cl}, 3.74 \mathrm{mM}\right)$, sodium phosphate monobasic dehydrate $\left(\mathrm{NaH}_{2} \mathrm{PO}_{4} .2 \mathrm{H}_{2} \mathrm{O}, 0.32 \mathrm{mM}\right)$ and trace elements (4.75 $\mathrm{mL} / \mathrm{L}$ ) was prepared as the synthetic wastewater. The solution was prepared to maintain a specific concentration of $\mathrm{COD}(420 \mathrm{mg} / \mathrm{L}), \mathrm{SO}_{4}{ }^{2-}(50 \mathrm{mg} / \mathrm{L}), \mathrm{NH}_{4}{ }^{+}-\mathrm{N}(50 \mathrm{mg} / \mathrm{L})$ and $\mathrm{PO}_{4}{ }^{3-}-\mathrm{P}(10 \mathrm{mg} / \mathrm{L})$. A 4-L tank containing a ferric chloride solution $\left(\mathrm{FeCl}_{3} \cdot 6 \mathrm{H}_{2} \mathrm{O}, 10.25\right.$ $\mathrm{mM}$ ) was used as a ferric source for the bioreactor and $\mathrm{pH}$ of the ferric solution was adjusted to 4-4.2 using a sodium hydroxide solution $(\mathrm{NaOH}, 5 \mathrm{~N})$. The influent and effluent samples were collected daily and later intermittently to measure the concentrations of $\mathrm{NH}_{4}{ }^{+}, \mathrm{COD}, \mathrm{SO}_{4}{ }^{2-}$, iron, $\mathrm{P}$ to examine the treatment performance. Additionally, microscopic analyses were performed to characterize the elemental composition of the produced sludge materials.

\subsubsection{Analytical Methods}

All the chemical analyses were done following the Standard Methods (APHA et al., 2005). Briefly, COD concentration was measured by following a closed reflux, colorimetric method (Standard Method 5220 D) using a spectrophotometer (HACH, DR 2800). Soluble sulfate concentration was measured by a turbidimetric method (USEPA method 375.4) using a spectrophotometer (Thermo Scientific, GENESYS 10UV). Total $\mathrm{NH}_{4}^{+}-\mathrm{N}$ 
concentration was measured using the Phenate method (4500 F). P concentrations in the filtrate samples were measured by Ascorbic Acid method (Standard Method $4500 \mathrm{E}$ ). Total iron concentration was measured using an atomic absorption spectrophotometer (Perkin Elmer 3100) after the samples were acidified with a $70 \%$ nitric acid $\left(\mathrm{HNO}_{3}\right)$ solution. Ferrous iron concentration was determined using 1, 10 phenanthroline method (Standard Method 3500 B) and ferric iron concentration was calculated by the difference between the total and ferrous iron concentrations.

\subsubsection{Sludge Characterization}

A scanning electron microscope (SEM) equipped with an energy dispersion spectroscopy (SEM-EDS, Hitachi S 4700) was used to examine the morphological and elemental composition of the sludge. The sludge samples were first dried in a closed desiccator filled with calcium sulfate and flushed with $\mathrm{N}_{2}$ gas to prevent sludge oxidation. The SEM scanning was performed under an accelerating voltage of 10-20 kV and qualitative elemental analysis of the sludge samples was conducted by EDS spectrometry under an accelerating voltage of $10 \mathrm{kV}$. The powdered sludge samples were also used to determine the chemical states of $\mathrm{Fe}, \mathrm{N}$ and $\mathrm{P}$ to investigate the presence of $\mathrm{FAP}$ by $\mathrm{X}$-ray photoelectron spectroscopy (XPS) analysis (PHI 5000 Versaprobe). The sample powder was mounted on a sample holder with a zero reflective quartz plate (MTI corporation, CA) located underneath. XPS spectra were obtained with a monochromatized Al Ka X-ray source $(1487 \mathrm{eV})$ while base pressure of the analytical chamber was on the order of $10^{-7}$ $\mathrm{Pa}$. A pass energy of $23.5 \mathrm{eV}$ was used to conduct elemental scans of $\mathrm{Fe}, \mathrm{N}$ and $\mathrm{P}$.

\subsection{Results and Discussion}

\subsubsection{Treatment Performance}

The water quality analyses on the influent and effluent samples showed fairly consistent removal of organics, $\mathrm{N}$ (as ammonium), $\mathrm{P}$ (as phosphate) and $\mathrm{SO}_{4}{ }^{2-}$ from the wastewater (Fig. 28). Average removal efficiencies of $\mathrm{COD}, \mathrm{PO}_{4}{ }^{3-}-\mathrm{P}, \mathrm{SO}_{4}{ }^{2-}$ and $\mathrm{NH}_{4}{ }^{+}-\mathrm{N}$ was $97 \pm 2 \%$, $99.7 \pm 0.5 \%, 87.1 \pm 3 \%$ and $20.3 \pm 9.0 \%$, respectively. The high removal efficiency of COD is attributed to organics oxidation coupled to ferric reduction as well as sulfate reduction. Approximate $87 \%$ sulfate reduction and $89 \%$ iron removal indicated that both ferric iron and sulfate reduction played a significant role in COD oxidation. Significant $P$ 
removal was achieved due to precipitation as $\mathrm{FePO}_{4}$ and FAP. Removal of $\mathrm{N}$ may be associated with the Feammox process or FAP precipitation. Mean total iron and ferrous $\left(\mathrm{Fe}^{2+}\right)$ loading of the effluent samples were $21 \pm 9 \mathrm{mg} / \mathrm{d}$ and $6 \pm 4 \mathrm{mg} / \mathrm{d}$, respectively. The residual ferrous iron in the effluent represents an oxygen demand and can be oxidized by chlorine in a disinfection unit. There was not any significant presence of nitrate and nitrite in the effluent.

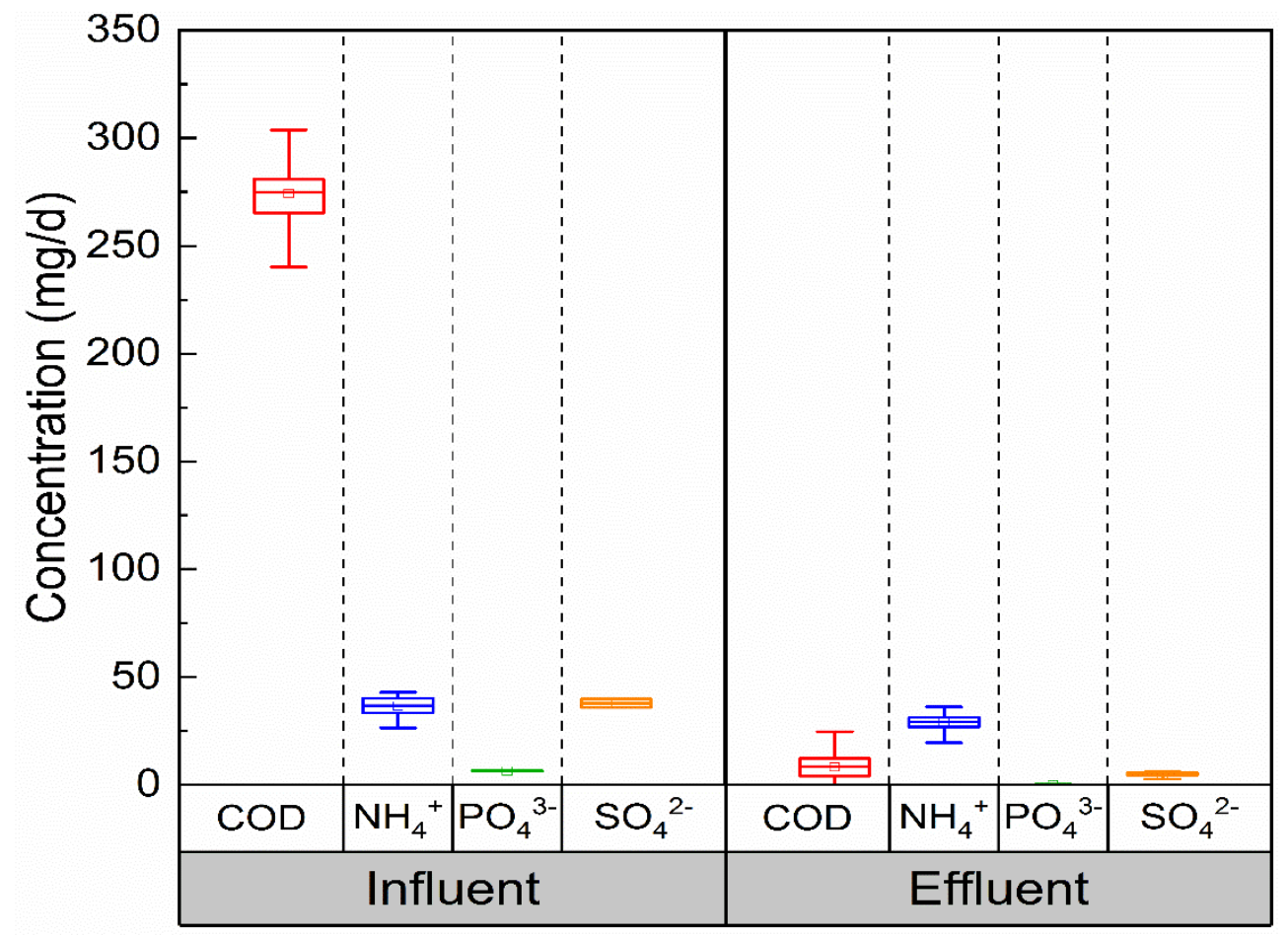

Fig. 28: Influent and effluent concentrations of $\mathrm{COD}, \mathrm{NH}_{4}{ }^{+}-\mathrm{N}, \mathrm{PO}_{4}{ }^{3-}-\mathrm{P}$ and $\mathrm{SO}_{4}{ }^{2-}$

\subsubsection{Sludge Characterization}

The SEM-EDS analysis showed major elements of the sludge sample as $\mathrm{C}, \mathrm{O}, \mathrm{N}, \mathrm{Fe}$, and $S$ (Fig. 29). The precipitate particles have a very disordered morphology with no specific pattern. Particle sizes were similar to structural descriptions of iron sulfide $(\approx 1-2$ $\mu \mathrm{m})$, FAP $(2-6 \mu \mathrm{m})$, and ferric phosphate $(1-2 \mu \mathrm{m})$ presented in previous studies (Bratkova et al., 2018; Csákberényi-Malasics et al., 2012; Li et al., 2014; Vaclavkova et al., 2014; Zhang et al., 2013). The identification of different compounds was not possible with the SEM-EDS analysis. 

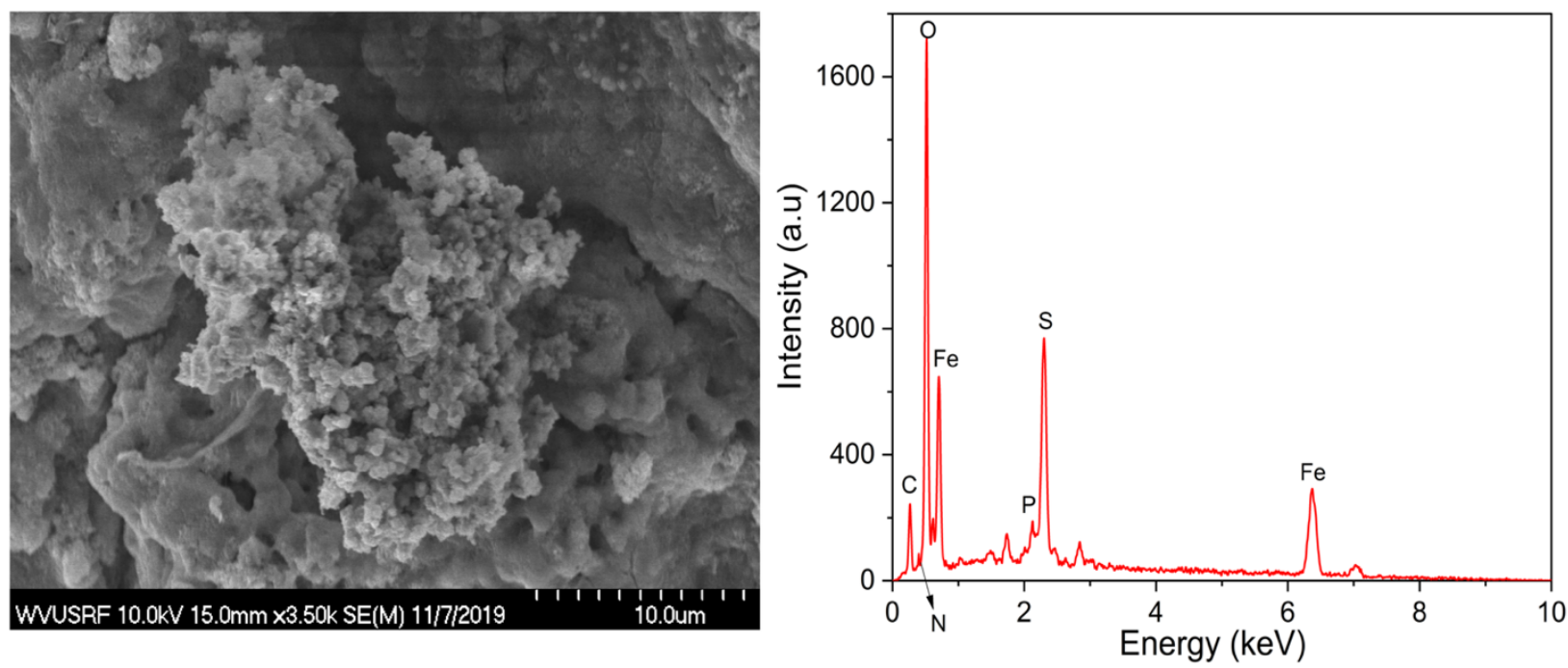

Fig. 29: SEM micrograph and EDS spectrum of the sludge material

To investigate the presence of FAP in the sludge materials, elemental scan of $\mathrm{Fe}, \mathrm{N}$ and $P$ was conducted using XPS. The narrow region in the spectrum of $F e 2 p_{3 / 2}$ revealed two major peaks at $708.5 \mathrm{eV}$ and $710.5 \mathrm{eV}$ (Fig. 30a), which represent $\mathrm{Fe}^{2+}$ and $\mathrm{Fe}^{3+}$, respectively (Deng and Lin, 2017). The N1s spectrum was fit with one significant peak at $400.2 \mathrm{eV}$ (Fig. 30b) which represents ammonium $\left(\mathrm{NH}_{4}{ }^{+}\right)$phase and $\mathrm{P} 2 \mathrm{p}_{3 / 2}$ spectrum was fit well with a peak at $133.1 \mathrm{eV}$ (Fig. 30c) which represents phosphate $\left(\mathrm{PO}_{4}{ }^{3-}\right)$ phase (Naumkin et al., 2012). Although, there was no specific binding energy of FAP reported in the literature, the presence of individual peaks of $\mathrm{Fe}^{2+}, \mathrm{NH}_{4}{ }^{+}$and $\mathrm{PO}_{4}{ }^{3-}$ suggest probable presence of FAP in the sludge sample. 

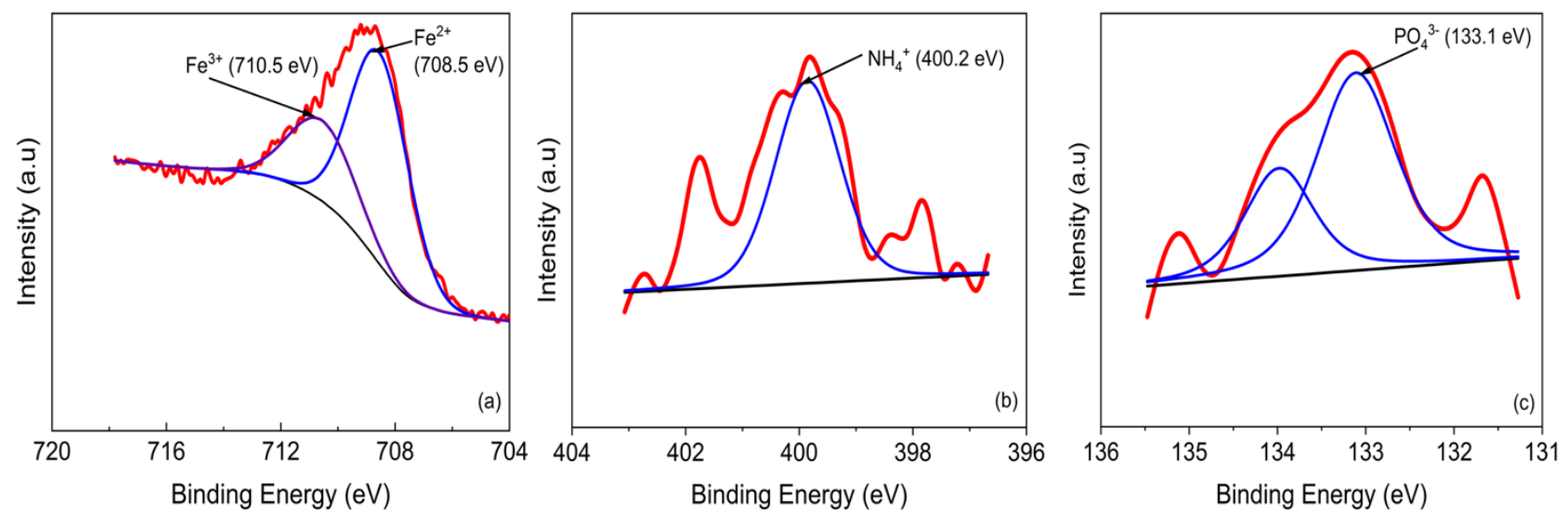

Fig. 30: XPS spectra of the sludge sample for (a) Fe2p $p_{3 / 2}$, (b) N1s, and (c) P2 $\mathrm{p}_{3 / 2}$

\subsection{Conclusion}

This study investigated the opportunity of removing and recovering nutrients in the newly developed $\mathrm{Fe}$ (III)-dosed anaerobic wastewater treatment system. This treatment method was found to effectively remove organics and phosphorus, and to a significant degree, $\mathrm{N}$ from wastewater in the same bioreactor. That reduces the necessity of multiple treatment units as in the existing technologies for $\mathrm{N}$ and $\mathrm{P}$ removal. For practical implementation of this treatment method, the iron dosing scheme will be a crucial factor to provide sufficient electron acceptor for organics and ammonium oxidation, as well as for ferrous ammonium phosphate precipitation. The beneficial applications of FAP, especially as a fertilizer, has created a new avenue of resource recovery from the sludge that would greatly enhance the sustainability of this treatment method. Future studies related to the microbiological composition and metabolic pathways responsible for the chemical transformations will give better insights into the biogeochemical reactions that facilitate the treatment.

\section{References}

ÆErtebjerg, G., Andersen, J. H., A., Hansen, O.S., 2003. Nutrients and Euthrophication in Danish Marine Waters, Ministry of the Environment, Danish Environmental protection Agency \& National Environmental Research Institute. https://doi.org/10.1146/annurev.nutr.25.050304.092633

Ahmed, M., Hasan, C.K., Rahman, H., Ali Hossain, M., Uddin, S.A., 2015. Prospects of using wastewater as a resource-nutrient recovery and energy generation. Am. J. Environ. Sci. https://doi.org/10.3844/ajessp.2015.99.114

Ahmed, M., Lin, O., Saup, C.M., Wilkins, M.J., Lin, L.S., 2019. Effects of Fe/S ratio on the 
kinetics and microbial ecology of an Fe(III)-dosed anaerobic wastewater treatment system. J. Hazard. Mater. 369, 593-600. https://doi.org/10.1016/j.jhazmat.2019.02.062

Ahmed, M., Saup, C.M., Wilkins, M.J., Lin, L.-S., 2020. Continuous ferric iron-dosed anaerobic wastewater treatment: treatment perfromance, sludge characteristics, and mirobial composition. J. Environ. Chem. Eng. 8.

APHA, AWWA, WEF, 2005. Standard methods for the examination of water and wastewater, 21st ed. American Public Health Association,American water Works Association, and Water Environment Federation.

Blackall, L.L., Crocetti, G.R., Saunders, A.M., Bond, P.L., 2002. A review and update of the microbiology of enhanced biological phosphorus removal in wastewater treatment plants. Antonie van Leeuwenhoek, Int. J. Gen. Mol. Microbiol. 81, 681691. https://doi.org/10.1023/A:1020538429009

Bratkova, S., Lavrova, S., Angelov, A., Nikolova, K., Ivanov, R., Koumanova, B., 2018. Treatment of wastewaters containing $\mathrm{Fe}, \mathrm{Cu}, \mathrm{Zn}$ and as by microbial hydrogen sulfide and subsequent emoval of COD, N and P. J. Chem. Technol. Metall. 53, 245-257.

Bunce, J.T., Ndam, E., Ofiteru, I.D., Moore, A., Graham, D.W., 2018. A review of phosphorus removal technologies and their applicability to small-scale domestic wastewater treatment systems. Front. Environ. Sci. 6, 1-15. https://doi.org/10.3389/fenvs.2018.00008

Clément, J.C., Shrestha, J., Ehrenfeld, J.G., Jaffé, P.R., 2005. Ammonium oxidation coupled to dissimilatory reduction of iron under anaerobic conditions in wetland soils. Soil Biol. Biochem. 37, 2323-2328. https://doi.org/10.1016/j.soilbio.2005.03.027

Cooper, P., Day, M., Thomas, V., 1994. Process Options for Phosphorus and Nitrogen Removal from Wastewater. Water Environ. J. 8, 84-92. https://doi.org/10.1111/j.1747-6593.1994.tb01096.x

Cornel, P., Schaum, C., 2009. Phosphorus recovery from wastewater: Needs, technologies and costs. Water Sci. Technol. 59, 1069-1076. https://doi.org/10.2166/wst.2009.045

Csákberényi-Malasics, D., Rodriguez-Blanco, J.D., Kis, V.K., Rečnik, A., Benning, L.G., Pósfai, M., 2012. Structural properties and transformations of precipitated FeS. Chem. Geol. 294-295, 249-258. https://doi.org/10.1016/j.chemgeo.2011.12.009

De Jonge, V.N., Elliott, M., Orive, E., 2002. Causes, historical development, effects and future challenges of a common environmental problem: Eutrophication. Hydrobiologia 475-476, 1-19. https://doi.org/10.1023/A:1020366418295

Deng, D., Lin, L.S., 2017. Continuous sulfidogenic wastewater treatment with iron sulfide sludge oxidation and recycle. Water Res. 114, 210-217. https://doi.org/10.1016/j.watres.2017.02.048

Ding, L.J., An, X.L., Li, S., Zhang, G.L., Zhu, Y.G., 2014. Nitrogen loss through anaerobic ammonium oxidation coupled to iron reduction from paddy soils in a 
chronosequence. Environ. Sci. Technol. 48, 10641-10647. https://doi.org/10.1021/es503113s

Farazaki, M., Gikas, P., 2019. Nitrification-denitrification of municipal wastewater without recirculation, using encapsulated microorganisms. J. Environ. Manage. 242, 258265. https://doi.org/10.1016/j.jenvman.2019.04.054

Huang, S., Jaffé, P.R., 2018. Isolation and characterization of an ammonium-oxidizing iron reducer: Acidimicrobiaceae sp. A6. PLoS One 13, 1-12. https://doi.org/10.1016/s0378-1097(97)00409-6

Huang, S., Jaffé, P.R., 2015. Characterization of incubation experiments and development of an enrichment culture capable of ammonium oxidation under ironreducing conditions. Biogeosciences 12, 769-779. https://doi.org/10.5194/bg-12769-2015

Lahav, O., Green, M., 2000. Ammonium removal from primary and secondary effluents using a bioregenerated ion-exchange process. Water Sci. Technol. 42, 179-185. https://doi.org/10.2166/wst.2000.0311

Li, P., Du, Y., Li, L., Huang, L., Rudolph, V., Nguyen, A. V, Xu, Z.P., 2014. Preparation and characterisation of manganese and iron compounds as potential control- release foliar fertilizers Peng. Biointerface Res. Appl. Chem. 4, 746-753. https://doi.org/10.1021/ed017p596.1

Li, X., Hou, L., Liu, M., Zheng, Y., Yin, G., Lin, X., Cheng, L., Li, Y., Hu, X., 2015. Evidence of Nitrogen Loss from Anaerobic Ammonium Oxidation Coupled with Ferric Iron Reduction in an Intertidal Wetland. Environ. Sci. Technol. 49, 11560-11568. https://doi.org/10.1021/acs.est.5b03419

Metcalf \& Eddy, I., Tchobanoglous, G., Stensel, H.D., Tsuchihashi, R., Burton, F., 2014. Wastewater Engineering: Treatment and Resorce Recovery. McGraw-Hill, New York.

Miles, A., Ellis, T.G., 2001. Struvite precipitation potential for nutrient recovery from anaerobically treated wastes. Water Sci. Technol. 43, 259-266. https://doi.org/10.2166/wst.2001.0690

Naumkin, A. V., Kraut-Vass, A., Gaarenstroom, S.W., Powell, C.J., 2012. NIST X-ray Photoelectron Spectroscopy Database [WWW Document]. https://doi.org/http://dx.doi.org/10.18434/T4T88K

Olajire, A.A., Imeokparia, F.E., 2001. Water quality assessment of Osun river: Studies on inorganic nutrients. Environ. Monit. Assess. 69, 17-28. https://doi.org/10.1023/A:1010796410829

Pratt, C., Parsons, S.A., Soares, A., Martin, B.D., 2012. Biologically and chemically mediated adsorption and precipitation of phosphorus from wastewater. Curr. Opin. Biotechnol. 23, 890-896. https://doi.org/10.1016/j.copbio.2012.07.003

Reboleiro-Rivas, P., Martín-Pascual, J., Juárez-Jiménez, B., Poyatos, J.M., VílchezVargas, R., Vlaeminck, S.E., Rodelas, B., González-López, J., 2015. Nitrogen 
removal in a moving bed membrane bioreactor for municipal sewage treatment: Community differentiation in attached biofilm and suspended biomass. Chem. Eng. J. 277, 209-218. https://doi.org/10.1016/j.cej.2015.04.141

Sengupta, S., Nawaz, T., Beaudry, J., 2015. Nitrogen and Phosphorus Recovery from Wastewater. Curr. Pollut. Reports 1, 155-166. https://doi.org/10.1007/s40726-0150013-1

Shrestha, J., Rich, J.J., Ehrenfeld, J.G., Jaffe, P.R., 2009. Oxidation of ammonium to nitrite under iron-reducing conditions in wetland soils: Laboratory, field demonstrations, and push-pull rate determination. Soil Sci. 174, 156-164. https://doi.org/10.1097/SS.0b013e3181988fbf

Vaclavkova, S., Jørgensen, C.J., Jacobsen, O.S., Aamand, J., Elberling, B., 2014. The Importance of Microbial Iron Sulfide Oxidation for Nitrate Depletion in Anoxic Danish Sediments. Aquat. Geochemistry 20, 419-435. https://doi.org/10.1007/s10498-0149227-x

Vaneeckhaute, C., Lebuf, V., Michels, E., Belia, E., Vanrolleghem, P.A., Tack, F.M.G., Meers, E., 2017. Nutrient Recovery from Digestate: Systematic Technology Review and Product Classification. Waste and Biomass Valorization 8, 21-40. https://doi.org/10.1007/s12649-016-9642-x

Walczyk, T., Kastenmayer, P., Storcksdieck Genannt Bonsmann, S., Zeder, C., Grathwohl, D., Hurrell, R.F., 2013. Ferrous ammonium phosphate (FeNH4PO4) as a new food fortificant: Iron bioavailability compared to ferrous sulfate and ferric pyrophosphate from an instant milk drink. Eur. J. Nutr. 52, 1361-1368. https://doi.org/10.1007/s00394-012-0445-y

Wang, J., Pan, F., Soininen, J., Heino, J., Shen, J., 2016. Nutrient enrichment modifies temperature-biodiversity relationships in large-scale field experiments. Nat. Commun. 7, 1-9. https://doi.org/10.1038/ncomms13960

Yang, W.H., Weber, K.A., Silver, W.L., 2012. Nitrogen loss from soil through anaerobic ammonium oxidation coupled to iron reduction. Nat. Geosci. 5, 538-541. https://doi.org/10.1038/ngeo1530

Yao, Z., Wang, F., Wang, C., Xu, H., Jiang, H., 2019. Anaerobic ammonium oxidation coupled to ferric iron reduction in the sediment of a eutrophic lake. Environ. Sci. Pollut. Res. 1-11. https://doi.org/10.1007/s11356-019-04907-7

Zhang, T.B., Lu, Y.C., Luo, G.S., 2013. Iron phosphate prepared by coupling precipitation and aging: Morphology, crystal structure, and $\mathrm{Cr}(\mathrm{III})$ adsorption. Cryst. Growth Des. 13, 1099-1109. https://doi.org/10.1021/cg301441t 


\section{Chapter 7: Conclusions}

An innovative $\mathrm{Fe}$ (III)-dosed anaerobic wastewater treatment method has been developed in this Ph.D. research by incorporating Fe and $\mathrm{S}$ biogeochemical reactions in a laboratoryscale engineered biological treatment system. Overall, this novel treatment method has multiple benefits over the typical aerobic treatment technologies including potential use of iron containing wastes, no need for aeration, significant organics and nutrient removal, and recovery of nutrients and useful sludge byproducts.

Based on a thorough literature review, several critical factors related to applications of ferric reduction in developing such a Fe(III)-dosed treatment system were identified and research objectives were designed accordingly to develop this treatment method. Types of ferric compounds, organics type and concentrations, microorganisms, and ferric bioavailability are identified as the major factors affecting organic oxidation coupled to iron reduction. In this research, typical wastewater constituents (acetate, lactate, ethanol) and conditions ( $\mathrm{pH}$, temperature, alkalinity) were used to prepare synthetic wastewaters, which mimicked the real municipal wastewater. Commonly, ferric compounds are precipitated as ferric hydroxide $\left(\mathrm{Fe}(\mathrm{OH})_{3}\right)$ in the environment, therefore, $\mathrm{Fe}(\mathrm{OH})_{3}$ was used as ferric compound. As an ubiquitous constituent of domestic wastewater, sulfate was also considered as an electron acceptor responsible for organics oxidation.

Consistent high removal of organics in this $\mathrm{Fe}(\mathrm{III})$-dosed treatment process indicates the efficient functionality of this process for practical applications. Nutrient removal and potential recovery in one-stage treatment not only reduce the requirement of complex treatment train for full-scale applications but also improve the sustainability of this system. Generation of valuable magnetic particles through a simple thermal treatment method reduces the burden of sludge management and creates opportunities of beneficial applications. Microbiological composition obtained in this research has provided a baseline for the types of microorganisms and their interrelations occurred in this treatment system, which was not described previously. Due to substantial advantages of energy efficiency, excellent pollutant removal, and innovative resource recovery opportunities, this $\mathrm{Fe}(\mathrm{III})$-dosed treatment can be a viable alternative to existing aerobic treatment 
technologies. Broad applications of this technology are expected to lead to more sustainable wastewater management and create opportunities for utilizing iron-containing wastes.

Future studies are warranted to further develop this treatment technology in the following areas:

- Additional experiments can be designed and conducted by dosing various ferric compounds (ferric hydroxide, different forms of ferric oxides) to evaluate their effects on the treatment performance as well as sludge production and composition. Additionally, effects of environmental conditions ( $\mathrm{pH}$, temperature) need to be investigated.

- A comprehensive sludge treatment method can be developed for production of sludge byproducts with targeted properties (e.g., size, magnetization) and separation of nutrient products (e.g., FAP, vivianite $\left(\mathrm{Fe}_{3}\left(\mathrm{PO}_{4}\right)_{2} \bullet 8 \mathrm{H}_{2} \mathrm{O}\right)$ ).

- Reusing the sludge or the sludge byproducts within the treatment process (e.g., coagulant, iron recycling) can create opportunities for more intensified treatment process (i.e., process intensification). The scope of reusing sludge and its byproducts within the system warrants further investigations.

- Prospects of other metabolic pathways such as Feammox need to be investigated under different iron dosing schemes through comprehensive chemical and microbiological studies on its transformations and chemical fate.

- Iron reducing bacteria such as Geobacter and Shewanella sp. are observed to generate the highest electrical current density among exoelectrogenic bacteria, given their diverse and efficient electron transfer mechanisms. They can be used in bioelectrochemical systems for electricity generation from wastewater and/or sludge to further enhance energy efficiency of the iron-dosed treatment approach. 